\title{
A scientific framework for evaluating coral reef resilience to climate change
}

\author{
by \\ Hannah Catherine Barkley \\ A.B., Princeton University, 2011 \\ Submitted in partial fulfillment of the requirements for the degree of \\ Doctor of Philosophy \\ at the \\ MASSACHUSETTS INSTITUTE OF TECHNOLOGY \\ and the \\ WOODS HOLE OCEANOGRAPHIC INSTITUTION
}

September 2016

(c) 2016 Hannah Catherine Barkley.

All rights reserved.

The author hereby grants to MIT and WHOI permission to reproduce and to distribute publicly paper and electronic copies of this thesis document in whole or in part in any medium now known or hereafter created.

Author

Joint Program in Oceanography/Applied Ocean Science and Engineering

Massachusetts Institute of Technology and Woods Hole Oceanographic Institution

July 29, 2016

Certified by

Anne L. Cohen

Associate Scientist, Department of Geology and Geophysics, WHOI

Thesis Supervisor

Accepted by

Timothy L. Grove

Professor of Earth, Atmospheric, and Planetary Sciences, MIT Chairman, Joint Committee for Marine Geology and Geophysics 


\title{
A scientific framework for evaluating coral reef resilience to climate change
}

\author{
by \\ Hannah Catherine Barkley
}

Submitted to the Joint Program in Oceanography/Applied Ocean Science and Engineering Massachusetts Institute of Technology and Woods Hole Oceanographic Institution on July 29, 2016, in partial fulfillment of the requirements for the degree of Doctor of Philosophy

\begin{abstract}
The $21^{\text {st }}$ century warming and acidification of tropical oceans will impact the structure and function of coral reef ecosystems. Consequently, conservation efforts are increasingly focused on identifying and protecting reef communities that demonstrate resilience to these changes. In this thesis, I develop a scientific framework for identifying climate change resilience in coral communities and, using Palau's coral reefs as a case study, demonstrate the application of this approach. First, I use coral skeletal records to evaluate the sensitivity of coral communities to episodes of severe thermal stress. This information reveals coral reef communities that consistently exhibit weak responses to multiple high temperature events. Second, I evaluate coral reef community structure across a strong, natural $\mathrm{pH}$ gradient using metrics informed by laboratory ocean acidification studies. The coral communities of Palau's Rock Island reefs show a level of $\mathrm{pH}$ tolerance that is unique amongst reefs studied to date. Third, I conduct laboratory and field experiments to constrain the $\mathrm{pH}$ thresholds of these resilient corals and investigate potential mechanisms for $\mathrm{pH}$ tolerance. Finally, I combine archipelago-wide coral temperature and $\mathrm{pH}$ sensitivity data to construct climate change resilience indices. My study succeeds in identifying a small number of coral communities that have the potential to withstand $21^{\text {st }}$ century climate change and highlights the spatial variability in community responses to ocean warming and acidification. Critically, I present a set of scientific tools and approaches for identifying resilient coral reef communities that has applicability to coral reefs worldwide.
\end{abstract}

Thesis Supervisor: Anne L. Cohen

Title: Associate Scientist, Department of Geology and Geophysics, WHOI 


\section{Acknowledgments}

This thesis represents the collective knowledge, effort, and support of very many people spanning numerous institutions and countries. I give my thanks to everyone who has participated in my research and helped me along in this journey.

I offer deepest gratitude to my thesis advisor, Anne Cohen, for her incredible guidance as a mentor and for opportunities that continue to defy my wildest dreams and expectations. This thesis has become my passion project, and anything that I have achieved in these pages ultimately reflects her support of me pursuing my scientific interests, her enthusiastic participation in my research goals, and her continued belief in me.

I also appreciate the guidance, knowledge, and advice of my thesis committee members, Dan McCorkle, Steve Lentz, Janelle Thompson, and Lizzie Mcleod, whose diverse backgrounds and expertise have helped me to create a thesis spanning many scientific disciplines and who have allowed me to merge rigorous science with coral reef conservation. I also thank Rubao Ji, Kris Karnauskas, and Delia Oppo, who chaired my thesis defense, thesis proposal defense, and generals examination, respectively, and provided valuable insight into my research questions and results. In addition, my thesis benefitted enormously from the contributions of Yimnang Golbuu, Vicke Starczak, and Rod Salm, who helped me to collect, analyze, and interpret environmental and ecological data from Palau.

I thank all of the members of the Cohen Lab past and present - Katie Shamberger, Liz Drenkard, Alice Alpert, Tom DeCarlo, Sara Bosshart, Hanny Rivera, Nathan Mollica, Michael Holcomb, and Neal Cantin - for their scientific knowledge, assistance in the field, camaraderie in research, and friendship. I am grateful to Kathryn Pietro and Pat Lohmann for their help in collecting field samples; Liz Bonk, Katherine Hoering, Dave Wellwood, and Paul Henderson for assistance in carbonate chemistry, salinity, and nutrient analyses; Julie Arruda and Scott Cramer for CT-scanning my coral cores; and Ed O'Brien and the WHOI Diving Program for helping with SCUBA diving operations. In addition, I thank the WHOI Academic Programs Office for their tireless assistance, support, and guidance.

My extensive field research was made possible by the scientists and staff of the Palau International Coral Reef Center, who provided me with essential logistical aid during six field expeditions to Palau, drove me all over the archipelago to sample water and coral, helped me set up my laboratory experiments, and taught me about Palau's coral reefs. Sulang!

The completion of this five-year journey is very much a result of the amazing love and endless support of my incredible family and friends. In particular, I thank my parents, Ron and Barbara, and my brother, Ben, who have celebrated my victories, carried me through my struggles, journeyed with me on my crazy adventures, and always kept me laughing.

Finally, and above all else, I thank my Lord and Savior, from whom I drew the strength to undertake this work and to whom all the glory of its completion ultimately belongs.

Funding for this research was provided by the Next Wave Fund Fellowship, a National Science Foundation Graduate Student Fellowship, the NSF-funded National Network for Ocean and Climate Change Interpretation, the James Stratton Fellowship, National Science Foundation awards OCE-1220529 and OCE-1031971 to Anne Cohen, The Tiffany \& Co. Foundation, The Nature Conservancy, The Dalio Foundation, Inc., through the Dalio Explore Fund, and Ray Dalio through the WHOI Access to the Sea Fund. 


\section{Contents}

1 Introduction $\quad 9$

2 Skeletal records of community-level bleaching in Porites corals from Palau 21

3 Changes in coral reef communities across a natural gradient in seawater $\mathrm{pH}$

4 Mechanisms and thresholds for $\mathrm{pH}$ tolerance in Palau corals $\quad 63$

5 Evaluating coral reef resilience to climate change in the Palau archipelago 87

6 Conclusion 131

Appendix A Supplementary materials for chapter 2 135

$\begin{array}{lll}\text { Appendix B Supplementary materials for chapter } 3 & 143\end{array}$

$\begin{array}{lll}\text { Appendix C Supplementary materials for chapter } 4 & 151\end{array}$

$\begin{array}{lll}\text { Appendix D Supplementary materials for chapter } 5 & 157\end{array}$

$\begin{array}{lll}\text { Appendix E A note on coral calcification rates } & 169\end{array}$ 


\section{Chapter 1}

\section{Introduction}

\subsection{Climate change impacts on coral reefs}

Coral reefs are among the most diverse, productive, and vibrant ecosystems on the planet. Although the total spatial extent of all reefs comprises less than $1 \%$ of the ocean floor, coral reefs host over a fourth of all described marine species and are among the most biologically rich ecosystems on earth (Moberg and Folke, 1999). They serve as a cornerstone of the world's fisheries, acting as essential nursery habitats and spawning grounds for hundreds of economically important fish species (Spalding et al., 2001). Coral reefs provide critical ecosystem goods and services, including protection from storms and coastal erosion, that are valued at $\$ 9.9$ trillion·year ${ }^{-1}$ (Costanza et al., 2014). They are the primary source of food and income for over 500 million people in 100 countries (Wilkinson, 2008). In addition, the cultural traditions and heritage of millions of people worldwide are intimately connected to corals and the reef animals that live within and depend upon the habitats that they provide. The goal of this thesis is to advance a scientific framework for protecting these ecosystems from the environmental impacts related to a changing climate.

Climate change presents a major threat to the continued health and survival of coral reef ecosystems through shifts in the temperature and chemistry of tropical oceans. Anthropogenic emissions from the burning of fossil fuels and land use change are increasing the concentration of carbon dioxide $\left(\mathrm{CO}_{2}\right)$ in the atmosphere at an unprecedented rate, thereby warming the world's atmosphere and oceans (Doney and Schimel, 2007). Over the past 250 years, $\mathrm{CO}_{2}$ concentrations have risen from preindustrial concentrations of $\approx 280 \mathrm{ppmv}$ (parts per million by volume) to concentrations greater than $400 \mathrm{ppmv}$, driving a global $0.8{ }^{\circ} \mathrm{C}$ increase in atmosphere and ocean temperatures over the last century (Hansen et al., 2006; Hartmann et al., 2013). Punctuating this underlying trend have been increases in the frequency and severity of elevated temperature anomalies during episodic warm events, particularly those associated with phases of the El Niño Southern Oscillation (ENSO), that 
can elevate ocean temperatures several degrees above climatological means for months at a time (Cai et al., 2014). If $\mathrm{CO}_{2}$ emissions continue at present rates, surface ocean temperatures are expected to continue to rise by as much as $2{ }^{\circ} \mathrm{C}$ by the end of the $21^{\text {st }}$ century with the possibility of further amplification of warming under intensifying ENSO activity (Collins et al., 2013).

Combined chronic warming trends and episodic high temperature events have increasingly exposed coral reef communities to temperatures that are above those that they generally experience and to which they are currently acclimatized. Sustained elevated sea surface temperatures even $1{ }^{\circ} \mathrm{C}$ above historical summertime means can trigger the breakdown of the delicate symbiosis that exists between the coral animal and the intracellular zooxanthellae algae that supply a major source of organic carbon to their host. The expulsion of these endosymbionts in response to thermal stress, a process known as coral bleaching (so called because the eviction of pigmented algae reveals the underlying white coral skeleton), results in coral starvation that frequently leads to widespread reef mortality if temperature stress is prolonged (Hoegh-Guldberg, 1999; Jones et al., 2006; Hoegh-Guldberg et al., 2007; Baker et al., 2008). Temperature-driven coral bleaching events are already directly responsible for the loss of $\approx 16 \%$ of global coral reef cover in the past two decades (Wilkinson, 2008). Model predictions suggest that, as the oceans warm, most coral reefs are likely to experience extended periods of bleaching-level temperatures annually by the year 2055 without sufficient time for recovery or adaptation (van Hooidonk et al., 2014).

In addition to driving ocean warming, anthropogenic emissions of $\mathrm{CO}_{2}$ are altering the chemistry of the world's oceans. A significant portion of the $\mathrm{CO}_{2}$ gas emitted into the atmosphere is rapidly absorbed in ocean surface waters. The resulting chemical reactions that occur in seawater drive down $\mathrm{pH}$, decrease carbonate ion $\left(\mathrm{CO}_{3}{ }^{2-}\right)$ concentration, and lower the saturation state of calcium carbonate $(\Omega)$, a process termed ocean acidification (Feely et al., 2004; Doney et al., 2009; Feely et al., 2009). Global ocean pH has already decreased by 0.1 units relative to preindustrial levels (Rhein et al., 2013), and will likely fall an additional 0.3 to 0.4 units by the end of this century under predicted emissions scenarios (Orr et al., 2005; Doney et al., 2009). The acidification of seawater jeopardizes the health and viability of coral reef ecosystems because it reduces the availability of the $\mathrm{CO}_{3}{ }^{2-}$ building blocks that corals and other calcifying reef organisms require to construct the calcium carbonate $\left(\mathrm{CaCO}_{3}\right)$ shells and skeletons that ultimately build reefs (Feely et al., 
2004). Laboratory $\mathrm{CO}_{2}$ manipulation experiments and in situ observations of coral reefs have demonstrated that reductions in $\mathrm{pH}$ and $\Omega$ may result in decreased calcification rates of reef-building corals and other reef calcifiers and accelerate rates of reef bioerosion. These processes in turn may drive large changes in benthic community structure and function and alter the balance between calcium carbonate accretion and dissolution within coral reef ecosystems (Pandolfi et al., 2011; Kroeker et al., 2011; Fabricius et al., 2011).

\subsection{Coral reef resilience to climate change}

In light of bleaching impacts over the last several decades and predictions for both the warming and acidification of ocean waters over the next century, understanding, predicting, and addressing coral reef responses to elevated temperature and declining $\mathrm{pH}$ have become major priorities for scientists, coral reef managers, conservation organizations, and coral reef nations. In particular, conservation efforts have increasingly focused on identifying and protecting climate change refugia, or coral reef communities that are naturally more resistant or resilient to climate change because they are either less exposed or less sensitive to shifts in ocean temperature and chemistry (West and Salm, 2003; Obura, 2005; Baker et al., 2008; van Woesik et al., 2012; Mcleod et al., 2013; van Hooidonk et al., 2013). Integral to the identification of climate change refugia is the principle of ecological resilience, or the ability of a coral reef community to withstand stress (resistance) and/or rebound from a disturbance (recovery) without fundamental changes in ecosystem structure or function (McClanahan et al., 2012). Resilient coral communities are important conservation priorities because they may be among the coral reefs most likely to survive climate change-related disturbances and subsequently serve as sources of larvae to support recovery in connected reefs that are more sensitive to or more heavily impacted by ocean warming and acidification. The inclusion of resilient coral reef communities in marine protected areas, combined with local management actions that reduce the severity of additional stressors at these sites, can help promote the persistence of coral reefs in the face of rapid climate change.

One way that coral reef communities may act as climate change refugia is if the conditions present in the reef environment reduce exposure to climate change stressors. Under ocean warming, coral reefs may be spared the impacts of elevated temperature if local environmental factors reduce temperature and/or light stress. Physical processes that may 
reduce the severity of warming include rapid seawater exchange between warmer nearshore reefs and the cooler open ocean, wind-driven mixing, or the upwelling of cold, deep water. Enhanced water movement, which can include fast currents, high wave energy, and large tidal ranges, can also flush toxic free radicals that are formed when corals bleach and thus minimize coral mortality. Light stress, which can amplify temperature stress and exacerbate bleaching responses, may be lower in coral communities that are located in areas with heavy shading by adjacent high-profile land, high turbidity, reduced sun exposure, or high cloud cover (West and Salm, 2003). Processes that may mitigate ocean acidification include removal of metabolic carbon dioxide on coral reefs by water renewal (flushing) with offshore ocean water, $\mathrm{pH}$ elevation by the photosynthetic activity of adjacent sea grass beds, or the buffering effect of carbonate inputs to seawater in carbonate rich areas (Unsworth et al., 2012; Mcleod et al., 2013).

Alternatively, coral reefs may qualify as climate change refugia if the reef communities themselves are less sensitive to ocean warming and acidification. The most likely means by which coral reef assemblages may be highly resilient to changes in temperature and/or $\mathrm{pH}$ is if they are already acclimatized or adapted to stressful environments, such as those that are chronically warmer or more acidic or where SST and/or pH are highly variable (West and Salm, 2003; Castillo and Helmuth, 2005; Middlebrook et al., 2008; Mcleod et al., 2013). For example, extreme temperatures have been shown to promote the inclusion of temperature-tolerant clade D symbionts that increase temperature resistance of the coral holobiont during bleaching events (Baker et al., 2004) or even select for genetic adaptation to elevated temperature in the coral host (Barshis et al., 2013; Palumbi et al., 2014). Coral reef communities may also be resilient to climate change impacts if they are highly diverse and if their community compositions include particularly temperature- or pH-tolerant reef taxa; if recovery potential is high due to increased reproduction rates, recruitment success, or larval connectivity; or if the abundance of disease, macroalgae, bioeroding organisms, or corallivores that may undermine resilience is low (West and Salm, 2003; McClanahan et al., 2012; Maynard et al., 2015).

Despite the importance of finding and protecting natural climate change refugia, to date very few have been identified. Only a small number of temperature- and bleachingresilient coral communities have been reported (West and Salm, 2003; Riegl and Piller, 2003; Berkelmans et al., 2004; Obura, 2005; van Woesik et al., 2012; Chollett and Mumby, 2013). 
The limited number of described temperature refugia sites is largely due to the enormous logistical challenges associated with assessing coral reef responses to elevated temperature in the field, which requires collecting pre-bleaching baseline data, surveying reefs for bleaching at the height of thermal stress, and monitoring recovery for months to years post stress (Glynn et al., 2001; West and Salm, 2003; Berkelmans et al., 2004; Baker et al., 2008; Gilmour et al., 2013). To date, no acidification refugia have been identified with confidence.

\subsection{Coral reefs of Palau: a case study for resilience}

This thesis presents a case study for identifying temperature- and acidification-resilient coral reefs in the Republic of Palau. Located in the far western tropical Pacific, the small island nation of Palau supports some of the healthiest and most diverse coral reefs on the planet (Golbuu et al., 2005; Marino et al., 2008). The unusual geomorphology of the Palau archipelago gives rise to a wide variety of reef environments and benthic communities that range in character from the wave-battered barrier reefs forming the circumference of the Palauan islands to the highly sheltered reefs fringing the labyrinth of mushroom-shaped karstic Rock Islands. The variety of environmental conditions and diversity of coral reef communities found within Palau create a unique setting for evaluating the resilience of different benthic communities to the impacts of climate change.

The enormous wealth of marine resources in Palau has given rise to a local culture tightly interwoven with the sea as a source of livelihood, sustenance, spiritual and cultural importance, and recreation. As a result, the Palau government has demonstrated an unprecedented commitment to protecting its marine resources, including the designation of more than 40 protected or managed areas that cover $>40 \%$ of Palau's nearshore marine areas (Golbuu et al., 2005; Marino et al., 2008). Stringent conservation measures have largely sheltered Palau's reefs from the bevy of severe coastal anthropogenic impacts that have already devastated many coral reef systems around the world. However, Palau's coral reefs are not immune to impacts from climate change and natural climate variability. ENSO-driven periods of elevated temperature in 1998 and 2010, combined with global warming, led to widespread bleaching and mortality throughout the archipelago. During the 1998 event, approximately one third of Palau's corals died in response to high temperature anomalies, with reported mortality as high as $90 \%$ in some areas (Bruno et al., 2001). In 2010, a less severe 
thermal stress event drove bleaching levels of 10-50\% across Palau's reefs (van Woesik et al., 2012). Observed bleaching levels and recovery trajectories have suggested that temperature tolerance is spatially variable, with the inshore lagoonal reefs showing both higher tolerance to and recovery from bleaching and thermal stress (Bruno et al., 2001; Golbuu et al., 2007; van Woesik et al., 2012).

In contrast to the historical evidence for bleaching resistance across two events, comparatively little information exists about the sensitivity of Palau's coral reefs to ocean acidification. A handful of studies on seawater carbonate chemistry at a few sites in Palau have shown that there is a strong gradient in $\mathrm{pH}$ and $\Omega_{a r}$ (saturation state of calcium carbonate with respect to the mineral aragonite) between the offshore barrier reefs and the inner Rock Island lagoons that is largely driven by biological activity in seawater with a long residence time (Kayanne et al., 2005; Watanabe et al., 2006; Shamberger et al., 2014). However, despite living in heavily acidified conditions, the coral reefs of Palau's Rock Island bays remain diverse and coral-dominated (Shamberger et al., 2014). This surprising observation may be indicative of acclimatization or even adaptation to ocean acidification conditions in chronically acidified and highly isolated coral communities. The possible pH-tolerance of Rock Island communities, combined with evidence for the spatial variability in bleaching resistance across reef environments, suggests that there may be varying levels of coral community resilience to both ocean warming and acidification across Palau's coral reefs.

\subsection{Thesis objectives}

This thesis seeks to evaluate coral reef resilience to ocean warming and acidification and identify the coral reef communities most likely to be resilient to $21^{\text {st }}$ century climate change impacts. Specifically, the goals of my thesis are to:

1. assess whether resilience to ocean warming and acidification varies spatially both within and between coral reef communities,

2. examine mechanisms for coral resilience to climate change impacts, and

3. develop tools and analyses for identifying the coral communities most likely to survive predicted changes in temperature and $\mathrm{pH}$ over the next several decades. 
Chapter 2 evaluates coral reef resilience to ocean warming. In order to examine variability in thermal tolerance and bleaching resistance across reefs, I analyze records of coral temperature responses preserved in the skeletons of massive Porites corals. I find that the prevalence of high-density stress markers - called stress bands - archived within the skeletons of a population of Porites corals track levels of observed site-specific bleaching during two bleaching events in Palau. This demonstrates that stress bands can be used as a proxy for reconstructing historical levels of coral reef community-level bleaching in the absence of comprehensive ecological monitoring data. Stress band data reveal significant spatial variability in temperature sensitivities across Palau reefs, with the sheltered lagoon reefs of the Rock Islands demonstrating lower bleaching levels across two events than the exposed barrier reefs. These results introduce skeletal stress bands as a tool for tracking spatial and temporal patterns in bleaching resistance in coral reef communities, document the differences in temperature resilience that exist across Palau's reef environments, and demonstrate the particularly high bleaching resilience present in Rock Island coral reefs.

In Chapters 3 and 4, I examine coral reef resilience to ocean acidification. Chapter 3 presents an ecological analysis of benthic community structure along the acidification gradient in Palau ( $\mathrm{pH}=8.1$ to $7.8, \Omega_{a r}=3.7$ to 2.3 ). In contrast to prior studies of coral reef ecosystem responses to ocean acidification, I find that Palau's acidified Rock Island reefs are diverse and coral-dominated, and calcification rates of two major reef-building coral genera are maintained in low-pH conditions. The single significant acidification sensitivity I observe on Palau's coral reefs is an increase in the macrobioerosion of coral skeletons with decreasing $\mathrm{pH}$. Comparisons of coral reef responses to acidification between Palau and three other ocean acidification analog sites suggest that while coral community resilience to decreasing $\mathrm{pH}$ may vary depending on local environmental, ecological, and/or biological factors, increased bioerosion under low-pH appears to be a persistent signature of ocean acidification on coral reef ecosystems.

In Chapter 4, I examine mechanisms for and test thresholds of ocean acidification tolerance. The results of Chapter 3 reveal that corals living in Palau's acidified reef environments are able to calcify as quickly as those in higher-pH conditions. This surprising insensitivity to $\mathrm{pH}$ likely results either from the mitigation of acidification impacts by some co-varying environmental variable or from coral adaptation to chronically low-pH conditions in highly isolated bays. To untangle these factors, I conducted combined onsite laboratory $\mathrm{CO}_{2}$ ma- 
nipulation and reciprocal transplant experiments. In the laboratory experiment, Porites corals collected from a low-pH and a high-pH reef site were incubated under three $\mathrm{pH}$ conditions ( $\mathrm{pH}=7.6,7.8,8.0)$ for eight weeks. Corals showed no sensitivity to $\mathrm{pH}$ regardless of their reef of origin. Moreover, corals from both reefs were able to calcify well at pH levels as low as 7.6, indicating that these corals may not reach their $\mathrm{pH}$ thresholds by the end of this century. At the same time, I conducted a field reciprocal transplant in which corals were collected from the same reefs sites and then either returned to their original reef or transplanted to the opposite reef. After 17 months, the corals that were returned to their reef of origin showed high growth and survival rates, while mortality was $>80 \%$ in all transplanted corals. Considered with the demonstrated $\mathrm{pH}$ insensitivity of the same coral populations in the laboratory $\mathrm{CO}_{2}$ manipulation, these results are suggestive of an adaptive, rather than environmental, mechanism for acidification tolerance in Palau.

In Chapter 5, I use the analyses and tools for assessing coral reef climate change resilience that I have developed and the results from the previous three chapters to map spatial patterns in temperature and acidification resilience for Palau's coral reefs. I combine archipelago-scale maps of seawater temperature and carbonate chemistry with spatial/temporal bleaching and benthic ecology data and to create climate change resilience indices. The resulting resilience maps reveal the spatial variability in predicted climate change sensitivity across Palau's coral reefs and highlight the coral reef communities that may be best able to survive increasing temperature and decreasing ocean $\mathrm{pH}$ over the course of the $21^{\text {st }}$ century. 


\subsection{References}

Baker, A. C., Glynn, P. W., Riegl, B., 2008. Climate change and coral reef bleaching: An ecological assessment of long-term impacts, recovery trends and future outlook. Estuarine, Coastal and Shelf Science 80 (4), 435-471.

Baker, A. C., Starger, C. J., McClanahan, T. R., Glynn, P. W., 2004. Coral reefs: corals' adaptive response to climate change. Nature 430 (7001), 741.

Barshis, D. J., Ladner, J. T., Oliver, T. A., Seneca, F. O., Traylor-Knowles, N., Palumbi, S. R., 2013. Genomic basis for coral resilience to climate change. Proceedings of the National Academy of Sciences of the United States of America 110 (4), 1387-92.

Berkelmans, R., De'ath, G., Kininmonth, S., Skirving, W. J., 2004. A comparison of the 1998 and 2002 coral bleaching events on the Great Barrier Reef: spatial correlation, patterns, and predictions. Coral Reefs 23 (1), 74-83.

Bruno, J. F., Siddon, C., Witman, J., Colin, P., Toscano, M., 2001. El Niño related coral bleaching in Palau, Western Caroline Islands. Coral Reefs 20 (2), 127-136.

Cai, W., Borlace, S., Lengaigne, M., van Rensch, P., Collins, M., Vecchi, G., Timmermann, A., Santoso, A., McPhaden, M. J., Wu, L., England, M. H., Wang, G., Guilyardi, E., Jin, F.-F., 2014. Increasing frequency of extreme El Niño events due to greenhouse warming. Nature Climate Change 5 (2), 1-6.

Castillo, K. D., Helmuth, B. S. T., 2005. Influence of thermal history on the response of Montastraea annularis to short-term temperature exposure. Marine Biology 148 (2), 261270.

Chollett, I., Mumby, P. J., 2013. Reefs of last resort: locating and assessing thermal refugia in the wider Caribbean. Biological conservation 167, 179-186.

Collins, M., Knutti, R., Arblaster, J., Dufresne, J.-L., T. Fichefet, T., Friedlingstein, P., Gao, X., Gutowski, W., Johns, T., Krinner, G., Shongwe, M., Tebaldi, C., Weave, A., Wehner, M., 2013. Long-term Climate Change: Projections, Commitments, and Irreversibility. In: Stocker, T., Qin, D., Plattner, G.-K., Tignor, M., Allen, S., Boschung, J., Nauels, A., Xia, Y., Bex, V., Midgley, P. (Eds.), Climate Change 2013: The Physical Science Basis. Contribution of Working Group I to the Fifth Assessment Report of the Intergovernmental Panel on Climate Change. Cambridge University Press, Cambridge, United Kingdom and New York, NY, USA.

Costanza, R., de Groot, R., Sutton, P., van der Ploeg, S., Anderson, S. J., Kubiszewski, I., Farber, S., Turner, R. K., 2014. Changes in the global value of ecosystem services. Global Environmental Change 26, 152-158.

Doney, S. C., Fabry, V. J., Feely, R. A., Kleypas, J. A., 2009. Ocean acidification: the other $\mathrm{CO}_{2}$ problem. Annual Review of Marine Science 1 (1), 169-192.

Doney, S. C., Schimel, D. S., 2007. Carbon and climate system coupling on timescales from the Precambrian to the anthropocene. Annual Review of Environment and Resources 32, $31-66$. 
Fabricius, K. E., Langdon, C., Uthicke, S., Humphrey, C., Noonan, S., De'ath, G., Okazaki, R., Muehllehner, N., Glas, M. S., Lough, J. M., 2011. Losers and winners in coral reefs acclimatized to elevated carbon dioxide concentrations. Nature Clim Change 1 (3), 165169.

Feely, R. A., Doney, S., Cooley, S., 2009. Ocean acidification: present conditions and future changes in a high $\mathrm{CO}_{2}$ world. Oceanography 22 (4), 36-47.

Feely, R. A., Sabine, C. L., Lee, K., Berelson, W., Kleypas, J., Fabry, V. J., Millero, F. J., 2004. Impact of anthropogenic $\mathrm{CO}_{2}$ on the $\mathrm{CaCO}_{3}$ system in the oceans. Science 305 (5682), 362-6.

Gilmour, J. P., Smith, L. D., Heyward, A. J., Baird, A. H., Pratchett, M. S., 2013. Recovery of an isolated coral reef system following severe disturbance. Science 340 (6128), 69-71.

Glynn, P. W., Maté, J. L., Baker, A. C., 2001. Coral bleaching and mortality in Panama and Ecuador during the 1997-1998 El Niño-Southern Oscillation event: spatial/temporal patterns and comparisons with the 1982-1983 event. Bulletin of Marine Science 69 (1), 79-109.

Golbuu, Y., Bauman, A., Kaurtei, J., Victor, S., 2005. The state of coral reef ecosystems of the Republic of Palau. In: Waddell, J., Clark, A. (Eds.), The State of Coral Reef Ecosystems of the United States and Pacific Freely Associated States: 2005. NOAA Technical Memorandum NOS NCCOS 11. NOAA/NCCOS Center for Coastal Monitoring and Assessment's Biogeography Team, Silver Spring, MD, pp. 488-507.

Golbuu, Y., Victor, S., Penland, L., Idip, D., Emaurois, C., Okaji, K., Yukihira, H., Iwase, A., Woesik, R., 2007. Palau's coral reefs show differential habitat recovery following the 1998-bleaching event. Coral Reefs 26 (2), 319-332.

Hansen, J., Sato, M., Ruedy, R., Lo, K., Lea, D. W., Medina-Elizade, M., 2006. Global temperature change. Proceedings of the National Academy of Sciences of the United States of America 103 (39), 14288-14293.

Hartmann, D., Klein Tank, A., Rusticucci, M., Alexander, L., Brönnimann, S., Charabi, Y., Dentener, F., Dlugokencky, E., Easterling, D., Kaplan, A., Soden, B., Thorne, P., Wild, M., Zhai, P., 2013. Observations: Atmosphere and Surface. In: Stocker, T., Qin, D., Plattner, G.-K., Tignor, M., Allen, S., Boschung, J., Nauels, A., Xia, Y., Bex, V., Midgley, P. (Eds.), Climate Change 2013: The Physical Science Basis. Contribution of Working Group I to the Fifth Assessment Report of the Intergovernmental Panel on Climate Change. Cambridge University Press, Cambridge, United Kingdom and New York, NY, USA.

Hoegh-Guldberg, O., 1999. Climate Change, coral bleaching and the future of the world's coral reefs. Marine \& Freshwater Research 50, 839-866.

Hoegh-Guldberg, O., Mumby, P. J., Hooten, A. J., Steneck, R. S., Greenfield, P., Gomez, E., Harvell, C. D., Sale, P. F., Edwards, A. J., Caldeira, K., Knowlton, N., Eakin, C. M., Iglesias-Prieto, R., Muthiga, N., Bradbury, R. H., Dubi, A., Hatziolos, M. E., 2007. Coral reefs under rapid climate change and ocean acidification. Science 318 (5857), 1737-42.

Jones, R. J., Larkum, A. W. D., Schreiber, U., 2006. Temperature-induced bleaching of 
corals begins with impairment of the $\mathrm{CO}_{2}$ fixation mechanism in zooxanthellae. Plant, Cell and Environment 21 (1998), 1219-1230.

Kayanne, H., Hata, H., Kudo, S., Yamano, H., Watanabe, A., Ikeda, Y., Nozaki, K., Kato, K., Negishi, A., Saito, H., 2005. Seasonal and bleaching-induced changes in coral reef metabolism and $\mathrm{CO}_{2}$ flux. Global Biogeochemical Cycles 19 (3), GB3015.

Kroeker, K. J., Micheli, F., Gambi, M. C., Martz, T. R., 2011. Divergent ecosystem responses within a benthic marine community to ocean acidification. Proceedings of the National Academy of Sciences of the United States of America 108 (35), 14515-20.

Marino, S., Bauman, A., Miles, J., Kitalong, A., Bukurou, A., Mersai, C., Verheij, E., Olkeriil, I., Basilius, K., Colin, P., Patris, S., Victor, S., Andrew, W., Golbuu, Y., 2008. The state of coral reef ecosystems of the Republic of Palau. In: Waddell, J., Clark, A. (Eds.), The State of Coral Reef Ecosystems of the United States and Pacific Freely Associated States: 2008. NOAA Technical Memorandum NOS NCCOS 73. NOAA/NCCOS Center for Coastal Monitoring and Assessment's Biogeography Team, Silver Spring, MD, pp. $511-539$.

Maynard, J. A., McKagan, S., Raymundo, L., Johnson, S., Ahmadia, G. N., Johnston, L., Houk, P., Williams, G. J., Kendall, M., Heron, S. F., van Hooidonk, R., Mcleod, E., Tracey, D., Planes, S., 2015. Assessing relative resilience potential of coral reefs to inform management. Biological Conservation 192, 109-119.

McClanahan, T. R., Donner, S. D., Maynard, J. A., MacNeil, M. A., Graham, N. A. J., Maina, J., Baker, A. C., Alemu I., J. B., Beger, M., Campbell, S. J., Darling, E. S., Eakin, C. M., Heron, S. F., Jupiter, S. D., Lundquist, C. J., McLeod, E., Mumby, P. J., Paddack, M. J., Selig, E. R., van Woesik, R., 2012. Prioritizing key resilience indicators to support coral reef management in a changing climate. PLoS ONE 7 (8).

Mcleod, E., Anthony, K. R., Andersson, A., Beeden, R., Golbuu, Y., Kleypas, J., Kroeker, K., Manzello, D., Salm, R. V., Schuttenberg, H., Smith, J. E., 2013. Preparing to manage coral reefs for ocean acidification: lessons from coral bleaching. Frontiers in Ecology and the Environment 11 (1), 20-27.

Middlebrook, R., Hoegh-Guldberg, O., Leggat, W., 2008. The effect of thermal history on the susceptibility of reef-building corals to thermal stress. The Journal of Experimental Biology 211 (7), 1050-6.

Moberg, F., Folke, C., 1999. Ecological Goods and Services of Coral Reef Ecosystems. Ecological Economics 29, 215-233.

Obura, D. O., 2005. Resilience and climate change: lessons from coral reefs and bleaching in the Western Indian Ocean. Estuarine, Coastal and Shelf Science 63 (3), 353-372.

Orr, J. C., Fabry, V. J., Aumont, O., Bopp, L., Feely, R. A., Doney, S. C., Gnanadesikan, A., Gruber, N., Ishida, A., Joos, F., Key, R. M., Lindsay, K., Maier-Reimer, E., Matear, R., Monfray, P., Mouchet, A., Najjar, R. G., Plattner, G.-K., Rodgers, K. B., Sabine, C. L., Sarmiento, J. L., Schlitzer, R., Slater, R. D., Totterdell, I. J., Weirig, M.-F., Yamanaka, Y., Yool, A., 2005. Anthropogenic ocean acidification over the twenty-first century and its impact on calcifying organisms. Nature 437 (7059), 681-6. 
Palumbi, S. R., Barshis, D. J., Traylor-Knowles, N., Bay, R. A., 2014. Mechanisms of reef coral resistance to future climate change. Science 344 (6186), 895-8.

Pandolfi, J. M., Connolly, S. R., Marshall, D. J., Cohen, A. L., 2011. Projecting coral reef futures under global warming and ocean acidification. Science 333 (6041), 418-22.

Rhein, M., Rintoul, S. R., Aoki, S., Campos, E., Chambers, D., Feely, R. A., Gulev, S., Johnson, G. C., Josey, S. A., Kostianoy, A., Mauritzen, C., Roemmich, D., Wang, F., 2013. Observations: Ocean. In: Stocker, T., Qin, D., Plattner, G.-K., Tignor, M., Allen, S., Boschung, J., Nauels, A., Xia, Y., Bex, V., Midgley, P. (Eds.), Climate Change 2013: The Physical Science Basis. Contribution of Working Group I to the Fifth Assessment Report of the Intergovernmental Panel on Climate Change. Cambridge University Press, Cambridge, United Kingdom and New York, NY, USA.

Riegl, B., Piller, W. E., 2003. Possible refugia for reefs in times of environmental stress. International Journal of Earth Sciences 92 (4), 520-531.

Shamberger, K. E. F., Cohen, A. L., Golbuu, Y., McCorkle, D. C., Lentz, S. J., Barkley, H. C., 2014. Diverse coral communities in naturally acidified waters of a Western Pacific reef. Geophysical Research Letters 41, 499-504.

Spalding, M. D., Ravilious, C., Green, E. P., 2001. World Atlas of Coral Reefs. University of California Press, Berkeley, USA.

Unsworth, R. K. F., Collier, C. J., Henderson, G. M., McKenzie, L. J., 2012. Tropical seagrass meadows modify seawater carbon chemistry: implications for coral reefs impacted by ocean acidification. Environmental Research Letters 7, 024026.

van Hooidonk, R., Maynard, J. A., Manzello, D., Planes, S., 2014. Opposite latitudinal gradients in projected ocean acidification and bleaching impacts on coral reefs. Global change biology 20 (1), 103-12.

van Hooidonk, R., Maynard, J. A., Planes, S., 2013. Temporary refugia for coral reefs in a warming world. Nature Climate Change 3 (5), 508-511.

van Woesik, R., Houk, P., Isechal, A. L., Idechong, J. W., Victor, S., Golbuu, Y., 2012. Climate-change refugia in the sheltered bays of Palau: analogs of future reefs. Ecology and evolution 2 (10), 2474-84.

Watanabe, A., Kayanne, H., Hata, H., Kudo, S., Nozaki, K., Kato, K., Negishi, A., Ikeda, Y., Yamano, H., 2006. Analysis of the seawater $\mathrm{CO}_{2}$ system in the barrier reef-lagoon system of Palau using total alkalinity-dissolved inorganic carbon diagrams. Science and Technology 51 (4), 1614-1628.

West, J. M., Salm, R. V., 2003. Resistance and resilience to coral bleaching: implications for coral reef conservation and management. Conservation Biology 17 (4), 956-967.

Wilkinson, C., 2008. Status of coral reefs of the world: 2008. Tech. rep., Global Coral Reef Monitoring Network and Reef and Rainforest Research Centre, Townsville. 


\section{Chapter 2}

\section{Skeletal records of community-level bleaching in Porites corals from Palau}

\section{$2.1 \quad$ Abstract}

Tropical Pacific sea surface temperature is projected to rise an additional $2-3{ }^{\circ} \mathrm{C}$ by the end of this century, driving an increase in the frequency and intensity of coral bleaching. With significant global coral reef cover already lost due to bleaching-induced mortality, efforts are underway to identify thermally tolerant coral communities that might survive projected warming. Massive, long-lived corals accrete skeletal bands of anomalously high density in response to episodes of thermal stress. These "stress bands" are potentially valuable proxies for thermal tolerance, but to date their application to questions of community bleaching history has been limited. Ecological surveys recorded bleaching of coral communities across the Palau archipelago during the 1998 and 2010 warm events. Between 2011 and 2015, we extracted skeletal cores from living Porites colonies at 10 sites spanning barrier reef and lagoon environments and quantified the proportion of stress bands present in each population during bleaching years. Across Palau, the prevalence of stress bands tracked the severity of thermal stress, with more stress bands occurring in 1998 (degree heating weeks $=13.57^{\circ} \mathrm{C}$ week) than during the less severe 2010 event (degree heating weeks $=4.86{ }^{\circ} \mathrm{C}$-week). Stress band prevalence also varied by reef type, as more corals on the exposed barrier reef formed stress bands than did corals from sheltered lagoon environments. Comparison of Porites stress band prevalence with bleaching survey data revealed a strong correlation between percent community bleaching and the proportion of colonies with stress bands in each year. Conversely, calcification rates did not decline consistently during bleaching years nor did annually-resolved calcification histories always track interannual variability in temperature. Our data suggest that stress bands in massive corals contain valuable information about spatial and temporal trends in coral reef bleaching and can aid in conservation efforts to identify temperature-tolerant coral reef communities.

This chapter is published as: Hannah C. Barkley and Anne L. Cohen, 2016. Skeletal records of community-level bleaching in Porites corals from Palau. Coral Reefs, doi: 10.1007/s00338-016-1483-3. The final publication is available at Springer via http://dx.doi.org/10.1007/s00338-016-1483-3, and this article is reprinted as published with permission granted in the original copyright agreement. 


\subsection{Introduction}

The tropical oceans that sustain coral reef ecosystems have warmed by $0.09{ }^{\circ} \mathrm{C}$ per decade from 1950 to 2011, a trend that is expected to continue over the course of this century (Lough, 2012). An increase in sea surface temperature (SST) just $1^{\circ} \mathrm{C}$ above climatological summer SST can trigger the breakdown of the coral host-zooxanthellae symbiosis, resulting in coral bleaching and, if prolonged, to mortality (Hoegh-Guldberg, 1999; Jones et al., 2006). More than $16 \%$ of global coral reef cover has been lost in the last two decades due to bleachinginduced mortality (Wilkinson, 2008). If model projections of future rates of SST rise are realized, most tropical reef ecosystems could experience severe bleaching every year by 2055 with insufficient time for recovery (van Hooidonk et al., 2014).

These projections raise concerns about the ability of coral reef ecosystems to survive through the twenty-first century. Nevertheless, thermal thresholds of corals vary by genera, habitat, and depth, and thus, considerable efforts are underway to exploit this natural variability, identify thermally tolerant reef communities, and prioritize their protection with the goal to maximize their chances of surviving future warming (West and Salm, 2003; Baker et al., 2008; van Woesik et al., 2012). Identification of thermally tolerant reef communities is challenging, however, because it requires in situ monitoring over extensive areas during bleaching events. Observations spanning multiple bleaching events are considered most valuable in the forecasting of future thermal tolerance (West and Salm, 2003; Obura, 2005; Baker et al., 2008). Yet, despite multiple mass bleaching events in the last $30 \mathrm{yrs}$, few comprehensive ecological datasets exist that report spatial patterns in coral reef bleaching within a single reef system. Even fewer span multiple events (Glynn et al., 2001; Berkelmans et al., 2004; Obura, 2005; Gilmour et al., 2013).

Previous studies have reported the presence of discrete, anomalously high-density bands in the skeletons of massive reef-building corals (Druffel and Linick, 1978; Hudson, 1978; Scoffin et al., 1992; Dodge et al., 1993; Smithers and Woodroffe, 2001; Mendes and Woodley, 2002; Hendy et al., 2003; Carilli et al., 2009, 2010; Cantin et al., 2010; Cantin and Lough, 2014; Mallela et al., 2015). These high-density regions, termed "stress bands," are considered to reflect episodes of sublethal thermal stress (and possibly bleaching) from which the colony later recovered. Prominent stress bands in coral skeletal cores have been documented in several species (e.g. Orbicella spp., Colpophyllia natans, and Porites spp.) and on coral 
reefs in the Caribbean, Pacific, and Indian Oceans (Hudson, 1978; Carilli et al., 2010; Cantin and Lough, 2014; Mallela et al., 2015). Most evidence suggests that stress bands form in response to warmer than average temperatures (Hendy et al., 2003; Cantin et al., 2010; Carilli et al., 2010, 2012; Cantin and Lough, 2014; Mallela et al., 2015), with anomalously low-density bands attributed to periods of cold water stress (Lough and Cooper, 2011). Thus, the presence of skeletal stress bands can serve as an archive of thermal stress responses to historical high-temperature events in the absence of extensive observational data. However, to date, the interpretation of coral stress bands has remained largely qualitative and restricted to the scale of individual coral colonies.

Here we combine coral skeletal records with in situ observational data to investigate the relationship between stress bands and community bleaching. SST on Palau has increased by $\approx 0.7^{\circ} \mathrm{C}$ since 1970 , consistent with the global trend (Osborne et al. 2013). Superimposed upon this warming have been multiple periods of high temperature associated with phases of the El Niño Southern Oscillation (ENSO). Approximately 6-10 months after the peak El Niño, sustained elevated SSTs in the western Pacific led to moderate to high levels of bleaching on Palau reefs (Bruno et al., 2001; van Woesik et al., 2012). The availability of bleaching data collected on Palau during both events enables us to quantitatively connect colony-scale stress markers with community-level bleaching. We address four main questions regarding the potential use of coral skeletal records as proxies for community-level bleaching. First, we asked whether stress band prevalence could be used to reconstruct past bleaching events within the coral community. Second, we tested whether evidence of bleaching or stress in one bleaching event predisposed a colony to stress in a subsequent event. Third, we tracked spatial and temporal variability in stress band prevalence and used stress band data to interpret spatial and temporal patterns in bleaching on Palau. Finally, we assessed the sensitivity of annual calcification rates to thermal stress during specific bleaching years and over the longer-term rise in temperature. Our findings explore the potential of coral skeletal records to reconstruct the spatial and temporal patterns in thermal stress responses of coral communities over multiple high-temperature events. 


\subsection{Methods}

\subsubsection{Sea surface temperature}

Monthly satellite SST and SST anomaly records (January 1990 to December 2013) at $0.25^{\circ}$ resolution were acquired from the National Oceanic and Atmospheric Administration (NOAA) optimum interpolated sea surface temperature (OI-SST) database (downloaded from http://coastwatch.pfeg.noaa.gov) for Palau (centered at $7.250^{\circ} \mathrm{N}, 134.375^{\circ} \mathrm{E}$ ) and analyzed as netCDF files in MATLAB (version 2013a). Data for 1 June to 30 November of 1998 and 2010 were extracted to calculate SST anomalies experienced by Palau reefs during the warmest months (SST anomalies $>1{ }^{\circ} \mathrm{C}$ ) of both events. OI-SST anomalies are calculated relative to a 30-yr climatological mean (1971-2000). In addition, degree heating weeks (DHW) were calculated following the standard NOAA procedure to measure accumulated thermal stress during each bleaching period (Gleeson and Strong, 1995).

\subsubsection{Coral skeletal core collection}

We collected 101 skeletal cores from massive Porites coral colonies at 10 reef sites representing two major reef environments, barrier reef and lagoon, the latter including fringing reefs around the uplifted karst Rock Islands (Table A.1). The two environments are broadly distinguishable in both physical (flow, temperature, and light regimes) and chemical (carbon system parameters, salinity) characteristics with generally higher flow, light, $\mathrm{pH}$, and salinity and lower SST on the barrier reefs (Shamberger et al., 2014; Barkley et al., 2015).

Skeletal cores (20-40 cm in length) were collected in April 2011, September 2011, April 2012, August 2014, and January 2015 vertically from live coral colonies at 1-6 m depth using pneumatic drills with 3.8-cm-diameter diamond drill bits (Table A.1). Core holes were filled with cement plugs hammered flush with the colony surface and sealed with underwater epoxy. Visual inspections of colonies 6-12 months after coring revealed significant overgrowth of plugs and no long-term impacts to the corals. Coral cores were oven-dried and scanned with a Siemens Volume Zoom Helical Computerized Tomography (CT) Scanner at WHOI. 3-D CT scans of coral cores were analyzed using OsiriX freeware to visualize the 3-D image (Cantin et al., 2010; Crook et al., 2013) and an automated MATLAB code to quantify skeletal growth parameters and stress banding (DeCarlo and Cohen, 2016). 


\subsubsection{Stress bands}

Coral cores that included growth records prior to 1998 were assessed for the presence of high-density stress bands associated with elevated temperatures in 1998 ( $\mathrm{n}=86)$, and all cores were examined for stress bands in 2010. A stress band was defined as a region of the coral core $>1 \mathrm{~mm}$ in height and extending the entire width of the core where density values exceeded two standard deviations of the whole-core density mean (Figure 2-1). We defined a minimum band thickness in order to filter out smaller-scale density variability and high-density noise. A value of $1 \mathrm{~mm}$ for this thickness threshold was selected based on the average linear extension rates of Palau Porites corals $\left(0.88 \mathrm{~cm} \cdot \mathrm{yr}^{-1}\right.$, interquartile range $=0.35 \mathrm{~cm} \cdot \mathrm{yr}^{-1}$ ), where $1 \mathrm{~mm}$ represents, on average, approximately $10 \%$ of overall annual linear extension. High-density anomalies of this width therefore represent significant perturbations in growth. Density thresholds were set based on standard deviations from mean values in order to account for significant differences in density means and variability between individuals. Densities values are normally distributed within coral cores, and values greater than two standard deviations were defined as the threshold for a stress band. This threshold was selected to aid in the identification of only the most anomalously high-density areas (i.e. areas with densities greater than approximately $95 \%$ of all values) while also minimizing the probability of type II errors in coral cores where stress bands exist, but highdensity values are slightly less extreme. Stress bands were identified as occurring within a particular year (specifically, 1998 and 2010) based on annual patterns of density banding, in which successive low-density bands were counted down from the top of the core and subsequently dated based on the known date of collection. Although a small number of coral skeletal cores had occasional high-density regions in additional years, we did not consistently detect stress bands corresponding to years other than 1998 and 2010.

The percentage of Porites corals with stress bands was compared with community bleaching data for each reef site collected during the 1998 and 2010 high-temperature events. Bleaching data from 1998 were collected at 9 reef sites in November 1998 using a pointintercept technique with three replicate $20 \mathrm{~m}$ transect surveys per site conducted at $3-5 \mathrm{~m}$ depth (Bruno et al., 2001). A subset of 6 of 9 nine sites was used to compare bleaching data to stress band records based on proximity to our core collection sites. Data from 2010 were collected at 80 randomly assigned reef sites in July and August 2010 with three replicate 
$30 \mathrm{~m}$ transect surveys conducted at 2-5 $\mathrm{m}$ depth (van Woesik et al., 2012). A subset of 31 of these sites was included in this study. Because in situ bleaching data were collected at randomized locations, the spatial matches between sites with bleaching data and sites with coral cores were not always exact. Therefore, for each coral core collection site, we averaged bleaching data from the two or three sites that both fell within a $10 \mathrm{~km}$ radius of each core site and that represented the same environment type to calculate a community bleaching estimate. Bleaching information about specific coral colonies from which we collected cores was not available.

\subsubsection{Coral calcification histories}

Calcification rates were calculated as the product of annual linear extension and density following the automated procedure described in DeCarlo et al. (2015), which traces density variations along individual corallites identified within the entire 3-D core. Extension rates (upward linear growth) were measured between the successive low-density bands of annual high-low density couplets. Annual density banding was clearly represented in all cores, with low density bands formed at the beginning of each year (c. February) and high-density bands accreted toward the mid- to late months of the year (c. September). Band identifications were verified using cross-dating, a dendrochronology technique in which shared years of lower growth rates are identified and matched across core records (Fritts, 1976; Yamaguchi, 1991). Annual skeletal densities were calculated from CT scan intensities converted to calcium carbonate density values using nine coral standards $\left(0.81-1.54 \mathrm{~g} \cdot \mathrm{cm}^{-3}\right)$, where independent measurements of weight and volume for each standard were used to derive a linear relationship between CT scan intensity values (in Hounsfield units) and calcium carbonate density (in $\mathrm{g} \cdot \mathrm{cm}^{-3}$ ) (DeCarlo et al., 2015).

\subsubsection{Statistical analysis}

All statistical analyses were conducted in $\mathrm{R}$ (version 3.0.1). We evaluated the effect of year, reef type (lagoon or barrier), and their interaction in the presence of high-density stress bands in Porites coral cores. Stress band proportion data calculated for each individual reef site met criteria for normality and homoscedasticity, and were evaluated with twoway ANOVAs with post hoc Tukey honest significant difference (HSD) tests. Stress band proportions were compared to site and event-specific bleaching data with generalized linear 
models. To evaluate coral calcification records, linear mixed effects models were constructed using the nlme package (Pinherio et al., 2012) following the statistical procedures outlined in De'ath et al. (2009) and Castillo et al. (2011, 2012). In our mixed effects models, coral cores were considered to be random effects, and individual slopes and intercepts were fit to each core record to account for repeated, nonrandom measurements on the same colonies through time, controlling for the fact that coral colonies often have very different underlying calcification rates. In addition, residual correlation structures were included to account for the temporal autocorrelation present in the calcification time series. We constructed models to evaluate the relationship between annual coral calcification rates and 1) year, 2) reef type, 3) growth after 1998 and 2010, and 4) annual SST anomaly. The year predicator was centered in 2001 to improve model fit, and calcification rates after the two major bleaching events were coded as binary variables for post-1998 (1998-2000) and post-2010 (2010-2012). Models were scored and selected by minimizing the Akaike information criterion (AIC).

\subsection{Results}

Satellite SST records show that temperatures in Palau have increased significantly over the period 1990-2013 by $0.03{ }^{\circ} \mathrm{C} \cdot \mathrm{yr}$ (generalized linear model, $\mathrm{p}<0.001$ ). In addition to longterm warming, Palau's reefs experienced ENSO-driven elevated temperature anomalies in mid- to late 1998 and 2010 (Figure 2-2a). During the 1998 bleaching event (1 June to 30 November 1998), Palau reefs experienced mean \pm SD SST anomalies of $1.02{ }^{\circ} \mathrm{C} \pm 0.46{ }^{\circ} \mathrm{C}$ and maximum DHW $=13.57^{\circ} \mathrm{C}$-week (Figure $2-2 \mathrm{~b}$ ). Over the same six month period in 2010, mean SST anomalies reached $0.90{ }^{\circ} \mathrm{C} \pm 0.26^{\circ} \mathrm{C}$ with maximum $\mathrm{DHW}=4.82{ }^{\circ} \mathrm{C}$-week. The spatial resolution of OI-SST data was not high enough to confidently distinguish SST anomalies and DHW between Palau's barrier and lagoon reef environments.

Stress bands were identified in lagoon and barrier Porites skeletal cores during both 1998 and 2010 high-temperature events (Figure 2-3; Table A.1). Stress band prevalence varied significantly by year (two-way ANOVA, $\mathrm{F}_{1,16}=38.03, \mathrm{p}<0.001$ ), as the occurrence of stress bands across all reefs was greater in response to elevated temperatures in 1998 than in 2010, which was a less severe thermal stress event (Tukey HSD, p $<0.001$ ). We found no effect of multiple bleaching events on the occurrence of stress bands, as only $10 \%$ of all corals analyzed had a stress band during both events, and corals with a stress band in 
1998 were no more likely to have a stress band in 2010 than were those with no evidence of stress during the 1998 event (odds ratio $=2.1,95 \%$ confidence interval $=0.7,6.1$ ). Stress band prevalence also varied significantly by reef type (two-way ANOVA, $\mathrm{F}_{1,16}=14.57, \mathrm{p}$ $=0.001)$, with more corals on the barrier reefs showing stress responses than corals on the lagoon reefs. In 1998, stress band prevalence was greater on barrier reefs (50-67\%) than inshore reefs $(18-50 \%$; Tukey HSD, $\mathrm{p}=0.002)$. However, in 2010, stress band presence was more evenly distributed across reefs (10-30\%), and there was no significant difference across reef types (Tukey HSD, $\mathrm{p}=0.79$ ). The percentage of coral cores with a stress band and the observed extent of community bleaching that same year were significantly correlated $(\mathrm{n}=15, \mathrm{r}=0.96, \mathrm{p}<0.001)$. In addition, Porites stress band prevalence was a strong predictor of reef community bleaching across reef sites over two bleaching events (Figure 2-4; generalized linear model, slope $=0.89, \mathrm{SE}=0.07, \mathrm{p}<0.001)$.

Periods of anomalously high SST did not consistently result in declines in calcification (Figure 2-5a; Table A.2). Significantly reduced site-averaged calcification rates during or post-1998 were detected at only one site on the western (leeward) barrier reef (Siaes) and one inshore Rock Islands site (Mecherchar) and during or post-2010 at one inshore Rock Islands site (Risong). Calcification rates at all other sites were maintained after these periods of thermal stress, even in coral assemblages with a high prevalence of skeletal stress markers during both bleaching events.

Trajectories in annual calcification from 1990 to 2013 varied across reef environments and between reef sites, with variations in the change in calcification rates over time generally corresponding with distance inshore from the open ocean (Figure 2-5, Table A.2, Table A.3). Overall barrier reef coral calcification rates declined by $0.009 \pm 0.003 \mathrm{~g} \cdot \mathrm{cm}^{-2} \cdot \mathrm{yr}^{-1}$ (mean $\pm \mathrm{SE} ; \mathrm{p}=0.003,95 \%$ confidence interval: -0.014, -0.003) from 1990 to 2013. Within the barrier reef environment, calcification rates from two forereef sites (Short Drop Off and Siaes) decreased significantly, while there was no change in calcification at two sites on the reef crest (Ngerdiluches and Uchelbeluu) or a patch reef slightly inshore (Ngerchelong). The growth rates of barrier corals also corresponded significantly to variability in SST anomalies, with calcification rates declining $0.090 \pm 0.032 \mathrm{~g} \cdot \mathrm{cm}^{-2} \cdot \mathrm{yr}^{-1}$ with increases in SST (mean \pm $\mathrm{SE} ; \mathrm{p}=0.006,95 \%$ confidence interval: $-0.154,-0.025$; Table A.4).

There was no overall temporal trend in calcification rates of corals in lagoon reefs or a significant relationship between lagoon growth rates and SST from 1990 to 2013. However, 
within the lagoon reef environment, trends also varied across sites: Calcification rates decreased significantly at the two more exposed Rock Island reefs (PICRC and Taoch), but increased significantly over the same period at the three highly sheltered reefs (Mecherchar, Nikko Bay, and Risong). At all lagoon reef sites, the observed changes in calcification over time were relatively small (ranging from -0.019 to $0.007 \mathrm{~g} \cdot \mathrm{cm}^{-2} \cdot \mathrm{yr}^{-1}$ ) and were less than $<5 \%$ of measured annual calcification rates.

Calcification data also revealed significant differences in growth rates between reef types. On average, growth rates of barrier reef corals (1990-2013 mean $\pm \mathrm{SD}=1.31 \pm 0.42$ $\left.\mathrm{g} \cdot \mathrm{cm}^{-2} \cdot \mathrm{yr}^{-1}\right)$ were greater than corals from lagoon reefs $\left(0.85 \pm 0.23 \mathrm{~g} \cdot \mathrm{cm}^{-2} \cdot \mathrm{yr}^{-1}\right)(\mathrm{p}<$ 0.001). This difference between barrier and reef interior was driven in large part by the high calcification rates of corals on the western (leeward) barrier reef $\left(1.39 \pm 0.39 \mathrm{~g} \cdot \mathrm{cm}^{-2} \cdot \mathrm{yr}^{-1}\right)$, which were significantly greater than those on the eastern (windward) barrier $(1.15 \pm 0.43$ $\left.\mathrm{g} \cdot \mathrm{cm}^{-2} \cdot \mathrm{yr}^{-1} ; \mathrm{p}=0.019\right)$ (see Appendix E).

\subsection{Discussion}

As the oceans warm and episodes of coral reef bleaching become more frequent, identifying and protecting coral reef communities with high thermal thresholds and rapid recovery after bleaching becomes an increasingly attractive and viable strategy to maximize survival of coral reefs under global climate change. Yet, the identification of temperature-tolerant reefs on a large scale remains a challenging task despite the occurrence of multiple mass bleaching events in the last few decades; reef environments are often environmentally and compositionally heterogeneous, and the logistical and financial constraints associated with intensive on-site monitoring are exacerbated in remote areas. For this reason, massive longlived coral colonies that have experienced and survived those events and recorded their responses in their skeletons may serve as valuable sources of information in the absence of, or in addition to, in situ survey data.

Our results reveal a high level of agreement between Porites coral stress band prevalence and observed community bleaching levels across two distinct high-temperature events on Palau. Prevalence of stress bands was within one standard error of mean observed bleaching during the two events for 10 coral reef sites representing two distinct types of reef environments and community assemblages. While we do not know how the presence of stress bands 
in a Porites skeleton reflects the timing and extent of bleaching at the scale of the coral colony, this suggests that Porites skeletal stress markers may quantitatively estimate levels of community-scale bleaching regardless of levels of individual colony bleaching. The strong relationship between stress bands in Porites corals that survived repeat bleaching events and the average extent of community bleaching observed here may exist because Porites is a moderately to highly temperature-tolerant genus (van Woesik et al., 2011; Guest et al., 2012). Under this hypothesis, evidence of sublethal stress preserved within skeletons of Porites colonies would be indicative of bleaching of less tolerant species and approximate average levels of stress experienced by the broader coral community.

While Porites stress band data provide an approximation of community responses to temperature in Palau, future work should evaluate the broad applicability of this proxy to other reef systems with different community compositions. In our study area, stress band prevalence accurately reflected community-level bleaching across a variety of reef environments and community compositions. However, in other reef systems, it is possible that Porites stress band prevalence could underestimate bleaching levels if communities are dominated by coral genera with relatively low thermal tolerances or overestimate bleaching sensitivity in communities with an abundance of very thermally tolerant species. Another aspect that requires evaluation is the possibility of reduced thermal tolerance during the lifetime of a single colony, for which there is some evidence from experimental data (Schoepf et al., 2015). We do not find strong evidence for this in our coral cores, as we found that accreting a stress band during the 1998 bleaching event did not change the odds that an individual coral would form a stress band during the 2010 event. This suggests that thermal thresholds of coral colonies that were stressed by the 1998 warming did not decline or that colonies had already recovered by the time the 2010 warm event occurred.

Despite these potential caveats, our results suggest that stress bands in massive longlived corals contain critical information about spatial and temporal variability in bleaching sensitivity within and across reef assemblages. We propose that it is possible to develop skeletal stress markers in Porites and other long-lived massive species to retroactively document spatial and temporal variability in coral reef bleaching in of the absence of extensive visual surveys. Where survey data are available, application of this index in combination with other ecological metrics, such as coral cover or diversity, would strengthen assessments of reef-scale thermal sensitivities and assist in the identification of reef assemblages with 
particularly high resistance to temperature stress.

Our study revealed differences in thermal tolerance across Palau's reefs. In 1998, the prevalence of stress bands was significantly higher in corals collected from barrier reef environments than in those collected inshore, a result supported by anecdotal evidence from sheltered lagoon sites (Fabricius et al., 2004; Penland et al., 2004). Observational bleaching data collected in November 1998 found no overall influence of reef type on bleaching extent, but did record significant differences in bleaching between the individual reef sites considered in this study (Bruno et al., 2001). This inconsistency between the survey data and the stress band result may relate to the exact sites surveyed or the timing of the survey, which occurred several weeks after peak temperature anomalies. In 2010, when SST anomalies and DHW were less severe than 1998, we observed fewer skeletal stress markers in Porites corals across our study sites. While not statistically significant, corals from barrier reef sites again showed generally higher occurrence of stress bands than those on the inshore reefs. This observation is consistent with monitoring data collected from July to August 2010 (van Woesik et al., 2012), implying that inshore corals displayed persistently higher thermal tolerance than barrier reef corals on Palau through two bleaching events.

The differences in stress band prevalence between barrier and inshore sites, which we interpret as reflecting differences in bleaching extent, could relate to a number of localized environmental or physiological factors. For example, Palau's lagoon reefs are highly turbid and heavily shaded by the surrounding Rock Islands, factors which may alleviate stress from excess temperature or irradiance during bleaching events (West and Salm, 2003; Golbuu et al., 2007; Cacciapaglia and van Woesik, 2015). Alternatively, temperatures on Palau barrier reefs are cooler than the temperatures experienced by lagoon reefs (Figure A-1), and experimental evidence suggests that corals living in chronically warm environments may be better able to survive elevated temperatures than individuals acclimatized to cooler conditions (Castillo and Helmuth, 2005; Middlebrook et al., 2008). Furthermore, some coral genera within the Rock Islands have also been shown to host more thermally tolerant clade D symbionts. However, because Porites corals in Palau appear to consistently harbor clade C symbionts even within the very warm lagoon, variation in symbiont type cannot necessarily explain the variations in temperature sensitivity that we observe even within Porites corals (Fabricius et al., 2004).

There is strong evidence that coral calcification is sensitive to temperature. Studies that 
have examined both skeletal stress markers and calcification rates post-stress have generally, but not always, found marked calcification declines after the presence of stress bands (Mendes and Woodley, 2002; Carilli et al., 2009, 2010; Cantin and Lough, 2014; Mallela et al., 2015). In Palau, we did not consistently detect large changes in annually resolved calcification following periods of known bleaching, even in corals forming stress bands during bleaching years. This might imply a high level of resilience in the Palau Porites corals, with colonies recovering very quickly after the bleaching event. Or, assuming our method is sensitive enough to detect potential changes in calcification, it may reveal that interannual variability in calcification rates is not a reliable proxy for acute stress.

Over longer time scales, Palau barrier reef corals exhibited overall small, but significant declines in calcification rates, although there was considerable variability in calcification trends across individual reef sites within the barrier environment. This observation is consistent with multiple studies that have reported marked decreases in coral growth over the past few decades, including data from the Great Barrier Reef (Cooper et al., 2008; De'ath et al., 2009), Red Sea (Cantin et al., 2010), Belize (Castillo et al., 2011), Andaman Sea (Tanzil et al., 2009), the Thai-Malay Peninsula (Tanzil et al., 2013), and Panama (Manzello, 2010). On many of these reefs, declining trends in growth have been linked to increasing SST, suggesting that ocean warming may have already produced temperatures that surpass the thermal thresholds of many reef-building corals worldwide. However, the same overall declines in calcification over time were not observed in Palau's inshore corals. Our results are consistent with those from Belize, where calcification declines were observed in exposed, forereef communities relative to more sheltered inshore reef environments (Castillo et al., 2011, 2012). One explanation for this pattern is that thermal tolerances of inshore corals are higher than barrier reef corals. Alternatively, the distinct calcification trajectories between the barrier and inshore reefs may reflect differential changes in other environmental parameters such as light or $\mathrm{pH}$. If declines in calcification of Porites on the barrier reef are causally linked to thermal stress or the result of some other driver, they may be indicative of a common underlying level of stress experienced across the reef community. For example, concurrent with declining Porites calcification rates has been a $>50 \%$ decline in coral cover on Palau barrier reefs since 1992 (Golbuu et al., 2007). On their own, significant decreases in the skeletal growth of Porites and other major reef-building genera may reduce rates of overall reef accretion and ultimately compromise the structural integrity of reef habitats 
(De'ath et al., 2009).

As ocean temperatures continue to rise over the next few decades, monitoring, tracking, and evaluating coral reef temperature sensitivities will become increasingly important if we are to project coral reef trajectories under climate change and to protect coral reef communities that have the highest thermal tolerances. Coral skeletal records may be invaluable

tools in these efforts. As such, it is vital that we continue to fine-tune our understanding of coral skeletal stress markers across coral species and reef assemblages so that we may better apply the historical insight that they provide into coral conservation efforts over the next century.

\subsection{Acknowledgments}

The authors thank Y. Golbuu, T. DeCarlo, G.P. Lohmann, K. Pietro, K. Karnauskas, A. Shalapyonok, D. Ketten, J. Arruda, S. Cramer, C. MacDonald, G. Mereb, A. Merep, M. Kaplan, H. Rivera, and the staff of the Palau International Coral Reef Center (PICRC) for assistance with fieldwork and analyses. This work was supported by a NSF Graduate Research Fellowships and a Next Wave Fellowship to H. Barkley, National Science Foundation award OCE-1031971, the Dalio Foundation, Inc., through the Dalio Explore Fund, Ray Dalio through the WHOI Access to the Sea Fund, the Tiffany \& Co. Foundation, and the Nature Conservancy. 


\subsection{References}

Baker, A. C., Glynn, P. W., Riegl, B., 2008. Climate change and coral reef bleaching: An ecological assessment of long-term impacts, recovery trends and future outlook. Estuarine, Coastal and Shelf Science 80 (4), 435-471.

Barkley, H. C., Cohen, A. L., Golbuu, Y., Starczak, V. R., DeCarlo, T. M., Shamberger, K. E. F., 2015. Changes in coral reef communities across a natural gradient in seawater $\mathrm{pH}$. Science Advances 1, 1-7.

Berkelmans, R., De'ath, G., Kininmonth, S., Skirving, W. J., 2004. A comparison of the 1998 and 2002 coral bleaching events on the Great Barrier Reef: spatial correlation, patterns, and predictions. Coral Reefs 23 (1), 74-83.

Bruno, J. F., Siddon, C., Witman, J., Colin, P., Toscano, M., 2001. El Niño related coral bleaching in Palau, Western Caroline Islands. Coral Reefs 20 (2), 127-136.

Cacciapaglia, C., van Woesik, R., 2015. Climate-change refugia: shading reef corals by turbidity. Global Change Biology, 1145-1154.

Cantin, N. E., Cohen, A. L., Karnauskas, K. B., Tarrant, A. M., McCorkle, D. C., 2010. Ocean warming slows coral growth in the central Red Sea. Science 329, 322-325.

Cantin, N. E., Lough, J. M., 2014. Surviving coral bleaching events: Porites growth anomalies on the Great Barrier Reef. PloS one 9 (2), e88720.

Carilli, J., Donner, S. D., Hartmann, A. C., 2012. Historical temperature variability affects coral response to heat stress. PLoS ONE 7 (3), e34418.

Carilli, J. E., Norris, R. D., Black, B., Walsh, S. M., McField, M., 2009. Local stressors reduce coral resilience to bleaching. PLoS ONE 4 (7), e6324.

Carilli, J. E., Norris, R. D., Black, B., Walsh, S. M., McField, M., 2010. Century-scale records of coral growth rates indicate that local stressors reduce coral thermal tolerance threshold. Global Change Biology 16 (4), 1247-1257.

Castillo, K. D., Helmuth, B. S. T., 2005. Influence of thermal history on the response of Montastraea annularis to short-term temperature exposure. Marine Biology 148 (2), 261270 .

Castillo, K. D., Ries, J. B., Weiss, J. M., 2011. Declining coral skeletal extension for forereef colonies of Siderastrea siderea on the Mesoamerican Barrier Reef System, Southern Belize. PLoS ONE 6 (2), e14615.

Castillo, K. D., Ries, J. B., Weiss, J. M., Lima, F. P., 2012. Decline of forereef corals in response to recent warming linked to history of thermal exposure. Nature Climate Change 2 (10), 756-760.

Cooper, T. F., De'ath, G., Fabricius, K. E., Lough, J. M., 2008. Declining coral calcification in massive Porites in two nearshore regions of the northern Great Barrier Reef. Global Change Biology 14 (3), 529-538.

Crook, E., Cohen, A. L., Rebolledo-Vieyra, M., Hernandez, L., Paytan, A., 2013. Reduced 
calcification and lack of acclimatization by coral colonies growing in areas of persistent natural acidification. Proceedings of the National Academy of Sciences of the United States of America 110 (27), 11044-9.

De'ath, G., Lough, J. M., Fabricius, K. E., 2009. Declining coral calcification on the Great Barrier Reef. Science 323 (January), 116-119.

DeCarlo, T., Cohen, A. L., Barkley, H., Shamberger, K., Cobban, Q., Young, C., Brainard, R. E., Golbuu, Y., 2015. Coral bioerosion is accelerated by ocean acidification and nutrients. Geology 43, 7-10.

DeCarlo, T. M., Cohen, A. L., 2016. coralCT: software tool to analyze computerized tomography $(\mathrm{CT})$ scans of coral skeletal cores for calcification and bioerosion rates. http://dx.doi.org/10.5281/zenodo.57855.

Dodge, R. E., Szmant-Froelich, A., Garcia, R., Swart, P. K., 1993. Skeletal structural basis of density banding in the reef coral Montastrea Annularis. Proceedings of the 7th International Coral Reef Symposium 1, 186-195.

Druffel, E., Linick, T., 1978. Radiocarbon in annual coral rings of Florida. Geophysical Research Letters 5 (11), 913-916.

Fabricius, K. E., Mieog, J. C., Colin, P. L., Idip, D., van Oppen, M. J. H., 2004. Identity and diversity of coral endosymbionts (zooxanthellae) from three Palauan reefs with contrasting bleaching, temperature and shading histories. Molecular Ecology 13 (8), 2445-58.

Fritts, H., 1976. Tree Rings and Climate. Academic, New York.

Gilmour, J. P., Smith, L. D., Heyward, A. J., Baird, A. H., Pratchett, M. S., 2013. Recovery of an isolated coral reef system following severe disturbance. Science 340 (6128), 69-71.

Gleeson, M., Strong, A., 1995. Applying MCSST to coral reef bleaching. Advances in Space Research 16 (10), 151-154.

Glynn, P. W., Maté, J. L., Baker, A. C., 2001. Coral bleaching and mortality in Panama and Ecuador during the 1997-1998 El Niño-Southern Oscillation event: spatial/temporal patterns and comparisons with the 1982-1983 event. Bulletin of Marine Science 69 (1), 79-109.

Golbuu, Y., Victor, S., Penland, L., Idip, D., Emaurois, C., Okaji, K., Yukihira, H., Iwase, A., Woesik, R., 2007. Palau's coral reefs show differential habitat recovery following the 1998-bleaching event. Coral Reefs 26 (2), 319-332.

Guest, J. R., Baird, A. H., Maynard, J. A., Muttaqin, E., Edwards, A. J., Campbell, S. J., Yewdall, K., Affendi, Y. A., Chou, L. M., 2012. Contrasting patterns of coral bleaching susceptibility in 2010 suggest an adaptive response to thermal stress. PLoS ONE 7 (3), e33353.

Hendy, E. J., Lough, J. M., Gagan, M. K., 2003. Historical mortality in massive Porites from the central Great Barrier Reef, Australia: evidence for past environmental stress? Coral Reefs 22 (3), 207-215.

Hoegh-Guldberg, O., 1999. Climate Change, coral bleaching and the future of the world's 
coral reefs. Marine \& Freshwater Research 50, 839-866.

Hudson, J. H., 1978. Growth rates in Montastraea annularis: a record of environmental change in Key Largo coral reef marine sanctuary, Florida. Bulletin of Marine Science $31(2), 444-459$.

Jones, R. J., Larkum, A. W. D., Schreiber, U., 2006. Temperature-induced bleaching of corals begins with impairment of the $\mathrm{CO}_{2}$ fixation mechanism in zooxanthellae. Plant, Cell and Environment 21 (1998), 1219-1230.

Lough, J. M., 2012. Small change, big difference: sea surface temperature distributions for tropical coral reef ecosystems, 1950-2011. Journal of Geophysical Research: Oceans $117(9)$.

Lough, J. M., Cooper, T. F., 2011. New insights from coral growth band studies in an era of rapid environmental change. Earth-Science Reviews 108 (3-4), 170-184.

Mallela, J., Hetzinger, S., Halfar, J., 2015. Thermal stress markers in Colpophyllia natans provide an archive of site-specific bleaching events. Coral Reefs 35, 181-187.

Manzello, D. P., 2010. Coral growth with thermal stress and ocean acidification: lessons from the eastern tropical Pacific. Coral Reefs 29 (3), 749-758.

Mendes, J. M., Woodley, J. D., 2002. Effect of the 1995-1996 bleaching event on polyp tissue depth, growth, reproduction and skeletal band formation in Montastraea annularis. Marine Chemistry 235, 93-102.

Middlebrook, R., Hoegh-Guldberg, O., Leggat, W., 2008. The effect of thermal history on the susceptibility of reef-building corals to thermal stress. The Journal of Experimental Biology 211 (7), 1050-6.

Obura, D. O., 2005. Resilience and climate change: lessons from coral reefs and bleaching in the Western Indian Ocean. Estuarine, Coastal and Shelf Science 63 (3), 353-372.

Penland, L., Idip, D., Kloulechad, J., van Woesik, R., 2004. Coral spawning in the western Pacific Ocean is related to solar insolation: evidence of multiple spawning events in Palau. Coral Reefs 23 (1), 133-140.

Pinherio, J., Bates, D., Saikat, D., Sarkar, D., Team., R. D. C., 2012. nlme: Linear and nonlinear mixed effects models: $R$ package version 3.1-105. https://cran.rproject.org/web/packages/nlme/nlme.pdf.

Schoepf, V., Grottoli, A., Levas, S. J., Aschaffenburg, M. D., Baumann, J. H., Matsui, Y., Warner, M. E., 2015. Annual coral bleaching and the long-term recovery capacity of coral. Proceedings of the Royal Society B: Biological Sciences 282.

Scoffin, T., Tudhope, A., Brown, B., Chansan, H., Cheeney, R., 1992. Patterns and possible environmental controls of skeletogenesis of Porites lutea, South Thailand. Coral Reefs 11, $1-11$.

Shamberger, K. E. F., Cohen, A. L., Golbuu, Y., McCorkle, D. C., Lentz, S. J., Barkley, H. C., 2014. Diverse coral communities in naturally acidified waters of a Western Pacific reef. Geophysical Research Letters 41, 499-504. 
Smithers, S. G., Woodroffe, C. D., 2001. Coral microatolls and 20th century sea level in the eastern Indian Ocean. Earth and Planetary Science Letters 191, 173-184.

Tanzil, J. T. I., Brown, B. E., Dunne, R. P., Lee, J. N., Kaandorp, J. A., Todd, P. A., 2013. Regional decline in growth rates of massive Porites corals in Southeast Asia. Global Change Biology 19 (10), 3011-3023.

Tanzil, J. T. I., Brown, B. E., Tudhope, A. W., Dunne, R. P., 2009. Decline in skeletal growth of the coral Porites lutea from the Andaman Sea, South Thailand between 1984 and 2005. Coral Reefs 28 (2), 519-528.

van Hooidonk, R., Maynard, J. A., Manzello, D., Planes, S., 2014. Opposite latitudinal gradients in projected ocean acidification and bleaching impacts on coral reefs. Global change biology 20 (1), 103-12.

van Woesik, R., Houk, P., Isechal, A. L., Idechong, J. W., Victor, S., Golbuu, Y., 2012. Climate-change refugia in the sheltered bays of Palau: analogs of future reefs. Ecology and evolution 2 (10), 2474-84.

van Woesik, R., Sakai, K., Ganase, A., Loya, Y., 2011. Revisiting the winners and the losers a decade after coral bleaching. Marine Ecology Progress Series 434, 67-76.

West, J. M., Salm, R. V., 2003. Resistance and resilience to coral bleaching: implications for coral reef conservation and management. Conservation Biology 17 (4), 956-967.

Wilkinson, C., 2008. Status of coral reefs of the world: 2008. Tech. rep., Global Coral Reef Monitoring Network and Reef and Rainforest Research Centre, Townsville.

Yamaguchi, D., 1991. A simple method for cross-dating increment cores from living trees. Canadian Journal of Forest Research 21 (414-416). 


\subsection{Figures and Tables}

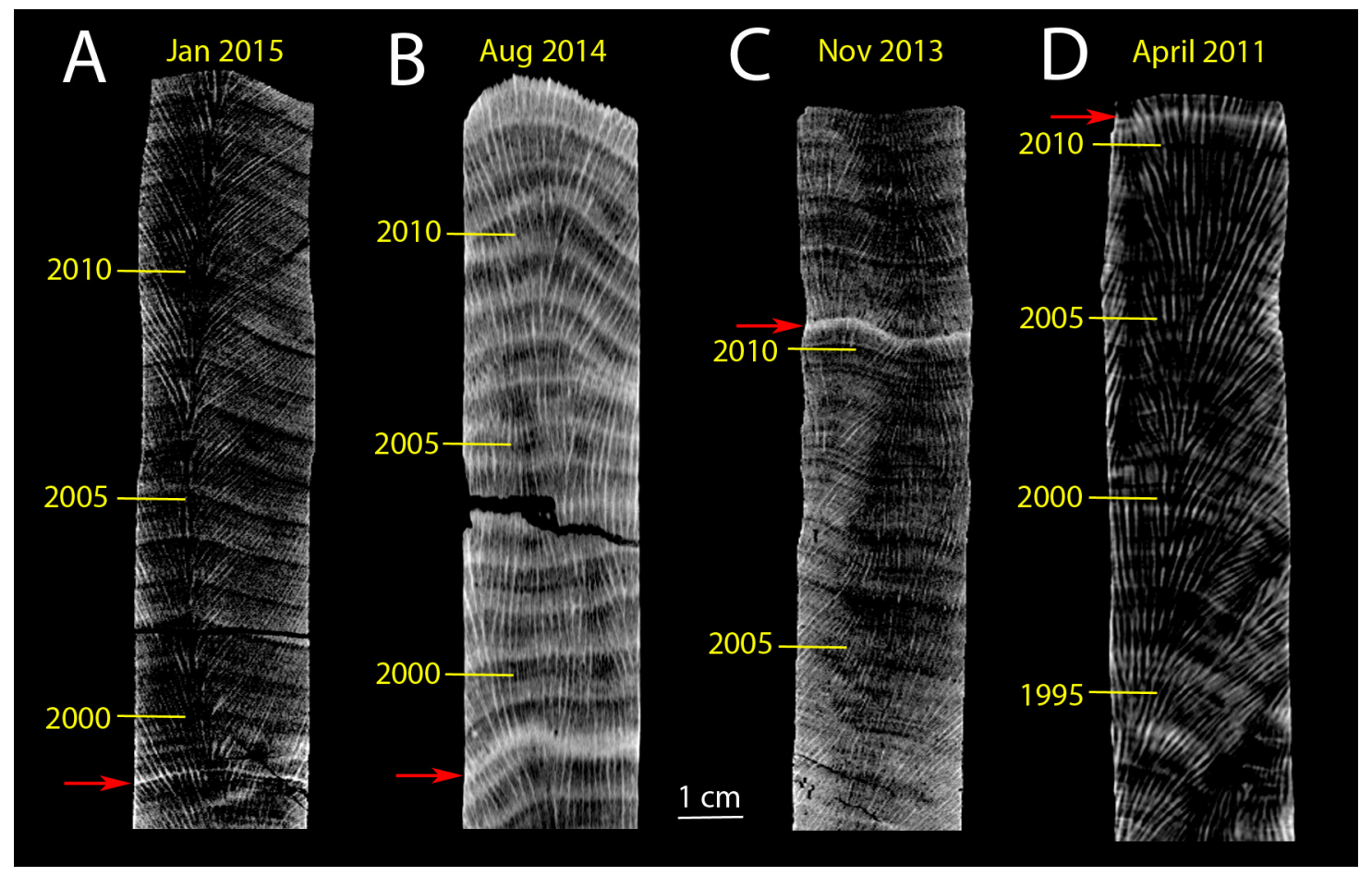

Figure 2-1: Example CT scans showing stress bands (red arrows) in Porites skeletal cores in relation to annual high-low density bands, which provide the chronology (every 5 years indicated in yellow). (A and B) Accreted stress bands in 1998 but not 2010; (C and D) accreted stress bands in 2010 but not 1998. Date of collection is indicated at the top of each core. CT scan images are displayed in negative, where areas of high density (such as stress bands) appear white, while areas of lower density appear black. 

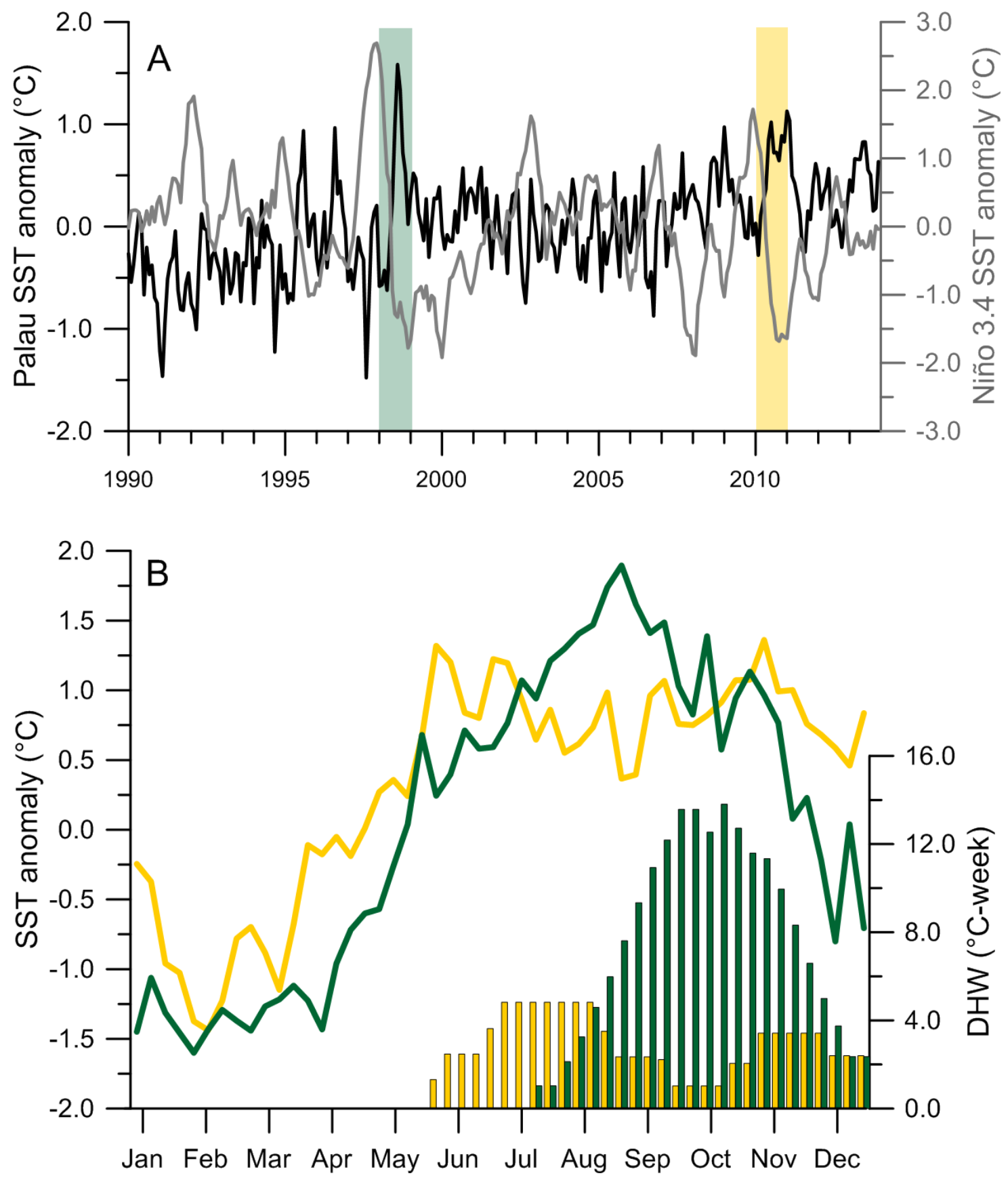

Figure 2-2: (A) Monthly sea surface temperature (SST) anomalies on Palau (black) versus Niño 3.4 (gray) from 1990-2013. (B) Weekly SST anomalies and degree heating weeks (DHW) corresponding to shaded areas during 1998 (green) and 2010 (yellow). 

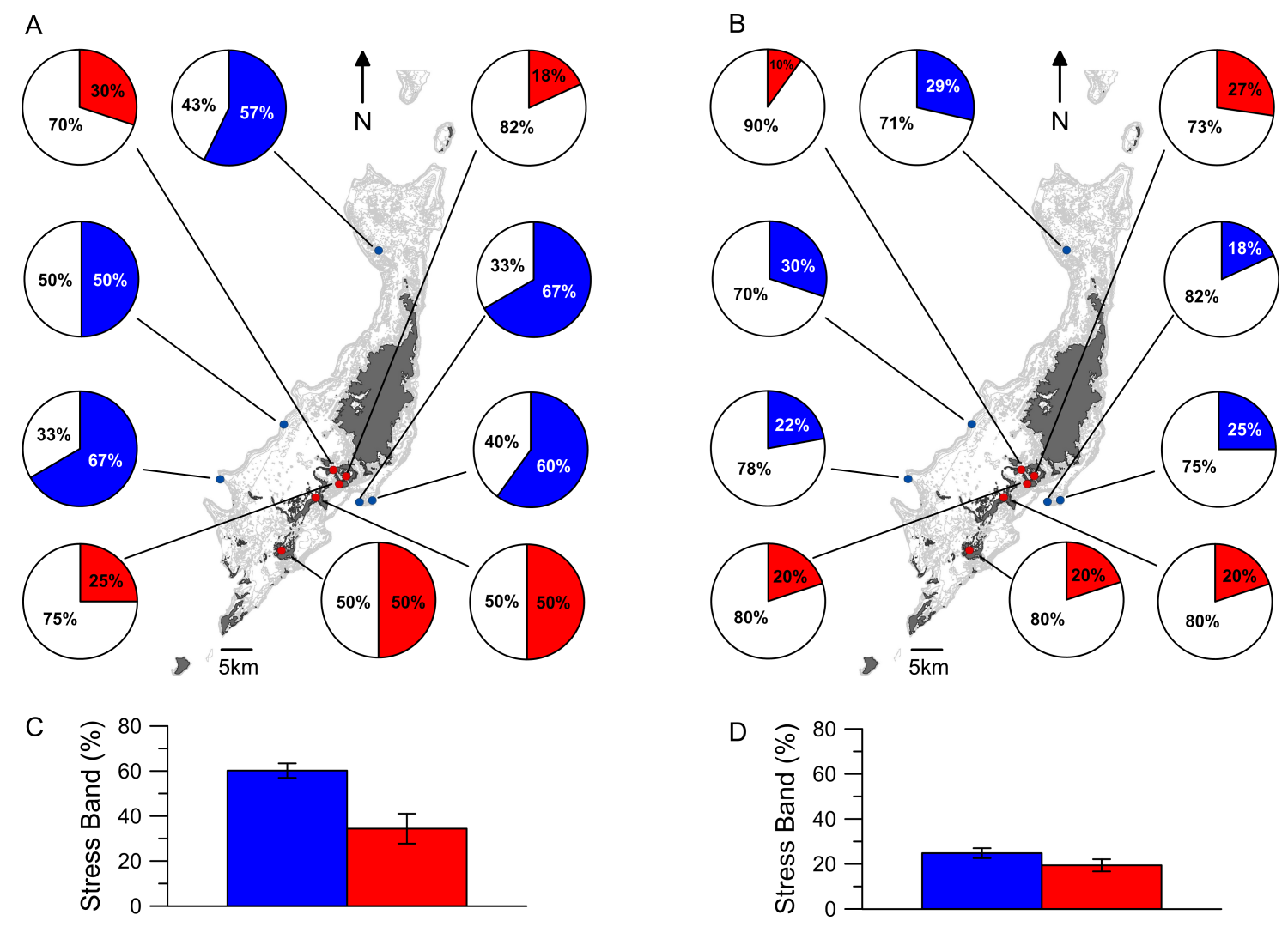

Figure 2-3: Map of Palau reef and study sites: dark gray shading indicates land, light gray shading indicates reef. (A and B) Pie charts show the distribution of Porites stress band prevalence corresponding with elevated temperatures in (A) 1998 and (B) 2010. Colored slices represent percent of coral cores with a stress band on either barrier (blue) or lagoon (red) reefs, compared with percent of corals with no stress bands (white). (C and D) Average percent $( \pm$ one standard error) of coral population from each reef type with stress bands during the (C) 1998 and (D) 2010 events. 


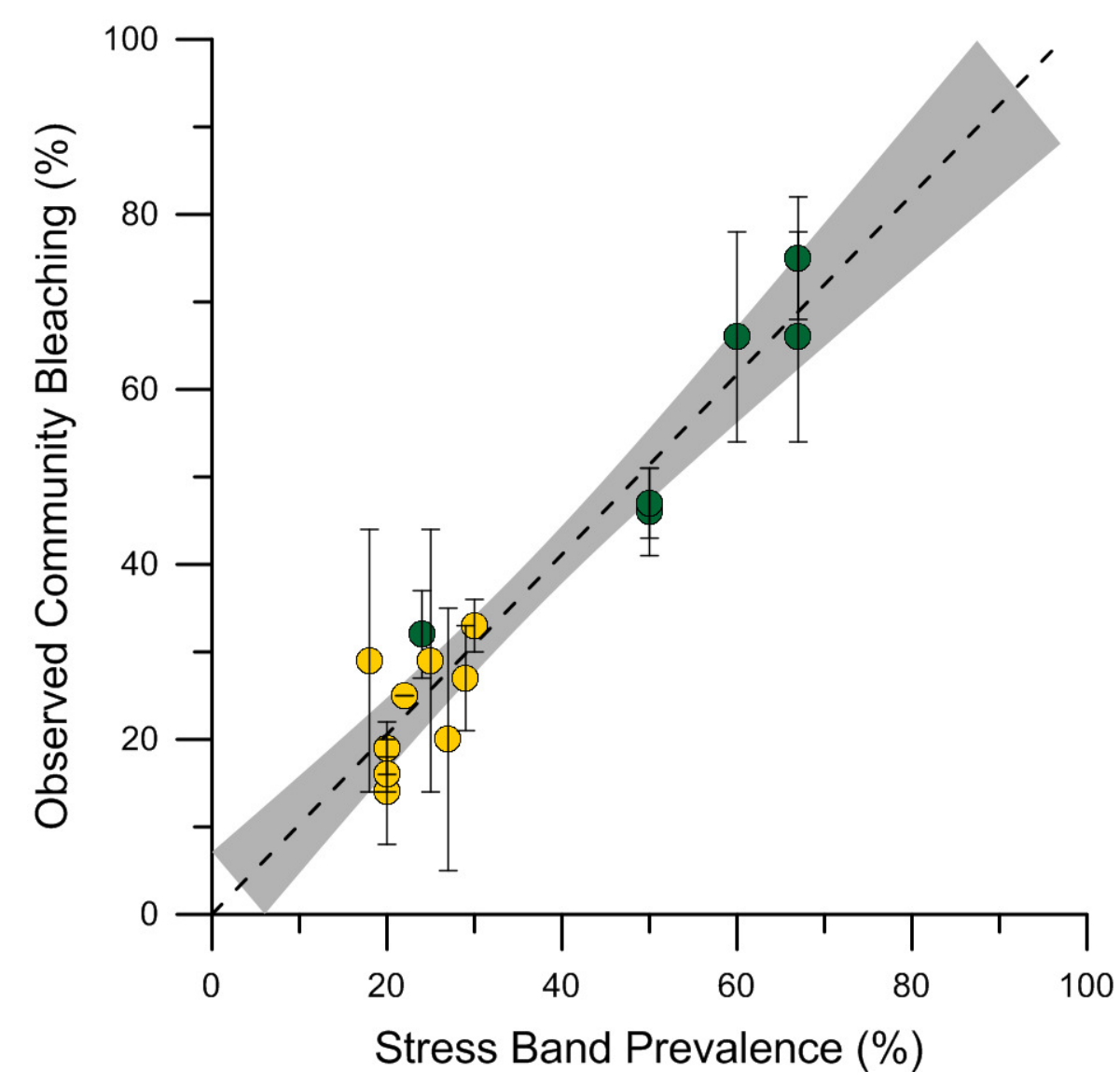

Figure 2-4: Percent of Porites coral skeletal cores forming a stress band during the 1998 (green) and 2010 (yellow) thermal anomalies plotted against the mean ( \pm one SE) percent community bleaching observed from each reef during the same event (1998 data from Bruno et al. (2001) and 2010 data from van Woesik et al. (2012)). Data are plotted with a line of best fit with a $95 \%$ confidence interval (shaded gray). 
A
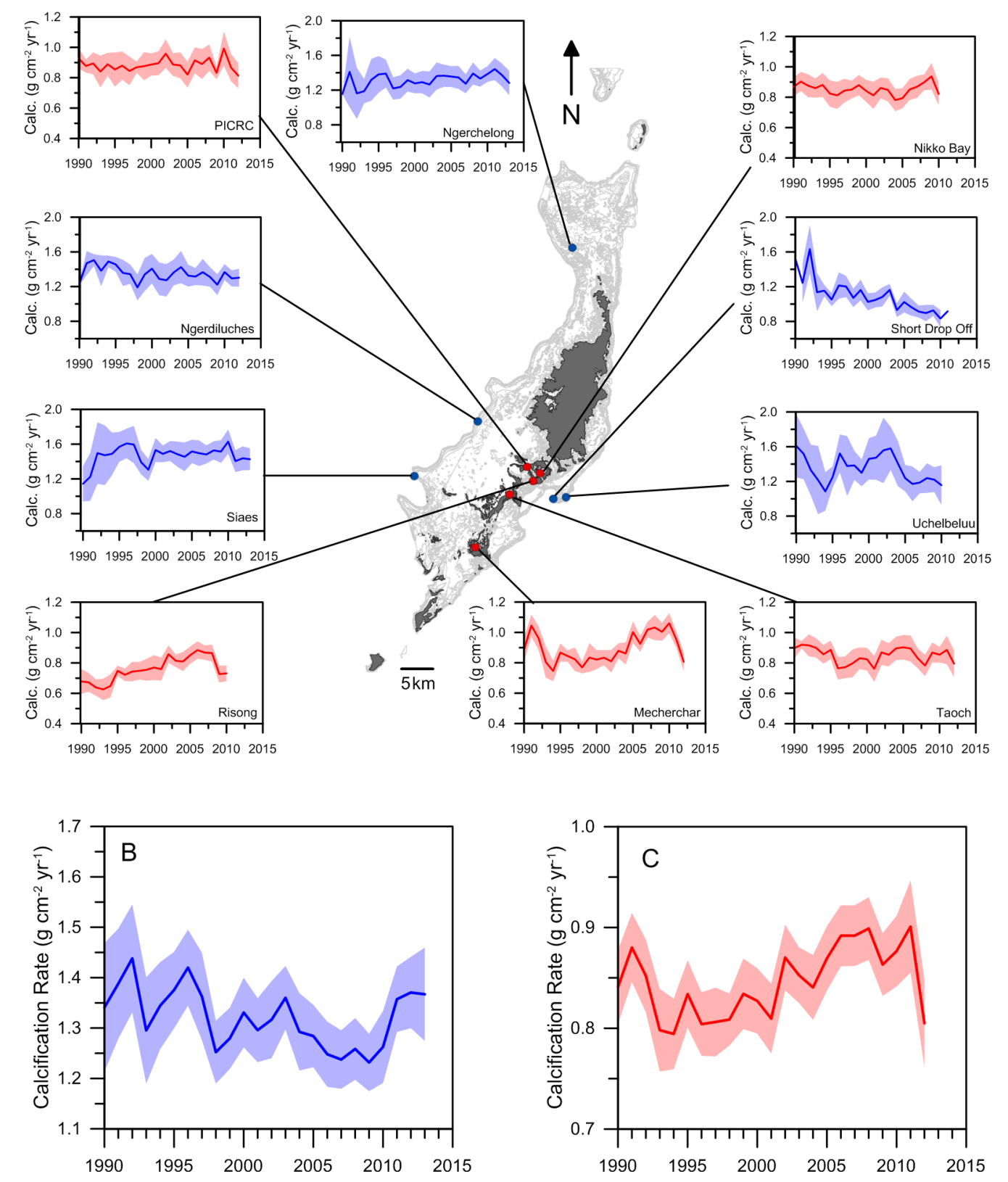

Figure 2-5: (A) Annual calcification histories for corals from 10 reef sites representing lagoon (red) and barrier (blue) reef environments, and mean annual calcification rates for corals from (B) barrier and (B) lagoon reefs. Calcification time series are presented as master chronologies for each reef site, created by averaging the yearly growth records from individual cores. Shaded regions are one standard error of the annual mean calcification rate. Trends in coral core records through time were analyzed using linear mixed effects models, which fit random slopes and intercepts to each individual core time series (C.f. Tables A.3 and A.2, Figure A-2). 


\section{Chapter 3}

\section{Changes in coral reef communities across a natural gradient in seawater $\mathrm{pH}$}

\subsection{Abstract}

Ocean acidification threatens the survival of coral reef ecosystems worldwide. The negative effects of ocean acidification observed in many laboratory experiments have been seen in studies of naturally low-pH reefs, with little evidence to date for adaptation. Recently, we reported initial data suggesting that low-pH coral communities of the Palau Rock Islands appear healthy despite the extreme conditions in which they live. Here, we build on that observation with a comprehensive statistical analysis of benthic communities across Palau's natural acidification gradient. Our analysis revealed a shift in coral community composition but no impact of acidification on coral richness, coralline algae abundance, macroalgae cover, coral calcification, or skeletal density. However, coral bioerosion increased 11-fold as $\mathrm{pH}$ decreased from the barrier reefs to the Rock Island bays. Indeed, a comparison of the naturally low-pH coral reef systems studied so far revealed increased bioerosion to be the only consistent feature among them, as responses varied across other indices of ecosystem health. Our results imply that whereas community responses may vary, escalation of coral reef bioerosion and acceleration of a shift from net accreting to net eroding reef structures will likely be a global signature of ocean acidification.

This chapter is published as: Hannah C. Barkley, Anne L. Cohen, Yimnang Golbuu, Victoria R. Starczak, Thomas M. DeCarlo, and Kathryn E. F. Shamberger, 2015. Changes in coral reef communities across a natural gradient in seawater $\mathrm{pH}$. Science Advances 1, 1-7.

This article was originally published at http://advances.sciencemag.org/content/1/5/e1500328, and is reprinted as published with permission granted in the original copyright agreement. 


\subsection{Introduction}

Shifts in ocean chemistry are likely occurring more rapidly now than in the past 300 million years (Caldeira and Wickett, 2003). Excess $\mathrm{CO}_{2}$ released from fossil fuel emissions and deforestation is absorbed by the surface oceans, driving down seawater $\mathrm{pH}$ and calcium carbonate $\left(\mathrm{CaCO}_{3}\right)$ saturation state $(\Omega)$, a process termed ocean acidification (OA) (Langdon and Atkinson, 2005). Coral reefs are considered especially vulnerable to OA. Reefs are made of $\mathrm{CaCO}_{3}$ produced by calcifying organisms, including corals and coralline algae, and laboratory experiments have shown that biogenic calcification is slowed and its destruction is accelerated at levels of OA projected for the end of this century (Langdon and Atkinson, 2005; Pandolfi et al., 2011). Some experiments have raised key questions regarding the potential for coral reef organisms to adapt to OA or for covarying environmental factors, such as light, water flow, and nutrient availability, to modulate the impacts of OA (Cohen and Holcomb, 2009; Suggett et al., 2012; Anthony et al., 2013; Drenkard et al., 2013; Comeau et al., 2014). However, most studies of naturally low-pH reefs, including $\mathrm{CO}_{2}$ vents in Papua New Guinea (PNG) and Japan, freshwater seeps in Mexico, and upwelling regions of the eastern tropical Pacific, have yielded no evidence to support either scenario (Doney et al., 2009; van Hooidonk et al., 2014).

In our previous report (Shamberger et al., 2014), we presented our initial data showing that coral communities of the Palau Rock Islands, formed by a labyrinthine maze of uplifted karst, appear healthy despite the relatively extreme $\mathrm{pH}$ conditions in which they live. As water flows from the open ocean over the barrier reefs and into the Rock Island bays, its carbonate system chemistry is altered by a combination of biological and hydrographic processes that elevate $p \mathrm{CO}_{2}$ and drive down $\mathrm{pH}$ and $\Omega$, a natural form of acidification (Shamberger et al., 2014). The long residence time of seawater within the Rock Islands exacerbates this process, and as a result, the benthic communities in Palau's most acidified reefs live in conditions with $\mathrm{pH}$ and $\Omega$ levels equivalent to those predicted for the western tropical Pacific open ocean by 2100 (Figure 3-1) (Feely et al., 2009). Recent continuous pH data collected in situ over multiple, consecutive diel cycles (Figure 3-1, inset) reveal that whereas natural acidification decreases the mean $\mathrm{pH}$ within the Rock Islands, the diel range in $\mathrm{pH}$ is maintained across Palau's natural OA gradient. The downward shift in $\mathrm{pH}$ and $\Omega$ without change in amplitude or frequency of variability contrasts the extreme and highly 
variable conditions at $\mathrm{CO}_{2}$ vent sites and freshwater seeps (Fabricius et al., 2011; Crook et al., 2013), and is more consistent with the predicted nature of the progression of OA in the marine environment (Feely et al., 2009).

Here, we assess coral reef benthic community structure and key ecosystem processes across a natural gradient in seawater $\mathrm{pH}$ and $\Omega$ in Palau. We evaluate these response variables against a comprehensive characterization of carbon chemistry to investigate whether measureable changes in benthic community structure; coral community composition; declines in skeletal extension, density, and calcification; and/or increases in the prevalence and rates of bioerosion seen in laboratory experiments and analog sites can be detected and attributed to OA in Palau. Finally, we compare our data with those collected at other naturally low-pH reefs to identify response variables common across all sites, independent of the mechanism of acidification, biogeography, frequencies of variability, and presence of other environmental factors that may exacerbate or mask the OA impact.

\subsection{Results}

\subsubsection{Carbon system chemistry}

Characterization of Palau's carbonate chemistry environment was achieved by discrete water sampling at 11 study sites during multiple tidal cycles, seasons, and years from dawn (6:00 a.m.) to dusk (6:00 p.m.), combined with continuous, 4-day-long $\mathrm{pH}$ sensor deployment and water sampling to characterize diurnal variability at a subset of these sites (Figure 3-1, Figure B-1, and Tables B.1 and B.2). Site average dawn-to-dusk pH and $\Omega$ of the $\mathrm{CaCO}_{3}$ mineral aragonite $\left(\Omega_{a r}\right)$ are typically within error of 24 -hour mean values (DeCarlo et al., 2015) and are thus considered representative of the full diel range in carbon system chemistry. Average $\mathrm{pH} / \Omega_{a r}$ ranged from $8.05( \pm 0.04 \mathrm{SD}) / 3.7( \pm 0.3)$ at the highest-pH $/ \Omega_{a r}$ barrier reef site to $7.84( \pm 0.03) / 2.3( \pm 0.2)$ at the lowest-pH/ $\Omega_{a r}$ Rock Island site, falling as low as 7.61/1.86 in the early hours of the morning. Mean $\mathrm{pH} / \Omega_{a r}$ levels were significantly different across study sites [ANOVA (analysis of variance), $\mathrm{F}_{10,14}=21.4, \mathrm{p}<0.001$ ], but were not correlated with concentrations of $\mathrm{NO}_{2}{ }^{-} / \mathrm{NO}_{3}{ }^{-}(\mathrm{r}=-0.42, \mathrm{p}=0.19), \mathrm{PO}_{4}{ }^{3-}(\mathrm{r}=$ $-0.36, \mathrm{p}=0.27)$, or $\mathrm{NH}_{4}{ }^{+}(\mathrm{r}=-0.34, \mathrm{p}=0.31)$. A comparison of our mean 2011-2013 $\Omega_{a r}$ $(3.68 \pm 0.05 \mathrm{SE})$ measured at site 10 (Figure B-1) just offshore of Palau's northwest barrier reef with $\Omega_{a r}$ at the same site in $1994(3.87 \pm 0.04)$ and 2000 (3.80 \pm 0.02$)$ (Kayanne et al., 
2005; Watanabe et al., 2006) shows a 0.19 decrease over 20 years (see Appendix B.1). This is similar to the direction and magnitude of change (-0.24) recorded at the open ocean station ALOHA over the same period $\left(\Omega_{a r}=3.75\right.$ to $\left.\Omega_{a r}=3.51\right)$ (Dore et al., 2009), suggesting that the strong influence of local processes on Palau's carbon system chemistry is superimposed on a steady decline in $\Omega_{a r}$ caused by air-sea exchange of anthropogenic $\mathrm{CO}_{2}$.

\subsubsection{Benthic community cover}

Benthic communities were compared across eight sites spanning the full range of carbonate chemistry using cover and composition estimates derived from five $50 \mathrm{~m}$ transect lines per site collected at $3 \mathrm{~m}$ depth (Figure B-1 and Tables B.1 and B.2). Despite the steep decline in $\mathrm{pH}$ and $\Omega_{a r}$, our analysis revealed no significant change in the cover of live hard coral, macroalgae, and crustose coralline algae or in coral genera richness or diversity [Figure 3-2 and Table B.2; generalized linear model (GLMs), $\mathrm{p}>0.05]$. Coral communities within the lowest- $\Omega_{a r}$ reef site $\left(\Omega_{a r}=2.32\right)$ hosted the highest coral cover $(>60 \%)$ and genus richness (12.6 genera.transect $\left.{ }^{-1}\right)$ and the lowest macroalgae cover $(<1 \%)$.

\subsubsection{Coral community composition}

Whereas coral cover and richness were insensitive to differences in $\mathrm{pH}$ among sites, we detected a significant relationship between $\mathrm{pH} / \Omega_{a r}$ and coral community composition as well as shifts in the presence and abundance of coral genera across sites (Figure 3-3, redundancy analysis, pseudo- $F_{7,32}=8.80, \mathrm{p}<0.001$ ). The coral compositions of the barrier sites (highest $\mathrm{pH}$ and $\Omega_{a r}$ ) were similar to each other, defined by abundant Acropora, Montipora, and Pocillopora. Coral communities occupying the lagoonal sites (lowest $\mathrm{pH}$ and $\Omega_{a r}$ ) were distinct from the barrier communities but were also distinct from each other: one site $\left(\Omega_{a r}\right.$ $=3.24)$ was Porites-dominated, whereas another $\left(\Omega_{a r}=2.67\right)$ was defined by populations of Leptastrea, Platygyra, Favites, and Favia. Our lowest- $\Omega_{a r}$ site identified to date $\left(\Omega_{a r}=2.32\right)$ uniquely hosted Pachyseris, Symphyllia, Mycedium, Lobophyllia, Plerogyra, and Merulina. In general, Porites abundance increased with decreasing pH (log-linear GLM, $\mathrm{P}<0.05)$, whereas the abundances of Acropora, Montipora, and Pocillopora declined (negative binomial GLM, p $<0.01 ;$ Table B.3). 


\subsubsection{Coral skeletal growth and macrobioerosion}

The skeletal extension, density, and calcification rates of two coral genera (Porites and Favia) did not exhibit statistically significant changes across the $\mathrm{pH}$ gradient (Figure 34 and Tables B.4; GLMs, $\mathrm{p}>0.05)$. The presence of macrobioerosion in Porites corals increased significantly at low $\Omega_{a r}$ (logistic regression, $\mathrm{p}<0.001$ ), and the volume percent of skeleton removed by bioeroding organisms, predominantly the bivalve Lithophaga, increased 11-fold from the highest- $\Omega_{a r}$ to the lowest- $\Omega_{a r}$ sites (log-linear GLM, $\mathrm{p}=0.03$ ) in coral skeletons with nonzero bioerosion. We did not detect a significant relationship between skeletal density and the volume of coral skeleton eroded (log-linear GLM, $\mathrm{p}=0.35$ ), but the likelihood that Porites coral skeletons were bioeroded increased as skeletal density decreased (logistic regression, $\mathrm{p}<0.001$ ).

\subsection{Discussion}

Despite the $\mathrm{pH}$ and $\Omega_{a r}$ conditions already at predicted end-of-century open ocean levels and $p \mathrm{CO}_{2}$ up to $720 \mu \mathrm{atm}$, the Rock Islands support high coral cover, richness, and diversity and very low macroalgae cover. This observation counters expectations based on some laboratory $\mathrm{CO}_{2}$ manipulation experiments and studies of other naturally low-pH reefs in which severe declines in coral richness and coralline algal cover and increases in macroalgae are signature impacts of OA (Fabricius et al., 2011; Crook et al., 2013). In general, coral cover on Palau's high-pH barrier reefs (28 to 37\%) was lower than that of the low-pH bay reefs (32 to 63\%), a trend likely exacerbated by a bleaching event in 1998 that caused declines in coral cover on the barrier reef but not the bays. Nevertheless, the relatively high cover and diversity in the low-pH reefs cannot be solely attributed to differential bleaching-induced mortality: the pre-1998 cover on the barrier (50\% in 1992) was already lower than the current coral cover on Palau's lowest-pH reefs (63\%) (Golbuu et al., 2007). The skeletal extension, density, and calcification rates of Porites and Favia corals did not change significantly with declining $\mathrm{pH}$ and $\Omega_{a r}$, indicating that the rates of $\mathrm{CaCO}_{3}$ production, a physiological process considered one of the most sensitive to OA, are maintained across Palau's OA gradient. In contrast, many laboratory $\mathrm{CO}_{2}$ manipulation experiments with Porites and Favia corals have shown significant declines in calcification of these genera with declining $\mathrm{pH} / \Omega_{a r}$ (Anthony et al., 2008; DePutron et al., 2010; Albright and Langdon, 2011; Drenkard et al., 2013). 
We observed significant changes in coral community structure that track changes in $\mathrm{pH}$ and $\Omega_{a r}$. However, the compositional heterogeneity among low-pH, low- $\Omega_{a r}$ sites on Palau suggests that coral community structure under OA conditions is not deterministic, and there is no single community of acidification "winners" within Palau's low-pH reefs. Indeed, other local environmental and/or ecological factors, including changes in wave energy, temperature, and/or light, all of which covary as $\mathrm{pH}$ decreases from the barrier reefs to the Rock Island bays, may play a larger role in shaping community composition. Several observations support this interpretation. First, the shift from offshore Acropora-abundant to inshore Porites-abundant communities is consistent with worldwide reef zonation patterns (Done and Navin, 1990). Second, the presence and abundance of other genera (including Favia and Favites) did not change with decreasing pH. Finally, a number of branching and foliose genera (for example, Pachyseris, Anacropora, Mycedium, Merulina, and Lobophyllia) typically associated with lower wave energy and/or light levels, and not considered insensitive to $\mathrm{pH}$ (Sorokin, 1995), were more abundant on Palau's lowest-pH reefs than on the high-pH barrier reefs.

We also found that coral macrobioerosion increases significantly as $\mathrm{pH}$ decreases in Palau. In contrast to the change in community composition, factors other than $\mathrm{pH}$ are unlikely to explain this trend. Across multiple studies of coral bioerosion, there is no consistent correlation between macrobioerosion rates and degrees of wave exposure or intensity of flow (Chazottes et al., 1995; Perry, 1998; Londoño-Cruz et al., 2003; Osorno et al., 2005; Tribollet and Golubic, 2005). Elevated nutrient concentrations have been shown to correlate with increased coral macrobioerosion (Edinger et al., 2000; DeCarlo et al., 2015), but nutrient concentrations do not change with decreasing seawater $\mathrm{pH}$ or with increased bioerosion in Palau. Our hypothesis that low $\mathrm{pH}$ causes the observed increase in coral macrobioerosion is supported by multiple laboratory experiments that show elevated bioerosion at low $\mathrm{pH}$ (Tribollet et al., 2009; Wisshak et al., 2012; Reyes-Nivia et al., 2013). Furthermore, in a recent field study, $\mathrm{pH} / \Omega_{a r}$ emerged as a consistent factor in Porites macrobioerosion on 11 Pacific reef systems (DeCarlo et al., 2015) spanning a wide range of $\mathrm{pH}$, wave energy, and flow conditions (Gove et al., 2013). There are several potential mechanisms by which OA can cause increased macrobioerosion of live corals. One hypothesis is that skeletons accreted under OA are less dense, making them easier for bioeroders to penetrate (Sammarco and Risk, 1990). Although low-pH conditions in Palau do not necessarily produce lower-density 
skeletons, colonies with less dense skeletons are, in general, more likely to show evidence of bioerosion. In addition, lower $\mathrm{pH}$ may facilitate bioerosion by increasing the efficiency of biochemical dissolution (Kobluk and Risk, 1977; Wisshak et al., 2012), one of the methods Lithophaga employs to excavate coral skeletons (Glynn, 1997).

We compared our results with those obtained from similar analyses of naturally lowpH coral reef ecosystems near volcanic $\mathrm{CO}_{2}$ vents in Milne Bay, PNG (Fabricius et al., 2011), submarine freshwater springs (ojos) in Puerto Morelos, Mexico (Crook et al., 2011, 2013), and low-pH upwelling zones in the eastern tropical Pacific (Manzello et al., 2008, 2014) in an effort to identify common response variables solely attributable to changes in pH (Table B.3). Despite the paucity of naturally more acidified reefs identified to date, across-site comparisons are necessary because none are perfect analogs for coral reefs under future OA. $\mathrm{CO}_{2}$ accumulation is not always the primary or only driver of low $\mathrm{pH} / \Omega_{a r}$, and $\mathrm{pH}$ variability can be extreme relative to projected future values, as well as spatially and temporally heterogeneous. Covariability among $\mathrm{pH}$ and other variables including nutrients, salinity, light, water flow, and/or temperature can make it difficult to attribute specific ecological changes solely to acidification. Furthermore, scales of larval connectivity and recruitment sources vary between sites and may influence the adaptive potential of coral communities.

Our across-site comparison reveals few commonalities among low-pH reefs studied to date (Table 3.1). Despite comparable natural gradients in $\mathrm{pH} / \Omega_{a r}$, trends in coral cover and richness and cover of macroalgae and coralline algae are inconsistent, with the Rock Islands unique in showing no sensitivity to $\mathrm{pH}$ in any of these response variables. Coral richness declined steeply with declining $\mathrm{pH}$ in Mexico, PNG, and the eastern tropical Pacific, but did not change in Palau. Macroalgae cover increased at low pH in PNG only. On a $\mathrm{CO}_{2}$ reef vent site in Japan (not included in Table 3.1), hard coral-dominated communities gave way to soft coral-dominated reef communities as $\mathrm{pH}$ declined from the fringing reef to the shallow back reef pools cut off from the ocean at low tide (Inoue et al., 2013). This did not occur at the PNG $\mathrm{CO}_{2}$ vent site. Porites abundance increased with $\mathrm{pH}$ decline in Palau and PNG, but it was not affected by low $\mathrm{pH}$ in Mexico. Porites calcification in Palau and PNG was insensitive to decreasing $\mathrm{pH}$, whereas in Mexico, the eastern tropical Pacific, and in laboratory OA experiments, Porites calcification declined with low pH (Anthony et al., 2008; Albright and Langdon, 2011; Iguchi et al., 2012; Drenkard et al., 2013). 
The inconsistencies in community responses to acidification across naturally low-pH reef systems, and between reefs and laboratory experiments, may be due to a number of different factors. Although ultimately producing similar average $\mathrm{pH}$ and $\Omega_{a r}$ conditions, distinct mechanisms of acidification at each site lead to differences in extremes and frequencies of variability. For example, whereas the maximum seawater $p \mathrm{CO}_{2}$ levels in the Palau Rock Islands $\left(p \mathrm{CO}_{2} \approx 720 \mu \mathrm{atm}\right)$ are close to the $2100 \mathrm{AD}$ projections for the open ocean, the maximum concentrations at the Yucatan $\left(p \mathrm{CO}_{2} \approx 5120 \mu \mathrm{atm}\right)$ (Crook et al., 2013) and PNG $\left(p \mathrm{CO}_{2} \approx 5740 \mu \mathrm{atm}\right)$ (Fabricius et al., 2011) sites are about seven to eight times higher. $\mathrm{pH}$ variability in Palau is dominated by the diurnal and tidal cycles as it will be on future reefs, whereas PNG and Mexico are characterized by high-frequency spikes associated with pulses of $\mathrm{CO}_{2}$ and groundwater discharge (Fabricius et al., 2011; Hofmann et al., 2011; Crook et al., 2013). Yet, the hydrographic and biological processes that lower $\mathrm{pH} / \Omega_{a r}$ in Palau also result in low total alkalinity (TA) and dissolved inorganic carbon (DIC) conditions, which are not expected under future OA. Furthermore, in the eastern tropical Pacific, temperature and nutrient concentrations covary with $\mathrm{pH}$, making it difficult to attribute patterns in reef communities solely to upwelling-driven acidification (Manzello et al., 2014).

Across the handful of naturally low-pH sites studied to date, Palau appears unique in showing no obvious sensitivity to OA across a range of key ecological indices. Laboratory experiments suggest that covarying environmental factors including light, flow, nutrients, and food availability can modulate the negative impact of OA on calcification. None of these factors can explain the apparent OA tolerance of Palau's benthic communities. Most factors that alleviate the impacts of $\mathrm{pH}$ in laboratory experiments are absent from Palau's Rock Island bays, where high temperature, high shade, low flow, and low nutrient concentrations accompany OA conditions (Golbuu et al., 2007; Cohen and Holcomb, 2009; Suggett et al., 2012; Comeau et al., 2014) (Table B.1). The low-pH communities in Palau differ from other naturally low-pH sites studied to date in their relative isolation within bays and inlets and in OA conditions that are chronic and of less extreme ranges. It is possible that selective pressure has driven local, communitywide adaptation to low $\mathrm{pH}$ over long time scales (that is, thousands of years). In contrast, in PNG and Mexico, low-pH communities are more exposed, scales of connectivity may be larger than in low-pH areas, and the possibility that larvae are recruited to low-pH reefs from populations under less acidification pressure may preclude adaptation (Shamberger et al., 2014). 
Increases in macrobioerosion with declining $\mathrm{pH}$ are the only consistent coral reef community response to natural acidification across low-pH reefs. In Palau, bioerosion increased significantly at low $\Omega_{a r}$. The same patterns have been reported at low-pH reef sites in PNG (93\% increase in bioeroder density from high $\mathrm{pH}$ to low $\mathrm{pH}$ ) and Mexico (78\% increase in Porites coral skeleton eroded) (Fabricius et al., 2011; Crook et al., 2013). In the eastern tropical Pacific, elevated rates of reef bioerosion $\left(87 \%\right.$ increase from $\Omega_{a r}=3.5$ to $\left.\Omega_{a r}=2.5\right)$ and decreased reef cementation have also been observed in low-pH, nutrient-rich upwelling zones (Manzello et al., 2008), a component of which is attributable to low pH (DeCarlo et al., 2015). Enhanced bioerosion and lack of cementation threaten the structural integrity of corals and reef systems, increasing the impact of predation and the risk of physical destruction by storms (Bruggemann et al., 1996; Wisshak et al., 2012). Moreover, if macrobioerosion is indicative of larger-scale reef erosion and dissolution (Chazottes et al., 1995; Holmes et al., 2000; DeCarlo et al., 2015), increases in $\mathrm{CaCO}_{3}$ erosion under OA will have significant implications for the persistence of reef structures. Structural fragility is incompatible with the ability of barrier and fringing reefs to absorb and dissipate the energy associated with the constant day-to-day pounding of waves, seasonal storms, and the less frequent but more catastrophic tsunamis. Indeed, that bioerosion rates are elevated in all naturally low-pH coral reef systems studied to date suggests that the signature of $21^{\text {st }}$ century OA will emerge most strongly and most universally through its impact on reef structural integrity.

\subsection{Methods}

\subsubsection{Water sample collection and analysis}

Surface water samples (0 to $3 \mathrm{~m}, \mathrm{n}=195$ ) for salinity, nutrients, TA, and DIC were collected at multiple time points between sunrise and sunset on 19 to 24 September 2011, 28 March to 7 April 2012, 7 to 9 December 2012, and 1 to 15 November 2013 [data for 2011-2012 previously published in Shamberger et al. (2014)]. TA and DIC analyses were performed using a Versatile INstrument for the Determination of Total inorganic carbon and titration Alkalinity (VINDTA, Marianda Analytics and Data), which uses open cell potentiometric (TA) and coulometric (DIC) titrations, and standardized using certified reference materials obtained from Andrew Dickson [Scripps Institution of Oceanography, (Dickson, 2001)]. Analysis of 
replicate samples $(\mathrm{n}=13)$ showed a mean precision of $2 \mu \mathrm{mol} \cdot \mathrm{kg}^{-1}$ for TA and $1 \mu \mathrm{mol} \cdot \mathrm{kg}^{-1}$ for DIC. Full $\mathrm{CO}_{2}$ system parameters were calculated from temperature, salinity, TA, and DIC using $\mathrm{CO}_{2} \mathrm{SYS}$ (Lewis and Wallace, 1998) with the constants of Mehrbach et al. (1973) refit by (Dickson and Millero, 1987). In situ $\mathrm{pH}$ time series were collected using a SAMI-pH sensor (Sunburst Sensors) deployed at three sites (1, 2, and 10) for 4 days in November 2013 (sites 2 and 10) and August 2014 (site 1).

\subsubsection{Benthic community data collection}

At each of eight sites (Figure B-1) : sites 1, 2, 5, 6, 7, 9, 10, and 11), five $50 \mathrm{~m}$ transects were laid on the reef at $3 \mathrm{~m}$ depth and a photograph of a $0.5 \mathrm{~m}$ x $0.5 \mathrm{~m}$ quadrat taken every meter. Photographs were analyzed using Coral Point Count with Excel extensions (Kohler and Gill, 2006). Benthic cover of each photograph was evaluated by randomly overlaying five crosses on each image and identifying the type of cover and taxa underneath each cross, with all corals identified to the genus level, for a total of 200 points evaluated per transect and 1000 points evaluated per site. Porites corals were identified as massive species, branching species, or other. All transects were conducted in 2010, except for those from site 2, which were conducted in 2012 .

\subsubsection{Coral skeletal core collection and analysis}

Coral skeletal cores were collected on SCUBA from 86 massive Porites colonies (Figure B-1: sites 1, 2, 3, 4, 5, 8, 9, and 10) and 25 Favia colonies (sites 1, 2, 8, and 9) in April 2011, September 2011, March to April 2012, and November 2013. Cores were scanned using a Siemens Volume Zoom Helical Computerized Tomography (CT) scanner, and extension, density, and calcification rates were calculated using annual banding patterns visualized from three-dimensional CT images in MATLAB [detailed procedure for analyzing coral growth rates in DeCarlo et al. (2015)]. The 2006-2010 averages of these parameters for each coral were used to compare growth rates across reef sites. CT scan images were used to determine the proportion of the skeleton eroded ( $>1 \mathrm{~mm}$ boring diameter) by boring organisms (including bivalves, worms, and sponges), calculated as the total volume of $\mathrm{CaCO}_{3}$ removed

relative to the total volume of the coral core, for each Porites coral. Boring percentage data for sites 1, 2, 7, and 8 were previously published in DeCarlo et al. (2015). 


\subsubsection{Statistical analysis}

Statistical analyses were conducted in $\mathrm{R}$ (version 3.0.1). To assess the health of Palau's benthic communities, percent cover (coral, macroalgae, and crustose coralline algae) and community ecological indices (genera richness, Shannon diversity, and Shannon evenness) were calculated for each of the five transects per reef site. GLMs were used to evaluate the relationship between $\Omega_{a r}$ and the site-mean benthic cover data and ecological indices. Linear, log-linear, and polynomial models were evaluated for all response variables, but no model fits showed significant relationships between any community index and $\Omega_{a r}(\mathrm{p}<0.05)$. Detrended correspondence analysis (DCA) on coral genera abundance data was conducted using the vegan package (Oksanen et al., 2013) to evaluate spatial trends in community structure across reef sites. Differences in community structure across the $\Omega_{a r}$ gradient were formally tested using redundancy analysis with a Monte Carlo permutation test $(10,000$ permutations). Loglinear or negative binomial count models were constructed to assess the relationship between the presence/absence and abundance of the eight most abundant genera on Palauan reefs (total abundance $>50$ individuals) and $\Omega_{a r}$. Linear models were used to evaluate the relationship between $\Omega_{a r}$ and Porites and Favia mean annual rates of extension, density, and calcification rates and Porites tissue thickness. Porites bioerosion data were fit to two separate models to evaluate changes in the presence/absence of bioerosion and volume percent of boring with changes in $\Omega_{a r}$ and skeletal density: binary presence/absence data were fit to a logistic regression model, and a log-linear model was fit to site means of all nonzero boring percent data.

\subsection{Acknowledgments}

We thank G. P. Lohmann, K. Pietro, A. Shalapyonok, J. Arruda, D. Ketten, D. McCorkle, E. Bonk, K. Hoering, D. Wellwood, S. Lentz, G. Mereb, A. Merep, and the staff of the Palau International Coral Reef Center (PICRC) for assistance with fieldwork and analyses. We acknowledge the invaluable contribution of J. Andrew (deceased 2013). This work was supported by an NSF Graduate Research Fellowship to H.C.B. and T.M.D., A New Wave Fellowship to H.C.B., National Science Foundation awards OCE-1220529 and OCE-1031971, The Dalio Foundation Inc., through the Dalio Explore Fund, Ray Dalio through the WHOI Access to the Sea Fund, The Tiffany \& Co. Foundation and The Nature Conservancy. 


\subsection{References}

Albright, R., Langdon, C., 2011. Ocean acidification impacts multiple early life history processes of the Caribbean coral Porites astreoides. Global Change Biology 17 (7), 24782487.

Anthony, K. R. N., Diaz-Pulido, G., Verlinden, N., Tilbrook, B., Andersson, A. J., 2013. Benthic buffers and boosters of ocean acidification on coral reefs. Biogeosciences 10 (7), 4897-4909.

Anthony, K. R. N., Kline, D. I., Diaz-Pulido, G., Dove, S., Hoegh-Guldberg, O., 2008. Ocean acidification causes bleaching and productivity loss in coral reef builders. Proceedings of the National Academy of Sciences of the United States of America 105 (45), 17442-6.

Bruggemann, J., van Kessel, A., van Rooij, J., Breeman, A., 1996. Bioerosion and sediment ingestion by the Caribbean parrotfish Scarus vetula and Sparisoma viride:implications of fish size, feeding mode and habitat use. Marine Ecology Progress Series 134, 59-71.

Caldeira, K., Wickett, M., 2003. Anthropogenic carbon and ocean pH. Nature 425, 365.

Chazottes, V., Campion-Alsumard, T., Peyrot-Clausade, M., 1995. Bioerosion rates on coral reefs: interactions between macroborers, microborers and grazers (Moorea, French Polynesia). Palaeogeography, Palaeoclimatology, Palaeoecology 113 (2-4), 189-198.

Cohen, A. L., Holcomb, M., 2009. Why corals care about ocean acidification: uncovering the mechanism. Oceanography 22 (4), 118-127.

Comeau, S., Edmunds, P. J., Lantz, C. A., Carpenter, R. C., 2014. Water flow modulates the response of coral reef communities to ocean acidification. Scientific Reports 4, 6681.

Crook, E., Cohen, A. L., Rebolledo-Vieyra, M., Hernandez, L., Paytan, A., 2013. Reduced calcification and lack of acclimatization by coral colonies growing in areas of persistent natural acidification. Proceedings of the National Academy of Sciences of the United States of America 110 (27), 11044-9.

Crook, E., Potts, D., Rebolledo-Vieyra, M., Hernandez, L., Paytan, A., 2011. Calcifying coral abundance near low-pH springs: implications for future ocean acidification. Coral Reefs 31 (1), 239-245.

DeCarlo, T., Cohen, A. L., Barkley, H., Shamberger, K., Cobban, Q., Young, C., Brainard, R. E., Golbuu, Y., 2015. Coral bioerosion is accelerated by ocean acidification and nutrients. Geology 43, 7-10.

Denman, K., Christian, J. R., Steiner, N., Pornter, H.-O., Nojiri, Y., 2011. Potential impacts of future ocean acidification on marine ecosystems and fisheries: current knowledge and recommendations for future research. ICES Journal of Marine Science 68, 1019-1029.

DePutron, S. J., McCorkle, D. C., Cohen, A. L., Dillon, A. B., 2010. The impact of seawater saturation state and bicarbonate ion concentration on calcification by new recruits of two Atlantic corals. Coral Reefs 30 (2), 321-328.

Dickson, A., 2001. Reference materials for oceanic measurements. Oceanography 14, 21-22. 
Dickson, A., Millero, F., 1987. A comparison of the equilibrium constants for the dissociation of carbonic acid in seawater media. Deep-Sea Research Part A-Oceanographic Research Papers 34, 1733-1743.

Done, T., Navin, K., 1990. Shallow water benthic communities on coral reefs. Vanuatu Marine Resources: report of a biological survey, 10-37.

Doney, S. C., Fabry, V. J., Feely, R. A., Kleypas, J. A., 2009. Ocean acidification: the other $\mathrm{CO}_{2}$ problem. Annual Review of Marine Science 1 (1), 169-192.

Dore, J. E., Lukas, R., Sadler, D. W., Church, M. J., Karl, D. M., 2009. Physical and biogeochemical modulation of ocean acidification in the central North Pacific. Proceedings of the National Academy of Sciences of the United States of America 106 (30), 12235-40.

Drenkard, E. J., Cohen, A. L., McCorkle, D. C., de Putron, S. J., Starczak, V. R., Zicht, A. E., 2013. Calcification by juvenile corals under heterotrophy and elevated $\mathrm{CO}_{2}$. Coral Reefs 32 (3), 727-735.

Edinger, E. N., Limmon, G. V., Jompa, J., Widjatmoko, W., Heikoop, J. M., Risk, M. J., 2000. Normal coral growth rates on dying reefs: are coral growth rates good indicators of reef health? Marine Pollution Bulletin 40 (5), 404-425.

Fabricius, K. E., Langdon, C., Uthicke, S., Humphrey, C., Noonan, S., De'ath, G., Okazaki, R., Muehllehner, N., Glas, M. S., Lough, J. M., 2011. Losers and winners in coral reefs acclimatized to elevated carbon dioxide concentrations. Nature Clim Change 1 (3), 165169 .

Feely, R. A., Doney, S., Cooley, S., 2009. Ocean acidification: present conditions and future changes in a high $\mathrm{CO}_{2}$ world. Oceanography 22 (4), 36-47.

Glynn, P. W., 1997. Bioerosion and Coral Reef Growth: A Dynamic Balance. In: Birkeland, C. (Ed.), Life and Death of Coral Reefs. Chapman and Hall, New York, pp. 68-95.

Golbuu, Y., Victor, S., Penland, L., Idip, D., Emaurois, C., Okaji, K., Yukihira, H., Iwase, A., Woesik, R., 2007. Palau's coral reefs show differential habitat recovery following the 1998-bleaching event. Coral Reefs 26 (2), 319-332.

Gove, J. M., Williams, G. J., McManus, M. A., Heron, S. F., Sandin, S. A., Vetter, O. J., Foley, D. G., 2013. Quantifying climatological ranges and anomalies for Pacific coral reef ecosystems. PloS one 8 (4), e61974.

Hofmann, G. E., Smith, J. E., Johnson, K. S., Send, U., Levin, L. A., Micheli, F., Paytan, A., Price, N. N., Peterson, B., Takeshita, Y., Matson, P. G., Crook, E. D., Kroeker, K. J., Gambi, M. C., Rivest, E. B., Frieder, C. A., Yu, P. C., Martz, T. R., 2011. High-frequency dynamics of ocean pH: a multi-ecosystem comparison. PloS one 6 (12), e28983.

Holmes, K. E., Edinger, E. N., Limmon, G. V., Risk, M. J., 2000. Bioerosion of live massive corals and branching coral rubble on Indonesian coral reefs. Marine Pollution Bulletin $40(7), 606-617$.

Iguchi, A., Ozaki, S., Nakamura, T., Inoue, M., Tanaka, Y., Suzuki, A., Kawahata, H., Sakai, K., 2012. Effects of acidified seawater on coral calcification and symbiotic algae on the massive coral Porites australiensis. Marine Environmental Research 73, 32-6. 
Kayanne, H., Hata, H., Kudo, S., Yamano, H., Watanabe, A., Ikeda, Y., Nozaki, K., Kato, K., Negishi, A., Saito, H., 2005. Seasonal and bleaching-induced changes in coral reef metabolism and $\mathrm{CO}_{2}$ flux. Global Biogeochemical Cycles 19 (3), GB3015.

Kobluk, D. R., Risk, M. J., 1977. Rate and nature of infestation of a carbonate substraum by a boring alga. Journal of Experimental Marine Biology and Ecology 27 (114), 107-115.

Kohler, K. E., Gill, S. M., 2006. Coral Point Count with Excel extensions (CPCe): A Visual Basic program for the determination of coral and substrate coverage using random point count methodology. Computers \& Geosciences 32 (9), 1259-1269.

Langdon, C., Atkinson, M., 2005. Effect of elevated $p \mathrm{CO}_{2}$ on photosynthesis and calcification of corals and interactions with seasonal change in temperature/irradiance and nutrient enrichment. Journal of Geophysical Research 110 (C9), C09S07.

Lewis, E., Wallace, D., 1998. Program Developed for CO2 System Calculations (Carbon Dioxide Information Analysis Center, Oak Ridge National Laboratory, US Dept. of Energy, Oak Ridge, TN).

Londoño-Cruz, E., Cantera, J., Toro-Farmer, G., Orozco, C., 2003. Internal bioerosion by macroborers in Pocillopora spp. in the tropical eastern Pacific. Marine Ecology Progress Series 265, 289-295.

Manzello, D. P., Enochs, I. C., Bruckner, A., Renaud, P. G., Kolodziej, G., 2014. Galápagos coral reef persistence after ENSO warming across an acidification gradient. Geophysical Research Letters 41, 1-8.

Manzello, D. P., Kleypas, J. A., Budd, D. A., Eakin, C. M., Glynn, P. W., Langdon, C., 2008. Poorly cemented coral reefs of the eastern tropical Pacific: possible insights into reef development in a high- $\mathrm{CO}_{2}$ world. Proceedings of the National Academy of Sciences of the United States of America 105 (30), 10450-5.

Mehrbach, C., Culberso, C., Hawley, J., Pytkowic, R., 1973. Measurement of apparent dissociation-constants of carbon-acid in seawater at atmospheric-pressure. Limnology and Oceanography 18, 897-907.

Oksanen, J., Blanchet, F. G., Kindt, R., 2013. vegan: community ecology package. urlhttp://vegan.r- forge.r-project.org/.

Osorno, A., Peyrot-Clausade, M., Hutchings, P. A., 2005. Patterns and rates of erosion in dead Porites across the Great Barrier Reef (Australia) after 2 years and 4 years of exposure. Coral Reefs 24 (2), 292-303.

Pandolfi, J. M., Connolly, S. R., Marshall, D. J., Cohen, A. L., 2011. Projecting coral reef futures under global warming and ocean acidification. Science 333 (6041), 418-22.

Perry, C. T., 1998. Macroborers within coral framework at Discovery Bay, north Jamaica: species distribution and abundance, and effects on coral preservation. Coral Reefs 17 (3), $277-287$.

Reyes-Nivia, C., Diaz-Pulido, G., Kline, D., Guldberg, O.-H., Dove, S., 2013. Ocean acidification and warming scenarios increase microbioerosion of coral skeletons. Global Change Biology 19 (6), 1919-29. 
Sammarco, P., Risk, M., 1990. Large-scale patterns in internal bioerosion of Porites: Cross continental shelf trends on the Great Barrier Reef. Marine Ecology Progress Series 59, $145-156$.

Shamberger, K. E. F., Cohen, A. L., Golbuu, Y., McCorkle, D. C., Lentz, S. J., Barkley, H. C., 2014. Diverse coral communities in naturally acidified waters of a Western Pacific reef. Geophysical Research Letters 41, 499-504.

Sorokin, Y., 1995. Coral Reef Ecology. Springer, New York.

Suggett, D. J., Dong, L. F., Lawson, T., Lawrenz, E., Torres, L., Smith, D. J., 2012. Light availability determines susceptibility of reef building corals to ocean acidification. Coral Reefs 32 (2), 327-337.

Tribollet, A., Godinot, C., Atkinson, M., Langdon, C., 2009. Effects of elevated $p \mathrm{CO}_{2}$ on dissolution of coral carbonates by microbial euendoliths. Global Biogeochemical Cycles $23(3)$.

Tribollet, A., Golubic, S., 2005. Cross-shelf differences in the pattern and pace of bioerosion of experimental carbonate substrates exposed for 3 years on the northern Great Barrier Reef, Australia. Coral Reefs 24 (3), 422-434.

van Hooidonk, R., Maynard, J. A., Manzello, D., Planes, S., 2014. Opposite latitudinal gradients in projected ocean acidification and bleaching impacts on coral reefs. Global change biology 20 (1), 103-12.

Watanabe, A., Kayanne, H., Hata, H., Kudo, S., Nozaki, K., Kato, K., Negishi, A., Ikeda, Y., Yamano, H., 2006. Analysis of the seawater $\mathrm{CO}_{2}$ system in the barrier reef-lagoon system of Palau using total alkalinity-dissolved inorganic carbon diagrams. Science and Technology 51 (4), 1614-1628.

Wisshak, M., Schonberg, C., Form, A., Freiwald, A., 2012. Ocean acidification accelerates reef bioerosion. PloS one 7 (9), 3-10. 


\subsection{Figures and Tables}

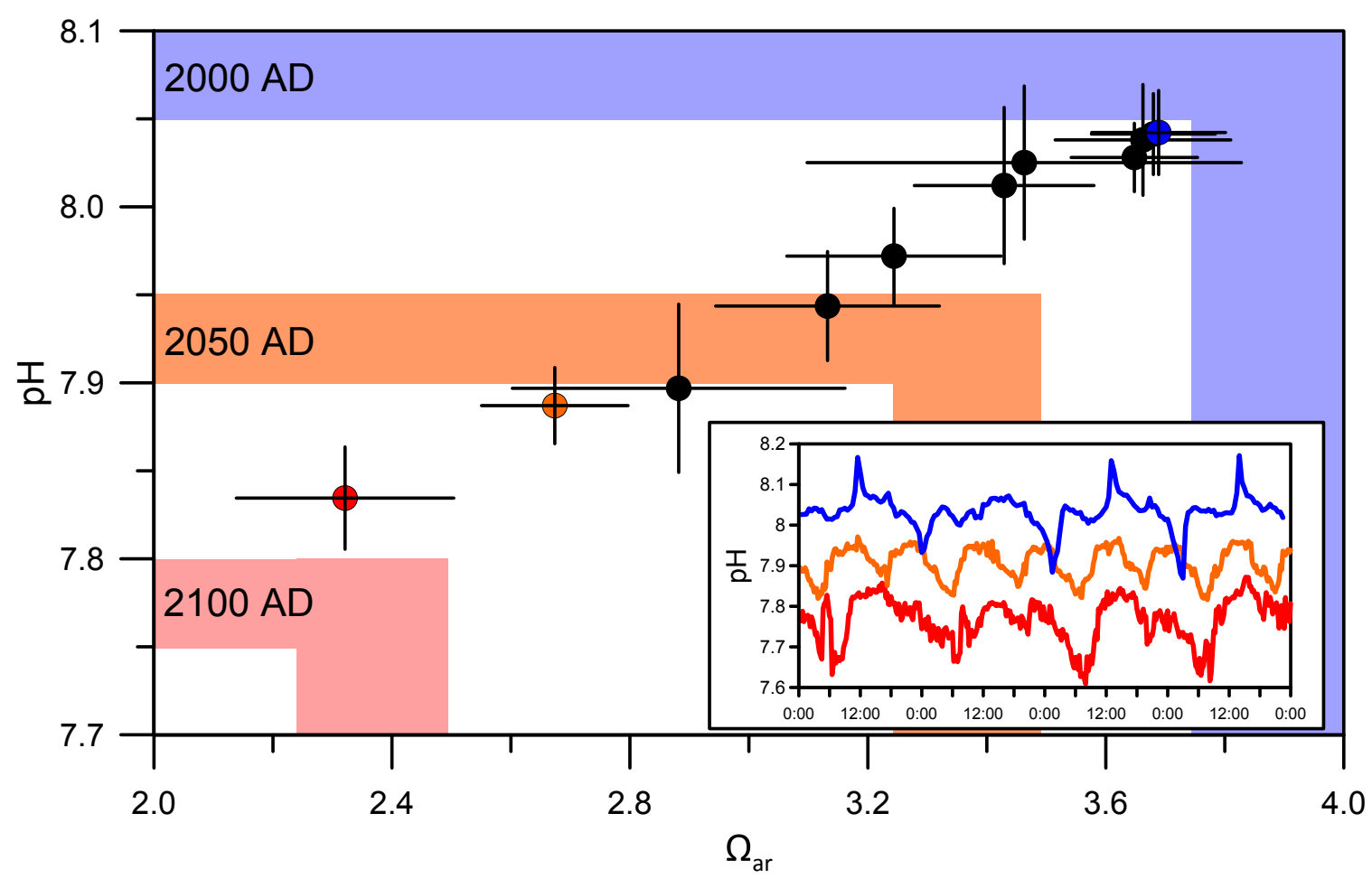

Figure 3-1: Natural acidification gradient across Palau mirrors projected anthropogenic $\mathrm{CO}_{2}$-driven changes in ocean chemistry. Shown are the mean $( \pm 1 \mathrm{SD})$ dawn-to-dusk $\mathrm{pH}$ and $\Omega_{a r}$ for our 11 reef study sites and diurnal $\mathrm{pH}$ variability at three of those sites over 4 days (inset) (Figure B-1: sites 1, 2, and 10). Shaded regions indicate the range of western tropical Pacific open ocean $\mathrm{pH}$ and $\Omega_{a r}$ levels in 2000 (blue) and open ocean values predicted for 2050 (orange) and 2100 (red) (Feely et al., 2009; Denman et al., 2011). Colored points correspond to $\mathrm{pH}$ time series in inset. 

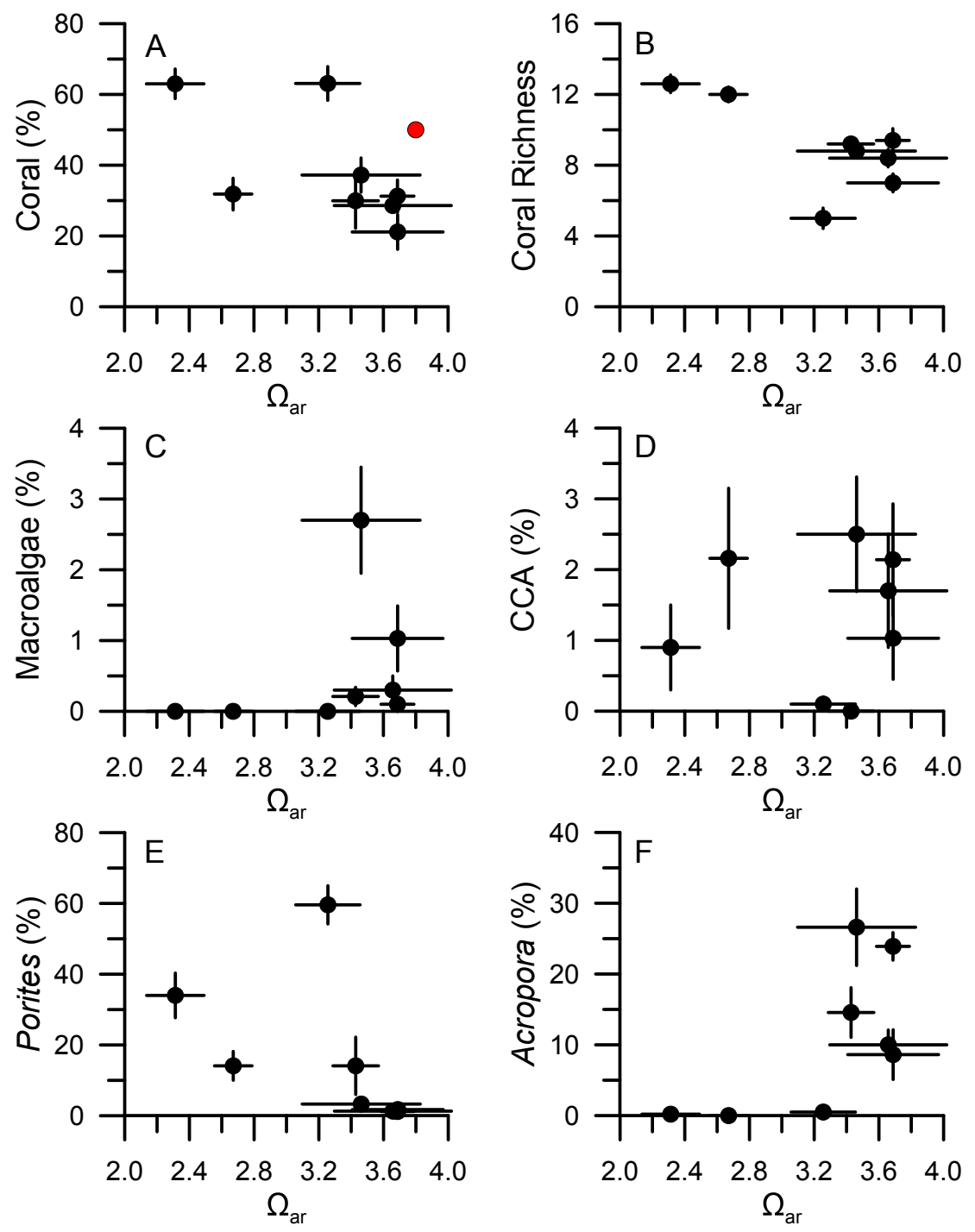

Figure 3-2: Palau coral reef community responses to acidification. (A) Mean ( $\pm 1 \mathrm{SE}$ ) percent coral cover per transect $(\mathrm{n}=5$ per site) from 2010 to 2012 (circles) versus site mean $\Omega_{a r}$ ( \pm 1 SD) with pre-1998 bleaching barrier coral cover (Golbuu et al., 2007) and estimated $\Omega_{a r}$ (Kayanne et al., 2005) from 1992 to 1994 (red circle). (B) Number of coral genera observed (richness). (C and D) Macroalgae (C) and crustose coralline algae (CCA) (D). (E and F) Percent cover of Porites spp. (E) and Acropora spp. (F). 


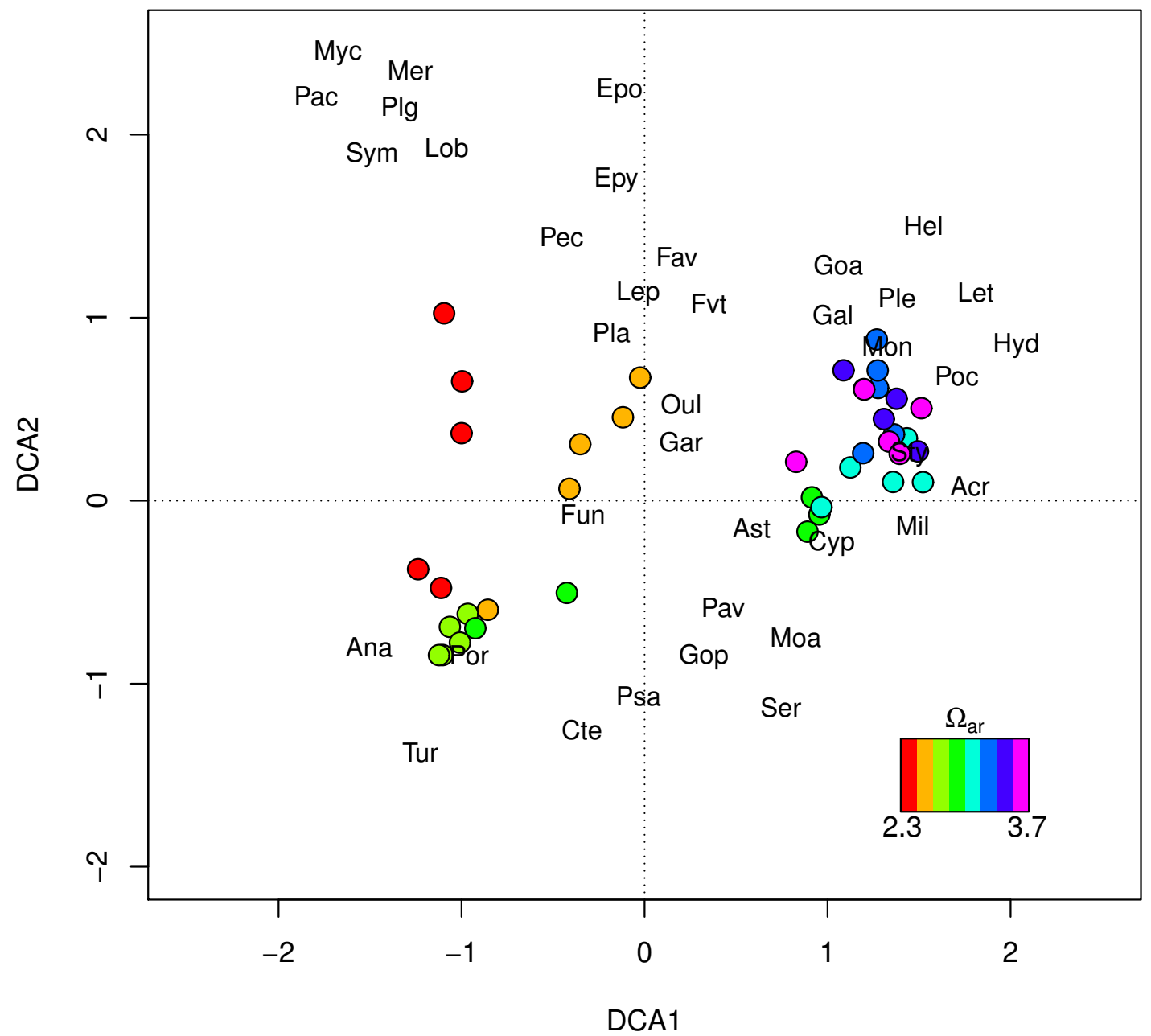

Figure 3-3: Detrended correspondence analysis (DCA) scores for eight Palauan reef sites and coral genera. DCA scores are for each of five transects collected per reef site (circles, colored by mean $\Omega_{a r}$ for each site) and their coral genera (names abbreviated). See Table B.6 for genus abbreviations. 

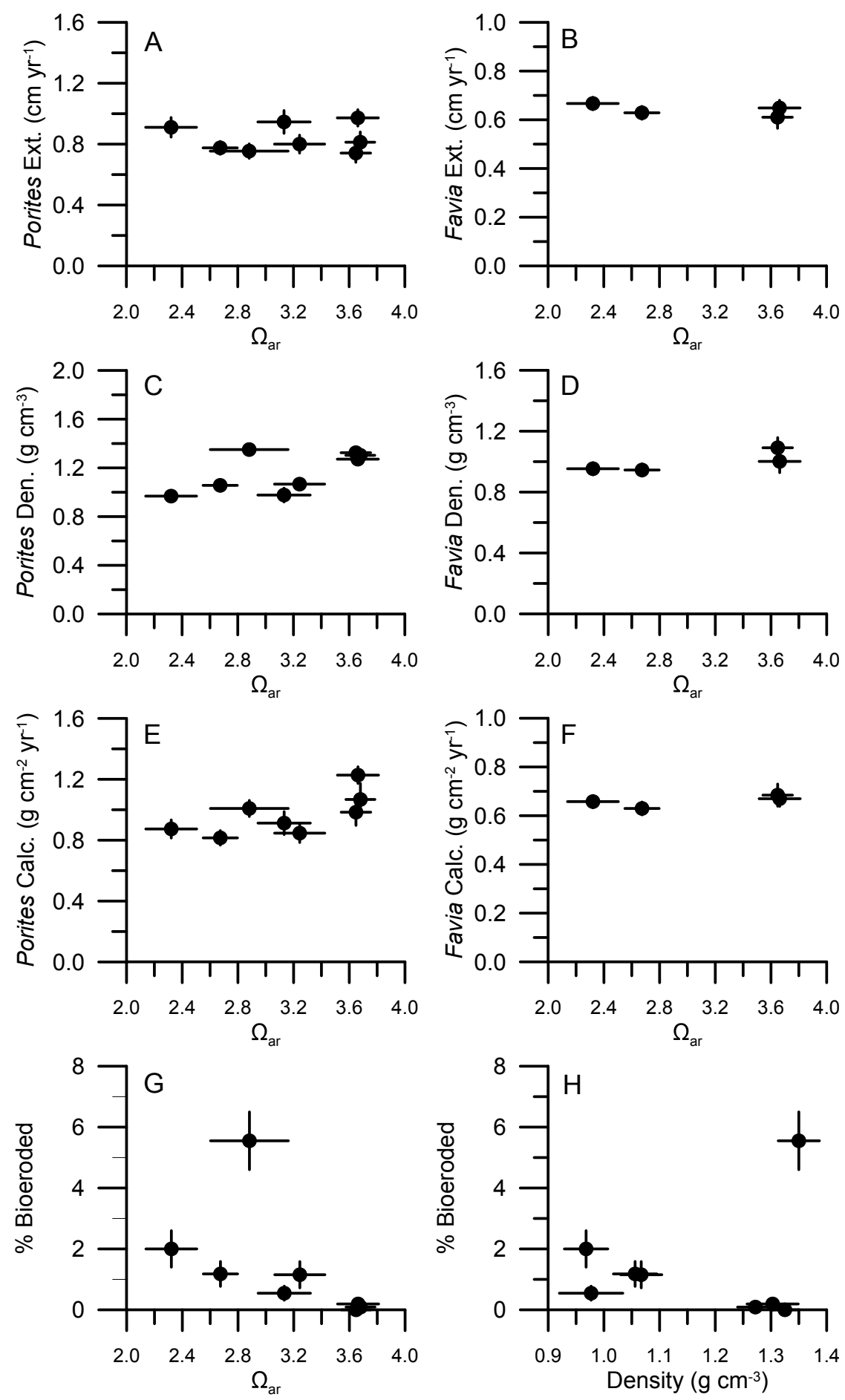

Figure 3-4: Skeletal growth responses of two coral genera to acidification. (A to H) Skeletal analyses include 2006-2010 site mean ( \pm 1 SE) extension (ext.), density (den.), and calcification rates (calc.) for Porites (A, C, and E) and Favia (B, D, and F); percent Porites skeletal volume macrobioeroded $(\mathrm{G})$ versus $\Omega_{a r}( \pm 1 \mathrm{SD})$; and the relationship between Porites density and skeletal volume macrobioeroded $(\mathrm{H})$. 
Table 3.1: Diverse reef responses to natural acidification in the Palau Rock Islands, PNG $\mathrm{CO}_{2}$ vents, Mexico ojos, and eastern tropical Pacific (ETP) upwelling regions. For each site, response variables are reported as the ratio of each variable in low $/$ high $\mathrm{pH}$ sites. + indicates a significant increase in the response variable from high to low $\mathrm{pH}$, and - indicates a significant decrease. n.d., no data available.

\begin{tabular}{|c|c|c|c|c|c|c|c|c|}
\hline & Palau $\S$ & & $\mathrm{PNG}^{\dagger}$ & & Mexico $\ddagger$ & & $\mathrm{ETP}$ ฯ & \\
\hline Hard coral cover & 1.9 & & 1.1 & & 0.5 & $(-)$ & 0.0 & $(-)$ \\
\hline Macroalgae cover & 0.7 & & 2.1 & $(+)$ & n.d. & & n.d. & \\
\hline Coralline algae cover & 1.1 & & 0.2 & $(-)$ & n.d. & & n.d. & \\
\hline Hard coral richness & 1.6 & & 0.6 & $(-)$ & 0.3 & $(-)$ & 0.2 & $(-)$ \\
\hline Porites cover & 16.0 & $(+)$ & 2.3 & $(+)$ & 0.8 & & n.d. & \\
\hline Porites extension & 1.0 & & 1.1 & & 1.0 & & 0.6 & \\
\hline Porites density & 0.8 & & 1 & & 0.8 & $(-)$ & 0.8 & $(-)$ \\
\hline Porites calcification & 0.8 & & 1.1 & & 0.7 & $(-)$ & 0.5 & $(-)$ \\
\hline Bioerosion $^{*}$ & 11.3 & $(+)$ & 1.9 & $(+)$ & 1.8 & $(+)$ & 1.9 & $(+)$ \\
\hline
\end{tabular}

$\S$ For Palau, ratios are calculated for the two lowest and the two highest $\Omega_{a r}$ reefs, and the indicated significance is for the trend across all sites $\left(\Omega_{a r}=3.7\right.$ to 2.3 ).

$\dagger$ For PNG, ratios and trends are reported for $\Omega_{a r}=3.5$ to 2.9 (Fabricius et al., 2011). $\ddagger$ Community data for Mexico are reported for $\Omega_{a r}>2.5$ to $\Omega_{a r}<2.5$ (Crook et al., 2011), and skeletal growth parameters are reported for $\Omega_{a r}>2$ to $\Omega_{a r}<2$ (Crook et al., 2013).

ฯ For the ETP, hard coral cover, hard coral richness, and Porites extension, density, and calcification data are reported for four reef sites within the Galapagos $\left(\Omega_{a r}=3.3\right.$ to 2.4)(Manzello et al., 2014). Porites macrobioerosion rates are compared across the Galapagos, the Gulf of Panama, and Gulf of Chiriquí $\left(\Omega_{a r}=3.5\right.$ to 2.5) (Manzello, 2010).

${ }^{*}$ Trends in bioerosion are estimated by the percent volume of macrobioerosion of Porites skeletal cores (Palau and Mexico), Porites bioeroder density (PNG), or bioerosion rate (ETP). 


\section{Chapter 4}

\section{Mechanisms and thresholds for $\mathrm{pH}$ tolerance in Palau Porites corals}

\subsection{Abstract}

In Palau, calcification rates of two reef-building coral genera are maintained across a strong natural gradient in aragonite saturation state $\left(\Omega_{a r}\right)$ ranging from 3.7 to 2.3. This observation contrasts with the strong sensitivity to decreasing $\Omega_{a r}$ that these genera demonstrate in previous laboratory $\mathrm{CO}_{2}$ manipulation experiments and in field studies. Moreover, in contrast to other naturally more acidic coral reefs, benthic communities in Palau's low- $\Omega_{a r}$ $\left(\Omega_{a r}=2.3\right)$ Rock Island reefs display ecological indices consistent with healthy communities. A laboratory $\mathrm{CO}_{2}$ manipulation experiment and a field-based reciprocal transplant were used to investigate whether the apparent lack of sensitivity to ocean acidification of Palau's Porites corals can be attributed to local adaptation to chronic acidification or to environmental factors that allow corals to thrive despite extreme $\mathrm{pH}$ conditions. In a twomonth laboratory incubation, calcification rates of Palau Porites were insensitive to changes in $\Omega_{a r}$ over the range 1.5 to 3.0, suggestive of an adaptive, rather than environmental, mechanism for acidification tolerance. However, in the reciprocal transplant, corals transplanted between high- $\Omega_{a r}$ and low- $\Omega_{a r}$ reefs showed significant declines in calcification rates and high mortality, while corals returned back to their reef of origin were healthy after 17 months in the field. Interpreted within the framework of the experimental result, the failure of $\mathrm{pH} / \Omega_{a r}$-tolerant corals to successfully transplant between different reef sites hints at local adaptation to other (non-pH) environmental factors such as light, temperature, nutrients, and/or flow that co-vary with $\Omega_{a r}$ across Palau's natural acidification gradient.

Submitted as: Hannah C. Barkley, Anne L. Cohen, Daniel C. McCorkle, and Yimnang Golbuu. Mechanisms and thresholds for $\mathrm{pH}$ tolerance in Palau Porites corals. Journal of Experimental Marine Biology and Ecology, in review. 


\subsection{Introduction}

Anthropogenic emissions of carbon dioxide $\left(\mathrm{CO}_{2}\right)$ are altering the chemistry of the world's oceans with significant implications for the structure and function of coral reef ecosystems. The absorption of excess $\mathrm{CO}_{2}$ by surface waters drives down ocean $\mathrm{pH}$, decreases carbonate ion concentration $\left(\mathrm{CO}_{3}{ }^{2-}\right.$ ), and lowers the aragonite saturation state of seawater $\left(\Omega_{a r}\right)$ (Feely et al., 2009). This process, known as ocean acidification, threatens coral reef ecosystems because it decreases the availability of the carbonate ion building blocks that corals and other calcifying reef organisms need to construct the calcium carbonate $\left(\mathrm{CaCO}_{3}\right)$ skeletons that build reefs (Doney et al., 2009). A large number of laboratory $\mathrm{CO}_{2}$ manipulation experiments have shown that coral calcification is highly sensitive to decreasing $\mathrm{pH}$ and $\Omega_{a r}$ (Kroeker et al., 2010). Furthermore, studies of several naturally low- $\Omega_{a r}$ reefs reveal that in situ coral calcification rates usually, but not always, decline under chronically low-pH conditions (Fabricius et al., 2011; Crook et al., 2013; Enochs et al., 2015; Manzello et al., 2014). Together, experiment and field-based observations imply significantly reduced coral calcification rates and eventual shifts from net accretion to net erosion for coral reefs globally.

In light of predictions for coral reef responses to ocean acidification, finding coral reef communities that may be resilient to ocean acidification and elucidating mechanisms for acidification tolerance have become major conservation priorities. However, identification of $\mathrm{pH}$-tolerant reefs and reef communities is challenging because, unlike abrupt high temperature events that cause visible bleaching, $\mathrm{pH}$ tolerance must be identified experimentally. To date, only the coral reefs that fringe Palau's karstic Rock Islands stand in stark contrast to the depauperate coral communities observed at most low- $\Omega_{a r}$ reefs. Even though they currently exist at predicted end-of-century $\Omega_{a r}$ levels $\left(\Omega_{a r}=2.3\right)$, these coral reef communities remain diverse and coral-dominated (Shamberger et al., 2014; Barkley et al., 2015). Moreover, calcification rates of two reef-building coral genera (Porites and Favia) do not change across Palau's steep $\Omega_{a r}$ gradient $\left(\Omega_{a r}=3.7\right.$ to 2.3$)$. This observation contradicts other field-based and experimental results for these genera where significant calcification declines were observed with declining $\Omega_{a r}$ (Albright et al., 2008; Anthony et al., 2008; Muehllehner and Edmunds, 2008; DePutron et al., 2010; Crook et al., 2011; Iguchi et al., 2012; Crook et al., 2013; Drenkard et al., 2013; Manzello et al., 2014; Enochs et al., 2015). This apparent tolerance to acidification raises two key questions: 1) by what mechanisms are Palau's corals 
able to maintain calcification rates in chronically low-pH conditions, and 2) are Palau's corals currently at their thresholds for $\mathrm{pH}$ tolerance?

There are two likely explanations for coral reef community acidification tolerance. First, the particular combination of environmental conditions in Palau's more acidic bays could alleviate impacts of low $\Omega_{a r}$ on calcification. Laboratory experiments suggest that high light, strong flow, and elevated nutrients or food can offset acidification impacts on coral calcification rates (Cohen and Holcomb, 2009; Suggett et al., 2012; Drenkard et al., 2013; Comeau et al., 2014; Tanaka et al., 2014). Many of these environmental factors co-vary with $\Omega_{a r}$ across Palau's acidification gradient, although not necessarily in the direction required for modulation of $\mathrm{pH}$ effects (Barkley et al., 2015). Alternatively, Palau's thriving Rock Island coral reef communities may have acclimatized or adapted to naturally low- $\Omega_{a r}$ conditions. The low-pH Rock Island reefs are relatively isolated within bays and inlets, and were even more isolated prior to the mid-Holocene high stand when sea level was significantly lower than it is today. It is possible that strong selective pressure over hundreds to thousands of years has driven community-wide adaptation to chronically low- $\Omega_{a r}$ levels. Distinguishing between these mechanisms can help inform best practices for conservation by protecting environmental features that promote tolerance or prioritizing connectivity between $\mathrm{pH}$-adapted and $\mathrm{pH}$-sensitive communities and can aid in the identification of any additional acidification-tolerant reefs.

Palau's Rock Island coral communities exist today at $\mathrm{pH} / \Omega_{a r}$ levels predicted for many coral reefs by 2100 . However, it is unknown how $\Omega_{a r}$ will change within these bays over the next few decades as open ocean acidification progresses and whether these coral communities are approaching or already at their acidification thresholds. While trends in $\Omega_{a r}$ on inshore reefs might proceed independently of changes in open ocean $\Omega_{a r}$, acidification in the open ocean may also lead to concurrent decreases in $\Omega_{a r}$ in already low- $\Omega_{a r}$ areas. If this is the case, corals currently living under low- $\Omega_{a r}$ conditions might reach acidification thresholds much sooner than those on high- $\Omega_{a r}$ reefs. On the other hand, equivalent incremental decreases in $\Omega_{a r}$ across all reefs may have less of an impact on the coral communities chronically exposed and possibly adapted to and/or environmentally buffered against low $\Omega_{a r}$ levels. Thus, understanding both the mechanism of coral tolerance to acidification and the $\Omega_{a r}$ thresholds of coral calcification are critically important in predicting how apparently acidification-tolerant communities will cope with changes in $\Omega_{a r}$ over the next few decades. 
To address these questions, combined onsite laboratory $\mathrm{CO}_{2}$ manipulation and reciprocal transplant experiments were conducted to 1) determine sensitivities of corals from a high- $\Omega_{a r}$ reef and a low- $\Omega_{a r}$ reef to a range of $\Omega_{a r}$ conditions and 2) establish whether the calcification insensitivity to $\Omega_{a r}$ observed in the field may be best explained by environmental mitigation of acidification stress or by coral adaptation to low- $\Omega_{a r}$ conditions. Specifically, if environmental mitigation explains acidification-tolerance in low-pH reefs, corals should be dependent on the presence of a specific suite of environmental variables in order to survive transplantation into highly acidified conditions. If adaptation is responsible for acidification tolerance, Palau's corals should be able to calcify in a different low- $\Omega_{a r}$ environment without the presence of particular environmental conditions. Thus, laboratory $\mathrm{CO}_{2}$ perturbation experiments test coral responses solely to $\Omega_{a r}$ with all other environmental variables constant, while reciprocal transplants examine coral responses to $\Omega_{a r}$ in the context of all the other environmental variability present between high- $\Omega_{a r}$ barrier reefs and low- $\Omega_{a r}$ Rock Island reefs. In addition, observing coral responses to a range of $\mathrm{CO}_{2}$ levels can help to evaluate $\Omega_{a r}$ thresholds and improve predictions of how coral communities currently living under low- $\Omega_{a r}$ conditions will respond to future changes in seawater chemistry.

\subsection{Methods}

\subsubsection{Coral collection}

Coral plugs were collected in December 2012 from massive Porites colonies at a naturally low $-\Omega_{a r}$ reef site $\left(7.324^{\circ} \mathrm{N}, 134.493^{\circ} \mathrm{E} ;\right.$ mean $\left.\Omega_{a r}=2.3 ; \mathrm{n}=78\right)$ and a naturally high $-\Omega_{a r}$ reef site $\left(7.268^{\circ} \mathrm{N}, 134.522^{\circ} \mathrm{E} ;\right.$ mean $\left.\Omega_{a r}=3.7 ; \mathrm{n}=75\right)$. At each reef site, small skeletal cores $($ diameter $=3.5 \mathrm{~cm}$ ) were removed from massive colonies using underwater pneumatic drills, and cores were cut with a lapidary table saw to approximately $1 \mathrm{~cm}$ below the tissue layer. The plugs were affixed to nylon square base screws with marine epoxy, secured to egg crate racks, and returned to their original reefs to allow the corals to recover from the coring procedure. All corals survived two months of recovery on the reef and on all corals living tissue had fully overgrown the sides of the plugs so that no underlying skeleton was exposed. Corals were recovered in February 2013. 


\subsection{2 $\quad \mathrm{CO}_{2}$ manipulation experiment}

Corals from two reefs were cultured at three $\mathrm{CO}_{2}$ levels for eight weeks in March to May 2013 ( $\mathrm{n}=10$ corals per treatment, $\mathrm{n}=60$ corals total). The corals were individually incubated in plastic cups (volume $=750 \mathrm{ml}$ ) within a large, temperature-controlled water bath. The corals were maintained at mean $( \pm \mathrm{SD})$ temperatures of $29.4{ }^{\circ} \mathrm{C} \pm 0.1{ }^{\circ} \mathrm{C}$ and light levels of $334 \pm 48 \mu \mathrm{mol} \cdot$ photons $\cdot \mathrm{m}^{-2} \cdot \mathrm{s}^{-1}$ on a $12 \mathrm{~h}: 12 \mathrm{~h}$ light:dark schedule. Corals were fed live Artemia brine shrimp nauplii every other evening and cups were cleaned weekly to prevent algae overgrowth.

Mean $\mathrm{pH} / \Omega_{a r}$ levels for the three treatment conditions were $7.98 / 3.0,7.83 / 2.3$, and 7.60/1.5 (Table 4.1). In each coral cup, carbon system chemistry was regulated using a combination of flow-through pre-equilibrated water and bubbling of mixed air $/ \mathrm{CO}_{2}$ gas. Incoming filtered seawater from the reef was aerated and split into three header tanks. In the low- $\mathrm{CO}_{2}$ header tank, water was bubbled with air. In the mid- $\mathrm{CO}_{2}$ and high- $\mathrm{CO}_{2}$ header tanks, $\mathrm{CO}_{2}$ levels were regulated by a $\mathrm{pH}$ controller (Drs. Foster and Smith) connected to a solenoid valve that introduced $\mathrm{CO}_{2}$ gas into the header tank through a column diffuser. Water was siphoned from the three header tanks into each coral cup at a rate of approximately $375 \mathrm{ml} \cdot \mathrm{hr}^{-1}$. Each coral cup was also bubbled with mixed compressed air and $\mathrm{CO}_{2}$ gas controlled by pairs of mass flow controllers (Aarlborg Instruments) at approximately $200 \mathrm{ml} \cdot \mathrm{min}^{-1}$. Low alkalinity levels in the source water to the Palau International Coral Reef Center (drawn from within the acidified Rock Islands) prevented $\Omega_{a r}$ in the low- $\mathrm{CO}_{2}$ condition $\left(\Omega_{a r}=3.0\right)$ from reaching values that were as high as those measured on the barrier reef site $\left(\Omega_{a r}=3.7\right)$.

To characterize the carbonate chemistry in each cup, total alkalinity (TA), pH, temperature, and salinity were measured weekly. Spectrophotometric $\mathrm{pH}$ measurements were made with $2 \mathrm{mM} \mathrm{m}$-Cresol purple indicator dye using a spectrometer with a $100 \mathrm{~mm}$ flow cell $($ Ocean Optics, mean precision $=0.005)$ following procedures in Clayton and Byrne (1993) and Dickson et al. (2007) and using the equation of Liu et al. (2011). Samples for TA were collected in $20 \mathrm{ml}$ glass vials and poisoned with saturated mercuric chloride. Automated gran titrations for TA were run on duplicate $1 \mathrm{ml}$ samples using a Metrohm Titrando 808 and 730 Sample Changer (mean precision $=4 \mu \mathrm{mol} \cdot \mathrm{kg}^{-1}$ ), and TA values were standardized to certified reference materials obtained from Andrew Dickson [Scripps Institution of 
Oceanography (Dickson, 2001)]. Salinity was measured in each cup using a YSI salinity probe, and temperatures were measured using an Omega thermocouple. Full $\mathrm{CO}_{2}$ system parameters were calculated from temperature, salinity, TA, and $\mathrm{pH}$ using $\mathrm{CO}_{2} \mathrm{SYS}$ (Lewis and Wallace, 1998) with the constants of Mehrbach et al. (1973) as refit by Dickson and Millero (1987).

\subsubsection{Coral calcification analysis}

Calcification rates were measured using both buoyant weight (Davies, 1989) and alkalinity anomaly (Chisholm and Gattuso, 1991) techniques. Buoyant weights for each coral were collected at the beginning of the experiment, after three weeks in experimental $\mathrm{CO}_{2}$ conditions, and then weekly during weeks four to eight. Corals were weighed using a weigh-below hook while entirely submerged in their experimental cups that were maintained at treatment $\mathrm{pH}$ levels. Wet weight data were converted to dry weights using an aragonite density of $2.93 \mathrm{~g} \cdot \mathrm{cm}^{-3}$ and the density of seawater determined using a standard of known weight and density. Repeated buoyant weight measurements on the same coral yielded mean precision estimates of $\pm 0.03 \mathrm{~g}$.

Day/night alkalinity depletion experiments were conducted at the end of the eight-week experiment. Water flow to each coral cup was stopped during this time but gas bubbling was continued in order to maintain $\mathrm{pH}$ levels. Samples for total alkalinity were collected for each coral cup at the beginning and end of two four-hour periods (one four-hour period during the day and one at night). Coral calcification was assumed to be the only process impacting the alkalinity in the cups, where two moles of alkalinity were consumed for every one mole of calcium carbonate produced. TA pre- and post-incubation was determined following the titration procedure described above with samples run in triplicate.

Calcification rates for both buoyant weight and alkalinity anomaly measurements were normalized to surface areas estimated using electrical tape wrapping, in which the entire coral tissue area was wrapped in electrical tape and the weight of tape necessary to cover the coral tissue surface area determined. Weights of tape used to cover the coral tissue were converted to surface areas using a weight to area calibration. Replicated electrical tape surface area estimates produced a mean precision of $0.43 \mathrm{~cm}^{2}$, or $\approx 1 \%$ of calculated coral surface areas. 


\subsubsection{Reciprocal transplant experiment}

The reciprocal transplant experiment was conducted concurrent with the $\mathrm{CO}_{2}$ manipulation experiment. Initial buoyant weight measurements were obtained for all corals prior to transplantation. Of the corals collected from the low- $\Omega_{a r}$ reef $(\mathrm{n}=47)$ and from the high- $\Omega_{a r}$ reef $(\mathrm{n}=45)$, half of each group was returned to their reef of origin, while the remaining half were transplanted to the opposite reef. In May 2013, after eight weeks in the field (and at the end of the $\mathrm{CO}_{2}$ manipulation experiment), half of the corals from each reef $(\mathrm{n}=23$ for both reefs) were recovered and weighed. The remaining corals were left out on the two reefs for seventeen months $(\mathrm{n}=22-24)$. In August 2014, the remaining corals were recovered and weighed. All corals were evaluated for partial or total mortality, and were judged to be alive (no visible tissue death observed), partially dead (visible tissue death and/or recession but some living tissue remaining), or dead (no living tissue remaining).

\subsubsection{Statistical analyses}

All statistical analyses were conducted in $\mathrm{R}$ (version 3.0.1). For the $\mathrm{CO}_{2}$ manipulation experiment, calcification rates derived from overall buoyant weight changes (final - initial) and alkalinity depletion measurements were fit to generalized linear models to explore the relationship between $\Omega_{a r}$ and coral calcification rates. Calcification rates calculated from weekly changes in buoyant weight were fit to linear mixed effects models using the nlme package (Pinherio et al., 2012). The Akaike Information Criterion (AIC) best-fit model included $\Omega_{a r}$, reef of origin, and week as fixed effects and considered individual coral colonies as a random effect to account for repeated weight measurements on the same coral. All reciprocal transplant growth rate data met assumptions for normality (Shapiro-Wilk test) and heteroscedasticity (Levene's Test) and were thus analyzed with two-way ANOVAs with post-hoc Tukey tests.

\subsection{Results}

\subsection{1 $\mathrm{CO}_{2}$ manipulation experiment}

Regardless of reef of origin, corals in the $\mathrm{CO}_{2}$ manipulation experiment showed no calcification sensitivity to $\Omega_{a r}$ and all corals appeared healthy at the end of eight weeks in experi- 
mental conditions. Comparisons between alkalinity anomaly calcification measurements and buoyant weight estimates collected during the last week of the experiment showed that calcification rates produced by both methods were significantly correlated for individual corals $(\mathrm{r}=0.67, \mathrm{p}<0.001 ;$ Figure 4-1). Buoyant weight measurements collected at the beginning and end of the eight-week incubation demonstrated no significant effect of reef of origin (generalized linear model, $\mathrm{p}=0.85), \Omega_{a r}$ level $(\mathrm{p}=0.18)$, or their interaction $(\mathrm{p}=0.72)$ on coral calcification rates $\left(\mathrm{R}^{2}=0.06\right.$; Figure 4-2a; Table C.1). Similarly, day/night alkalinity depletion experiments conducted after eight weeks in experimental treatments indicated no difference in calcification rates across all corals regardless of reef of origin $(\mathrm{p}=0.35), \Omega_{a r}$ level $(\mathrm{p}=0.15)$, or their interaction $\left(\mathrm{p}=0.62, \mathrm{R}^{2}=0.10\right.$; Figure $4-2 \mathrm{~b}$; Table C.1).

Linear mixed effects models showed that calcification rates changed significantly over time. Calcification rates were lower at the beginning of the incubation than in later weeks (estimate $=1.55 \mathrm{mg} \cdot \mathrm{cm}^{-2} \cdot \mathrm{wk}^{-1}, \mathrm{p}<0.001 ;$ Figure 4-3, Table C.2), and $53 \%$ of corals lost weight during the first three weeks of the experiment. However, weekly calcification rates were not significantly impacted by $\Omega_{a r}$, reef of origin, or their interaction $(\mathrm{p}>0.05)$, although during the final month of the experiment the low $\mathrm{CO}_{2}$ treatments from each reef consistently showed the highest calcification rates.

\subsubsection{Reciprocal transplant experiment}

After two months in the field, there were significant differences in calcification rates and mortality related to transplant conditions (Figure 4-4, Figure 4-5; Table C.3). Corals originally collected from the high- $\Omega_{a r}$ site had similar growth rates and $>80 \%$ survival at both high and low $\Omega_{a r}$ (Tukey HSD, $\mathrm{p}=0.99$ ) and grew as fast in low- $\Omega_{a r}$ conditions as corals originally from the low- $\Omega_{a r}$ site $(\mathrm{p}=0.20)$. However, the corals transplanted from the low$\Omega_{a r}$ reef to the high- $\Omega_{a r}$ reef had significantly lower calcification rates relative to the other three transplant groups ( $\mathrm{p}<0.01$ for all pairs), with $29 \%$ of individuals showing partial or total mortality after two months.

After 17 months in the field, only the corals that had been returned to their original reef (i.e. low- $\Omega_{a r}$ to low- $\Omega_{a r}$ and high- $\Omega_{a r}$ to high- $\Omega_{a r}$ ) had high growth and survival rates. There was no significant difference in calcification between the two control groups of corals returned to their original reef $(\mathrm{p}=0.84)$, and calcification rates were significantly higher than those of transplanted corals from both reefs $(\mathrm{p}<0.01$ for all pairs). Corals transplanted from one reef 
to the other showed very low, mostly net negative growth, and very high mortality $(73-90 \%$ partial or total mortality). However, a small number of corals transplanted to the opposite reef were able survive transplantation: $27 \%$ (3 individuals) of the corals transplanted from high- $\Omega_{a r}$ to low- $\Omega_{a r}$ and $10 \%$ (1 individual) of the corals transplanted from low- $\Omega_{a r}$ to high- $\Omega_{a r}$ were alive with no visible tissue death after seventeen months in the field.

\subsection{Discussion}

The healthy coral communities in Palau's low- $\Omega_{a r}$ Rock Island bays provide a unique opportunity to evaluate $\mathrm{pH}$ tolerance in corals chronically exposed to more acidic conditions. As strategies for coral reef conservation focus increasingly on identification of areas most likely to be resilient, a robust understanding of both the mechanisms that increase tolerance and the $\mathrm{pH}$ thresholds beyond which tolerance declines will be important to inform conservation decisions. Where tolerance is afforded by a specific combination of environmental conditions, controlling coastal anthropogenic activities that negatively affect those features will become critically important to address ocean acidification. Where tolerance is identified as adaptive, ensuring the protection of those communities and their connectivity with neighboring reefs should be a high priority.

Palau's Porites corals incubated at three $p \mathrm{CO}_{2}$ levels in a laboratory manipulation experiment demonstrated no overall calcification response to acidification and were able to maintain calcification rates over a $\Omega_{a r}$ range from 3.0 to 1.5. This result is consistent with the absence of a calcification response in Porites corals at the same reef sites in situ over a narrower range in $\Omega_{a r}$ (Barkley et al., 2015). The $\Omega_{a r}$ tolerance observed in the $\mathrm{CO}_{2}$ manipulation experiment is suggestive of adaptation, as Porites coral populations were able to maintain their calcification rates despite extreme declines in $\Omega_{a r}$ and in the absence of variability in other environmental factors. In addition, these corals were incubated under experimental $\mathrm{pH}$ and $\Omega_{a r}$ levels much lower than those they experience in situ. Thus, the maintenance of calcification rates at $\mathrm{pH}=7.6$ and $\Omega_{a r}=1.5$ indicates that corals in Palau are not living close to their threshold $\Omega_{a r}$ and are tolerant to acidification levels far below those to which they are currently exposed. In addition, this suggests that calcification rates may be sustained regardless of how carbonate chemistry conditions change in Rock Island lagoons relative to the open ocean over the next several decades. 
There was no significant overall trend in coral calcification with decreasing $\Omega_{a r}$, but individual corals exhibited a large range in calcification rates within each treatment group. The range in calcification rates observed in the experiment is comparable to that observed in the field at both reef sites. To ensure statistical power, this experiment examined the $\Omega_{a r}$ sensitivities of distinct populations of corals within each treatment group rather than the response of the same individual colonies to multiple $\Omega_{a r}$ levels. Thus, it is not possible to distinguish whether the observed range in calcification rates relates solely to the variability in growth rates inherent in these coral populations or, instead, to differences in the $\Omega_{a r}$ tolerance of individual corals. However, if the latter is true, it is likely that not all colonies will be able to tolerate declining $\Omega_{a r}$ conditions even within a population with no overall sensitivity to acidification. At the same time, those corals able to maintain high rates of growth despite decreasing $\Omega_{a r}$ might be those best able to survive and repopulate any communities that succumb to future ocean acidification.

Somewhat surprisingly, calcification responses to $\Omega_{a r}$ were no different between corals collected from naturally high- $\Omega_{a r}$ and naturally low- $\Omega_{a r}$ reefs. Corals collected from the chronically low- $\Omega_{a r}$ reef $\left(\Omega_{a r}=2.3\right)$ calcified as fast in experimental conditions and were equally insensitive to declining $\Omega_{a r}$ as corals collected from the high- $\Omega_{a r}$ reef $\left(\Omega_{a r}=3.7\right)$. This suggests that at least two Porites coral populations, separated by a distance of about $10 \mathrm{~km}$, are able to acclimatize or adapt to $\Omega_{a r}$ conditions lower than those to which they are presently exposed. Hydrodynamic models of the Palau archipelago suggest that the isolated coral communities of the Rock Island bays are likely largely self-seeded and have high rates of larval retention but that some larval exchange may occur between lagoon and barrier reefs (Golbuu et al., 2012). If there is even a small degree of larval connectivity between these populations, any evolved trait that allows Rock Island corals to survive under low- $\Omega_{a r}$ conditions could be shared by barrier reef communities and may explain the $\mathrm{pH}$ tolerance of barrier reef corals that do not currently experience low- $\Omega_{a r}$ conditions.

A review of all laboratory-based and in situ studies of Porites sensitivity to ocean acidification indicates this genus is, in general, not particularly tolerant to declining $\Omega_{a r}$. Indeed, most laboratory experiments demonstrate significant declines in Porites calcification across ranges in $\Omega_{a r}$ and time scales comparable to those tested in this study (Ohde and Hossain, 2004; Albright et al., 2008; Anthony et al., 2008; DePutron et al., 2010; Iguchi et al., 2012). Field observations of calcification rates across natural acidification gradients in the Yucatan 
ojos, Eastern Tropical Pacific low- $\Omega_{a r}$ upwelling regions, and Maug $\mathrm{CO}_{2}$ vent sites also show a negative response to acidification (Crook et al., 2013; Manzello et al., 2014; Enochs et al., 2015). Of ten other laboratory and field studies that explored massive Porites responses to $\Omega_{a r}$ across three or more treatments or acidification levels, eight found that Porites calcification was highly sensitive to changes in $\Omega_{a r}$ (Ohde and Hossain, 2004; Albright et al., 2008; Anthony et al., 2008; DePutron et al., 2010; Iguchi et al., 2012; Crook et al., 2013; Manzello et al., 2014; Enochs et al., 2015), while two found no sensitivity (Edmunds, 2012; Comeau et al., 2014) (Figure C-2). This suggests that the observed insensitivity of Porites calcification to acidification in Palau may be unusual amongst populations of this genus.

There are several possible mechanisms by which corals can maintain calcification rates under low-pH conditions. Some studies have suggested that acidification-tolerant corals are able to use both bicarbonate and carbonate ions for calcification (Jury et al., 2010; Comeau et al., 2013). However, if this were the case, then calcification would increase under ocean acidification as bicarbonate ion concentrations rise. Elevated nutrient concentrations and heterotrophic feeding have also been shown to increase calcification rates of corals in low-pH conditions relative to low-nutrient/unfed corals (Holcomb et al., 2010; Edmunds, 2011; Drenkard et al., 2013; Towle et al., 2015). There is no evidence that Palau corals have adopted this strategy, as nutrient levels do not vary across Palau's reef environments (Barkley et al., 2015). Another hypothesized mechanism is that corals maintain the $\mathrm{pH}$ and $\Omega_{a r}$ of the extra-cellular calcifying medium despite low seawater pH (Ries, 2011; McCulloch et al., 2012; Venn et al., 2013; Vidal-Dupiol et al., 2013). This occurs through increased activity of $\mathrm{Ca}^{2+}$ ATPase, an enzyme concentrated in the calicoblastic epithelial cells that removes protons and elevates $\mathrm{pH} / \Omega_{a r}$ of the coral's calcifying medium (Cohen and McConnaughey, 2003; Zoccola et al., 2004). Boron isotope analyses of two Porites corals each from the low- $\Omega_{a r}$ and high- $\Omega_{a r}$ reefs considered in this study suggest that this may be the case. On average, the two low-pH corals elevated their calcifying fluid $\mathrm{pH}$ by 0.51 units above that of the external seawater $(\mathrm{pH}=7.84)$ to achieve an average calcifying $\mathrm{pH}$ of 8.35 . Conversely, the two high-pH corals elevated their calcifying fluid $\mathrm{pH}$ by only 0.38 units above that of the external seawater $(\mathrm{pH}=8.04)$ to achieve a calcifying $\mathrm{pH}$ of 8.42 (DeCarlo et al., 2016). Thus, the elevation of calcifying medium $\mathrm{pH}$ may be the likely mechanism by which corals in Palau's low-pH reefs are able maintain calcification rates equivalent to those living in high-pH reef environments. 
Corals in the reciprocal transplant experiment showed extreme sensitivity to differences in the suite of environmental variables that change across reef types in Palau. Corals collected from a low- $\Omega_{a r}$ Rock Island reef and returned to the low- $\Omega_{a r}$ reef and corals collected from and returned to a high- $\Omega_{a r}$ barrier reef had equivalent calcification rates and high survival rates after 17 months in the field. However, corals collected from one reef and then transplanted to the other had very low growth rates and very high mortality over the same time period, with only a small number of individuals alive at the end of the experiment. The healthy control populations and the fact that most transplanted individuals were still alive after two months rule out the transplantation procedure itself as the primary cause of mortality. The poor growth and survival of both groups of transplanted corals is striking, as corals collected from the same initial reef populations demonstrated very high tolerance to a more extreme range of $\Omega_{a r}$ in the laboratory $\mathrm{CO}_{2}$ experiment. This implies that environmental variables other than $\Omega_{a r}$ (e.g. temperature, light, water flow, etc.) were responsible for the very low survival of transplanted corals. Alternatively, ecological factors, such as predation, could be responsible for high mortality rates in transplanted corals, as evidenced by visible parrotfish bite scars on several corals transplanted from low- $\Omega_{a r}$ to high- $\Omega_{a r}$ reefs. The reciprocal transplant, in which each population showed the highest fitness in its native environment, displays archetypal local adaptation (Reed and Martiny, 2007; Savolainen et al., 2013). Combined with the laboratory $\Omega_{a r}$ manipulation results, the reciprocal transplant thus support an adaptive mechanism for acidification tolerance in Palau.

Results from the $\mathrm{CO}_{2}$ manipulation experiment and reciprocal transplant suggest both that adaptive mechanisms are at play and that Palau Porites corals could maintain calcification rates with progressive ocean acidification. Calcification rates of Favia corals were similarly maintained across the natural acidification gradient in Palau, indicating that more than one genus may have evolved the capability to deal with $\mathrm{pH}$ stress (Barkley et al., 2015). However, while coral calcification rates may be insensitive to acidification, rates of coral skeletal bioerosion become significantly elevated as $\mathrm{pH}$ falls in Palau and will likely increase under future levels of acidification (Barkley et al., 2015; DeCarlo et al., 2015). In order for Palau's pH-tolerant coral reefs to survive ocean acidification over the next several decades, rates of calcification must continue to outpace those of bioerosion. For this to be the case, local management efforts must regulate any coastal threats - such as nutrient eutrophication - that can accelerate rates of bioerosion and alter the balance between reef 
accretion and dissolution (DeCarlo et al., 2015). If properly managed, Palau's unique, potentially acidification-tolerant coral reefs may be among the coral reef communities best able to persist under predicted changes in ocean chemistry over the course of the $21^{\text {st }}$ century.

\subsection{Acknowledgments}

The authors thank L. Isechal, V. Nestor, G. Mereb, A. Merep, C. Doropoulos, M. Zupan, A. Bukurrou, J. Oruetamor, M. Saiwaichi, T. DeCarlo, K. Pietro, E. Bonk, and the staff of the Palau International Coral Reef Center (PICRC) for assistance with fieldwork and analyses. This work was supported by The Tiffany \& Co. Foundation, National Science Foundation [award OCE-1220529 to A. Cohen], The Dalio Foundation Inc., through the Dalio Explore Fund, Ray Dalio through the WHOI Access to the Sea Fund, and a NSF Graduate Research Fellowship to H. Barkley. 


\subsection{References}

Albright, R., Mason, B., Langdon, C., 2008. Effect of aragonite saturation state on settlement and post-settlement growth of Porites astreoides larvae. Coral Reefs 27 (3), 485-490.

Anthony, K. R. N., Kline, D. I., Diaz-Pulido, G., Dove, S., Hoegh-Guldberg, O., 2008. Ocean acidification causes bleaching and productivity loss in coral reef builders. Proceedings of the National Academy of Sciences of the United States of America 105 (45), 17442-6.

Barkley, H. C., Cohen, A. L., Golbuu, Y., Starczak, V. R., DeCarlo, T. M., Shamberger, K. E. F., 2015. Changes in coral reef communities across a natural gradient in seawater $\mathrm{pH}$. Science Advances 1, 1-7.

Chisholm, J., Gattuso, J.-P., 1991. Validation of the alkalinity anomaly technique for investigating calcification and photosynthesis in coral reef communities. Limnology and Oceanography 36 (6), 1232-1239.

Clayton, T. D., Byrne, R. H., 1993. Spectrophotometric seawater pH measurements: total hydrogen ion concentration scale calibration of m-cresol purple and at-sea results 40 (10), $2115-2129$.

Cohen, A. L., Holcomb, M., 2009. Why corals care about ocean acidification: uncovering the mechanism. Oceanography 22 (4), 118-127.

Cohen, A. L., McConnaughey, T. A., 2003. Geochemical perspectives on coral mineralization. In: Dove, P., Weiner, S., De Yoreo, J. (Eds.), Biomineralization: Reviews in mineralogy and geochemistry. Vol. 54. Mineralogical Society of America, pp. 151-187.

Comeau, S., Carpenter, R. C., Edmunds, P. J., 2013. Coral reef calcifiers buffer their response to ocean acidification using both bicarbonate and carbonate. Proceedings. Biological sciences / The Royal Society 280, 20122374.

Comeau, S., Edmunds, P. J., Lantz, C. A., Carpenter, R. C., 2014. Water flow modulates the response of coral reef communities to ocean acidification. Scientific Reports 4, 6681.

Crook, E., Cohen, A. L., Rebolledo-Vieyra, M., Hernandez, L., Paytan, A., 2013. Reduced calcification and lack of acclimatization by coral colonies growing in areas of persistent natural acidification. Proceedings of the National Academy of Sciences of the United States of America 110 (27), 11044-9.

Crook, E., Potts, D., Rebolledo-Vieyra, M., Hernandez, L., Paytan, A., 2011. Calcifying coral abundance near low-pH springs: implications for future ocean acidification. Coral Reefs 31 (1), 239-245.

Davies, P. S., 1989. Short-term growth measurements of coral using an accurate buoyant weighing technique. Marine Biology 101, 389-395.

DeCarlo, T., Cohen, A. L., Barkley, H., Shamberger, K., Cobban, Q., Young, C., Brainard, R. E., Golbuu, Y., 2015. Coral bioerosion is accelerated by ocean acidification and nutrients. Geology 43, 7-10.

DeCarlo, T. M., Gaetani, G. A., Cohen, A. L., Foster, G. L., Alpert, A. E., Stewart, J. A., 
2016. Coral Sr-U thermometry. Paleoceanography, 10.1002/2015PA002908.

DePutron, S. J., McCorkle, D. C., Cohen, A. L., Dillon, A. B., 2010. The impact of seawater saturation state and bicarbonate ion concentration on calcification by new recruits of two Atlantic corals. Coral Reefs 30 (2), 321-328.

Dickson, A., 2001. Reference materials for oceanic measurements. Oceanography 14, 21-22.

Dickson, A., Millero, F., 1987. A comparison of the equilibrium constants for the dissociation of carbonic acid in seawater media. Deep-Sea Research Part A-Oceanographic Research Papers 34, 1733-1743.

Dickson, A., Sabine, C., Christian, J., 2007. Determination of the pH of sea water using the indicator dye m-cresol purple. In: Dickson, A., Sabine, C., Christian, J. (Eds.), Guide to Best Practices for Ocean $\mathrm{CO}_{2}$ Measurements. PICES Special Publication, p. 191.

Doney, S. C., Fabry, V. J., Feely, R. A., Kleypas, J. A., 2009. Ocean acidification: the other $\mathrm{CO}_{2}$ problem. Annual Review of Marine Science 1 (1), 169-192.

Drenkard, E. J., Cohen, A. L., McCorkle, D. C., de Putron, S. J., Starczak, V. R., Zicht, A. E., 2013. Calcification by juvenile corals under heterotrophy and elevated $\mathrm{CO}_{2}$. Coral Reefs 32 (3), 727-735.

Edmunds, P. J., 2011. Zooplanktivory ameliorates the effects of ocean acidification on the reef coral. Limnology and Oceanography 56 (6), 2402-2410.

Edmunds, P. J., 2012. Effect of $p \mathrm{CO}_{2}$ on the growth, respiration, and photophysiology of massive Porites spp. in Moorea, French Polynesia. Marine Biology 159 (10), 2149-2160.

Enochs, I. C., Manzello, D. P., Donham, E. M., Kolodziej, G., Okano, R., Johnston, L., Young, C., Iguel, J., Edwards, C. B., Fox, M. D., Valentino, L., Johnson, S., Benavente, D., Clark, S. J., Carlton, R., Burton, T., Eynaud, Y., Price, N. N., 2015. Shift from coral to macroalgae dominance on a volcanically acidified reef. Nature Climate Change.

Fabricius, K. E., Langdon, C., Uthicke, S., Humphrey, C., Noonan, S., De'ath, G., Okazaki, R., Muehllehner, N., Glas, M. S., Lough, J. M., 2011. Losers and winners in coral reefs acclimatized to elevated carbon dioxide concentrations. Nature Clim Change 1 (3), 165169 .

Feely, R. A., Doney, S., Cooley, S., 2009. Ocean acidification: present conditions and future changes in a high $\mathrm{CO}_{2}$ world. Oceanography 22 (4), 36-47.

Golbuu, Y., Wolanski, E., Idechong, J. W., Victor, S., Isechal, A. L., Oldiais, N. W., Idip, D., Richmond, R. H., van Woesik, R., 2012. Predicting coral recruitment in Palau's complex reef archipelago. PloS one 7 (11), e50998.

Holcomb, M., McCorkle, D. C., Cohen, A. L., 2010. Long-term effects of nutrient and $\mathrm{CO}_{2}$ enrichment on the temperate coral Astrangia poculata (Ellis and Solander, 1786). Journal of Experimental Marine Biology and Ecology 386 (1-2), 27-33.

Iguchi, A., Ozaki, S., Nakamura, T., Inoue, M., Tanaka, Y., Suzuki, A., Kawahata, H., Sakai, K., 2012. Effects of acidified seawater on coral calcification and symbiotic algae on the massive coral Porites australiensis. Marine Environmental Research 73, 32-6. 
Jury, C. P., Whitehead, R. F., Szmant, A. M., 2010. Effects of variations in carbonate chemistry on the calcification rates of Madracis auretenra (= Madracis mirabilis sensu Wells, 1973): Bicarbonate concentrations best predict calcification rates. Global Change Biology 16 (5), 1632-1644.

Kroeker, K. J., Kordas, R. L., Crim, R. N., Singh, G. G., 2010. Meta-analysis reveals negative yet variable effects of ocean acidification on marine organisms. Ecology letters 13 (11), 1419-34.

Lewis, E., Wallace, D., 1998. Program Developed for CO2 System Calculations (Carbon Dioxide Information Analysis Center, Oak Ridge National Laboratory, US Dept. of Energy, Oak Ridge, TN).

Liu, X., Patsavas, M. C., Byrne, R. H., 2011. Purification and characterization of metacresol purple for spectrophotometric seawater $\mathrm{pH}$ measurements. Environmental Science \& Technology 45 (11), 4862-8.

Manzello, D. P., Enochs, I. C., Bruckner, A., Renaud, P. G., Kolodziej, G., 2014. Galápagos coral reef persistence after ENSO warming across an acidification gradient. Geophysical Research Letters 41, 1-8.

McCulloch, M., Falter, J., Trotter, J., Montagna, P., 2012. Coral resilience to ocean acidification and global warming through $\mathrm{pH}$ up-regulation. Nature Climate Change 2 (8), 623-627.

Mehrbach, C., Culberso, C., Hawley, J., Pytkowic, R., 1973. Measurement of apparent dissociation-constants of carbon-acid in seawater at atmospheric-pressure. Limnology and Oceanography 18, 897-907.

Muehllehner, N., Edmunds, P. J., 2008. Effects of ocean acidification and increased temperature on skeletal growth of two scleractinian corals, Pocillopora meandrina and Porites rus. Proceedings of the 11th International Coral Reef Symposium (3), 7-11.

Ohde, S., Hossain, M. M., 2004. Effect of $\mathrm{CaCO}_{3}$ (aragonite) saturation state of seawater on calcification of Porites coral. Geochemical Journal 38 (1999), 613-621.

Pinherio, J., Bates, D., Saikat, D., Sarkar, D., Team., R. D. C., 2012. nlme: Linear and nonlinear mixed effects models: $R$ package version 3.1-105. https://cran.rproject.org/web/packages/nlme/nlme.pdf.

Reed, H. E., Martiny, J. B. H., 2007. Testing the functional significance of microbial composition in natural communities. FEMS Microbiology Ecology 62, 161-170.

Ries, J. B., 2011. A physicochemical framework for interpreting the biological calcification response to $\mathrm{CO}_{2}$-induced ocean acidification. Geochimica et Cosmochimica Acta 75 (14), 4053-4064.

Savolainen, O., Lascoux, M., Merilä, J., 2013. Ecological genomics of local adaptation. Nature Reviews 14 (11), 807-820.

Shamberger, K. E. F., Cohen, A. L., Golbuu, Y., McCorkle, D. C., Lentz, S. J., Barkley, H. C., 2014. Diverse coral communities in naturally acidified waters of a Western Pacific reef. Geophysical Research Letters 41, 499-504. 
Suggett, D. J., Dong, L. F., Lawson, T., Lawrenz, E., Torres, L., Smith, D. J., 2012. Light availability determines susceptibility of reef building corals to ocean acidification. Coral Reefs 32 (2), 327-337.

Tanaka, Y., Iguchi, A., Nishida, K., Inoue, M., Nakamura, T., Suzuki, A., Sakai, K., 2014. Nutrient availability affects the response of juvenile corals and the endosymbionts to ocean acidification. Limnology and Oceanography 59 (5), 1468-1476.

Towle, E. K., Enochs, I. C., Langdon, C., 2015. Threatened Caribbean coral is able to mitigate the adverse effects of ocean acidification on calcification by increasing feeding rate. Plos One 10 (4), e0123394.

Venn, A., Tambutté, E., Holcomb, M., Laurent, J., Allemand, D., Tambutté, S., 2013. Impact of seawater acidification on $\mathrm{pH}$ at the tissue-skeleton interface and calcification in reef corals. Proceedings of the National Academy of Sciences of the United States of America 110 (5), 1634-9.

Vidal-Dupiol, J., Zoccola, D., Tambutté, E., Grunau, C., Cosseau, C., Smith, K. M., Freitag, M., Dheilly, N. M., Allemand, D., Tambutté, S., 2013. Genes related to ion-transport and energy production are upregulated in response to $\mathrm{CO}_{2}$-driven $\mathrm{pH}$ decrease in corals: new insights from transcriptome analysis. PLoS ONE 8 (3).

Zoccola, D., Tambutté, E., Kulhanek, E., Puverel, S., Scimeca, J. C., Allemand, D., Tambutté, S., 2004. Molecular cloning and localization of a PMCA P-type calcium ATPase from the coral Stylophora pistillata. Biochimica et Biophysica Acta 1663 (1-2), 117-126. 


\subsection{Figures and Tables}

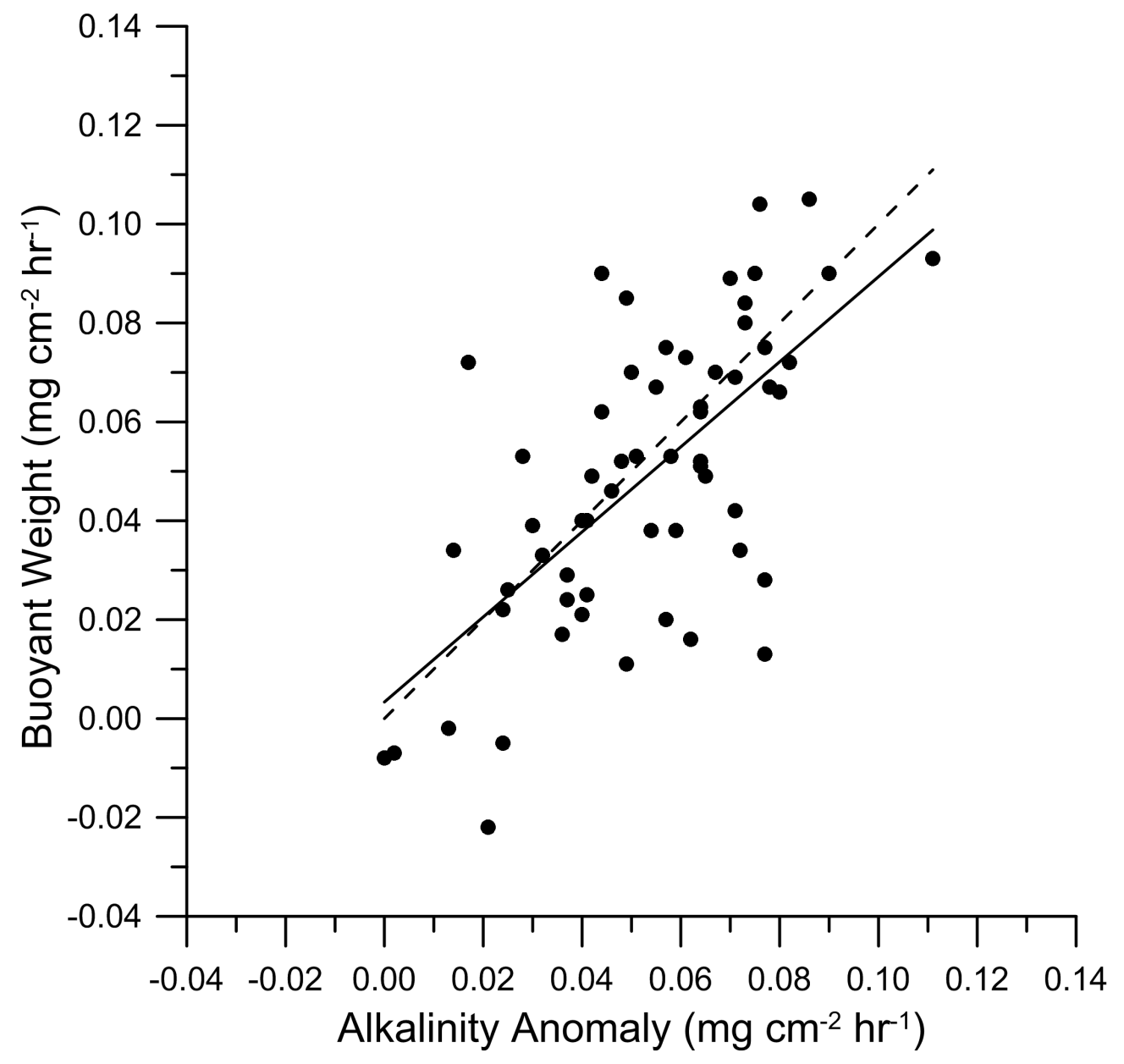

Figure 4-1: Comparison of calcification estimates derived from buoyant weight and alkalinity anomaly techniques. Day/night average alkalinity anomaly estimates for calcification rates of each coral colony at the end of the 8-week experiment plotted against buoyant weight calcification rates collected during the last week of the experiment $(\mathrm{n}=60)$. The solid line shows the line of best fit $(\mathrm{r}=0.67, \mathrm{p}<0.001)$, and the dotted represents a theoretical 1:1 relationship between calcification estimates derived by the two techniques. 

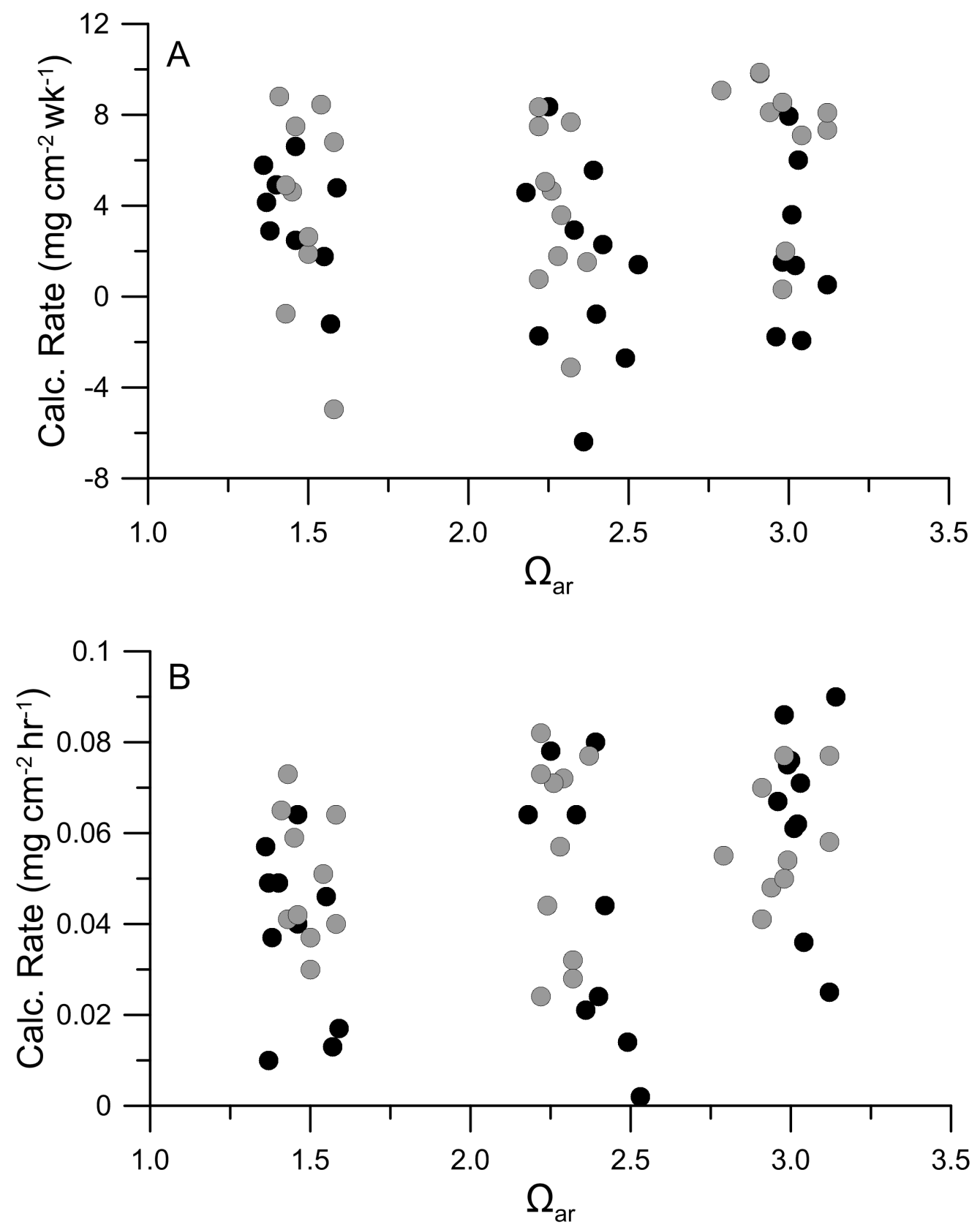

Figure 4-2: Calcification rates of Porites corals collected from a naturally high- $\Omega_{a r}$ reef (gray) and a naturally low- $\Omega_{a r}$ reef (black) incubated at three $\Omega_{a r}$ conditions. (A) Overall coral calcification rates calculated as the surface area normalized difference between weight at the end of the 8-week experiment and initial weight (measured by buoyant weighing). (B) Calcification rates derived from paired 4-hour day/night alkalinity depletion measurements conducted at the end of the 8-week experiment. Coral colony calcification rates are plotted against the average $\Omega_{a r}$ measured in each experimental cup $(\mathrm{n}=10$ corals per treatment group). Neither set of rate measurements showed significant differences as a function of either $\Omega_{a r}$ or reef of origin. 


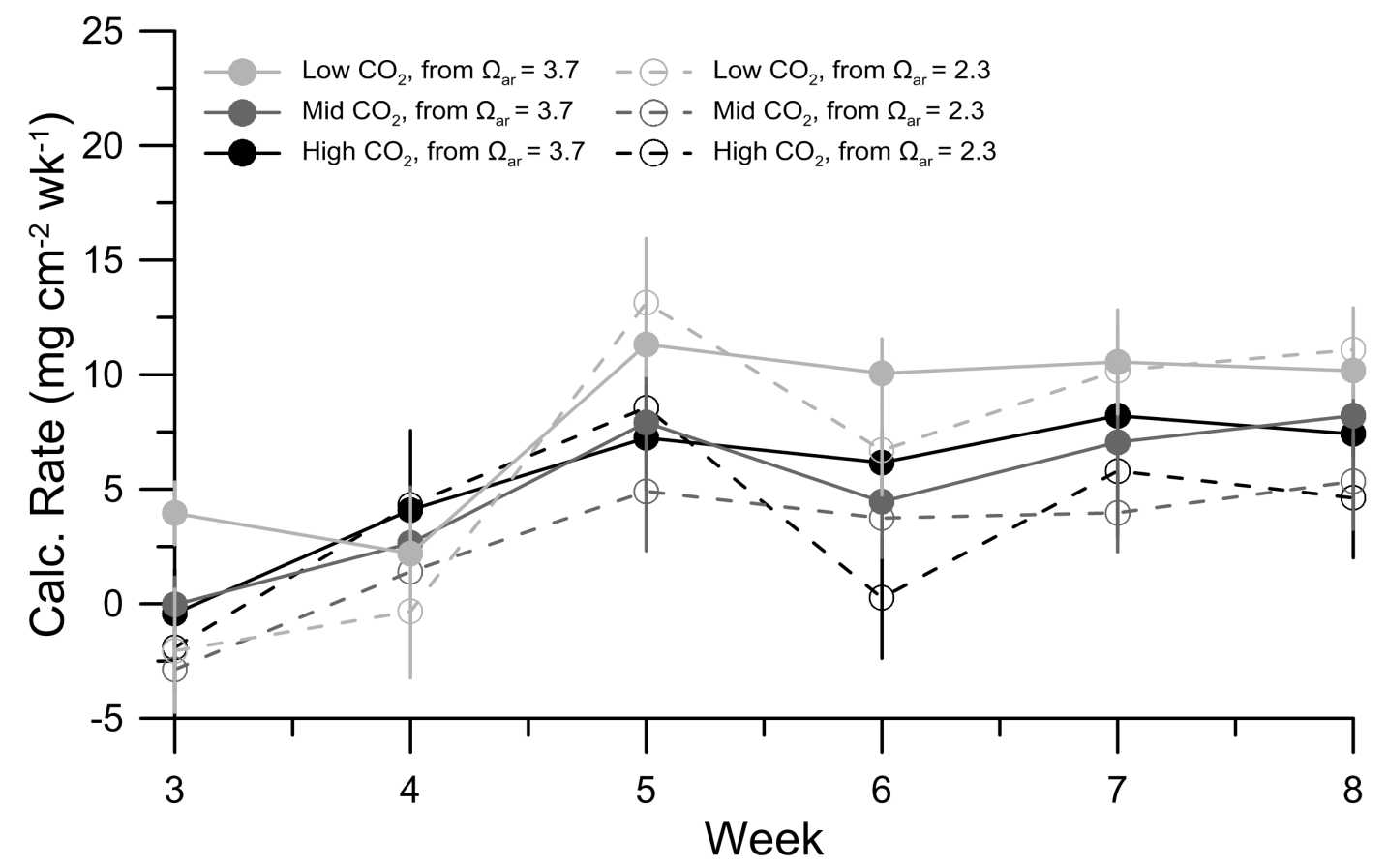

Figure 4-3: Weekly coral calcification rates in the $\mathrm{CO}_{2}$ manipulation experiment. Mean $( \pm 1 \mathrm{SE})$ calcification rates of Porites corals $(\mathrm{n}=10$ per treatment group) collected from a naturally high- $\Omega_{a r}$ reef (solid lines and points) and a naturally low- $\Omega_{a r}$ reef (open lines and points) were incubated for 8 weeks at three $\mathrm{CO}_{2} / \Omega_{a r}$ conditions: $\Omega_{a r}=1.5$ (black), 2.3 (dark gray), and 3.0 (light gray). Buoyant weight data were collected at the beginning of the experiment and then weekly from weeks 3-8. Weekly calcification estimates were calculated as the mean change in area normalized weight per week, with calcification estimates for week 3 calculated as the change in weight between initial and week 3 weight divided by 3 . 

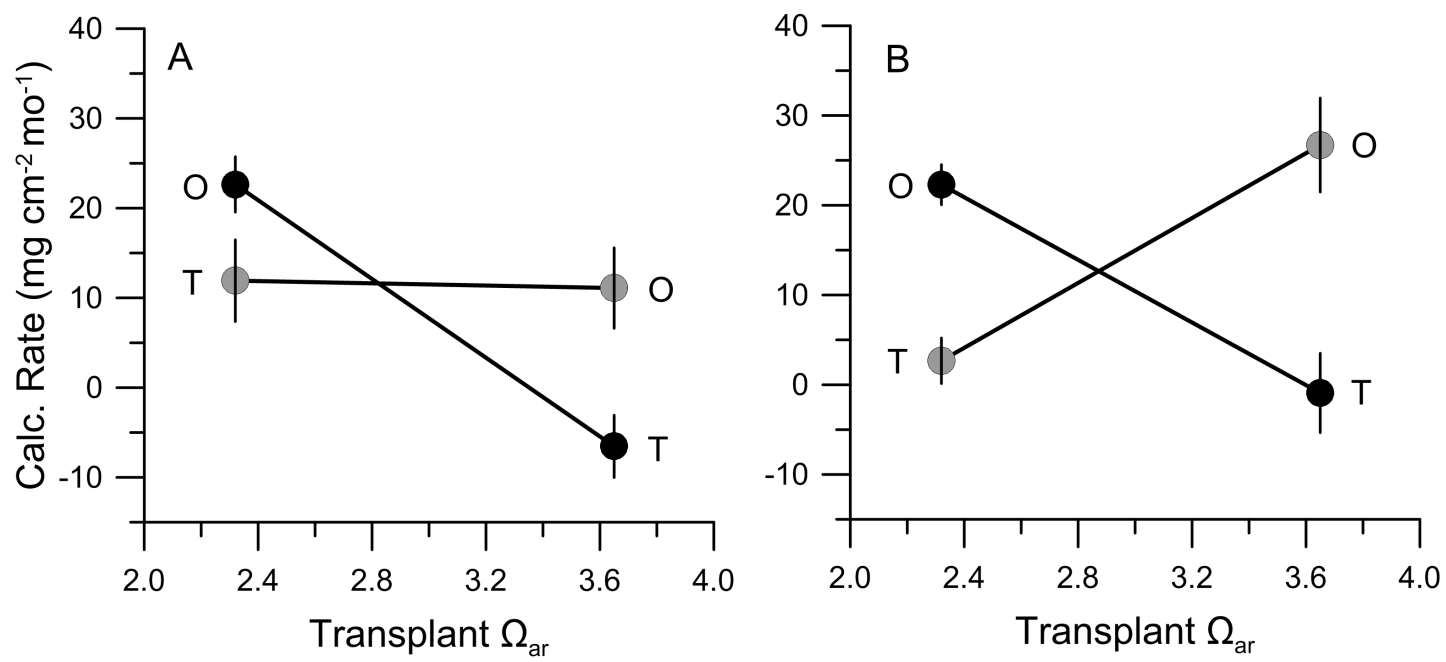

Figure 4-4: Coral calcification rates in the reciprocal transplant experiment. Mean calcification rates of Porites corals that were collected from a naturally high- $\Omega_{a r}$ reef (gray) and a naturally low- $\Omega_{a r}$ reef (black) and either returned to their original reef ("O") or transplanted to the opposite reef ("T"). Transplant experiments were conducted for (A) 2 months and (B) 17 months ( $\mathrm{n}=9-12$ per treatment group). Mean calcification rates per group $( \pm 1 \mathrm{SE})$, determined by buoyant weighing before and after the specified time period, are colored by reef of origin and plotted by the $\Omega_{a r}$ of the reef to which corals were transplanted. Groups of corals originally collected from the same reef are connected by solid lines. 

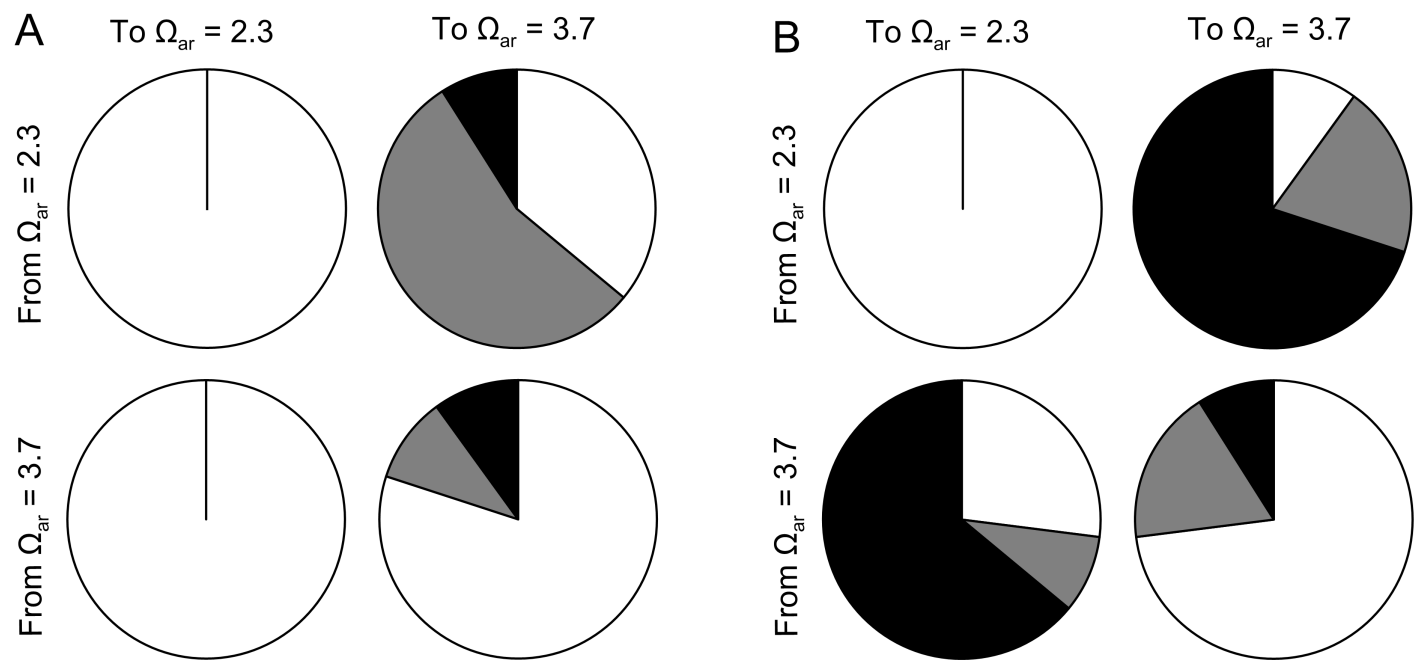

Figure 4-5: Coral morality in the reciprocal transplant experiment. Observed mortality in Porites corals collected from a naturally high- $\Omega_{a r}$ reef and a naturally low- $\Omega_{a r}$ reef and either returned to their original reef or transplanted to the opposite reef $(n=10-12$ per treatment group). Coral mortality was evaluated in groups of corals collected either after (A) 2 months or (B) 17 months in the field. Corals were judged to be alive (white), partially dead (gray), or dead (black). After 17 months, corals that had been transplanted showed significantly higher mortality than corals returned to their original reef. 
Table 4.1: Mean ( $\pm \mathrm{SD}$ ) seawater carbonate system conditions for laboratory $\mathrm{CO}_{2}$ manipulation experiment and field reciprocal transplant. Reciprocal transplant site chemistry data were previously reported in Barkley et al. (2015).

\begin{tabular}{|c|c|c|c|c|c|c|c|c|c|}
\hline Experiment & $\mathrm{CO}_{2}$ Treatment & $\begin{array}{c}\text { Salinity } \\
(\mathrm{psu})\end{array}$ & $\begin{array}{c}\mathrm{T} \\
\left({ }^{\circ} \mathrm{C}\right) \\
\end{array}$ & $\begin{array}{c}\mathrm{pH} \\
\text { (total scale) }\end{array}$ & $\begin{array}{c}\mathrm{TA} \\
\left(\mu \mathrm{mol} \cdot \mathrm{kg}^{-1}\right)\end{array}$ & $\begin{array}{c}\text { DIC } \\
\left(\mu \mathrm{mol} \cdot \mathrm{kg}^{-1}\right) \\
\end{array}$ & $\begin{array}{c}p \mathrm{CO}_{2} \\
(\mu \mathrm{atm}) \\
\end{array}$ & $\begin{array}{c}{\left[\mathrm{CO}_{3}{ }^{2-}\right]} \\
\left(\mu \mathrm{mol} \cdot \mathrm{kg}^{-1}\right)\end{array}$ & $\Omega_{a r}$ \\
\hline \multirow[t]{6}{*}{$\mathrm{CO}_{2}$ Manipulation } & Low $\mathrm{CO}_{2}$ & 33.7 & 29.4 & 7.98 & 2029 & 1762 & 429 & 184 & 3.0 \\
\hline & & \pm 0.1 & \pm 0.1 & \pm 0.02 & \pm 36 & \pm 37 & \pm 24 & \pm 7 & \pm 0.1 \\
\hline & $\operatorname{Mid} \mathrm{CO}_{2}$ & 33.7 & 29.4 & 7.83 & 2061 & 1866 & 652 & 142 & 2.3 \\
\hline & & \pm 0.1 & \pm 0.1 & \pm 0.02 & \pm 27 & \pm 33 & \pm 46 & \pm 6 & \pm 0.1 \\
\hline & High $\mathrm{CO}_{2}$ & 33.7 & 29.4 & 7.60 & 2063 & 1960 & 1198 & 90 & 1.5 \\
\hline & & \pm 0.1 & \pm 0.1 & \pm 0.03 & \pm 25 & \pm 28 & \pm 83 & \pm 5 & \pm 0.1 \\
\hline \multirow[t]{4}{*}{ Reciprocal Transplant } & Low $\mathrm{CO}_{2}$ & 33.6 & 29.9 & 8.04 & 2179 & 1863 & 384 & 222 & 3.7 \\
\hline & & \pm 0.3 & \pm 0.8 & \pm 0.02 & \pm 30 & \pm 36 & \pm 26 & \pm 10 & \pm 0.2 \\
\hline & Mid $\mathrm{CO}_{2}$ & 32.4 & 30.3 & 7.84 & 1977 & 1783 & 604 & 140 & 2.3 \\
\hline & & \pm 0.6 & \pm 1.0 & \pm 0.03 & \pm 27 & \pm 25 & \pm 48 & \pm 10 & \pm 0.2 \\
\hline
\end{tabular}




\section{Chapter 5}

\section{Evaluating coral reef resilience to climate change in the Palau archipelago}

\subsection{Abstract}

Ocean warming and acidification are projected to significantly impact coral reef ecosystems over the next few decades. As a result, coral reef conservation efforts have focused on identifying and promoting natural resilience, where the coral reef communities that are likely to be best able to survive and/or recover from climate change impacts are protected from additional localized anthropogenic stressors. However, factoring climate change resilience into management practices remains challenging, in large part because critical data concerning site-specific coral community sensitivities to environmental stressors such as elevated temperature and decreasing $\mathrm{pH}$ are not currently available. Here, we present a coral reef climate change resilience assessment for the Palau archipelago that evaluates potential coral reef tolerance to both ocean warming and acidification. We combine sea surface temperature and coral community bleaching data from bleaching events in 1998 and 2010, spatial patterns in carbonate chemistry and reef community ocean acidification sensitivities, and information on benthic community ecology to construct coral reef climate change resilience potential indices for Palau's coral reefs. Our results reveal considerable spatial variability in resilience potential between environmentally-distinct barrier and lagoon coral reefs. Our resilience indices suggest that the coral reef communities within Palau's Rock Islands may be among the coral reefs best able to survive ocean warming and acidification over the course of $21^{s t}$ century climate change. 


\subsection{Introduction}

Changes in ocean temperature and chemistry driven by increasing concentrations of atmospheric $\mathrm{CO}_{2}$ present a significant threat to coral reef ecosystems. Global ocean temperatures have warmed by $\approx 0.8{ }^{\circ} \mathrm{C}$ over the past century, a trend exacerbated by increasingly severe episodic high temperature events that are predominantly driven by phases of the El Niño Southern Oscillation (ENSO) (Hansen et al., 2006; Clement et al., 2010; Cai et al., 2014). Coral reef communities are vulnerable to ocean warming because the symbiosis between corals and their zooxanthellae algae is highly sensitive to extremes in sea surface temperature (SST). Exposure to elevated SST can provoke coral hosts to expel their photosynthetic endosymbionts in a process known as coral bleaching, leading to starvation and eventual mortality (Hoegh-Guldberg, 1999; Jones et al., 2006; Hoegh-Guldberg et al., 2007; Baker et al., 2008). An increasing number of mass coral bleaching events in the past few decades have already led to significant coral reef morality worldwide (Baker et al., 2008; Wilkinson, 2008), and model predictions suggest that the frequency and severity of bleaching events will continue to accelerate over this century with significant implications for the global health of coral reef ecosystems (van Hooidonk et al., 2014).

Concurrent to ocean warming, increasing atmospheric $\mathrm{CO}_{2}$ concentrations are driving unprecedented shifts in ocean chemistry. Currently, about a fourth of the $\mathrm{CO}_{2}$ gas emitted into the atmosphere by anthropogenic activity dissolves in ocean surface waters (Sabine et al., 2004). The resulting chemical reactions that take place drive down the $\mathrm{pH}$ of seawater in a process known as ocean acidification. Ocean acidification decreases the concentration of carbonate ions $\left(\mathrm{CO}_{3}{ }^{2-}\right)$ from which reef calcifers construct their calcium carbonate $\left(\mathrm{CaCO}_{3}\right)$ skeletons, lowers the $\mathrm{CaCO}_{3}$ saturation state with respect to the mineral aragonite $\left(\Omega_{a r}\right)$, and increases rates of carbonate erosion on coral reefs (Caldeira and Wickett, 2003; Langdon and Atkinson, 2005; Doney et al., 2009; Kroeker et al., 2011; Pandolfi et al., 2011). Global declines in seawater $\mathrm{pH}$ and $\Omega_{a r}$ have already been observed (Rhein et al., 2013), and the

levels of acidification projected for tropical oceans over the next few decades will likely shift the balance between calcification and dissolution on coral reefs and significantly impact coral reef community ecosystem health and dynamics (Feely et al., 2009; van Hooidonk et al., 2014; Collins et al., 2013).

The warming and acidification of tropical oceans jeopardize the continued survival of 
coral reefs and thus present an enormous challenge to managers attempting to protect reef ecosystems in the face of a rapidly changing climate. In response, many coral reef conservation efforts have begun to incorporate climate change stressors and coral reef responses to these impacts into management planning. In particular, conservation strategies have increasingly focused on resilience-based management, a practice in which coral reef resiliencethe ability of a coral reef ecosystem to withstand a disturbance (resistance) and/or rebound from stress (recovery) without fundamental changes in structure or function - is prioritized and the communities that are most likely to be tolerant to climate change impacts are identified and protected from additional stressors (Obura, 2005; Grimsditch and Salm, 2006; Nyström et al., 2008; McClanahan et al., 2012; Maynard et al., 2010, 2015; Anthony et al., 2015). Resilience assessments are usually based on the optimization of a suite of resilience indicators - environmental (e.g. temperature variability), ecological (e.g. coral recruitment, coral diversity, benthic community composition), and/or biological (e.g. growth rates, symbiont type) variables believed to correlate with increased coral reef community resilience to disturbances - and the minimization of stressors that may reduce resilience potential (e.g. sedimentation, nutrient pollution, disease) (McClanahan et al., 2012; Rowlands et al., 2012; Cinner et al., 2012; Maynard et al., 2010, 2015). While static indicators cannot directly measure resilience levels in dynamic ecosystems, these assessments highlight the coral reef areas that have the characteristics most likely to confer high levels of resilience in response to disturbances (Mumby et al., 2014).

Despite the importance of incorporating climate change criteria into resilience-based management practices, the resilience assessments conducted to date have not always included rigorous quantifications of coral temperature or acidification resilience. The absence of these factors is generally due to the lack of information needed to evaluate coral reef responses to these stressors and thereby identify the most resilient coral communities in a reef system. Specifically, community bleaching data collected at a variety of reef sites during multiple events combined with projections for future conditions are useful for forecasting coral reef responses to elevated temperature, but comprehensive spatial and temporal bleaching data are not available for most reef communities (Glynn et al., 2001; West and Salm, 2003; Obura, 2005; Baker et al., 2008; Berkelmans et al., 2004; Gilmour et al., 2013). In addition, because very few data sets document spatial variability in seawater carbonate chemistry on reefs, patterns in ocean acidification stress across most reef environments are not known 
and information on in situ coral reef responses to declining $\mathrm{pH} / \Omega_{a r}$ and data showing key community sensitivities to acidification are limited.

Here we present a resilience assessment that includes evaluations of coral reef sensitivity to climate change impacts in the Palau archipelago. Palau's coral reefs are an ideal setting for evaluating resilience to ocean warming and acidification because coral community exposure and responses to climate change impacts appear to vary between reef environments. In 1998 and 2010, ENSO-driven elevated temperatures events led to widespread bleaching and mortality on Palau's coral reefs (Barkley and Cohen, 2016). Bleaching during both events varied across reef environments, with the lagoonal reefs fringing the Rock Islands showing the greatest resistance to temperature stress (Bruno et al., 2001; Golbuu et al., 2007; van Woesik et al., 2012). In addition, Palau's coral reefs experience naturally distinct carbonate chemistry environments. Palau's barrier reefs are currently at $\mathrm{pH} / \Omega_{a r}$ conditions in line with those expected for the western tropical Pacific open ocean; however, in the sheltered Rock Island bays, the long residence time of seawater combined with biological processes that drive down $\mathrm{pH} / \Omega_{a r}$ produces chronically acidified conditions $\left(\mathrm{pH}=7.8, \Omega_{a r}=2.3\right)$. Despite the fact that these coral communities are exposed to relatively low $\mathrm{pH}$, they remain highly diverse and coral-dominated (Shamberger et al., 2014; Barkley et al., 2015). In addition, calcification rates of two major reef-building corals are unaffected by $\mathrm{pH}$ in situ (Barkley et al., 2015), and the results of a $\mathrm{CO}_{2}$ manipulation experiment demonstrate that Porites corals from both barrier and Rock Islands reefs can maintain calcification rates at $\mathrm{pH}$ levels as low as 7.6 (Chapter 4). This suggests that a number of Palau corals and, possibly, reef communities may be capable of calcifying under further acidification in the future. However, while calcification rates appear to be insensitive to $\mathrm{pH}$, rates of coral skeletal bioerosion increase significantly as pH falls (DeCarlo et al., 2015). This suggests that the most severe impacts of ocean acidification on Palau's reefs may be caused by compromised reef structural integrity as a result of elevated bioerosion rather than by decreases in reef accretion rates (Barkley et al., 2015).

The unique availability of historical bleaching records, comprehensive carbonate chemistry data, and information on benthic community ecology for Palau's coral reefs allows us to incorporate reef responses to ocean warming and acidification into archipelago-scale evaluations of climate change resilience. To do so, we combine SST and coral community bleaching data from bleaching events in 1998 and 2010 (expanded from data in Chapter 
2), spatial patterns in carbonate chemistry and reef community ocean acidification sensitivities (expanded from data in Chapter 3), and information on benthic community ecology (expanded from data in Chapter 3) to construct coral reef climate change resilience indices for Palau's coral reefs. These climate change resilience indices allow us to evaluate spatial variability in coral reef climate change resilience across the Palau archipelago and highlight the coral communities that may have the best chance of surviving $21^{\text {st }}$ century changes in ocean temperature and seawater chemistry.

\subsection{Methods}

We assessed climate change resilience for Palau's reefs based on temperature and bleaching resilience, ocean acidification resilience, and coral reef community ecology following general procedures in McClanahan et al. (2012) and Maynard et al. (2010, 2015) (detailed methods description below). Within these categories, we evaluated six climate change resilience indicators: 1) 1998 bleaching resistance, 2) 2010 bleaching resistance, 3) bioerosion resistance, 4) coral cover, 5) coral richness, and 6) coral diversity. These factors were chosen based on their potential relevance to coral reef resilience to climate change, identified importance in previous resilience assessments (Maynard et al., 2010; McClanahan et al., 2012; Maynard et al., 2015), and the availability of data for Palau coral reefs. All indicator values were unweighted because the relative contribution of each index to coral reef resilience is unknown. Indices were normalized on a uni-directional scale by dividing all data by the maximum value observed and inverted if necessary so that higher scores consistently reflected increased resilience potential. The six individual indicators were then averaged and normalized to calculate an overall climate change resilience score. Indicator values were compared across six major reef zones in Palau that represented the major reef environment types (Figure 5-1). Shoreline and benthic habitat data were accessed from the NOAA National Centers for Coastal Ocean Science (http://products.coastalscience.noaa.gov), and all data were mapped and analyzed in ArcMap (version 10.2). 


\subsubsection{Coral bleaching resistance}

\subsubsection{Satellite sea surface temperature data}

Gridded daytime satellite sea surface temperature (SST) data were downloaded as netCDF files (from http://coastwatch.pfeg.noaa.gov) and analyzed in MATLAB (version 2014a). For the 1998 event, SST data were obtained from the Advanced Very High Resolution Radiometer (AVHRR) Pathfinder dataset at 4.4-km resolution, and SST anomalies were calculated for the period 1 June to 30 October 1998 relative to the 1991-2000 climatological mean. For 2010, SST data were obtained from the Moderate-resolution Imaging Spectroradiometer (MODIS) Aqua dataset at 1.5-km resolution, and SST anomalies were calculated for the period 1 June to 30 October 2010 relative to the 2003-2012 climatological mean. Separate satellite records were used for 1998 and 2010 because MODIS data do not exist prior to 2002, and AVHRR data for Palau were poor quality for mid-to-late 2010.

\subsubsection{Coral community bleaching levels}

Community bleaching levels during the 1998 and 2010 high temperature events were reconstructed using both observational bleaching data and stress bands in Porites skeletal cores. In situ bleaching data were collected from a small number of sites in 1998 (Bruno et al., 2001) and at randomized locations throughout the Palau archipelago in 2010 (van Woesik et al., 2012). The prevalence of high-density stress bands analyzed in a population of Porites corals agrees within error of community-level bleaching in Palau for sites where both records are available, and thus skeletal records were used to reconstruct spatial and temporal patterns in bleaching in the absence of ecological monitoring data (Barkley and Cohen, 2016). Observational and/or stress band data were not available for all sites in Palau, so bleaching data derived from both sources were interpolated within barrier and lagoon reefs based on proximity to sites with known bleaching levels and reef environment type. Interpolation was restricted to zones where benthic cover was dominated by hard coral (Figure 5-1).

\subsubsection{Bleaching resistance index}

Coral community temperature resistance was evaluated by comparing the magnitude of SST anomalies experienced in the 1998 and 2010 bleaching events to site-specific coral community bleaching levels. A bleaching resistance index was constructed by dividing site- 
specific normalized bleaching prevalence data by normalized SST anomalies for each event. Scores were then inverted so that coral communities with the largest scores exhibited highest resistance to bleaching (i.e. low bleaching relative to SST anomalies experienced).

\subsubsection{Ocean acidification resilience}

Although there is a strong natural acidification gradient across Palau's reefs, the only significant coral community response to declining $\Omega_{a r}$ observed in Palau is an increase in rates of macrobioerosion in acidified conditions (Shamberger et al., 2014; DeCarlo et al., 2015; Barkley et al., 2015). Thus, potential resistance to bioerosion was the only indicator variable considered in the analysis of ocean acidification impacts. Because rates of bioerosion in Palau scale inversely with $\Omega_{a r}$ levels (Figure $3-4 \mathrm{G}$ ), a bioerosion resistance index was created based on spatial patterns in $\Omega_{a r}$.

\subsubsection{Water sampling}

Spatial maps of $\Omega_{a r}$ were created for Palau by interpolating $\Omega_{a r}$ values measured from discrete water samples. Surface water samples $(0-3 \mathrm{~m}, \mathrm{n}=659)$ for total alkalinity (TA), dissolved inorganic carbon (DIC), and salinity were collected at multiple time points between sunrise and sunset on 19 - 24 September 2011, 28 March - 7 April 2012, 7 - 9 December 2012, 1 - 15 November 2013, 9 - 24 August 2014, and 22 January - 7 February 2015 (Figure D-3). TA and DIC titration analyses were performed using a Versatile Instrument for the Determination of Total inorganic carbon and titration Alkalinity (VINDTA, Marianda Analytics) and standardized using certified reference materials obtained from Andrew Dickson [Scripps Institution of Oceanography (Dickson, 2001)]. Analysis of replicate samples yielded a mean precision of $1 \mu \mathrm{mol} \cdot \mathrm{kg}^{-1}$ for TA and $2 \mu \mathrm{mol} \cdot \mathrm{kg}^{-1}$ for DIC. In situ water temperatures were obtained using an Onset HOBO Tidbit v2 water temperature data logger (2011), a RBR XR-CTD (2012-2013), and a Sontek Castaway-CTD (2014-2015). Full $\mathrm{CO}_{2}$ system parameters were calculated from temperature, salinity, TA, and DIC using $\mathrm{CO}_{2} \mathrm{SYS}$ (Lewis and Wallace, 1998) with the constants of Mehrbach et al. (1973) refit by (Dickson and Millero, 1987). Data from 2011-2013 were previously published in Shamberger et al. (2014) and Barkley et al. (2015). 


\subsubsection{Spatial mapping of seawater carbonate chemistry}

Discrete samples for seawater chemistry data were not collected uniformly or comprehensively for the entire Palau archipelago. Therefore, we constructed seawater chemistry maps for the archipelago using a spatial interpolation framework informed by a mechanistic understanding of the processes that give rise to observed patterns in seawater chemistry in Palau. Four principles provided the framework for this interpolation: 1) the open ocean offshore of the barrier reef serves as the source of seawater to the lagoon, 2) seawater chemistry values cannot be mixed or interpolated over land, 3) seawater chemistry is altered by traveling over areas with calcifying coral reef communities, and 4) the changes to seawater chemistry that occur between the open ocean and inshore sheltered lagoon areas are accumulated over distance traveled from offshore.

Using these guidelines, we created a cost surface for Palau in which each grid cell in a $2.5 \mathrm{~m} \times 2.5 \mathrm{~m}$ grid was assigned a value representing the cost that the physical, chemical, and biological processes likely occurring in that cell might have on seawater chemistry (Figure D-4). The true change in chemistry that results as water travels over various benthic communities is not known. Therefore, we assumed the chemical cost to seawater traveling over calcifying communities was three times that accrued by traveling over other bottom types. Cells not colonized by coral communities or coralline algae were assumed to only impact chemistry through freshwater dilution and other physical processes, and were assigned a cost of 1 . Cells with calcifying reef communities (i.e. those dominated by coral or coralline algae) were assigned a cost of 3 . Cells colonized by macroalgae and seagrass were not distinguished from uncolonized seawater because the relationship between photosynthesis and respiration occurring in vegetation-dominated communities and carbonate chemistry in Palau is not currently known.

To incorporate the directionality of water flow and to account for the fact that costs are accumulated moving inshore from the open ocean, the cost surface was used to create a cost distance layer in which each grid cell was assigned a value equal to the total cost of traveling to that cell from an offshore source. This approximation serves as a rough proxy for the residence time of water, assuming that the distance that a parcel of water travels from offshore is proportional to its exchange rate in the lagoon. The seawater source to Palau was defined as a uniform 5-km perimeter offshore of the barrier reef, and the 
cost of traveling from this offshore source to each grid cell over the cost surface calculated. Discrete seawater chemistry values from water samples were then interpolated over this cost distance surface using diffusion interpolation with barriers. Diffusion interpolation is based on the dispersal of heat through a homogenous medium, and the inclusion of the cost surface replaces a default Euclidean solution for the cost of travel from one cell to the next (Chang, 2006; Jensen et al., 2006; Greenberg et al., 2011; Shi et al., 2015). Palau's shoreline was set as a physical diffusion barrier to prevent chemistry values from being interpolated over land. In addition, the entire perimeter of the offshore source was set at end point values based on the average seawater chemistry levels measured offshore in the open ocean. Comparisons between $\Omega_{a r}$ values from discrete samples and $\Omega_{a r}$ values at the same locations predicted by the spatial interpolation model produced a residual standard deviation of 0.21 ; the standard deviation for all water sample data was 0.46 , indicating that the interpolated $\Omega_{a r}$ map constrained $\approx 53 \%$ of the data variation. Additional maps created using the same interpolation procedure for salinity, $p \mathrm{CO}_{2}$, TA (measured and salinity-normalized), DIC (measured and salinity-normalized), and $\mathrm{pH}$ are presented in Appendix D.

A bioerosion resistance index was constructed from the normalized spatial map of $\Omega_{a r}$. Because bioerosion activity increases significantly with seawater acidity (DeCarlo et al., 2015; Barkley et al., 2015), reef areas with lower $\Omega_{a r}$ levels were considered to be more sensitive to bioerosion than those at higher $\Omega_{a r}$ values and received lower bioerosion resistance scores. While interpolations for carbonate chemistry were mapped for the entire Palau archipelago, bioerosion resistance scores were only assigned to the zones dominated by hard coral.

\subsubsection{Coral community ecology}

Coral communities were evaluated from $5 \times 50 \mathrm{~m}$ transects collected at $3-\mathrm{m}$ depth using methods described in Shamberger et al. (2014) and Barkley et al. (2015). Coral cover (percent of the benthic community comprised of hard coral), coral genera richness (number of hard coral genera observed), and coral genera diversity (Shannon's diversity index) were calculated for 13 reef sites. Macroalgae prevalence was not included in analysis because cover of fleshy macroalgae is very low on most of Palau's reefs $(<5 \%)$. Data were interpolated across Palau's reefs to estimate community ecology indices for hard coral reef areas. Normalized indices for community ecology assigned highest scores to reefs with higher hard coral cover, larger numbers of coral genera observed, and greater coral genera diversity because 
these ecological features are believed to increase reef resilience (Nyström and Folke, 2001; Elmqvist et al., 2003; Nyström et al., 2008; Maynard et al., 2010; McClanahan et al., 2012; Maynard et al., 2015).

\subsubsection{Analysis of climate change resilience}

To construct an overall climate change resilience index, 1998 and 2010 bleaching resistance indices, bioerosion resistance scores, and coral community ecology indicators were averaged and normalized so that the coral communities with the highest scores were those predicted to have the greatest resilience to climate change impacts. Reef areas were classified into four categories of relative climate change resilience based on their overall score: high (> mean $+1 \mathrm{SD})$, medium-high $(>$ mean and $<$ mean $+1 \mathrm{SD})$, medium-low $(<$ mean and $>$ mean - $1 \mathrm{SD})$, and low (< mean - $1 \mathrm{SD})$. To evaluate the variability and assess spatial differences in climate change indicators and the overall scores, 325 sites were randomly selected around the archipelago representing each of the six reef zones. For each of these sites, scores for bleaching resistance, ocean acidification resistance, and coral community ecology were examined using principal component analysis and redundancy analysis, and differences between reef zone scores were evaluated with analysis of variance (ANOVA) tests. All statistical tests were conducted in $\mathrm{R}$ (version 3.0.1).

\subsection{Results}

\subsubsection{Sea surface temperature and coral bleaching}

Elevated temperatures drove moderate to severe coral bleaching in 1998 and 2010. Satellite SST records showed that overall temperature anomalies in Palau were greater in 1998 (mean $\pm \mathrm{SD}=1.80^{\circ} \mathrm{C} \pm 0.27^{\circ} \mathrm{C}$, Figure $\left.5-2\right)$ than in 2010 (mean $=1.21^{\circ} \mathrm{C} \pm 0.19^{\circ} \mathrm{C}$, Figure 53). In 1998, satellite records suggested that temperature anomalies on the barrier reef $(1.80$ $\left.{ }^{\circ} \mathrm{C} \pm 0.23{ }^{\circ} \mathrm{C}\right)$ were larger than those in the Rock Islands $\left(1.66{ }^{\circ} \mathrm{C} \pm 0.31{ }^{\circ} \mathrm{C}\right)$; however, 2010 SST anomalies were generally larger on Rock Island reefs $\left(1.43^{\circ} \mathrm{C} \pm 0.22^{\circ} \mathrm{C}\right)$ than on the barrier $\left(1.22{ }^{\circ} \mathrm{C} \pm 0.17{ }^{\circ} \mathrm{C}\right)$. Coral community bleaching levels in the Palau archipelago tracked the severity of temperature stress across the two events, with combined observational and Porites skeletal stress band data estimating mean community bleaching levels of $53.0 \%$ $( \pm 9.4 \%)$ in 1998 (Figure 5-4) and 28.5\% ( \pm 6.4\%) in 2010 (Figure 5-5). Bleaching levels 
were also spatially variable across reef environments, with the lowest extent of bleaching observed in the sheltered Rock Islands (1998: mean $=44.6 \% \pm 8.9 \% ; 2010$ : mean $=19.3 \%$ $\pm 5.0 \%)$ and higher bleaching levels on the more exposed barrier reefs (1998: mean $=53.9 \%$ $\pm 9.0 \% ; 2010$ : mean $=29.6 \% \pm 5.6 \%$ ) during both events.

Bleaching resistance indices calculating by comparing coral community bleaching levels to the magnitude of temperature anomalies experienced by each community revealed that bleaching resistance was significantly spatially variable between reef zones in 2010 (ANOVA, $\left.\mathrm{F}_{1,323}=166.0, \mathrm{p}<0.001\right)$ but not in $1998\left(\right.$ ANOVA, $\left.\mathrm{F}_{1,323}=0.5, \mathrm{p}=0.50\right)$. The coral reefs in Palau's Rock Islands demonstrated the greatest overall temperature tolerance across both the 1998 and 2010 bleaching events (Figures 5-6 and 5-7, Table 5.1). However, bleaching resistance scores within the Rock Islands were both spatially and temporally variable. In 1998, the coral communities of Nikko Bay $(0.67 \pm 0.11)$ and Risong $(0.62 \pm 0.12)$ had low bleaching levels despite experiencing relatively high SST anomalies during the two events (i.e. high bleaching resistance scores), while bleaching resistance indices were smaller in the Rock Islands communities of Taoch $(0.31 \pm 0.04)$, and Mecherchar $(0.25 \pm 0.01)$, indicating lower temperature resistance (see Figure 5-1 for reef locations). In 2010, bleaching resistance scores for Nikko Bay (0.59 \pm 0.28$)$, Risong (0.46 \pm 0.08$)$, Taoch $(0.52 \pm 0.10)$, and Mecherchar $(0.53 \pm 0.10)$ were all within error. Bleaching resistance indices were less spatially and temporally variable across Palau's barrier reefs, ranging from 0.28 and 0.33 in 1998 and 0.21 to 0.32 in 2010 across the five barrier reef zones.

\subsubsection{Carbonate chemistry and ocean acidification}

Seawater carbonate chemistry varied dramatically between Palau's offshore barrier reefs and inshore sheltered Rock Island reefs (Figure 5-8). The mean \pm SD interpolated $\Omega_{a r}$ estimated for the barrier reefs was $3.88 \pm 0.05$. However, $\Omega_{a r}$ declined rapidly moving inshore into the southern lagoon. Low $\Omega_{a r}$ levels were observed within the Rock Islands (mean $=3.18$ \pm 0.26 ), with mean $\Omega_{a r}$ levels as low as 2.32 measured in Nikko Bay. Bioerosion resistance indices calculated from normalized inverse spatial patterns in $\Omega_{a r}$ identified gradients in bioerosion resistance decreasing with $\Omega_{a r}$ from offshore reefs to the inshore Rock Islands $\left(\right.$ ANOVA, $\left.\mathrm{F}_{1,323}=182.7, \mathrm{p}<0.001\right)$, with the lowest predicted bioerosion resistance present in the chronically acidified Rock Island bays (Figure 5-9). 


\subsubsection{Coral community ecology scores}

Ecological indices for Palau's coral reef communities revealed significant spatial differences in coral cover (ANOVA, $\left.\mathrm{F}_{1,323}=64.6, \mathrm{p}<0.001\right)$, coral richness $\left(\right.$ ANOVA, $\mathrm{F}_{1,323}=41,4$, $\mathrm{p}<0.001$ ), and coral diversity (ANOVA, $\mathrm{F}_{1,323}=139.5, \mathrm{p}<0.001$ ) across the archipelago (Table 5.1). Hard coral percent cover was relatively low on Palau's barrier reefs (mean = $23.9 \% \pm 6.5 \%$, range $=17.5-28.5 \%$; Figure $5-10)$. Rock Island reef communities had greater hard coral cover $($ mean $=44.6 \% \pm 12.5 \%$ ), with the highest percent cover observed in the sheltered reefs communities of Nikko Bay and Taoch $(\approx 63 \%)$. Coral genera richness

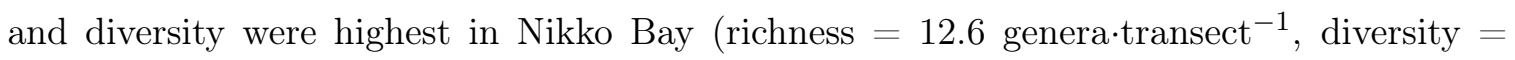
1.60 ), Risong (richness $=12.0$ genera $\cdot$ transect $^{-1}$, diversity $=1.79$ ), and western Babeldaob

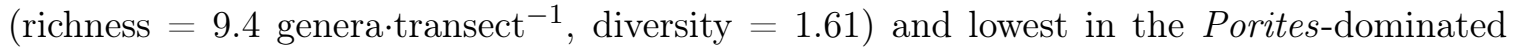
communities of northern Taoch reefs (richness $=5.0$ genera transect $^{-1}$, diversity $=0.30$ ) (Figures 5-11 and 5-12).

\subsubsection{Overall climate change resilience scores}

Overall scores for climate change resilience are shown in Figure 5-13 and Table 5.1. The average normalized overall score for climate change resilience was $0.61(\mathrm{SD}=0.07)$. Reef communities with scores greater than 0.68 were considered to have the highest level of climate change resilience, and those below 0.54 were considered to have the lowest (Figure 5-14). Climate change resilience scores were significantly different between reef zones (ANOVA, $\left.\mathrm{F}_{1,323}=13.9, \mathrm{p}<0.001\right)$. Average $\pm \mathrm{SD}$ scores for the six reef types were: Northern Lagoon $=0.56 \pm 0.03$, Southwestern Barrier $=0.62 \pm 0.03$, Southeastern Barrier $=0.62 \pm 0.02$, Western Babeldaob $=0.61 \pm 0.02$, Eastern Babeldaob $=0.59 \pm 0.01$, and Rock Islands $=$ $0.68 \pm 0.10$.

Rock Island reefs demonstrated the highest overall climate change resilience, and almost all reefs within the Rock Islands received resilience rankings of "high" or "medium-high". The coral communities of Nikko Bay received the greatest scores $(0.82 \pm 0.14)$ and were mostly classified as having "high" climate change resilience. Scores for Risong (0.72 \pm $0.05)$, Mecherchar $(0.66 \pm 0.03)$ and Taoch $(0.63 \pm 0.04)$ were lower that those for Nikko Bay, but still indicated above-average climate change resilience at the archipelago-scale. 


\subsection{Discussion}

Ocean warming and acidification present critical threats to the health and survival of coral reef ecosystems. As a result, incorporating these climate change impacts into management planning and identifying and protecting resilient reef communities are essential for $21^{\text {st }}$ century conservation efforts. Our resilience assessment for coral reefs in Palau combines information about coral reef community responses to ocean warming and acidification into archipelago-scale predictions for climate change resilience. The results of this analysis demonstrate the considerable spatial variability in resilience potential that exists across Palau's coral reefs and highlight the coral reef communities that may be particularly tolerant of climate change impacts over the next several decades.

\subsubsection{Coral bleaching resilience}

Our analysis of coral community resilience to elevated temperatures demonstrates that both exposure and resistance to ocean warming vary between coral reefs in Palau. Satellite SST records show that temperature anomalies were spatially heterogeneous during the 1998 and 2010 bleaching events. In 1998, temperature anomalies tended to be greater on the barrier reef than in the Rock Islands; however, a quantitatively rigorous interpretation of 1998 SST data is limited by both the courser resolution of the data set and the known poor quality of data close to land that frequently skew cool (Skirving et al., 2010). Thus, while 1998 satellite records are likely demonstrative of overall levels of temperature stress experienced at the archipelago-scale, the comparison across individual reefs may not accurately reflect absolute patterns in SST during this event (e.g. low SST anomalies in southern Taoch and Mecherchar relative to the barrier reefs). In contrast, 2010 temperature anomalies were generally higher on the lagoonal reefs than on the barrier. The higher resolution and quality of the satellite data in 2010 suggests that this spatial pattern in SST is likely more reflective of actual patterns in temperature anomalies during bleaching events. Futhermore, in situ logger data post-2010 show that temperatures on Rock Island reefs are consistently $\approx 0.5-1.0^{\circ} \mathrm{C}$ warmer than offshore (Figure A-1), and the low wave energy, reduced vertical mixing, and slow exchange of seawater with offshore waters present in Rock Island bays that contribute to chronically warmer temperatures could be exacerbated during periods of severely elevated temperatures. Worth additional consideration is the fact that satellite 
SST records (which are measurements of the temperature of the ocean surface skin) do not necessarily capture vertical temperature structure in a highly stratified water column. Therefore, remote sensing SST data may not accurately estimate temperatures experienced by reefs at depth. Together, these observations suggest that while remote sensing satellite data can be useful for reconstructing spatial and temporal variability in temperatures during bleaching events in the absence of in situ logger data, satellite-derived estimates for SST may be conservative relative to the actual temperatures experienced by reefs, particularly those in near-shore areas.

Bleaching data compiled from ecological monitoring and Porites skeletal records indicate that levels of coral community bleaching were spatially variable on Palau reefs during the 1998 and 2010 bleaching events, with lower bleaching levels observed on inshore Rock Island reefs than on barrier reefs during both events. Similarly, bleaching resistance scores calculated by scaling reef-specific bleaching levels to SST anomalies experienced highlighted the very high bleaching resistance in Rock Island coral communities. This high temperature tolerance was particularly striking in 2010, where bleaching levels were low across all Rock Island reefs despite exposure to very warm temperatures. In 1998, SST-normalized bleaching resistance was also very high in Nikko Bay and Risong but not in Taoch or Mecherchar, likely due to suspected poor-quality SST data that may have underestimated the actual SST anomalies experienced in the southern Rock Island reefs.

The ability of coral communities to survive periods of elevated temperature without significant bleaching or mortality (resistance) is an essential component of resilience to climate change. Another important resilience factor is the ability of coral reef communities to rebound quickly from disturbance (recovery). In Palau, annual monitoring of coral cover after the 1998 bleaching event revealed fairly rapid recovery across all reefs from widespread bleaching and mortality (Golbuu et al., 2007). Both coral cover and the rate of increase in coral cover from 2001-2004 were greatest on Rock Island reefs, indicative of lower bleaching mortality and/or higher initial recovery rates in these reefs. Recovery within the Rock Islands was largely driven by the growth of surviving coral remnants rather than by recruitment of new colonies, although low recruitment rates could be explained by lack of available substrate on already densely-colonized reefs. In contrast, coral cover and rates of recovery on exposed barrier reefs were initially low, but sexual reproduction and recruitment drove accelerating rates of reef recovery over time. However, even over a decade after bleaching 
occurred, coral cover on the barrier reefs has not yet recovered to pre-1998 levels (50\%) (Golbuu et al., 2007; Barkley et al., 2015). While not explicitly included in this assessment, these recovery trends suggest that even the more thermally-sensitive barrier reefs may be able to at least partially rebound from bleaching due to high recruitment rates and support the identification of Rock Island reefs as particularly temperature-resilient.

\subsubsection{Ocean acidification resilience}

The strong natural acidification gradient that exists between the offshore barrier reefs and the inshore Rock Islands creates a unique scenario in which Palau's coral reefs are exposed to different ambient $\Omega_{a r}$ levels. As a result, predicting ocean acidification impacts in Palau remains challenging because it is unclear exactly how $\mathrm{pH}$ and $\Omega_{a r}$ will change in the Rock Islands as acidification proceeds in the open ocean and how reef communities acclimatized to distinct levels of acidification will respond to these changes. It is possible that $\Omega_{a r}$ in the Rock Islands will decline in parallel with $\Omega_{a r}$ levels of offshore source water. Alternatively, $\Omega_{a r}$ conditions in the lagoon could decrease at faster rate than that of the open ocean due to interacting coastal processes (e.g. nutrient eutrophication) that exacerbate local acidification (Duarte et al., 2013). However, it is even possible that the carbonate chemistry differential between the barrier and lagoon may lessen if the calcification-driven decrease in $\mathrm{pH} / \Omega_{a r}$ by barrier reef communities that currently creates Palau's strong natural acidification gradient (Shamberger et al., 2014) lessens over time due to barrier reef mortality.

Despite this uncertainty, the field and experimental evidence collected to date largely suggest that Palau's coral reef communities are unusually resistant to highly acidified conditions. In the Rock Islands, healthy, diverse, coral-dominated, and net-calcifying coral reef communities are currently thriving at predicted end-of-century $\mathrm{pH}$ and $\Omega_{a r}$ conditions (Shamberger et al., 2014; Barkley et al., 2015). Furthermore, evidence from a laboratory $\mathrm{CO}_{2}$ manipulation experiment showed that calcification rates of Porites corals collected from both barrier and Rock Island reefs are not impacted by decreases in $\Omega_{a r}$ and that corals calcified as quickly at $\Omega_{a r}=1.5$ as at $\Omega_{a r}=3.0$. The surprising acidification insensitivity of barrier reef corals that are not exposed to chronically low- $\Omega_{a r}$ conditions reveals that acidification resistance could be shared across a number of Palau's reefs, and that calcification rates on at least two reefs in Palau may be maintained over the next few decades even if $\mathrm{pH} / \Omega_{a r}$ continue to fall as predicted in the open ocean (Chapter 4). 
Within Palau's apparently acidification-tolerant coral communities, increasing bioerosion in low- $\Omega_{a r}$ conditions is the only observed coral reef sensitivity to natural acidification, a trend shared across all low- $\Omega_{a r}$ coral reefs studied to date (Fabricius et al., 2011; Crook et al., 2013; Manzello et al., 2014; DeCarlo et al., 2015; Barkley et al., 2015). Therefore, bioerosion resistance was the only ocean acidification resilience indicator included in this assessment. We assume that rates of bioerosion in low- $\Omega_{a r}$ reef areas will either increase or be maintained at current levels over the next few decades under ocean acidification, as any future changes in seawater carbonate chemistry are unlikely to alleviate rates of bioerosion in the Rock Islands. Considering bioerosion as the sole risk factor under acidification in Palau, and assuming that bioerosion resistance scales directly with $\Omega_{a r}$, the patterns in ocean acidification sensitivity that we observe are broadly opposite of those estimated for temperature resilience. Predicted bioerosion rates are highest in the acidified Rock Island bays and lowest on the higher- $\Omega_{a r}$ barrier reefs, where minimal rates of skeletal bioerosion have been measured under less acidified conditions (Barkley et al., 2015).

The relationship between $\Omega_{a r}$ and bioerosion, measured as the Porites skeletal volume removed by macrobioeroders (in Palau, predominantly by Lithophaga bivalves), is likely due to an increase in biochemical dissolution efficiency in acidified conditions (Kobluk and Risk, 1977; Glynn, 1997; Wisshak et al., 2012; Barkley et al., 2015). While the severity of macrobioerosion in non-massive coral species in Palau has not been measured, elevated bioerosion might have an even more severe impact on the structural integrity of more fragile branching and tabular coral species. Coral skeletal bioerosion by itself does not necessarily threaten the survival of entire coral reef ecosystems. However, if macrobioerosion rates are reflective of broader reef-scale erosion and dissolution (Chazottes et al., 1995; Holmes et al., 2000; DeCarlo et al., 2015), the amalgamation of these processes could ultimately jeopardize the integrity of reef carbonate structures, particularly in areas that experience high wave energy (Wisshak et al., 2012). As a result, it is likely that the most severe impacts of ocean acidification in Palau will be manifested not through reduced rates of coral calcification and reef accretion, but instead through accelerated carbonate dissolution rates and compromised reef structural integrity (Barkley et al., 2015). 


\subsubsection{Ecological resilience}

Indices for coral reef community ecology were heterogenous across Palau's different reef environments. Similar to patterns in bleaching resistance, coral cover was highest in the Rock Islands and lowest on the barrier reefs. In contrast, coral richness and diversity were both greatest in western Babeldaob and lowest on average in the northern lagoon and Rock Islands reefs. However, within the Rock Islands there were large differences in these indices between individual reefs. For example, the coral reefs of Nikko Bay had the highest coral cover and diversity observed in the entire archipelago, but the Porites-dominated reefs of Taoch hosted coral communities with very high coral cover but the lowest genera diversity. This suggests that even within the Rock Islands there are considerable differences in factors - environmental and biological - determining local coral reef community composition and/or scales of larval connectivity and recruitment between individual reef sites.

The cover, richness, and diversity of hard coral in a reef ecosystem may be demonstrative of the ability of a coral community to resist or recover from stress, although evidence connecting coral community ecological indices to observed resilience is limited (Nyström and Folke, 2001; Elmqvist et al., 2003; Nyström et al., 2008). If significant cover of hard coral is maintained in a benthic community at the expense of macroalgal cover, the reduced coralalgae competition for space and resources could promote recovery potential (Diaz-Pulido et al., 2009; Mumby and Harborne, 2010; McClanahan et al., 2012). Furthermore, if high coral cover is also indicative of large larval supply and high coral recruitment rates, reef communities with high hard coral cover and recruitment may be able to recover more quickly from disturbances than those that are more sparsely populated (McClanahan et al., 2012). Yet, coral cover on its own does not necessarily directly confer elevated levels of resilience, as a few coral reefs in the Caribbean with high coral cover have historically demonstrated very low resilience to stress (Hughes et al., 2010). Similarly, high coral richness/diversity could increase the resistance and/or recovery of a community if the functional diversity of species promotes a variety of resilience levels and strategies for withstanding disturbances. However, this ability may depend greatly on the resilience potential of the specific genera that make up that community, as a diverse reef community comprised largely of highly temperaturesensitive coral genera is unlikely to survive or recover quickly from severe bleaching events (McClanahan et al., 2012). 
As a result, the coral reefs that receive the highest scores for coral cover, richness, and diversity in this assessment may be, at best, particularly resilient to climate change impacts because their benthic community composition boosts their resistance and/or recovery potential. In Palau, the coral communities that received the highest ecological scores for cover and diversity (Nikko Bay and Risong), also demonstrated the greatest temperature tolerance across the two bleaching events and recovery from severe bleaching in 1998, potentially supporting a strong link between coral reef community ecology and climate change resilience potential. Even if these ecological indices are unrelated to climate change resilience, these communities are likely no less tolerant to climate change impacts than those that receive lower scores for ecological indices.

\subsubsection{Climate change resilience in the Rock Islands}

Based on our archipelago-scale assessment of resilience potential for Palau's coral reefs, the small coral communities living within the Rock Islands emerge as the coral reef assemblages that we predict will be the most resilient to $21^{\text {st }}$ century climate change. This result supports previous identification of these reefs as particularly tolerant to elevated temperatures based on bleaching observations in 2010 (van Woesik et al., 2012). Within Rock Island reefs, high overall resilience scores were driven by low bleaching levels in these communities across multiple bleaching events and high ecological scores, particularly in the northern Rock Islands (i.e. Nikko Bay and Risong). This demonstrated resistance to historical, repeated temperature stress in healthy, diverse, and coral-dominated reef communities provides the best evidence we have to date that Rock Island reefs may be among those most capable of surviving the impacts of a rapidly changing climate over the next few decades.

Despite elevated temperatures in 1998 and 2010, bleaching levels in Rock Island coral communities were relatively low during both events. While the precise mechanism responsible for the high thermal tolerance of these communities remains unknown, there are a number of potential explanations. One is that community composition varies significantly across Palau's coral reefs. The barrier reef communities with higher observed bleaching levels are dominated by more thermally-sensitive Pocillopora and Acropora corals, while the Rock Islands host abundant populations of more temperature-tolerant coral genera like Porites and Favia (Golbuu et al., 2007; van Woesik et al., 2012). Another explanation is that the high turbidity and heavy shading present on the reefs fringing the Rock Islands may decrease 
stress levels related to elevated temperature and/or increased irradiance during bleaching events (West and Salm, 2003; Golbuu et al., 2007). It is also possible that chronic exposure to warmer average temperatures in the Rock Islands (Figure D-1 and Table B.1) has driven community-wide acclimatization or adaptation to elevated temperatures, allowing these reefs to preferentially survive bleaching events (Castillo and Helmuth, 2005; Middlebrook et al., 2008). Finally, some (but not all) of the coral genera within the Rock Islands host clade D symbionts, which have been shown to increase the thermal tolerance of the coral holobiont (Fabricius et al., 2004). Overall, the demonstrated temperature tolerance and lower bleaching levels observed within these coral reefs across two bleaching events suggests that these communities may also be able to survive additional bleaching events in the future.

However, the results of this resilience assessment also suggest that the high temperature tolerance and bleaching resistance observed in the Rock Islands could be undermined by elevated rates of bioerosion under ocean acidification. Increased bioerosion and carbonate dissolution thus represent key sensitivities of otherwise highly-tolerant coral reef communities to climate change impacts. As a result, elevated bioerosion is a threat that must be targeted through effective local management in these reef sites to promote the resilience potential of Rock Island coral reef communities.

\subsubsection{Impacts of other anthropogenic stressors}

While this analysis focuses specifically on climate change impacts to coral reef ecosystems, increasing temperature and ocean acidification are just two stressors in a large suite of anthropogenic impacts that threaten the health and survival of delicate coral reef ecosystems. In addition to facing a rapidly warming and acidifying ocean, Palau's coral reefs are already confronting a range of localized coastal threats unrelated to climate change, including nutrient eutrophication, pollution, overfishing, sedimentation, and other stressors associated with reef-based tourism (Golbuu et al., 2005; Marino et al., 2008; Golbuu et al., 2011). These impacts, either independently or synergistically with climate change, may ultimately determine the fate of coral reef ecosystems both in Palau and worldwide. It is therefore difficult to project coral reef responses to global climate change without consideration of the impacts that other local disturbances may have on reef health on often shorter time scales.

However, unlike global climate change impacts, many coastal anthropogenic threats are highly manageable at the local level. To this end, one goal of resilience-based management 
is to prioritize the mitigation of local impacts in particularly climate change-tolerant communities and, therefore, afford these coral reefs the best chance of surviving ocean warming and acidification in the absence of additional stressors. For example, elevated rates of bioerosion threaten the low- $\Omega_{a r}$ Rock Island coral reefs identified as being otherwise climate change-resilient. However, bioerosion is also a stressor that can be partially mitigated and controlled through effective local management, as bioerosion rates are significantly accelerated by elevated nutrient concentrations (i.e. $\left.\left[\mathrm{NO}_{3}{ }^{2-}\right]>1 \mu \mathrm{M}\right)$ (DeCarlo et al., 2015). Although Palau's Rock Islands are currently oligotrophic $\left(\left[\mathrm{NO}_{3}{ }^{2-}\right]<0.5 \mu \mathrm{M}\right.$, Table B.1), nutrient eutrophication driven by coastal development could exacerbate bioerosion impacts to already acidified reefs that exist close to shore. Thus, controlling coastal nutrient runoff represents a local management solution that can be employed to prevent increases in coral community stress in highly temperature-resilient reefs. Additional management efforts can similarly control other local threats that might otherwise raise baseline stress levels within coral communities classified as having high resilience potential.

\subsubsection{Limitations and priorities for future research}

This resilience assessment represents an initial estimate of climate change resilience for Palau's coral reefs. The indices included in this study make use of available data to forecast the ability of Palau's reefs to withstand and potentially recover from ocean warming and acidification stress. However, future versions of this assessment will be strengthened by the inclusion and revision of several factors. First, the collection of additional data at more reef sites around Palau will lessen the need to interpolate between reef sites to map spatial patterns in resilience indicators for the entire archipelago. Second, this resilience assessment does not include a number of critical variables that may contribute to climate change sensitivities. Data for several indicators believed to be important for resilience, and particularly for recovery (e.g. coral recruitment, herbivore biomass), as well as information on local stressors (e.g. pollution, sedimentation, disease, typhoon exposure, coastal population density) were not available for this analysis (McClanahan et al., 2012; Maynard et al., 2015). These indicators of vulnerability and recovery are likely to be increasingly important as bleaching events occur with greater frequency and intensity under rapidly acidifying ocean conditions. Third, the inclusion of more data will allow us to determine which factors contribute the most to variability in resilience. This, in turn, will make it possible to edit a 
large suite of potential indicators down to those most essential, and several of the indicators considered here may ultimately be less influential than others in predicting resilience potential (e.g. including both coral richness and coral diversity risks double-counting similar metrics of reef ecology). Fourth, incorporating output from hydrodynamic and connectivity models to establish links between larval sources and sinks will be critical for predicting rates of coral reef recovery. Finally, sea level rise has the potential to alter the hydrodynamic regimes, temperature conditions, and carbonate chemistry of Palau's reefs. Therefore, reef vulnerability to sea level rise should be considered in future efforts to constrain resilience potential on Palau's coral reefs.

In addition, determining the relative severity of stressors and the relative influence of resilience metrics in determining coral reef ecosystem health can improve the weighting of indicators. In this assessment, two bleaching events, three ecological indices, and an ocean acidification sensitivity index were given equal weights in the final resilience assessment. This procedure was used largely because the relative importance of each of these factors is not known. In previous resilience assessments, indicators have either been left unweighted or were assigned weights based on expert consensus concerning the contribution and relative importance of each factor (McClanahan et al., 2012; Maynard et al., 2015). We did not follow this methodology because our assessment includes resilience indicators that were not considered in previous studies (e.g. ocean acidification sensitivity) and for which opinion-based weights were not available. The risk of this approach is that the contribution of unweighted indicators to final resilience scores may be disproportionate to their actual influence on coral reef resilience potential. Future work should therefore seek to constrain the importance of these factors and improve the weighting procedure in subsequent assessments.

A major challenge of resilience assessments is reconciling the inclusion of stressors that act over a large variety of temporal scales and the time frames over which corals reefs respond to changes in the reef environment. For example, severe typhoons (such as those that occurred in Palau in December 2012 and December 2013) can cause widespread devastation on coral reefs over several hours to days. Episodic high temperature events caused by ENSO variability can drive coral bleaching over periods of several weeks to months. Localized pollution, nutrient eutrophication, sedimentation, overfishing, and disease can slowly impact coral reefs for months to years. Finally, steady ocean warming, ocean acidification, and sea level rise act on coral reef communities on the scale of years to decades. It becomes difficult, 
therefore, to compare interacting effects of stressors that impact coral reef communities on very different time scales. Moreover, static resilience assessments struggle to describe dynamic coral reef communities and cannot predict how community composition may change in response to disturbances or even how coral reefs may acclimatize or adapt to changing ocean conditions. These assessments, therefore, are able to produce predictions for the types of coral reef communities that may best survive future disturbances based on past responses to stress and present conditions, but remain limited in their ability to forecast dynamic ecosystem responses to stressors.

Despite these caveats, the results of an initial resilience assessment for Palau's coral reefs presented here highlight the considerable variability that exists in coral reef resilience potential. Critically, this analysis identifies the coral reef communities in Palau's Rock Islands as areas that may be particularly able to survive $21^{\text {st }}$ century climate change impacts. These places, therefore, are important candidates for both further study and local protection. 


\subsection{References}

Anthony, K. R. N., Marshall, P. A., Abdulla, A., Beeden, R., Bergh, C., Black, R., Eakin, C. M., Game, E. T., Gooch, M., Graham, N. A. J., Green, A., Heron, S. F., van Hooidonk, R., Knowland, C., Mangubhai, S., Marshall, N., Maynard, J. A., Mcginnity, P., Mcleod, E., Mumby, P. J., Nyström, M., Obura, D., Oliver, J., Possingham, H. P., Pressey, R. L., Rowlands, G. P., Tamelander, J., Wachenfeld, D., Wear, S., 2015. Operationalizing resilience for adaptive coral reef management under global environmental change. Global Change Biology 21 (1), 48-61.

Baker, A. C., Glynn, P. W., Riegl, B., 2008. Climate change and coral reef bleaching: An ecological assessment of long-term impacts, recovery trends and future outlook. Estuarine, Coastal and Shelf Science 80 (4), 435-471.

Barkley, H. C., Cohen, A. L., 2016. Skeletal records of community-level bleaching in Porites corals from Palau. Coral Reefs, doi: 10.1007/s00338-016-1483-3.

Barkley, H. C., Cohen, A. L., Golbuu, Y., Starczak, V. R., DeCarlo, T. M., Shamberger, K. E. F., 2015. Changes in coral reef communities across a natural gradient in seawater $\mathrm{pH}$. Science Advances 1, 1-7.

Berkelmans, R., De'ath, G., Kininmonth, S., Skirving, W. J., 2004. A comparison of the 1998 and 2002 coral bleaching events on the Great Barrier Reef: spatial correlation, patterns, and predictions. Coral Reefs 23 (1), 74-83.

Bruno, J. F., Siddon, C., Witman, J., Colin, P., Toscano, M., 2001. El Niño related coral bleaching in Palau, Western Caroline Islands. Coral Reefs 20 (2), 127-136.

Cai, W., Borlace, S., Lengaigne, M., van Rensch, P., Collins, M., Vecchi, G., Timmermann, A., Santoso, A., McPhaden, M. J., Wu, L., England, M. H., Wang, G., Guilyardi, E., Jin, F.-F., 2014. Increasing frequency of extreme El Niño events due to greenhouse warming. Nature Climate Change 5 (2), 1-6.

Caldeira, K., Wickett, M., 2003. Anthropogenic carbon and ocean pH. Nature 425, 365.

Castillo, K. D., Helmuth, B. S. T., 2005. Influence of thermal history on the response of Montastraea annularis to short-term temperature exposure. Marine Biology 148 (2), 261270 .

Chang, K.-t., 2006. Introduction to geographic information systems. McGraw-Hill Higher Education Boston.

Chazottes, V., Campion-Alsumard, T., Peyrot-Clausade, M., 1995. Bioerosion rates on coral reefs: interactions between macroborers, microborers and grazers (Moorea, French Polynesia). Palaeogeography, Palaeoclimatology, Palaeoecology 113 (2-4), 189-198.

Cinner, J. E., McClanahan, T. R., Graham, N. A. J., Daw, T. M., Maina, J., Stead, S. M., Wamukota, A., Brown, K., Bodin, O., 2012. Vulnerability of coastal communities to key impacts of climate change on coral reef fisheries. Global Environmental Change 22 (1), $12-20$.

Clement, A. C., Baker, A. C., Leloup, J., 2010. Patterns of tropical warming. Nature Geo- 
science $3(1), 8-9$.

Collins, M., Knutti, R., Arblaster, J., Dufresne, J.-L., T. Fichefet, T., Friedlingstein, P., Gao, X., Gutowski, W., Johns, T., Krinner, G., Shongwe, M., Tebaldi, C., Weave, A., Wehner, M., 2013. Long-term Climate Change: Projections, Commitments, and Irreversibility. In: Stocker, T., Qin, D., Plattner, G.-K., Tignor, M., Allen, S., Boschung, J., Nauels, A., Xia, Y., Bex, V., Midgley, P. (Eds.), Climate Change 2013: The Physical Science Basis. Contribution of Working Group I to the Fifth Assessment Report of the Intergovernmental Panel on Climate Change. Cambridge University Press, Cambridge, United Kingdom and New York, NY, USA.

Crook, E., Cohen, A. L., Rebolledo-Vieyra, M., Hernandez, L., Paytan, A., 2013. Reduced calcification and lack of acclimatization by coral colonies growing in areas of persistent natural acidification. Proceedings of the National Academy of Sciences of the United States of America 110 (27), 11044-9.

DeCarlo, T., Cohen, A. L., Barkley, H., Shamberger, K., Cobban, Q., Young, C., Brainard, R. E., Golbuu, Y., 2015. Coral bioerosion is accelerated by ocean acidification and nutrients. Geology 43, 7-10.

Diaz-Pulido, G., McCook, L. J., Dove, S., Berkelmans, R., Roff, G., Kline, D. I., Weeks, S., Evans, R. D., Williamson, D. H., Hoegh-Guldberg, O., 2009. Doom and boom on a resilient reef: climate change, algal overgrowth and coral recovery. PLoS ONE 4 (4).

Dickson, A., 2001. Reference materials for oceanic measurements. Oceanography 14, 21-22.

Dickson, A., Millero, F., 1987. A comparison of the equilibrium constants for the dissociation of carbonic acid in seawater media. Deep-Sea Research Part A-Oceanographic Research Papers 34, 1733-1743.

Doney, S. C., Fabry, V. J., Feely, R. A., Kleypas, J. A., 2009. Ocean acidification: the other $\mathrm{CO}_{2}$ problem. Annual Review of Marine Science 1 (1), 169-192.

Duarte, C. M., Hendriks, I. E., Moore, T. S., Olsen, Y. S., Steckbauer, A., Ramajo, L., Carstensen, J., Trotter, J. A., McCulloch, M., 2013. Is Ocean Acidification an OpenOcean Syndrome? Understanding Anthropogenic Impacts on Seawater pH. Estuaries and Coasts 36 (2), 221-236.

Elmqvist, T., Folke, C., Nyström, M., Peterson, G., Bengtsson, J., Walker, B., Norberg, J., 2003. Diversity, ecosystem change, and resilience. Frontiers in Ecology and the Environment 1 (9), 488-494.

Fabricius, K. E., Langdon, C., Uthicke, S., Humphrey, C., Noonan, S., De'ath, G., Okazaki, R., Muehllehner, N., Glas, M. S., Lough, J. M., 2011. Losers and winners in coral reefs acclimatized to elevated carbon dioxide concentrations. Nature Clim Change 1 (3), 165169 .

Fabricius, K. E., Mieog, J. C., Colin, P. L., Idip, D., van Oppen, M. J. H., 2004. Identity and diversity of coral endosymbionts (zooxanthellae) from three Palauan reefs with contrasting bleaching, temperature and shading histories. Molecular Ecology 13 (8), 2445-58.

Feely, R. A., Doney, S., Cooley, S., 2009. Ocean acidification: present conditions and future 
changes in a high $\mathrm{CO}_{2}$ world. Oceanography 22 (4), 36-47.

Gilmour, J. P., Smith, L. D., Heyward, A. J., Baird, A. H., Pratchett, M. S., 2013. Recovery of an isolated coral reef system following severe disturbance. Science 340 (6128), 69-71.

Glynn, P. W., 1997. Bioerosion and Coral Reef Growth: A Dynamic Balance. In: Birkeland, C. (Ed.), Life and Death of Coral Reefs. Chapman and Hall, New York, pp. 68-95.

Glynn, P. W., Maté, J. L., Baker, A. C., 2001. Coral bleaching and mortality in Panama and Ecuador during the 1997-1998 El Niño-Southern Oscillation event: spatial/temporal patterns and comparisons with the 1982-1983 event. Bulletin of Marine Science 69 (1), $79-109$.

Golbuu, Y., Bauman, A., Kaurtei, J., Victor, S., 2005. The state of coral reef ecosystems of the Republic of Palau. In: Waddell, J., Clark, A. (Eds.), The State of Coral Reef Ecosystems of the United States and Pacific Freely Associated States: 2005. NOAA Technical Memorandum NOS NCCOS 11. NOAA/NCCOS Center for Coastal Monitoring and Assessment's Biogeography Team, Silver Spring, MD, pp. 488-507.

Golbuu, Y., Van Woesik, R., Richmond, R. H., Harrison, P., Fabricius, K. E., 2011. River discharge reduces reef coral diversity in Palau. Marine Pollution Bulletin 62 (4), 824-831.

Golbuu, Y., Victor, S., Penland, L., Idip, D., Emaurois, C., Okaji, K., Yukihira, H., Iwase, A., Woesik, R., 2007. Palau's coral reefs show differential habitat recovery following the 1998-bleaching event. Coral Reefs 26 (2), 319-332.

Greenberg, J. A., Rueda, C., Hestir, E. L., Santos, M. J., Ustin, S. L., 2011. Least cost distance analysis for spatial interpolation. Computers \& Geosciences 37 (2), 272-276.

Grimsditch, G. D., Salm, R. V., 2006. Coral reef resilience and resistance to bleaching. IUCN, Gland, Switzerland.

Hansen, J., Sato, M., Ruedy, R., Lo, K., Lea, D. W., Medina-Elizade, M., 2006. Global temperature change. Proceedings of the National Academy of Sciences of the United States of America 103 (39), 14288-14293.

Hoegh-Guldberg, O., 1999. Climate Change, coral bleaching and the future of the world's coral reefs. Marine \& Freshwater Research 50, 839-866.

Hoegh-Guldberg, O., Mumby, P. J., Hooten, A. J., Steneck, R. S., Greenfield, P., Gomez, E., Harvell, C. D., Sale, P. F., Edwards, A. J., Caldeira, K., Knowlton, N., Eakin, C. M., Iglesias-Prieto, R., Muthiga, N., Bradbury, R. H., Dubi, A., Hatziolos, M. E., 2007. Coral reefs under rapid climate change and ocean acidification. Science 318 (5857), 1737-42.

Holmes, K. E., Edinger, E. N., Limmon, G. V., Risk, M. J., 2000. Bioerosion of live massive corals and branching coral rubble on Indonesian coral reefs. Marine Pollution Bulletin $40(7), 606-617$.

Hughes, T. P., Graham, N. A. J., Jackson, J. B. C., Mumby, P. J., Steneck, R. S., 2010. Rising to the challenge of sustaining coral reef resilience. Trends in Ecology and Evolution 25 (11), 633-642.

Jensen, O. P., Christman, M. C., Miller, T. J., 2006. Landscape-based geostatistics: a case 
study of the distribution of blue crab in chesapeake bay. Environmetrics 17 (6), 605-621.

Jones, R. J., Larkum, A. W. D., Schreiber, U., 2006. Temperature-induced bleaching of corals begins with impairment of the $\mathrm{CO}_{2}$ fixation mechanism in zooxanthellae. Plant, Cell and Environment 21 (1998), 1219-1230.

Kobluk, D. R., Risk, M. J., 1977. Rate and nature of infestation of a carbonate substraum by a boring alga. Journal of Experimental Marine Biology and Ecology 27 (114), 107-115.

Kroeker, K. J., Micheli, F., Gambi, M. C., Martz, T. R., 2011. Divergent ecosystem responses within a benthic marine community to ocean acidification. Proceedings of the National Academy of Sciences of the United States of America 108 (35), 14515-20.

Langdon, C., Atkinson, M., 2005. Effect of elevated $p \mathrm{CO}_{2}$ on photosynthesis and calcification of corals and interactions with seasonal change in temperature/irradiance and nutrient enrichment. Journal of Geophysical Research 110 (C9), C09S07.

Lewis, E., Wallace, D., 1998. Program Developed for CO2 System Calculations (Carbon Dioxide Information Analysis Center, Oak Ridge National Laboratory, US Dept. of Energy, Oak Ridge, TN).

Manzello, D. P., Enochs, I. C., Bruckner, A., Renaud, P. G., Kolodziej, G., 2014. Galápagos coral reef persistence after ENSO warming across an acidification gradient. Geophysical Research Letters 41, 1-8.

Marino, S., Bauman, A., Miles, J., Kitalong, A., Bukurou, A., Mersai, C., Verheij, E., Olkeriil, I., Basilius, K., Colin, P., Patris, S., Victor, S., Andrew, W., Golbuu, Y., 2008. The state of coral reef ecosystems of the Republic of Palau. In: Waddell, J., Clark, A. (Eds.), The State of Coral Reef Ecosystems of the United States and Pacific Freely Associated States: 2008. NOAA Technical Memorandum NOS NCCOS 73. NOAA/NCCOS Center for Coastal Monitoring and Assessment's Biogeography Team, Silver Spring, MD, pp. 511-539.

Maynard, J. A., Marshall, P. A., Johnson, J. E., Harman, S., 2010. Building resilience into practical conservation: Identifying local management responses to global climate change in the southern Great Barrier Reef. Coral Reefs 29 (2), 381-391.

Maynard, J. A., McKagan, S., Raymundo, L., Johnson, S., Ahmadia, G. N., Johnston, L., Houk, P., Williams, G. J., Kendall, M., Heron, S. F., van Hooidonk, R., Mcleod, E., Tracey, D., Planes, S., 2015. Assessing relative resilience potential of coral reefs to inform management. Biological Conservation 192, 109-119.

McClanahan, T. R., Donner, S. D., Maynard, J. A., MacNeil, M. A., Graham, N. A. J., Maina, J., Baker, A. C., Alemu I., J. B., Beger, M., Campbell, S. J., Darling, E. S., Eakin, C. M., Heron, S. F., Jupiter, S. D., Lundquist, C. J., McLeod, E., Mumby, P. J., Paddack, M. J., Selig, E. R., van Woesik, R., 2012. Prioritizing key resilience indicators to support coral reef management in a changing climate. PLoS ONE 7 (8).

Mehrbach, C., Culberso, C., Hawley, J., Pytkowic, R., 1973. Measurement of apparent dissociation-constants of carbon-acid in seawater at atmospheric-pressure. Limnology and Oceanography 18, 897-907. 
Middlebrook, R., Hoegh-Guldberg, O., Leggat, W., 2008. The effect of thermal history on the susceptibility of reef-building corals to thermal stress. The Journal of Experimental Biology 211 (7), 1050-6.

Mumby, P. J., Chollett, I., Bozec, Y.-M., Wolff, N. H., 2014. Ecological resilience, robustness and vulnerability: how do these concepts benefit ecosystem management? Current Opinion in Environmental Sustainability 7, 22-27.

Mumby, P. J., Harborne, A. R., 2010. Marine reserves enhance the recovery of corals on Caribbean reefs. PLoS ONE 5 (1), 1-7.

Nyström, M., Folke, C., 2001. Spatial resilience of coral reefs. Ecosystems 4 (5), 406-417.

Nyström, M., Graham, N. A. J., Lokrantz, J., Norstrom, A. V., 2008. Capturing the cornerstones of coral reef resilience: linking theory to practice. Coral Reefs 27 (4), 795-809.

Obura, D. O., 2005. Resilience and climate change: lessons from coral reefs and bleaching in the Western Indian Ocean. Estuarine, Coastal and Shelf Science 63 (3), 353-372.

Pandolfi, J. M., Connolly, S. R., Marshall, D. J., Cohen, A. L., 2011. Projecting coral reef futures under global warming and ocean acidification. Science 333 (6041), 418-22.

Rhein, M., Rintoul, S. R., Aoki, S., Campos, E., Chambers, D., Feely, R. A., Gulev, S., Johnson, G. C., Josey, S. A., Kostianoy, A., Mauritzen, C., Roemmich, D., Wang, F., 2013. Observations: Ocean. In: Stocker, T., Qin, D., Plattner, G.-K., Tignor, M., Allen, S., Boschung, J., Nauels, A., Xia, Y., Bex, V., Midgley, P. (Eds.), Climate Change 2013: The Physical Science Basis. Contribution of Working Group I to the Fifth Assessment Report of the Intergovernmental Panel on Climate Change. Cambridge University Press, Cambridge, United Kingdom and New York, NY, USA.

Rowlands, G., Purkis, S., Riegl, B., Metsamaa, L., Bruckner, A., Renaud, P., 2012. Satellite imaging coral reef resilience at regional scale. A case-study from Saudi Arabia. Marine Pollution Bulletin 64 (6), 1222-1237.

Sabine, C. L., Feely, R. A., Gruber, N., Key, R. M., Lee, K., Bullister, J. L., Wanninkhof, R., Wong, C. S., Wallace, D. W. R., Tilbrook, B., Millero, F. J., Peng, T.-H., Kozyr, A., Ono, T., Rios, A. F., 2004. The oceanic sink for anthropogenic $\mathrm{CO}_{2}$. Science 305 (5682), $367-371$.

Shamberger, K. E. F., Cohen, A. L., Golbuu, Y., McCorkle, D. C., Lentz, S. J., Barkley, H. C., 2014. Diverse coral communities in naturally acidified waters of a Western Pacific reef. Geophysical Research Letters 41, 499-504.

Shi, Y., Ren, C., Zheng, Y., Ng, E., 2015. Mapping the urban microclimatic spatial distribution in a sub-tropical high-density urban environment. Architectural Science Review, $1-15$.

Skirving, W., Heron, S., Steinberg, C., McLean, C., Parker, B., Eakin, C., Heron, M., Strong, A., Arzayus, L., 2010. Determining thermal capacitance for protected area network design in Palau. Tech. Rep. NOAA Technical Memorandum CRCP 12, NOAA Coral Reef Conservation Program, Silver Spring, MD.

van Hooidonk, R., Maynard, J. A., Manzello, D., Planes, S., 2014. Opposite latitudinal 
gradients in projected ocean acidification and bleaching impacts on coral reefs. Global change biology 20 (1), 103-12.

van Woesik, R., Houk, P., Isechal, A. L., Idechong, J. W., Victor, S., Golbuu, Y., 2012. Climate-change refugia in the sheltered bays of Palau: analogs of future reefs. Ecology and evolution 2 (10), 2474-84.

West, J. M., Salm, R. V., 2003. Resistance and resilience to coral bleaching: implications for coral reef conservation and management. Conservation Biology 17 (4), 956-967.

Wilkinson, C., 2008. Status of coral reefs of the world: 2008. Tech. rep., Global Coral Reef Monitoring Network and Reef and Rainforest Research Centre, Townsville.

Wisshak, M., Schonberg, C., Form, A., Freiwald, A., 2012. Ocean acidification accelerates reef bioerosion. PloS one 7 (9), 3-10. 


\subsection{Figures and Tables}
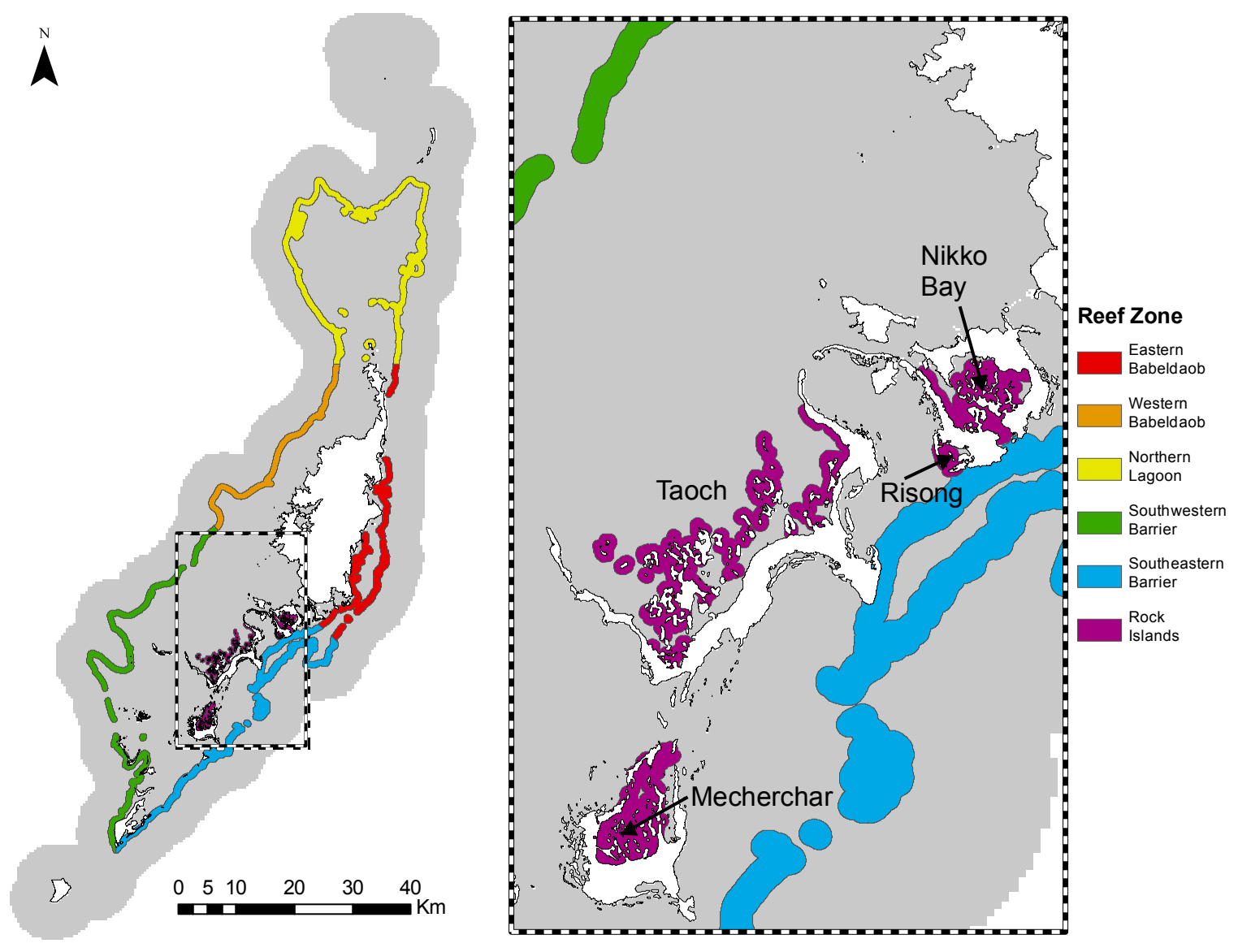

Figure 5-1: Divisions of the six reef zones considered in spatial analysis and locations of the four major groups of Rock Island reefs described in text. White areas represent land, and inset highlights Rock Islands. 

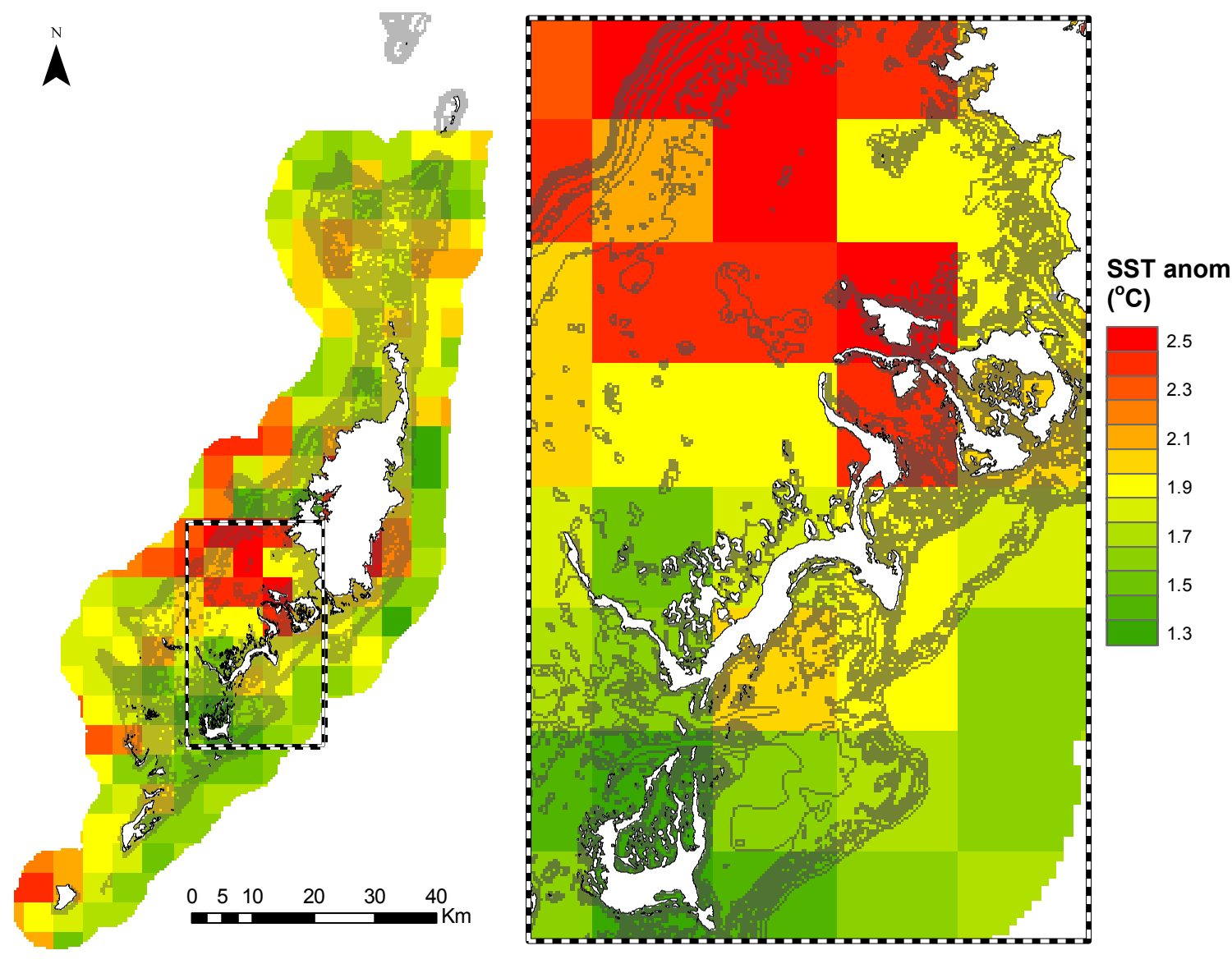

Figure 5-2: Satellite sea surface temperature (SST) anomalies for the Palau archipelago during the 1998 bleaching event (1 June - 30 October 1998) from the Advanced Very High Resolution Radiometer (AVHRR) Pathfinder sensor (4.4 km resolution). Anomalies are calculated for each grid cell relative to the 1991 - 2000 climatological mean. White areas represent land, gray shading indicates submerged reef. Inset shows Rock Islands. 

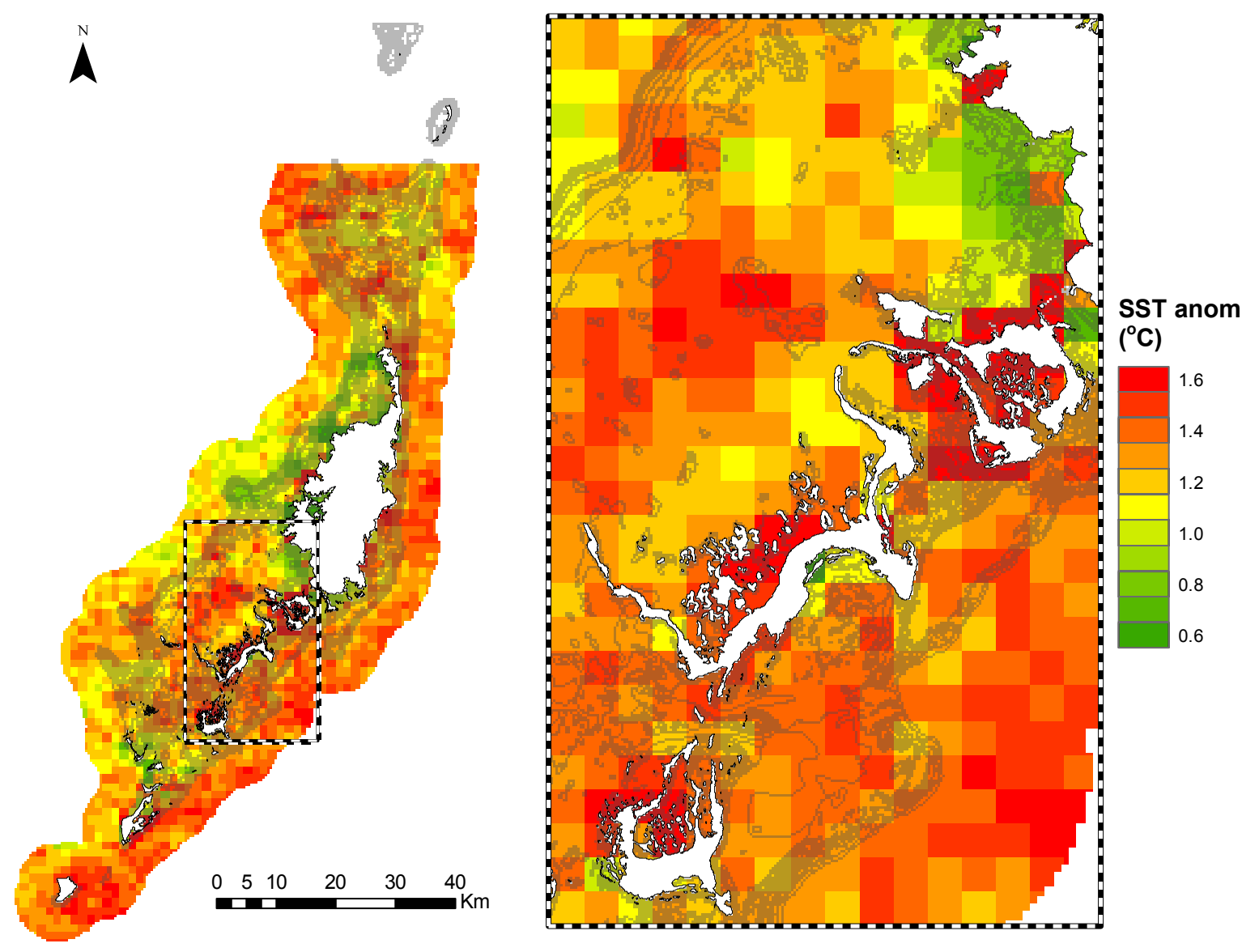

Figure 5-3: Satellite sea surface temperature (SST) anomalies for the Palau archipelago during the 2010 bleaching event (1 June - 30 October 2010) from the Moderate-resolution Imaging Spectroradiometer (MODIS) Aqua sensor (1.5 km resolution). Anomalies are calculated for each grid cell relative to the 2003 - 2011 climatological mean. White areas represent land, gray shading indicates submerged reef. Inset shows Rock Islands. 

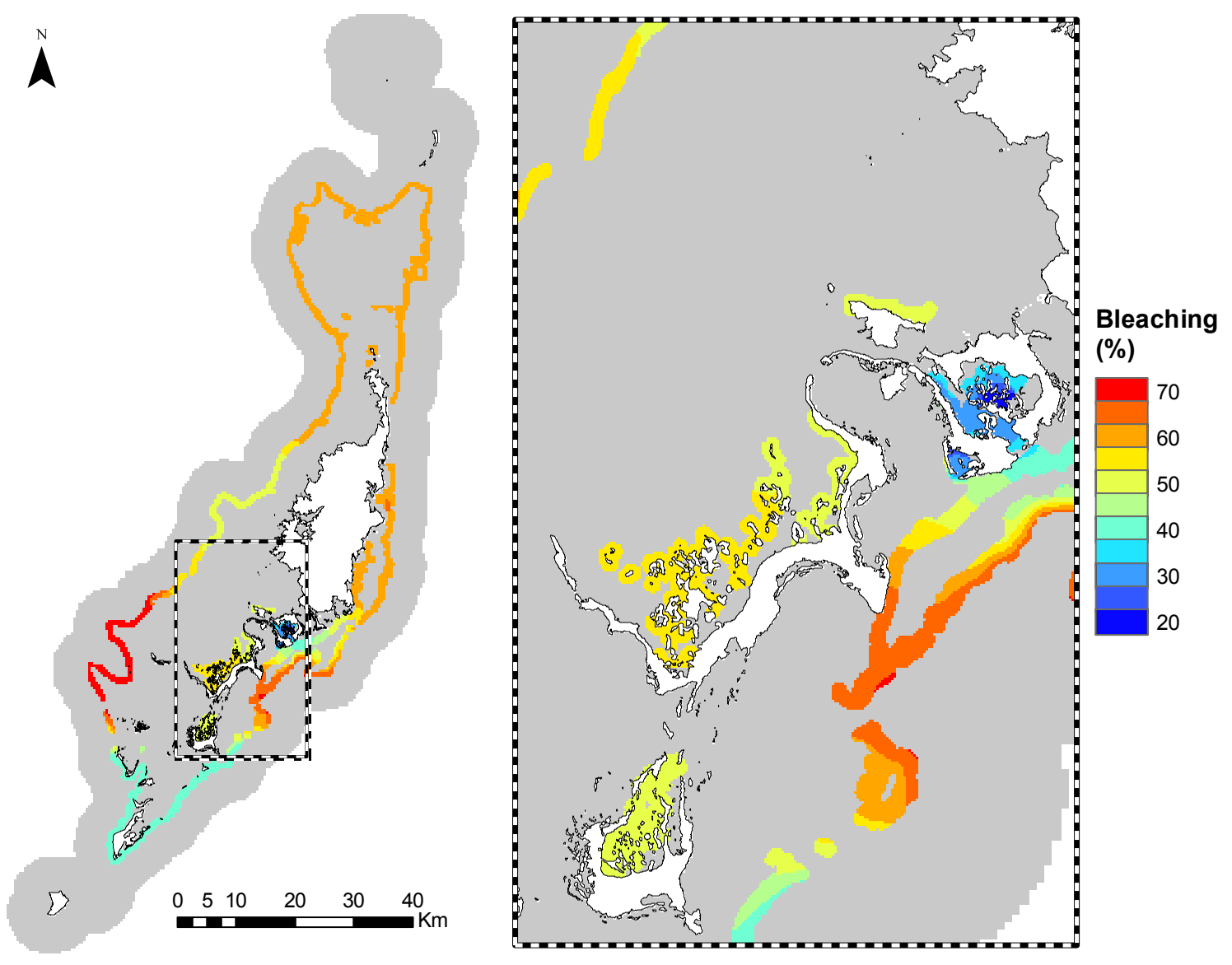

Figure 5-4: Community bleaching levels during the 1998 bleaching event for barrier and Rock Island coral reef communities (gray shaded reef areas not included in analysis). Spatial bleaching data were reconstructed from ecological monitoring data (Bruno et al., 2001) and records from stress bands in Porites coral cores (Chapter 2). 

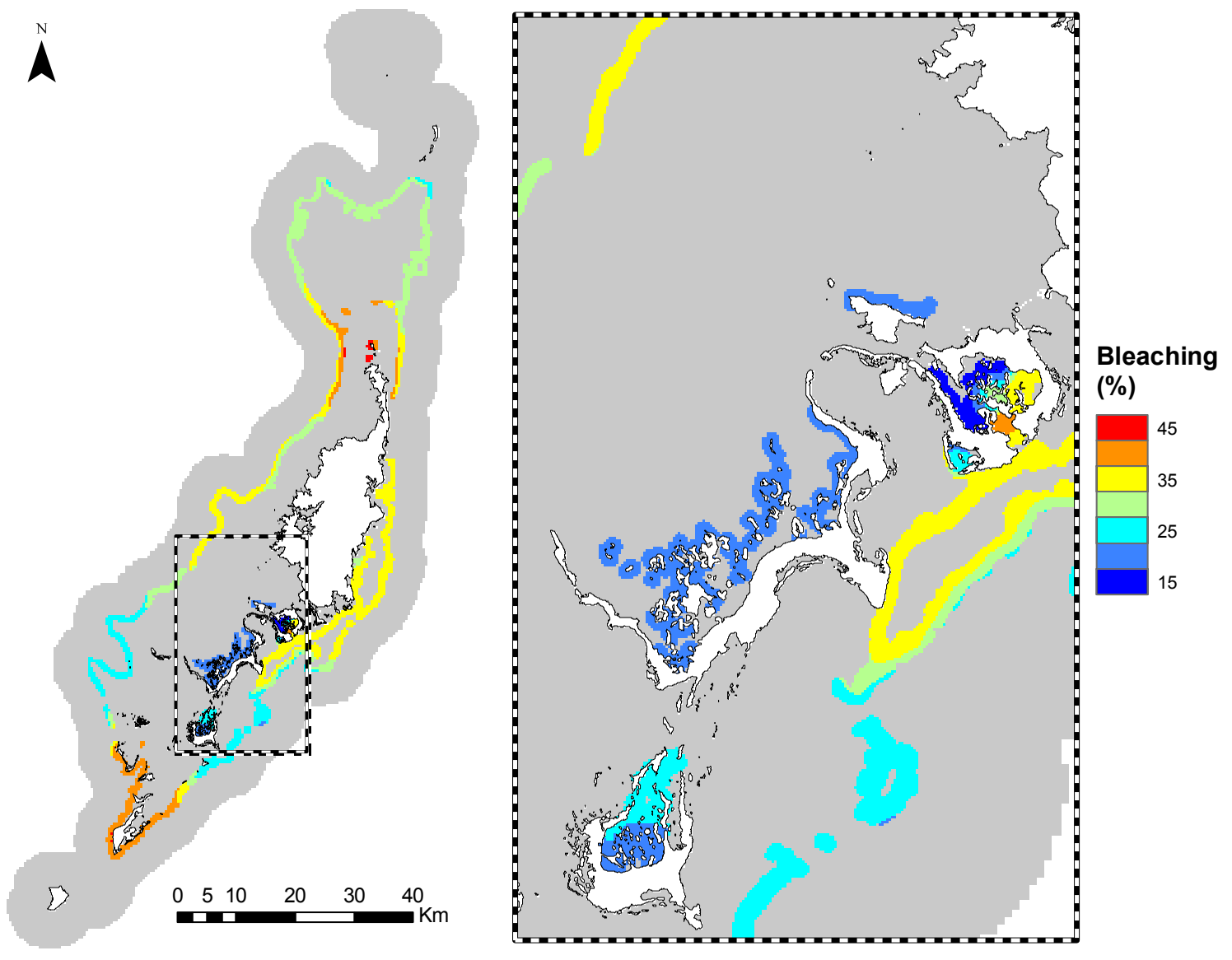

Figure 5-5: Community bleaching levels during the 2010 bleaching event for barrier and Rock Island coral reef communities (gray shaded reef areas not included in analysis). Spatial bleaching data were reconstructed from ecological monitoring data (van Woesik et al., 2012) and records from stress bands in Porites coral cores (Chapter 2). 

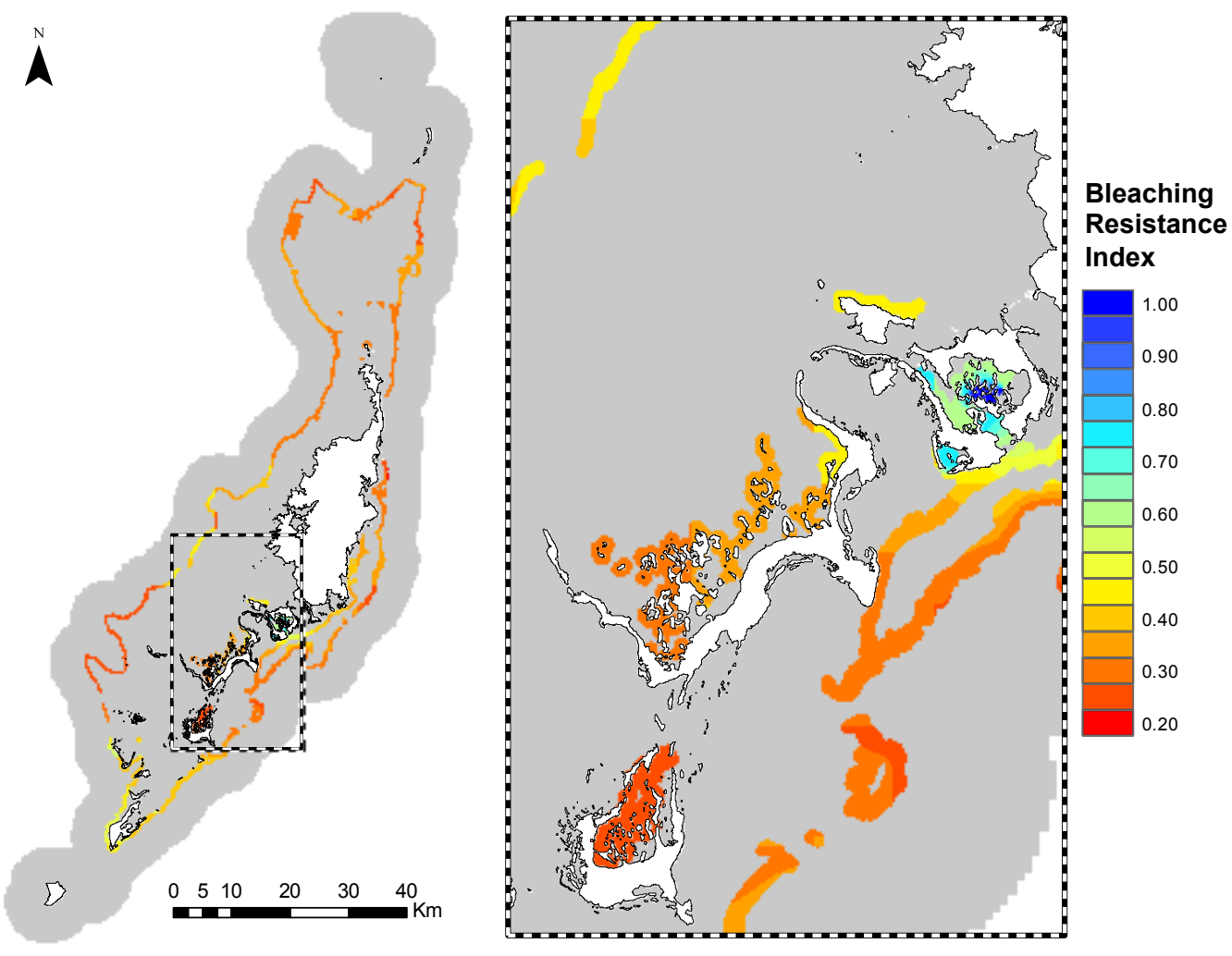

Figure 5-6: 1998 bleaching resistance index. Scores were calculated by dividing the normalized bleaching resistance index for 1998 by normalized 1998 SST anomalies. Scores are inverted so that higher scores (blue) indicate reefs with highest bleaching resistance (i.e. those that had lowest bleaching levels observed relative to the temperature anomalies they experienced). 

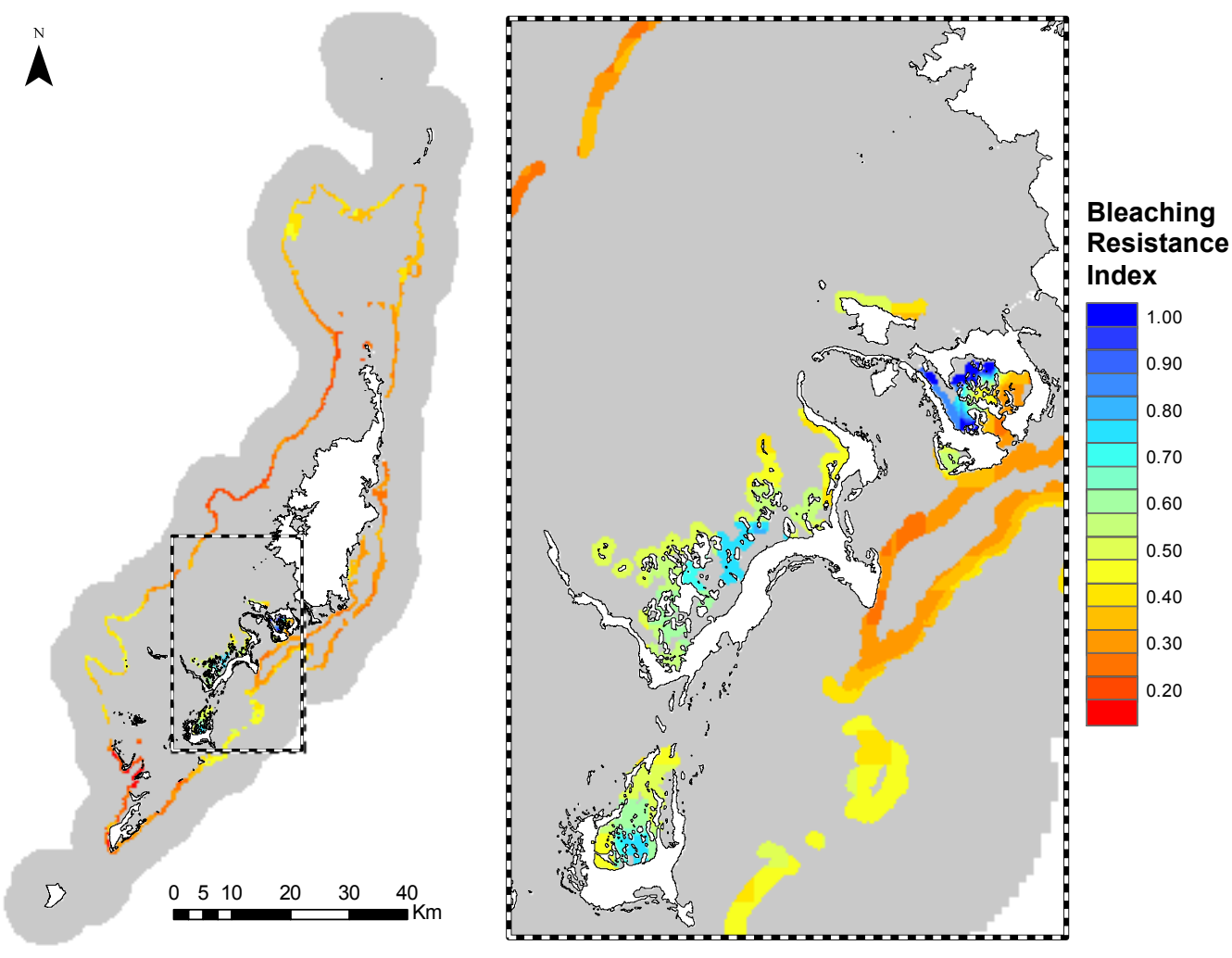

Figure 5-7: 2010 bleaching resistance index. Scores were calculated by dividing the normalized bleaching resistance index for 2010 by normalized 2010 SST anomalies. Scores are inverted so that higher scores (blue) indicate reefs with highest bleaching resistance (i.e. those that had lowest bleaching levels observed relative to the temperature anomalies they experienced). 

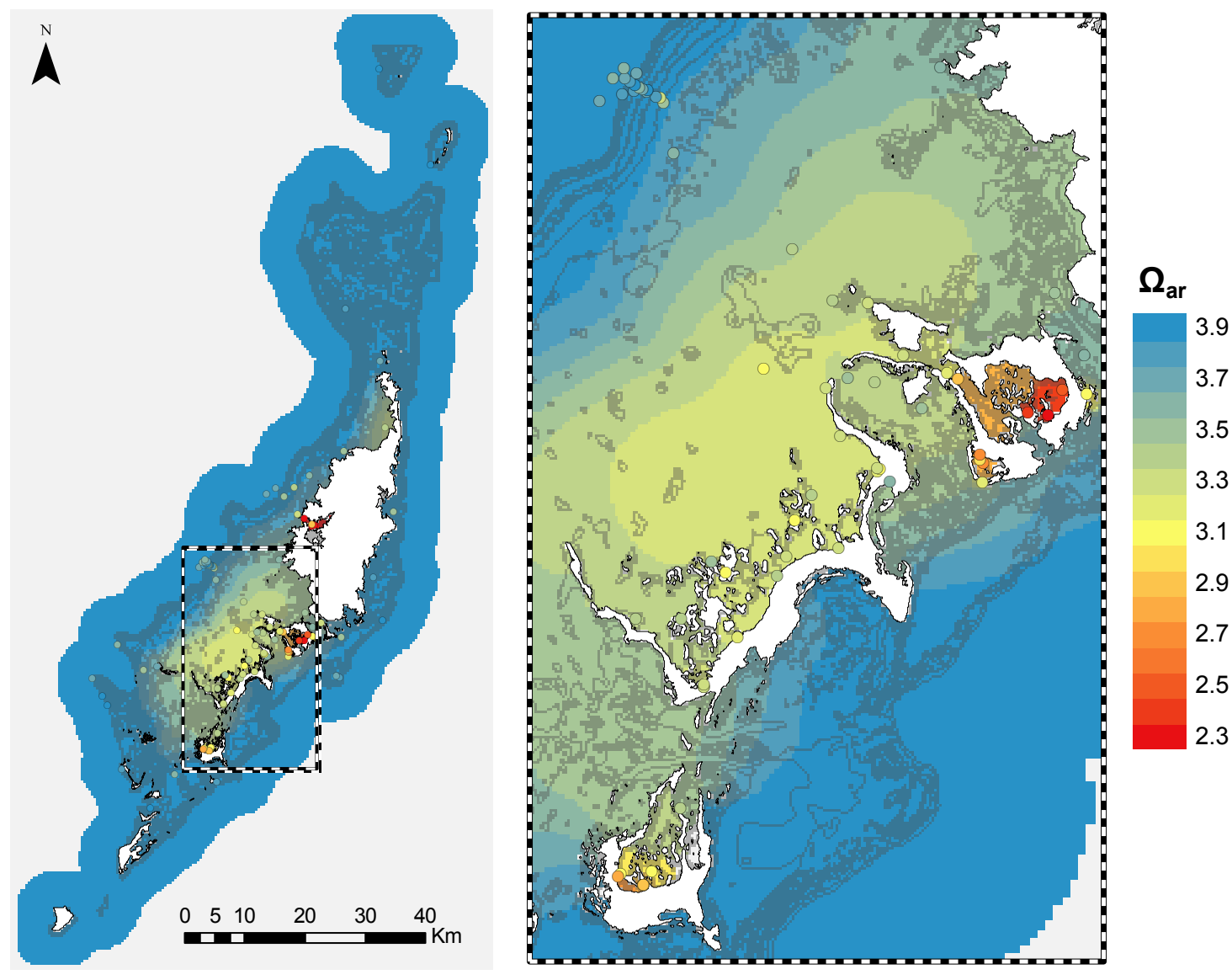

Figure 5-8: $\Omega_{a r}$ for the Palau archipelago. Points show the location and value of discrete water samples, with mean values shown for sites where multiple samples were collected. Shading contours were estimated between sample points using diffusion interpolation with land barriers over a cost surface derived from coral cover and distance from offshore (C.f. Figure D-4). Offshore open ocean values for $\Omega_{a r}$ were set to 3.9. White regions represent land, and shaded gray contours are submerged reef. Inset highlights the Rock Islands. 

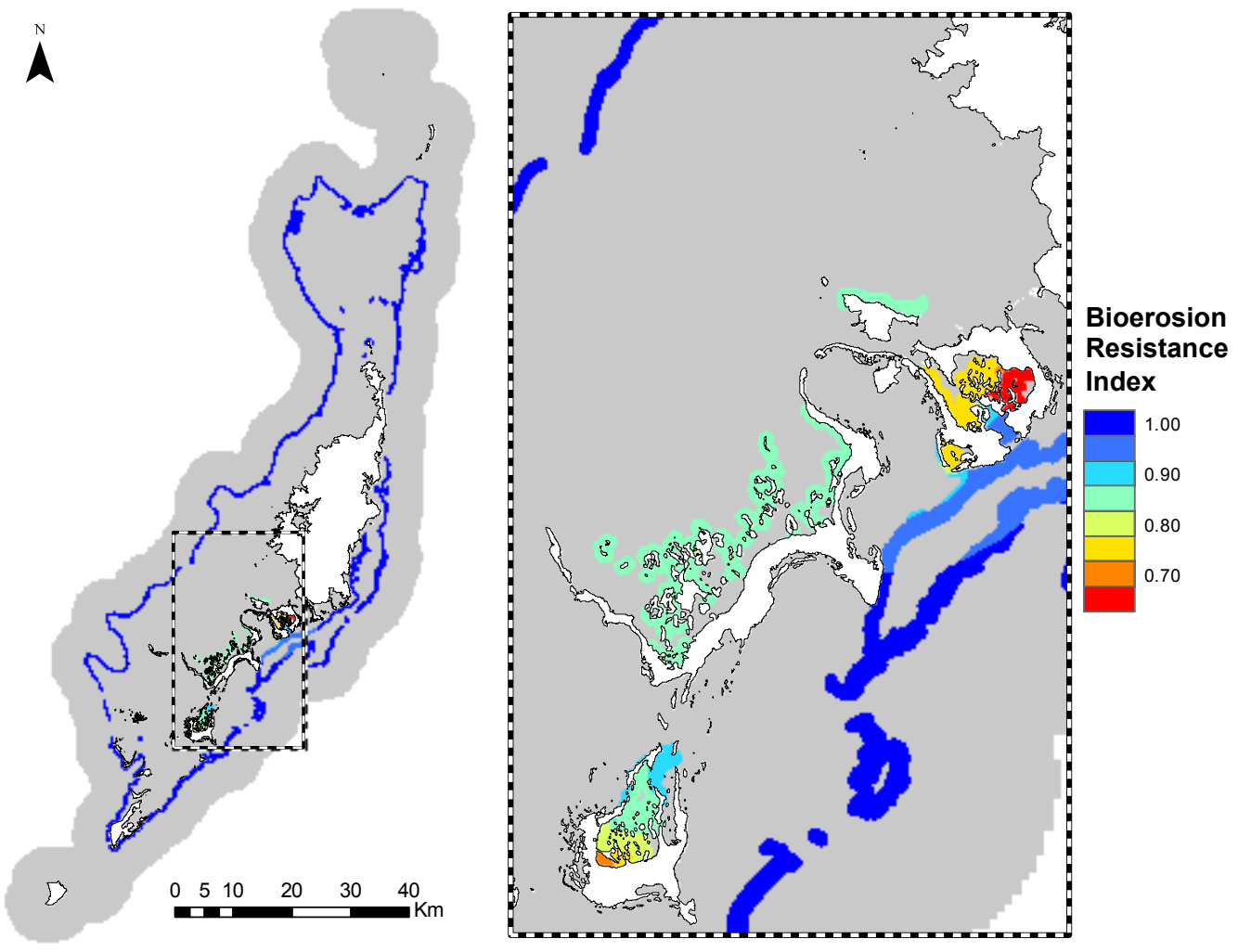

Figure 5-9: Bioerosion resistance index for Palau. Bioerosion resistance scales with $\Omega_{a r}$, and scores were calculated by dividing all values by the highest $\Omega_{a r}$ value observed. Areas with the highest values (blue) are those that are currently exposed to higher $\Omega_{a r}$ levels and are therefore considered less susceptible to bioerosion. 

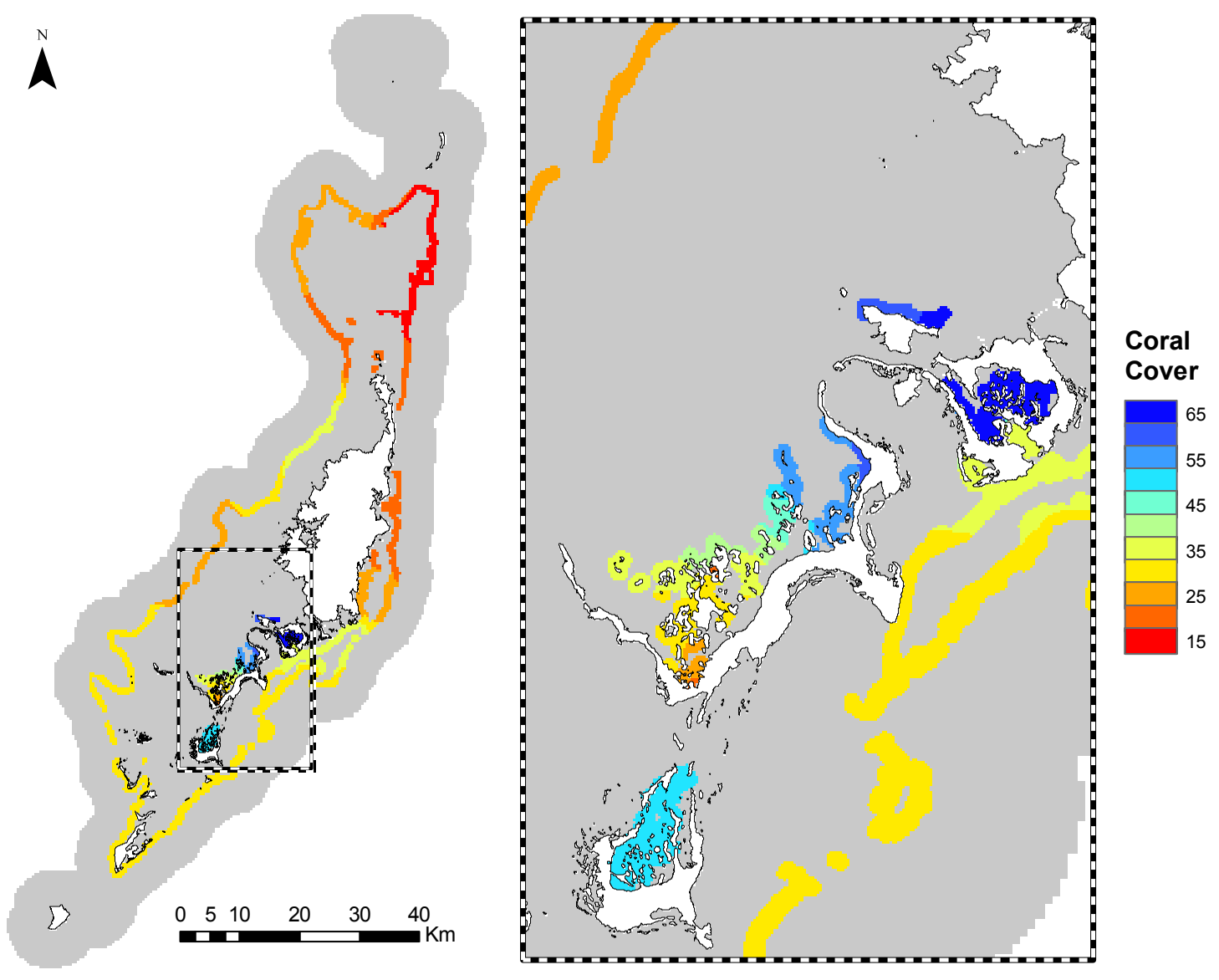

Figure 5-10: Hard coral percent cover. 

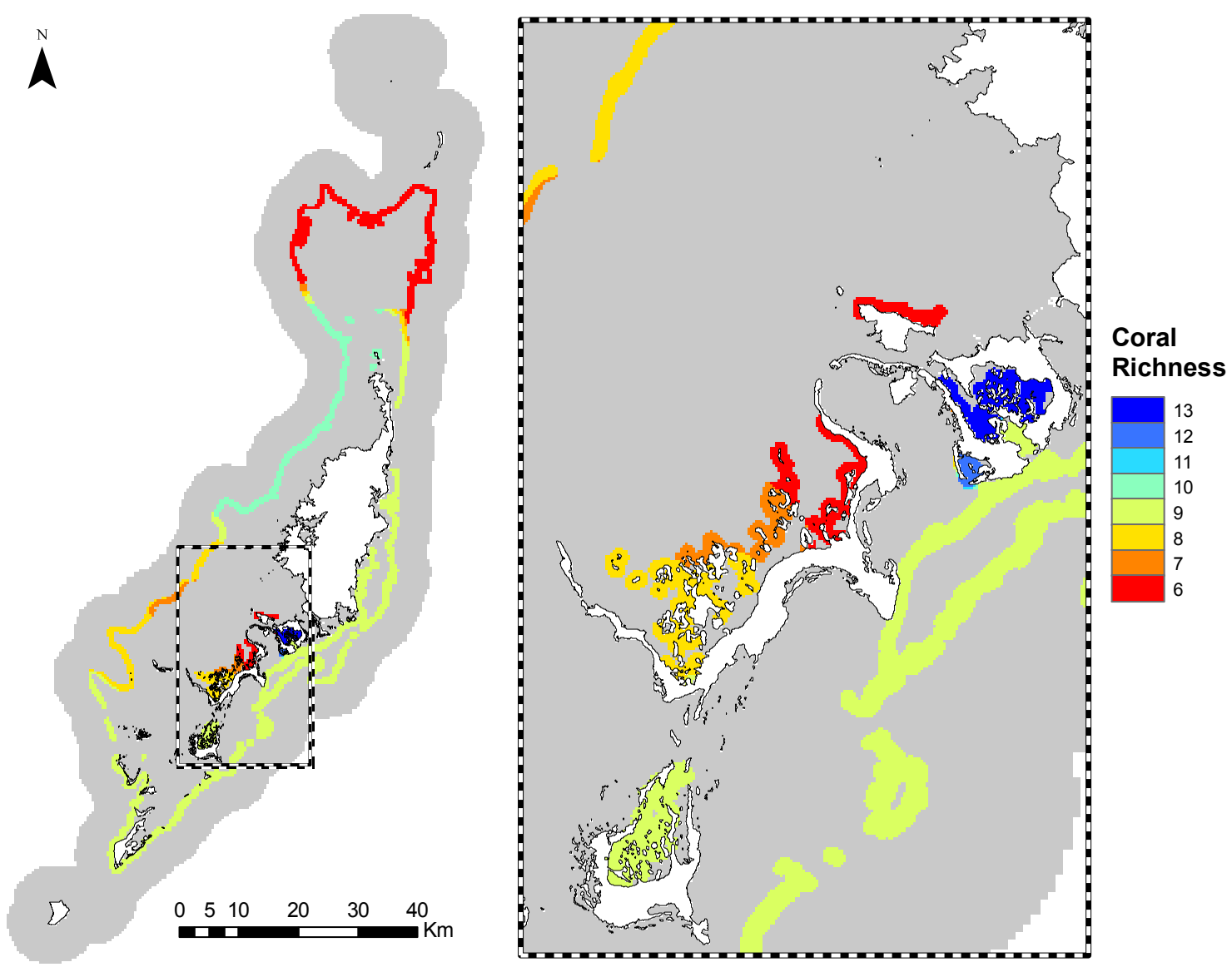

Figure 5-11: Coral richness (number of hard coral genera). 

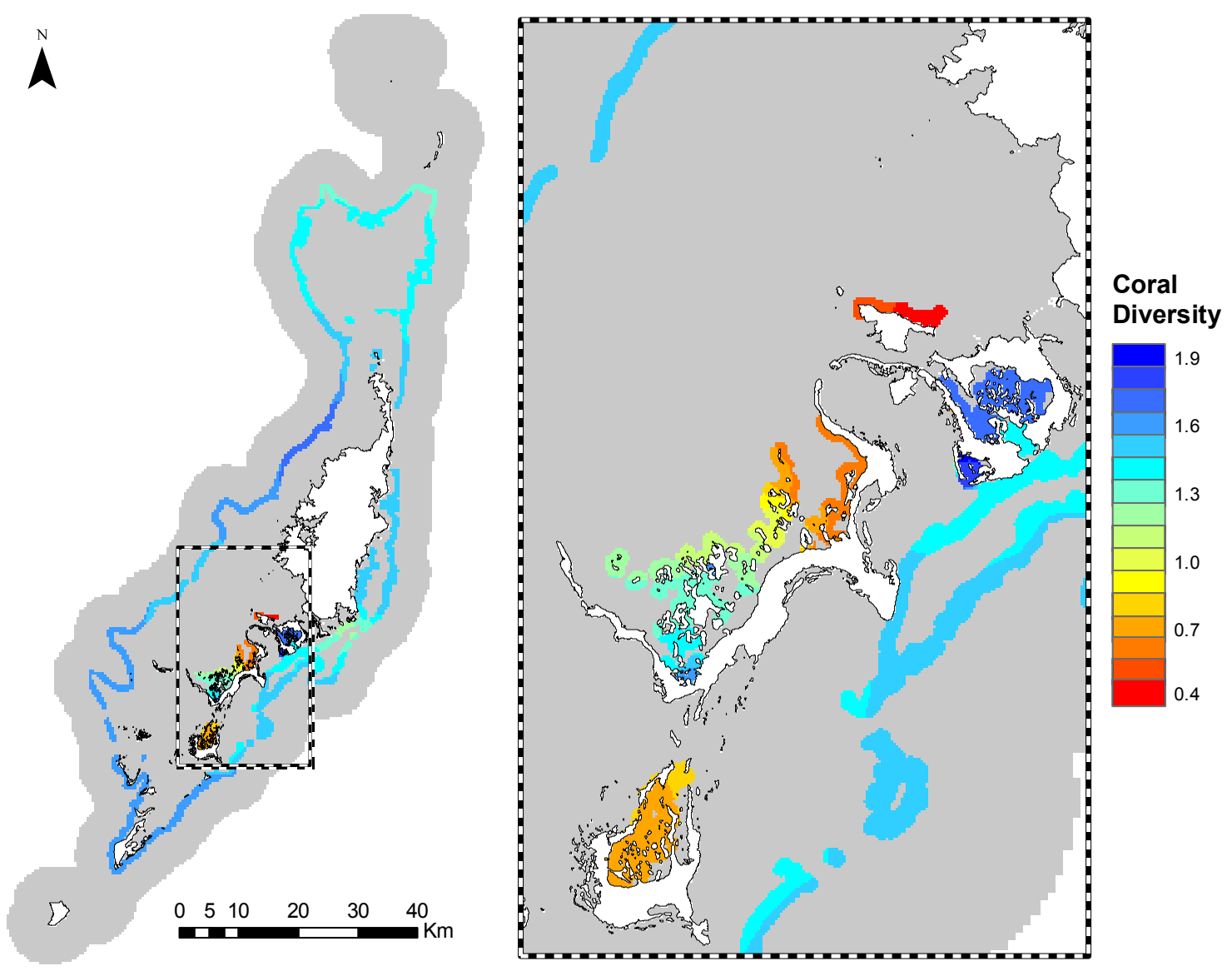

Figure 5-12: Coral diversity (Shannon). 

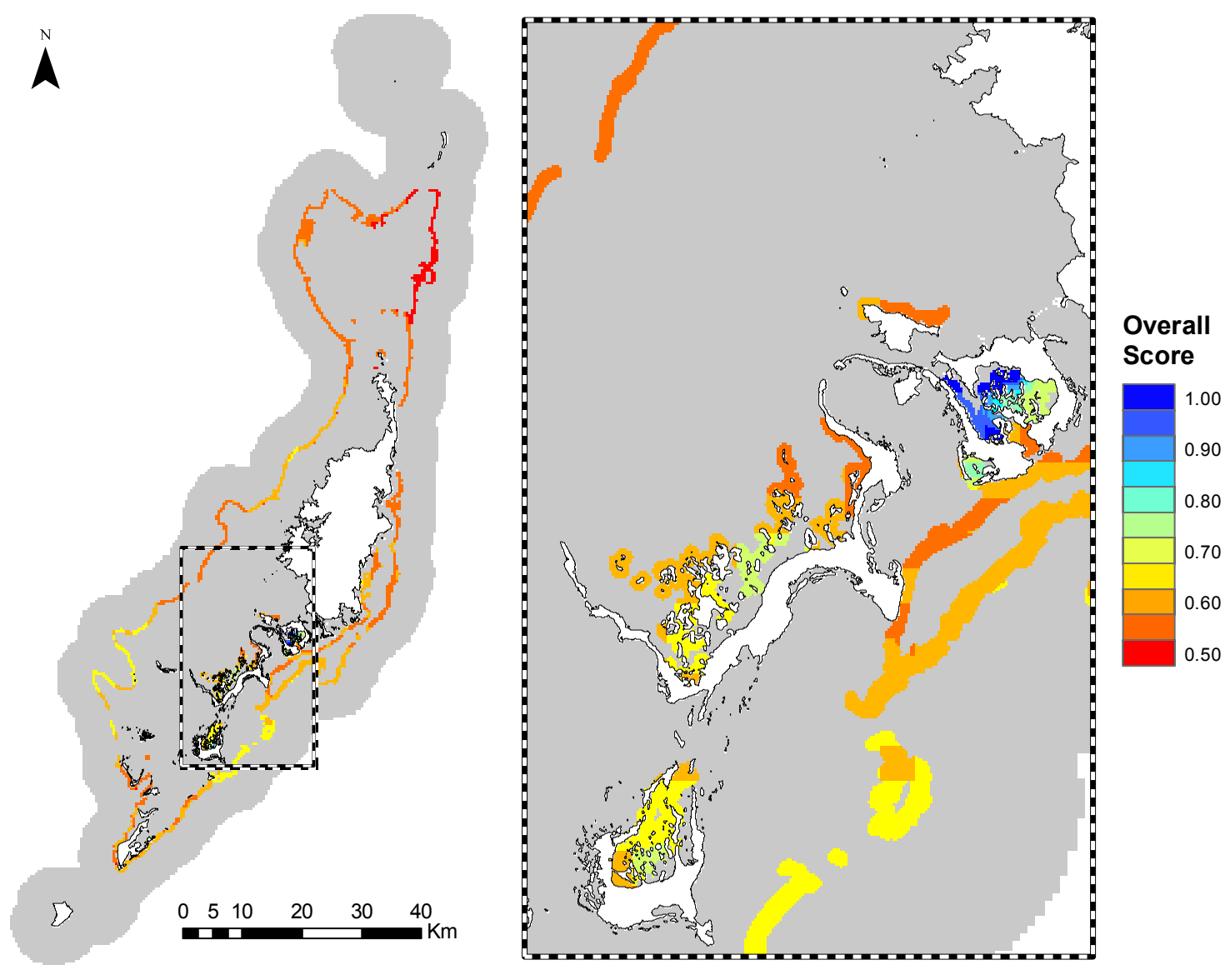

Figure 5-13: Climate change resilience index for Palau reefs. Scores are calculated as the normalized average of bleaching resistance, bioerosion resistance, and ecological resilience scores. Areas with higher scores (blue) are those that have the highest predicted potential of surviving climate change impacts based on historical bleaching resistance; susceptibility to bioerosion; and current ecological cover, richness, and diversity. Areas with lower scores are predicted to be more sensitive to climate change impacts. Gray regions were not included in analysis. 

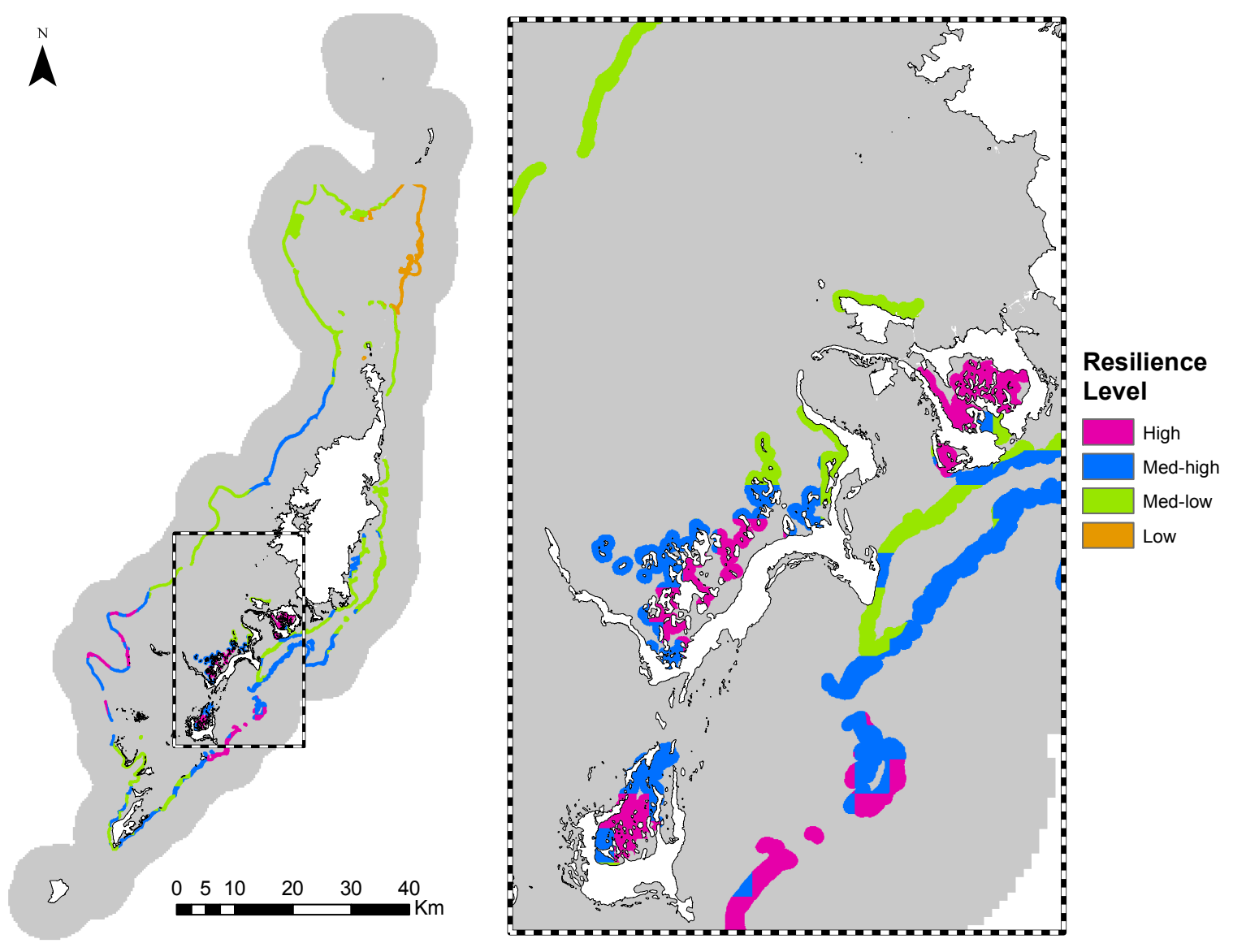

Figure 5-14: Climate change resilience scores for Palau reefs. Classifications were defined based on the mean and standard deviation (SD) of all data as: "high" (> mean $+1 \mathrm{SD}$ ), "med(ium)-high" ( $>$ mean and $<$ mean +1 SD), "med(ium)-low" ( $<$ mean and $>$ mean $1 \mathrm{SD})$, and "low" (< mean - $1 \mathrm{SD})$. 
Table 5.1: Resilience indicator and overall climate change resilience scores $( \pm \mathrm{SD})$ for six reef groups in Palau. 1998 and 2010 SST anomalies, 1998 and 2010 bleaching levels, $\Omega_{a r}$ values, coral cover, coral richness, and coral diversity are the reef group means of raw data; values for 1998 and 2010 bleaching resistance indices, bioerosion resistance, and overall score are mean normalized values. Indicators for which units are not specified are unitless. See Figure 5-1 for reef group locations.

\begin{tabular}{|c|c|c|c|c|c|c|}
\hline & Northern & Southwestern & Southeastern & Western & Eastern & Rock \\
\hline & Lagoon & Barrier & Barrier & Babeldaob & Babeldaob & Islands \\
\hline \multicolumn{7}{|l|}{ SST and bleaching } \\
\hline \multirow[t]{2}{*}{1998 SST anomaly $\left({ }^{\circ} \mathrm{C}\right)$} & 1.79 & 1.83 & 1.69 & 1.81 & 1.91 & 1.66 \\
\hline & \pm 0.16 & \pm 0.26 & \pm 0.18 & \pm 0.23 & \pm 0.30 & \pm 0.31 \\
\hline \multirow[t]{2}{*}{2010 SST anomaly $\left({ }^{\circ} \mathrm{C}\right)$} & 1.23 & 1.15 & 1.29 & 0.97 & 1.29 & 1.43 \\
\hline & \pm 0.13 & \pm 0.20 & \pm 0.12 & \pm 0.13 & \pm 0.13 & \pm 0.22 \\
\hline \multirow[t]{2}{*}{1998 Bleaching (\%) } & 57.4 & 53.2 & 47.9 & 51.6 & 57.8 & 44.6 \\
\hline & \pm 0.8 & \pm 13.8 & \pm 10.8 & \pm 4.3 & \pm 4.1 & \pm 8.9 \\
\hline \multirow[t]{2}{*}{2010 Bleaching (\%) } & 27.7 & 29.9 & 28.9 & 32.0 & 32.5 & 19.3 \\
\hline & \pm 4.6 & \pm 8.0 & \pm 6.3 & \pm 2.0 & \pm 1.8 & \pm 5.0 \\
\hline \multirow[t]{2}{*}{1998 Bleaching resistance index } & 0.28 & 0.33 & 0.33 & 0.32 & 0.31 & 0.37 \\
\hline & \pm 0.02 & \pm 0.09 & \pm 0.07 & \pm 0.06 & \pm 0.05 & \pm 0.17 \\
\hline \multirow[t]{2}{*}{2010 Bleaching resistance index } & 0.31 & 0.29 & 0.32 & 0.21 & 0.27 & 0.54 \\
\hline & \pm 0.06 & \pm 0.10 & \pm 0.07 & \pm 0.03 & \pm 0.03 & \pm 0.15 \\
\hline \multicolumn{7}{|l|}{ Ocean acidification } \\
\hline \multirow[t]{2}{*}{$\Omega_{a r}$} & 3.90 & 3.89 & 3.85 & 3.88 & 3.88 & 3.18 \\
\hline & \pm 0.01 & \pm 0.04 & \pm 0.08 & \pm 0.01 & \pm 0.01 & \pm 0.26 \\
\hline \multirow[t]{2}{*}{ Bioerosion resistance index } & 0.97 & 0.97 & 0.96 & 0.97 & 0.97 & 0.80 \\
\hline & \pm 0.00 & \pm 0.01 & \pm 0.02 & \pm 0.00 & \pm 0.00 & \pm 0.07 \\
\hline \multicolumn{7}{|l|}{ Coral community ecology } \\
\hline \multirow[t]{2}{*}{ Coral cover $(\%)$} & 17.5 & 28.5 & 28.0 & 27.5 & 22.5 & 44.6 \\
\hline & \pm 5.7 & \pm 3.1 & \pm 2.1 & \pm 3.5 & \pm 5.2 & \pm 12.5 \\
\hline \multirow[t]{2}{*}{ Coral richness (\# genera) } & 6.4 & 7.8 & 8.4 & 9.3 & 8.5 & 8.4 \\
\hline & \pm 1.6 & \pm 0.5 & \pm 0.1 & \pm 0.3 & \pm 0.1 & \pm 2.3 \\
\hline \multirow[t]{2}{*}{ Coral diversity } & 1.33 & 1.51 & 1.43 & 1.58 & 1.40 & 1.06 \\
\hline & \pm 0.05 & \pm 0.02 & \pm 0.07 & \pm 0.04 & \pm 0.09 & \pm 0.38 \\
\hline \multirow[t]{2}{*}{ Overall score } & 0.56 & 0.62 & 0.62 & 0.61 & 0.59 & 0.68 \\
\hline & \pm 0.03 & \pm 0.03 & \pm 0.02 & \pm 0.02 & \pm 0.01 & \pm 0.10 \\
\hline
\end{tabular}




\section{Chapter 6}

\section{Conclusion}

The goal of this thesis was to build a scientific framework for coral reef conservation under climate change by creating, testing, and employing the tools and analyses necessary to identify the communities that have the best chance of surviving $21^{\text {st }}$ century ocean warming and ocean acidification. To accomplish this task, in this thesis I have:

1. developed a new proxy for coral bleaching that can be used to reconstruct community bleaching levels and identify coral reefs with highest bleaching resistance (Chapter 2),

2. showed that coral community bleaching resistance varies spatially across reef environments (Chapter 2),

3. reported on the first coral reef communities in the world that appear to be resistant to ocean acidification and demonstrated that acidification sensitivities vary across reef systems (Chapter 3),

4. identified adaptation as the likely cause of acidification tolerance in these coral communities (Chapter 4),

5. showed that Porites corals currently living in low-pH conditions can still calcify well even at $\mathrm{pH}$ levels well below end-of-century predictions (Chapter 4), and

6. integrated spatial information on temperature and acidification exposure and sensitivity to predict coral reef communities with highest resilience potential (Chapter 5).

This "toolbox" for identifying coral reef communities with highest resilience potential not only reveals important information about the predicted response of coral reefs to climate change stressors, but also produces specific recommendations for the coral reefs that might be best able to survive climate change-driven ocean warming and acidification.

The findings of this thesis suggest that coral reef communities will likely vary both within and between reef systems in their ability to resist and/or recover from climate change-driven 
increasing ocean temperature and decreasing $\mathrm{pH}$. Stress band prevalence and bleaching data from the 1998 and 2010 bleaching events in Palau show that coral community sensitivity to thermal stress and bleaching susceptibility vary spatially, with the coral communities living in Palau's sheltered lagoon reefs showing generally higher temperature resistance across the two bleaching events than those on the exposed barrier reefs (Chapter 2). Similarly, coral community responses to ocean acidification appear to differ considerably across coral reef sites. Palau's sheltered Rock Islands present the first evidence to date that diverse, coral-dominated reef communities can thrive in predicted end-of-century $\mathrm{pH}$ conditions. A comparison across all coral reef sites similarly exposed to naturally low-pH conditions reveals that coral reef community responses to declining $\mathrm{pH}$ are highly inconsistent, with increased macrobioerosion at low-pH revealed as the only persistent signature of acidified conditions (Chapter 3).

Across all of Palau's reefs, the coral communities fringing the karstic Rock Islands emerge as those predicted to have the highest level of climate change resilience (Chapter 5). The corals living in these warm, acidified bays demonstrate high thermal thresholds during bleaching events, calcify well in extremely acidified conditions despite elevated rates of bioerosion, and host very high coral cover, richness, and diversity. The reason for this unusual tolerance to climate change impacts is still not fully understood. Combined laboratory $\mathrm{CO}_{2}$ manipulation and field reciprocal transplant experiments suggest that community adaptation to chronically acidified conditions may explain the unique $\mathrm{pH}$ insensitivity of Palau's Rock Island communities (Chapter 4). Adaptation to persistently warmer temperatures on these reefs may similarly result in higher thermal tolerance and bleaching resistance. The temperature and $\mathrm{pH}$ resilience observed in Rock Island reefs over the past twenty years suggests that these coral reefs may continue to survive climate change impacts over the next several decades. They may even qualify as refugia. Most critically, these results highlight the fact that there may be coral communities that are able to withstand both the temperature and $\mathrm{pH}$ conditions predicted for tropical oceans under $21^{\text {st }}$ century climate change and that it is possible to identify these places with a relatively simple set of tools and analyses.

This thesis focuses on climate change resilience within the coral reef communities of Palau. However, the tools for identifying climate change-resilient reefs outlined here are broadly applicable to all coral reef communities worldwide and similar analyses may be reproduced in other coral reef systems. To this end, a remaining question of particular 
interest is whether the ocean warming and acidification resilience observed in Palau's Rock Islands is distinct across all coral reef ecosystems globally. While comprehensive analyses of climate change sensitivity have not yet been conducted for most of the world's reefs, the heterogeneity in environmental conditions and coral reef community structure that exists within Palau and that likely give rise to variability in climate change resilience are not unique to the Palau archipelago. Elsewhere in the tropical Indo-Pacific - in Raja Ampat, Indonesia; Palawan, Philippines; Krabi, Thailand; and Halong Bay, Vietnam - mazes of towering karst islands offer the tantalizing possibility that replicate geomorphology may have also given rise to coral reef communities with an unusual insensitivity to climate change impacts. It is on these places that researchers should focus attention next. However, regardless of whether the proclivity to resist temperature and $\mathrm{pH}$ is unique to Palau's corals or shared across multiple reef systems worldwide, the coral reefs of Palau present perhaps the best evidence we have to date that small pockets of coral reef communities may be able to survive both ocean warming and acidification and persist into the future against the heavy odds dealt by a rapidly changing climate. 


\section{Appendix A}

\section{Supplementary materials for chapter 2}

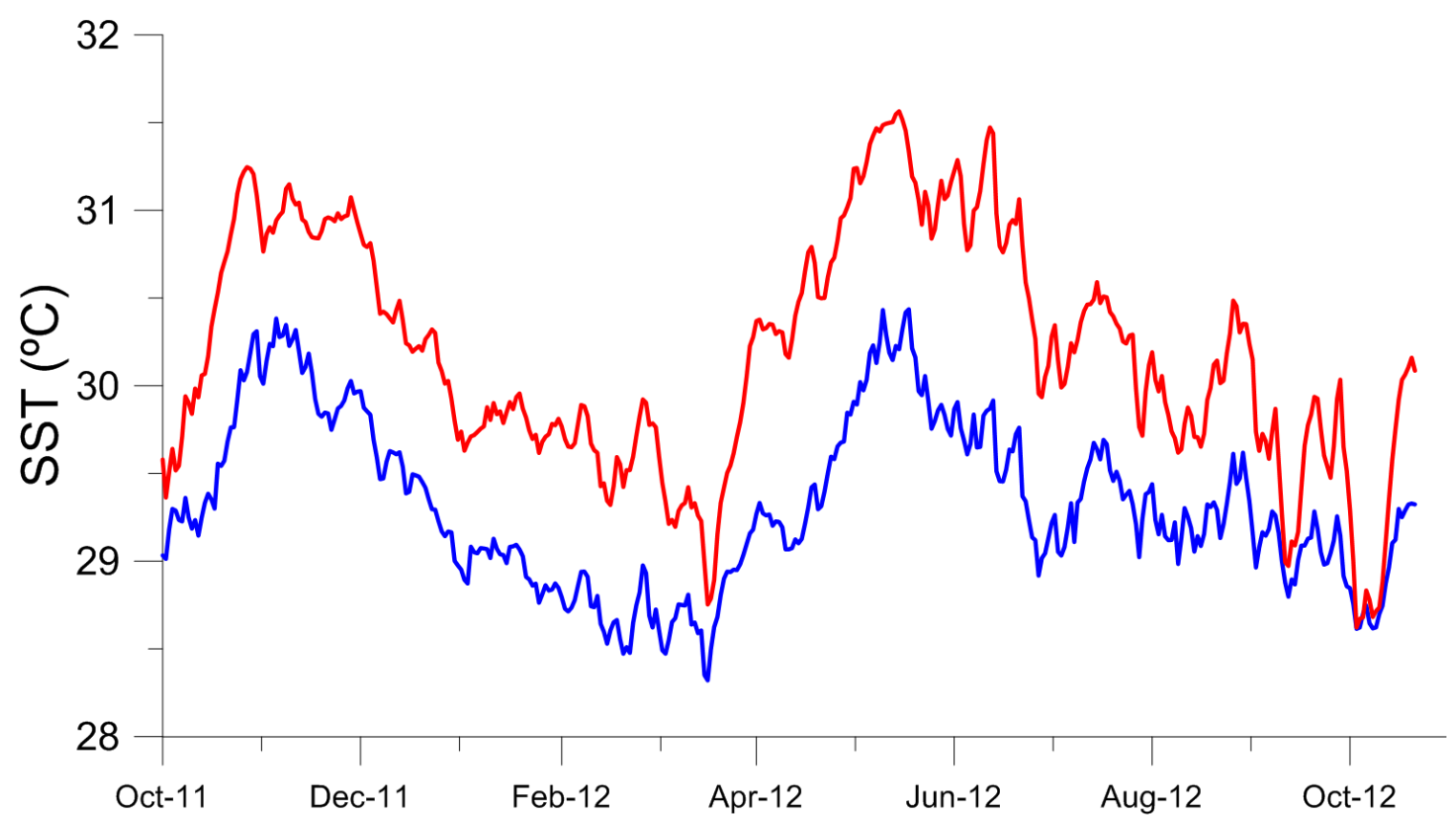

Figure A-1: Sea surface temperature records from a barrier reef (blue; Short Drop Off) and a lagoon reef (red; Nikko Bay) site measured in situ at 15-minute increments using HOBO temperature loggers from 1 October 2011 to 30 November 2012. Mean $\pm \mathrm{SD}$ temperatures were $29.33{ }^{\circ} \mathrm{C} \pm 0.46{ }^{\circ} \mathrm{C}$ for the barrier reef and $30.21{ }^{\circ} \mathrm{C} \pm 0.64{ }^{\circ} \mathrm{C}$ for the lagoon reef. 

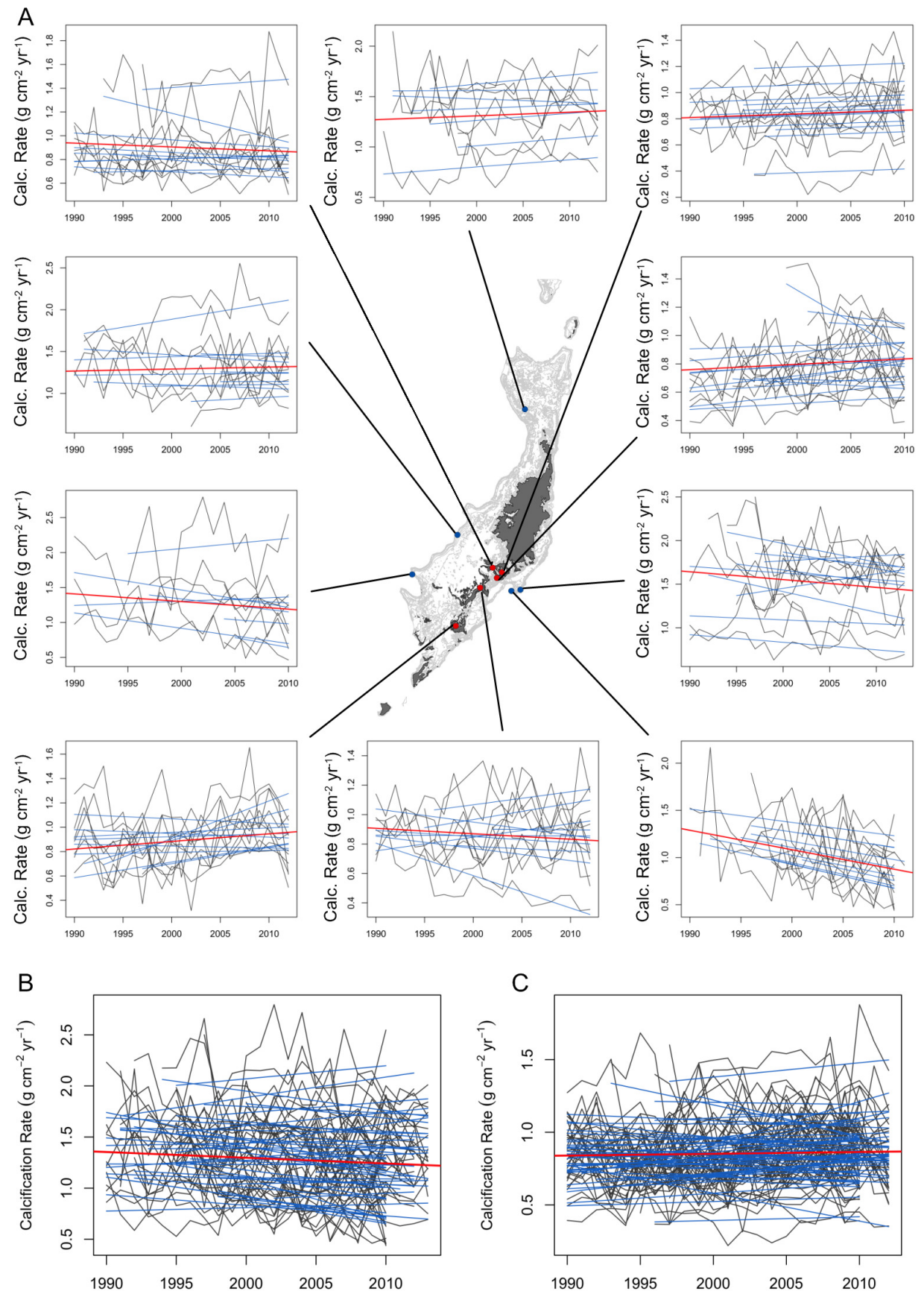

Figure A-2: All calcification time series for Palau corals. (A) Annual calcification histories for corals from ten reef sites and from (B) barrier and (C) lagoon reefs. Black lines show each individual coral calcification time series plotted with mixed effects model fits for each core record (blue) and the population mean (red). 
Table A.1: Latitude and longitude coordinates for core collection sites in Palau, reef type, number of cores analyzed for 1998 and 2010 stress bands (SB), the percent of cores possessing a stress band, and observed bleaching data from both events. The number of cores in 1998 represents the number of skeletal cores collected that were long enough to include 1998 growth records. All cores collected included growth data from 2010. Observed bleaching data are from Bruno et al. (2001) and van Woesik et al. (2012), and n.d. indicates that no bleaching data were available for the site during the specified bleaching event. Standard errors of a proportion are reported for stress band data, and standard errors of the mean are reported for bleaching data.

\begin{tabular}{|c|c|c|c|c|c|c|c|c|c|}
\hline Site Name & Reef Type & $\begin{array}{l}\text { Lat } \\
\left({ }^{\circ} \mathrm{N}\right) \\
\end{array}$ & $\begin{array}{l}\text { Lon } \\
\left({ }^{\circ} \mathrm{E}\right)\end{array}$ & $\begin{array}{r}1998 \\
\text { \# Cores } \\
\end{array}$ & $\begin{array}{l}1998 \mathrm{SB} \\
\%(\mathrm{SE})\end{array}$ & $\begin{array}{c}1998 \text { Bleaching } \\
\%(\mathrm{SE})\end{array}$ & $\begin{array}{c}2010 \\
\text { \# Cores } \\
\end{array}$ & $\begin{array}{l}2010 \mathrm{SB} \\
\%(\mathrm{SE})\end{array}$ & $\begin{array}{c}2010 \text { Bleaching } \\
\%(\mathrm{SE})\end{array}$ \\
\hline Ngerchelong & Barrier & 7.822 & 134.562 & 7 & $57(19)$ & n.d. & 7 & $29(17)$ & $27(6)$ \\
\hline Ngerdiluches & Barrier & 7.298 & 134.521 & 6 & $50(20)$ & $47(4)$ & 10 & $30(14)$ & $33(3)$ \\
\hline Short Drop Off & Barrier & 7.268 & 134.522 & 6 & $67(19)$ & $66(12)$ & 11 & $18(12)$ & $29(15)$ \\
\hline Siaes & Barrier & 7.317 & 134.220 & 9 & $67(16)$ & $75(7)$ & 9 & $22(14)$ & $25(0)$ \\
\hline Uchelbeluu & Barrier & 7.271 & 134.549 & 5 & $60(22)$ & $66(12)$ & 8 & $25(15)$ & $29(15)$ \\
\hline Mecherchar & Lagoon & 7.160 & 134.352 & 10 & $50(16)$ & $46(5)$ & 10 & $20(13)$ & $14(6)$ \\
\hline Nikko Bay & Lagoon & 7.324 & 134.493 & 11 & $18(12)$ & n.d. & 11 & $27(13)$ & $20(15)$ \\
\hline PICRC & Lagoon & 7.338 & 134.464 & 10 & $30(14)$ & n.d. & 10 & $10(9)$ & $n . d$. \\
\hline Risong & Lagoon & 7.307 & 134.477 & 12 & $25(13)$ & $32(5)$ & 15 & $20(13)$ & $19(3)$ \\
\hline Taoch & Lagoon & 7.277 & 134.426 & 10 & $50(16)$ & n.d. & 10 & $20(13)$ & $16(2)$ \\
\hline
\end{tabular}


Table A.2: Estimates from a mixed effects model evaluating the relationship between year (1990-2013), post-1998, post-2010, and the annual calcification rates for coral colonies from 10 sites. Models were constructed separately for each site with individual coral cores considered as random effects, and reported parameter estimates are the results of an AICbest fit model.

\begin{tabular}{|c|c|c|c|c|c|c|}
\hline Reef Site & Reef Type & Model Parameter & Estimate & SE & t-statistic & p-value \\
\hline \multirow[t]{4}{*}{ Ngerchelong } & \multirow[t]{4}{*}{ Barrier } & Intercept & 1.312 & 0.108 & 12.095 & $<0.001$ \\
\hline & & Year & 0.000 & 0.003 & 0.159 & 0.874 \\
\hline & & Post-1998 & -0.035 & 0.045 & -0.765 & 0.446 \\
\hline & & Post-2010 & 0.083 & 0.051 & 1.621 & 0.107 \\
\hline \multirow[t]{4}{*}{ Ngerdiluches } & \multirow[t]{4}{*}{ Barrier } & Intercept & 1.300 & 0.090 & 14.451 & $<0.001$ \\
\hline & & Year & 0.002 & 0.004 & 0.422 & 0.674 \\
\hline & & Post-1998 & -0.062 & 0.057 & -1.101 & 0.273 \\
\hline & & Post-2010 & 0.005 & 0.055 & 0.095 & 0.924 \\
\hline \multirow[t]{4}{*}{ Short Drop Off } & \multirow[t]{4}{*}{ Barrier } & Intercept & 1.064 & 0.059 & 18.126 & $<0.001$ \\
\hline & & Year & -0.019 & 0.005 & -4.284 & $<0.001$ \\
\hline & & Post-1998 & -0.001 & 0.056 & -0.016 & 0.987 \\
\hline & & Post-2010 & -0.056 & 0.079 & -0.712 & 0.478 \\
\hline \multirow[t]{4}{*}{ Siaes } & \multirow[t]{4}{*}{ Barrier } & Intercept & 1.570 & 0.112 & 13.971 & $<0.001$ \\
\hline & & Year & -0.014 & 0.003 & -3.932 & $<0.001$ \\
\hline & & Post-1998 & -0.164 & 0.051 & -3.201 & 0.002 \\
\hline & & Post-2010 & 0.055 & 0.056 & 0.991 & 0.323 \\
\hline \multirow[t]{4}{*}{ Uchelbeluu } & \multirow[t]{4}{*}{ Barrier } & Intercept & 1.300 & 0.146 & 8.916 & $<0.001$ \\
\hline & & Year & -0.011 & 0.006 & -1.694 & 0.093 \\
\hline & & Post-1998 & -0.067 & 0.093 & -0.719 & 0.474 \\
\hline & & Post-2010 & -0.046 & 0.128 & -0.356 & 0.723 \\
\hline \multirow[t]{4}{*}{ Mecherchar } & \multirow[t]{4}{*}{ Lagoon } & Intercept & 0.904 & 0.038 & 24.032 & $<0.001$ \\
\hline & & Year & 0.007 & 0.002 & 2.690 & 0.008 \\
\hline & & Post-1998 & -0.080 & 0.038 & -2.114 & 0.036 \\
\hline & & Post-2010 & -0.030 & 0.045 & -0.670 & 0.504 \\
\hline \multirow[t]{4}{*}{ Nikko Lagoon } & \multirow[t]{4}{*}{ Lagoon } & Intercept & 0.837 & 0.059 & 14.288 & $<0.001$ \\
\hline & & Year & 0.004 & 0.002 & 2.004 & 0.047 \\
\hline & & Post-1998 & 0.028 & 0.027 & 1.061 & 0.29 \\
\hline & & Post-2010 & -0.051 & 0.047 & -1.078 & 0.282 \\
\hline \multirow[t]{4}{*}{ PICRC } & \multirow[t]{4}{*}{ Lagoon } & Intercept & 0.904 & 0.072 & 12.587 & $<0.001$ \\
\hline & & Year & -0.005 & 0.002 & -2.282 & 0.024 \\
\hline & & Post-1998 & -0.036 & 0.031 & -1.171 & 0.243 \\
\hline & & Post-2010 & 0.034 & 0.038 & 0.915 & 0.361 \\
\hline \multirow[t]{4}{*}{ Risong } & \multirow[t]{4}{*}{ Lagoon } & Intercept & 0.804 & 0.047 & 16.948 & $<0.001$ \\
\hline & & Year & 0.006 & 0.002 & 3.563 & $<0.001$ \\
\hline & & Post-1998 & 0.022 & 0.025 & 0.858 & 0.392 \\
\hline & & Post-2010 & -0.127 & 0.039 & -3.271 & 0.001 \\
\hline \multirow[t]{4}{*}{ Taoch } & \multirow[t]{4}{*}{ Lagoon } & Intercept & 0.868 & 0.049 & 17.701 & $<0.001$ \\
\hline & & Year & -0.005 & 0.002 & -2.064 & 0.040 \\
\hline & & Post-1998 & -0.033 & 0.036 & -0.912 & 0.363 \\
\hline & & Post-2010 & 0.027 & 0.041 & 0.652 & 0.515 \\
\hline
\end{tabular}


Table A.3: Estimates from a mixed effects model evaluating the relationship between year (1990-2013) and annual calcification rates for coral colonies from two reef environments.

\begin{tabular}{lrrrr}
\hline Model Parameter & Estimate & SE & t-statistic & p-value \\
\hline Intercept & 1.310 & 0.052 & 25.336 & $<0.001$ \\
Year (-2001) & -0.009 & 0.003 & -2.934 & 0.003 \\
Reef Type (Lagoon) & -0.457 & 0.071 & -6.440 & 0.002 \\
Year (-2001) $\times$ Reef Type (Lagoon) & 0.009 & 0.004 & 2.209 & 0.027 \\
\hline
\end{tabular}

Parameter estimates are the results of an AIC-best fit mixed effects model examining the relationship between year and the calcification rates for coral colonies from two reef types. The year predicator was centered in 2001 to improve model fit. The parameters are reported with the barrier reefs as a reference group, with the lagoon reef model estimates reported relative to those of the barrier reef. P-values are reported for the relationship between the estimates for the lagoon group and the barrier group: "Year" parameter is the change in barrier reef growth rates over time, "Reef Type (Lagoon)" estimates the difference in growth rates in the lagoon reef corals relative to barrier corals, and "Year $\times$ Reef Type (Lagoon)" estimates the difference in the change in lagoon reef coral calcification rates over time relative to the relationship between barrier reef coral calcification rates and time. 
Table A.4: Estimates from a mixed effects model evaluating the relationship between sea surface temperature (SST) anomalies and annual calcification rates.

\begin{tabular}{lrrrr}
\hline Model Parameter & Estimate & SE & t-statistic & p-value \\
\hline Intercept & 1.295 & 0.053 & 23.907 & $<0.001$ \\
SST anomaly & -0.090 & 0.032 & -2.728 & 0.006 \\
Reef Type (Lagoon) & -0.440 & 0.075 & -5.899 & 0.004 \\
SST anomaly) $\times$ Reef Type (Lagoon) & 0.043 & 2.203 & 2.209 & 0.027 \\
\hline
\end{tabular}

Parameter estimates are the results of an AIC-best fit mixed effects model examining the relationship between SST anomalies and the calcification rates for coral colonies from two reef types. The parameters are reported with the barrier reefs as a reference group, with the lagoon reef model estimates reported relative to those of the barrier reef. P-values are reported for the relationship between the estimates for the lagoon group and the barrier group: "SST anomaly" parameter is the relationship between barrier reef calcification rates and SST, "Reef Type (Lagoon)" estimates the difference in growth rates in the lagoon reef corals relative to barrier corals, and "SST anomaly $\times$ Reef Type (Lagoon)" estimates the difference in the change in lagoon reef coral calcification rates with SST relative to the relationship between barrier reef coral calcification rates and SST. 
Table A.5: Collection date, range of years included in skeletal chronology, and presence of 1998 and 2010 stress bands for 101 Porites corals from Palau. "+" indicates that a stress band was present in response to warming in 1998 or 2010, "-" indicates no stress band present during the specific year, and $n . d$. indicates that coral core record was not long enough to evaluate stress band presence in 1998. All coral cores included records from 2010.

\begin{tabular}{|c|c|c|c|c|c|c|}
\hline Reef Site & Reef & Coral ID & Date Collected & Date Range & 1998 Stress Band & 2010 Stress Band \\
\hline Ngerchelong & Barrier & 958 & Aug 2014 & $1993-2013$ & + & - \\
\hline Ngerchelong & Barrier & 959 & Aug 2014 & $1998-2013$ & + & + \\
\hline Ngerchelong & Barrier & 960 & Aug 2014 & $1991-2013$ & + & - \\
\hline Ngerchelong & Barrier & 961 & Aug 2014 & $1990-2013$ & - & - \\
\hline Ngerchelong & Barrier & 962 & Aug 2014 & $1995-2013$ & - & - \\
\hline Ngerchelong & Barrier & 963 & Aug 2014 & $1991-2013$ & - & - \\
\hline Ngerchelong & Barrier & 964 & Aug 2014 & $1995-2013$ & + & + \\
\hline Ngerdiluches & Barrier & 772 & Nov 2013 & $1992-2012$ & - & - \\
\hline Ngerdiluches & Barrier & 773 & Nov 2013 & $1991-2012$ & - & - \\
\hline Ngerdiluches & Barrier & 774 & Nov 2013 & $1991-2012$ & + & - \\
\hline Ngerdiluches & Barrier & 775 & Nov 2013 & $1990-2012$ & + & + \\
\hline Ngerdiluches & Barrier & 776 & Nov 2013 & $2003-2012$ & n.d. & + \\
\hline Ngerdiluches & Barrier & 777 & Nov 2013 & $2002-2012$ & n.d. & + \\
\hline Ngerdiluches & Barrier & 778 & Nov 2013 & $2005-2012$ & n.d. & - \\
\hline Ngerdiluches & Barrier & 779 & Nov 2013 & $2005-2012$ & n.d. & - \\
\hline Ngerdiluches & Barrier & 780 & Nov 2013 & $1990-2012$ & + & - \\
\hline Ngerdiluches & Barrier & 781 & Nov 2013 & $1997-2012$ & - & - \\
\hline Short Drop Off & Barrier & 210 & Sep 2011 & $2000-2010$ & n.d. & - \\
\hline Short Drop Off & Barrier & 214 & Sep 2011 & $1991-2010$ & + & - \\
\hline Short Drop Off & Barrier & 221 & Sep 2011 & $1990-2010$ & - & - \\
\hline Short Drop Off & Barrier & 229 & Sep 2011 & $1995-2010$ & - & - \\
\hline Short Drop Off & Barrier & 230 & Sep 2011 & $1992-2010$ & + & - \\
\hline Short Drop Off & Barrier & 231 & Sep 2011 & $1996-2010$ & + & + \\
\hline Short Drop Off & Barrier & 232 & Sep 2011 & $1999-2010$ & n.d. & + \\
\hline Short Drop Off & Barrier & 233 & Sep 2011 & $2001-2010$ & n.d. & - \\
\hline Short Drop Off & Barrier & 234 & Sep 2011 & $1999-2010$ & n.d. & - \\
\hline Short Drop Off & Barrier & 235 & Sep 2011 & $2001-2010$ & n.d. & - \\
\hline Short Drop Off & Barrier & 325 & Apr 2012 & $1996-2011$ & + & - \\
\hline Siaes & Barrier & 970 & Jan 2015 & $1994-2013$ & + & + \\
\hline Siaes & Barrier & 971 & Jan 2015 & $1998-2013$ & + & - \\
\hline Siaes & Barrier & 972 & Jan 2015 & $1990-2013$ & - & - \\
\hline Siaes & Barrier & 973 & Jan 2015 & $1990-2013$ & - & - \\
\hline Siaes & Barrier & 974 & Jan 2015 & $1992-2013$ & + & - \\
\hline Siaes & Barrier & 975 & Jan 2015 & $1995-2013$ & + & - \\
\hline Siaes & Barrier & 976 & Jan 2015 & $1998-2013$ & + & + \\
\hline Siaes & Barrier & 977 & Jan 2015 & $1997-2013$ & + & - \\
\hline Siaes & Barrier & 978 & Jan 2015 & $1995-2013$ & - & - \\
\hline Uchelbeluu & Barrier & 211 & Sep 2011 & $1995-2010$ & + & - \\
\hline Uchelbeluu & Barrier & 237 & Sep 2011 & $1990-2010$ & + & - \\
\hline Uchelbeluu & Barrier & 239 & Sep 2011 & $1990-2010$ & - & - \\
\hline Uchelbeluu & Barrier & 240 & Sep 2011 & $2004-2010$ & n.d. & + \\
\hline Uchelbeluu & Barrier & 243 & Sep 2011 & $2004-2010$ & n.d. & - \\
\hline Uchelbeluu & Barrier & 244 & Sep 2011 & $1990-2010$ & - & - \\
\hline Uchelbeluu & Barrier & I & Sep 2011 & $2005-2010$ & n.d. & + \\
\hline Uchelbeluu & Barrier & 279 & April 2012 & $1997-2011$ & + & - \\
\hline Mecherchar & Lagoon & 782 & Nov 2013 & $1991-2012$ & - & - \\
\hline Mecherchar & Lagoon & 783 & Nov 2013 & $1990-2012$ & - & + \\
\hline Mecherchar & Lagoon & 784 & Nov 2013 & $1990-2012$ & + & - \\
\hline
\end{tabular}




\begin{tabular}{|c|c|c|c|c|c|c|}
\hline Reef Site & Reef & Coral ID & Date Collected & Date Range & 1998 Stress Band & 2010 Stress Band \\
\hline Mecherchar & Lagoon & 785 & Nov 2013 & $1993-2012$ & - & - \\
\hline Mecherchar & Lagoon & 786 & Nov 2013 & $1990-2012$ & + & - \\
\hline Mecherchar & Lagoon & 787 & Nov 2013 & $1990-2012$ & + & - \\
\hline Mecherchar & Lagoon & 788 & Nov 2013 & $1997-2012$ & - & - \\
\hline Mecherchar & Lagoon & 789 & Nov 2013 & $1990-2012$ & + & + \\
\hline Mecherchar & Lagoon & 790 & Nov 2013 & $1990-2012$ & + & - \\
\hline Mecherchar & Lagoon & 791 & Nov 2013 & $1990-2012$ & - & - \\
\hline Nikko Bay & Lagoon & 178 & Apr 2011 & $1992-2010$ & - & + \\
\hline Nikko Bay & Lagoon & 166 & Sep 2011 & $1990-2010$ & + & - \\
\hline Nikko Bay & Lagoon & 167 & Sep 2011 & $1995-2010$ & - & + \\
\hline Nikko Bay & Lagoon & 168 & Sep 2011 & $1996-2010$ & + & - \\
\hline Nikko Bay & Lagoon & 169 & Sep 2011 & $1998-2010$ & - & - \\
\hline Nikko Bay & Lagoon & $\mathrm{O}$ & Sep 2011 & $1996-2010$ & - & - \\
\hline Nikko Bay & Lagoon & 266 & April 2012 & $1990-2011$ & - & - \\
\hline Nikko Bay & Lagoon & 267 & April 2012 & $1990-2011$ & - & - \\
\hline Nikko Bay & Lagoon & 268 & April 2012 & $1991-2011$ & - & + \\
\hline Nikko Bay & Lagoon & 269 & April 2012 & $1995-2011$ & - & - \\
\hline Nikko Bay & Lagoon & 270 & April 2012 & $1990-2011$ & - & - \\
\hline PICRC & Lagoon & 854 & Nov 2013 & $1993-2012$ & + & + \\
\hline PICRC & Lagoon & 855 & Nov 2013 & $1990-2012$ & + & - \\
\hline PICRC & Lagoon & 856 & Nov 2013 & $1990-2012$ & - & - \\
\hline PICRC & Lagoon & 857 & Nov 2013 & $1990-2012$ & - & - \\
\hline PICRC & Lagoon & 858 & Nov 2013 & $1997-2012$ & - & - \\
\hline PICRC & Lagoon & 859 & Nov 2013 & $1992-2012$ & - & - \\
\hline PICRC & Lagoon & 860 & Nov 2013 & $1994-2012$ & - & - \\
\hline PICRC & Lagoon & 861 & Nov 2013 & $1990-2012$ & + & - \\
\hline PICRC & Lagoon & 862 & Nov 2013 & $1990-2012$ & - & - \\
\hline PICRC & Lagoon & 863 & Nov 2013 & $1990-2012$ & - & - \\
\hline Risong & Lagoon & 213 & Sep 2011 & $1996-2010$ & - & - \\
\hline Risong & Lagoon & 216 & Sep 2011 & $2003-2010$ & n.d. & - \\
\hline Risong & Lagoon & 217 & Sep 2011 & $1990-2010$ & - & - \\
\hline Risong & Lagoon & 218 & Sep 2011 & $1990-2010$ & - & - \\
\hline Risong & Lagoon & 219 & Sep 2011 & $2001-2010$ & n.d. & - \\
\hline Risong & Lagoon & 220 & Sep 2011 & $1990-2010$ & - & - \\
\hline Risong & Lagoon & 222 & Sep 2011 & $1994-2010$ & - & - \\
\hline Risong & Lagoon & 223 & Sep 2011 & $2001-2010$ & n.d. & - \\
\hline Risong & Lagoon & 224 & Sep 2011 & $1998-2010$ & - & - \\
\hline Risong & Lagoon & 225 & Sep 2011 & $1990-2010$ & + & + \\
\hline Risong & Lagoon & 271 & April 2012 & $1990-2011$ & - & + \\
\hline Risong & Lagoon & 272 & April 2012 & $1997-2011$ & + & + \\
\hline Risong & Lagoon & 275 & April 2012 & $1990-2011$ & - & - \\
\hline Risong & Lagoon & 276 & April 2012 & $1990-2011$ & + & - \\
\hline Risong & Lagoon & 277 & April 2012 & $1990-2011$ & - & - \\
\hline Taoch & Lagoon & 812 & Nov 2013 & $1998-2012$ & - & - \\
\hline Taoch & Lagoon & 813 & Nov 2013 & $1990-2012$ & + & - \\
\hline Taoch & Lagoon & 814 & Nov 2013 & $1995-2012$ & + & - \\
\hline Taoch & Lagoon & 815 & Nov 2013 & $1990-2012$ & + & - \\
\hline Taoch & Lagoon & 816 & Nov 2013 & $1990-2012$ & - & - \\
\hline Taoch & Lagoon & 817 & Nov 2013 & $1990-2012$ & + & - \\
\hline Taoch & Lagoon & 818 & Nov 2013 & $1998-2012$ & - & + \\
\hline Taoch & Lagoon & 819 & Nov 2013 & $1990-2012$ & - & - \\
\hline Taoch & Lagoon & 820 & Nov 2013 & $1990-2012$ & - & + \\
\hline Taoch & Lagoon & 821 & Nov 2013 & $1996-2012$ & + & - \\
\hline
\end{tabular}




\section{Appendix B}

\section{Supplementary materials for chapter 3}

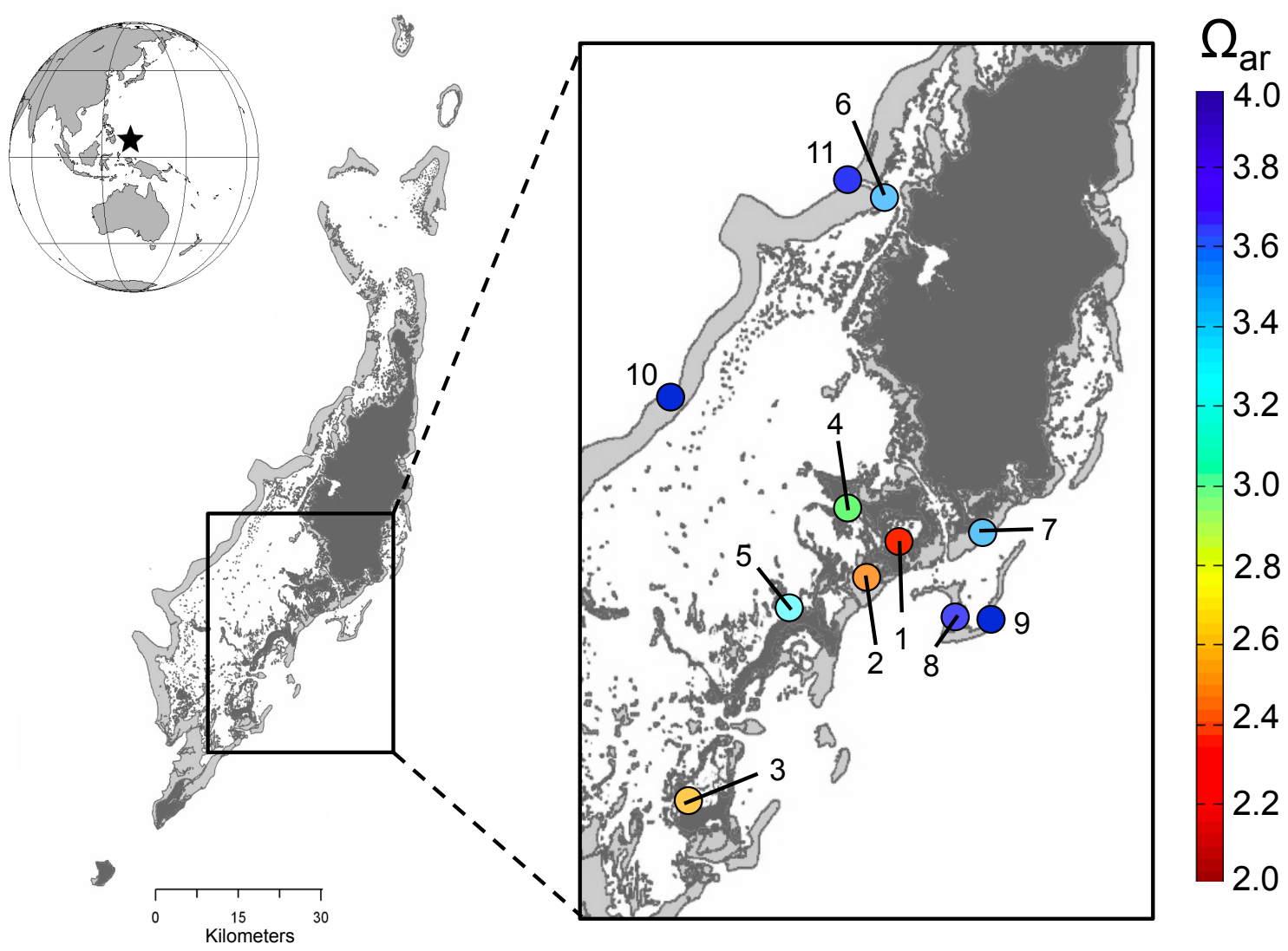

Figure B-1: Map of study sites in Palau. Inset of Palau shows the reef sites used in ecological $(1,2,5,6,7,9,10$, and 11) and skeletal analysis $(1,2,3,4,5,8,9$, and 10), with the color of the circles indicating the mean $\Omega_{a r}$ of each site. Cf. Tables B.1 and B.2. 
Table B.1: Environmental data for Palauan reef sites. Latitude and longitude coordinates, mean in situ temperature, salinity, and nutrient concentrations for each reef site \pm one standard error $(\mathrm{n}=195)$. Site numbers refer to Figure B-1.

\begin{tabular}{|c|c|c|c|c|c|c|c|c|}
\hline$\#$ & Site Name & $\begin{array}{l}\text { Lat } \\
\left({ }^{\circ} \mathrm{N}\right)\end{array}$ & $\begin{array}{l}\text { Lon } \\
\left({ }^{\circ} \mathrm{E}\right)\end{array}$ & $\begin{array}{l}\mathrm{SST} \\
\left({ }^{\circ} \mathrm{C}\right) \\
\end{array}$ & $\begin{array}{c}\text { Salinity } \\
(\mathrm{psu})\end{array}$ & $\begin{array}{c}{\left[\mathrm{NO}_{2 / 3}{ }^{-}\right]} \\
(\mu \mathrm{M})\end{array}$ & $\begin{array}{c}{\left[\mathrm{NH}_{4}^{+}\right]} \\
(\mu \mathrm{M})\end{array}$ & $\begin{array}{c}{\left[\mathrm{PO}_{4}{ }^{3-}\right]} \\
(\mu \mathrm{M})\end{array}$ \\
\hline \multirow[t]{2}{*}{1} & Nikko Bay & 7.324 & 134.492 & 30.3 & 32.4 & 0.37 & 0.46 & 0.05 \\
\hline & & & & \pm 0.1 & \pm 0.1 & \pm 0.08 & \pm 0.07 & \pm 0.00 \\
\hline \multirow[t]{2}{*}{2} & Risong & 7.304 & 134.477 & 30.0 & 33.2 & 0.21 & 0.10 & 0.05 \\
\hline & & & & \pm 0.1 & \pm 0.0 & \pm 0.05 & \pm 0.02 & \pm 0.00 \\
\hline \multirow[t]{2}{*}{3} & Mecherchar & 7.160 & 134.352 & 31.3 & 33.2 & 0.27 & 0.71 & 0.07 \\
\hline & & & & \pm 0.2 & \pm 0.1 & \pm 0.07 & \pm 0.12 & \pm 0.01 \\
\hline \multirow[t]{2}{*}{4} & PICRC & 7.338 & 134.454 & 30.5 & 33.5 & 0.51 & 0.52 & 0.09 \\
\hline & & & & \pm 0.2 & \pm 0.1 & \pm 0.03 & \pm 0.07 & \pm 0.00 \\
\hline \multirow[t]{2}{*}{5} & Taoch & 7.276 & 134.427 & 29.5 & 33.7 & 0.32 & 0.37 & 0.09 \\
\hline & & & & \pm 0.2 & \pm 0.1 & \pm 0.13 & \pm 0.15 & \pm 0.02 \\
\hline \multirow[t]{2}{*}{6} & Ngaremlengui Patch & 7.541 & 134.469 & 29.7 & 33.2 & 0.08 & 0.29 & 0.04 \\
\hline & & & & \pm 0.0 & \pm 0.1 & \pm 0.05 & \pm 0.15 & \pm 0.02 \\
\hline \multirow[t]{2}{*}{7} & Airai & 7.329 & 134.557 & 29.6 & 33.1 & 0.41 & 0.09 & 0.05 \\
\hline & & & & \pm 0.3 & \pm 0.3 & \pm 0.13 & \pm 0.03 & \pm 0.00 \\
\hline \multirow[t]{2}{*}{8} & Drop Off & 7.268 & 134.522 & 29.9 & 33.6 & 0.11 & 0.41 & 0.03 \\
\hline & & & & \pm 0.3 & \pm 0.1 & \pm 0.55 & \pm 0.12 & \pm 0.00 \\
\hline \multirow[t]{2}{*}{9} & Uchelbeluu & 7.271 & 134.549 & 29.7 & 33.5 & 0.32 & 0.29 & 0.04 \\
\hline & & & & \pm 0.1 & \pm 0.1 & \pm 0.08 & \pm 0.07 & \pm 0.01 \\
\hline \multirow[t]{2}{*}{10} & Ngerdiluches & 7.438 & 134.357 & 29.1 & 33.9 & 0.13 & 0.12 & 0.05 \\
\hline & & & & \pm 0.1 & \pm 0.00 & \pm 0.04 & \pm 0.05 & \pm 0.00 \\
\hline \multirow[t]{2}{*}{11} & Ngaremlengui Barrier & 7.544 & 134.444 & 29.6 & 33.4 & 0.03 & 0.30 & 0.03 \\
\hline & & & & \pm 0.1 & \pm 0.0 & \pm 0.00 & \pm 0.09 & \pm 0.00 \\
\hline
\end{tabular}


Table B.2: Mean seawater $\mathrm{CO}_{2}$ system data (total alkalinity (TA), total dissolved inorganic carbon (DIC), $p \mathrm{CO}_{2}$, carbonate ion concentration, $\mathrm{pH}$, and $\Omega_{a r}$ ) for each reef site \pm one standard error $(\mathrm{n}=195)$. Site numbers refer to Figure B-1.

\begin{tabular}{|c|c|c|c|c|c|c|c|}
\hline \# & Site Name & $\begin{array}{c}\mathrm{TA} \\
\left(\mu \mathrm{mol} \cdot \mathrm{kg}^{-1}\right)\end{array}$ & $\begin{array}{c}\text { DIC } \\
\left(\mu \mathrm{mol} \cdot \mathrm{kg}^{-1}\right)\end{array}$ & $\begin{array}{l}p \mathrm{CO} 2 \\
(\mu \mathrm{atm})\end{array}$ & $\begin{array}{c}{\left[\mathrm{CO}_{3}{ }^{2-}\right]} \\
\left(\mu \mathrm{mol} \cdot \mathrm{kg}^{-1}\right)\end{array}$ & $\begin{array}{c}\mathrm{pH} \\
\text { (total) } \\
\end{array}$ & $\Omega_{a r}$ \\
\hline \multirow[t]{2}{*}{1} & Nikko Bay & 1976.7 & 1782.7 & 604.2 & 139.8 & 7.84 & 2.32 \\
\hline & & \pm 4.3 & \pm 4.1 & \pm 0.2 & \pm 1.7 & \pm 0.00 & \pm 0.03 \\
\hline \multirow[t]{2}{*}{2} & Risong & 2063.8 & 1836.8 & 542.6 & 162.0 & 7.90 & 2.67 \\
\hline & & \pm 1.3 & \pm 1.7 & \pm 4.4 & \pm 1.0 & \pm 0.00 & \pm 0.02 \\
\hline \multirow[t]{2}{*}{3} & Mecherchar & 2082.9 & 1839.1 & 534.5 & 173.5 & 7.90 & 2.88 \\
\hline & & \pm 7.8 & \pm 6.3 & \pm 17.4 & \pm 4.2 & \pm 0.01 & \pm 0.07 \\
\hline \multirow[t]{2}{*}{4} & PICRC & 2131.6 & 1863.3 & 477.6 & 189.9 & 7.95 & 3.13 \\
\hline & & \pm 6.6 & \pm 2.9 & \pm 16.1 & \pm 4.8 & \pm 0.01 & \pm 0.08 \\
\hline \multirow[t]{2}{*}{5} & Taoch & 2163.1 & 1883.6 & 447.9 & 197.8 & 7.98 & 3.24 \\
\hline & & \pm 10.9 & \pm 9.4 & \pm 10.3 & \pm 3.5 & \pm 0.01 & \pm 0.06 \\
\hline \multirow[t]{2}{*}{6} & Ngaremlengui Patch & 2132.6 & 1835.3 & 395.5 & 208.5 & 8.02 & 3.43 \\
\hline & & \pm 8.1 & \pm 15.7 & \pm 19.2 & \pm 4.9 & \pm 0.02 & \pm 0.08 \\
\hline \multirow[t]{2}{*}{7} & Airai & 2107.0 & 1845.6 & 378.3 & 210.3 & 8.02 & 3.46 \\
\hline & & \pm 23.9 & \pm 24.2 & \pm 19.6 & \pm 8.9 & \pm 0.02 & \pm 0.15 \\
\hline \multirow[t]{2}{*}{8} & Drop Off & 2178.8 & 1862.7 & 384.4 & 221.9 & 8.04 & 3.65 \\
\hline & & \pm 9.9 & \pm 11.9 & \pm 8.6 & \pm 3.2 & \pm 0.00 & \pm 0.06 \\
\hline \multirow[t]{2}{*}{9} & Uchelbeluu & 2159.6 & 1841.0 & 373.6 & 223.0 & 8.05 & 3.66 \\
\hline & & \pm 7.7 & \pm 9.1 & \pm 13.4 & \pm 4.7 & \pm 0.01 & \pm 0.08 \\
\hline \multirow[t]{2}{*}{10} & Ngerdiluches & 2178.0 & 1882.8 & 372.8 & 225.5 & 8.05 & 3.68 \\
\hline & & \pm 15.7 & \pm 18.7 & \pm 8.3 & \pm 3.4 & \pm 0.01 & \pm 0.05 \\
\hline \multirow[t]{2}{*}{11} & Ngaremlengui Barrier & 2132.6 & 1835.3 & 369.6 & 224.6 & 8.05 & 3.69 \\
\hline & & \pm 8.1 & \pm 15.6 & \pm 8.4 & \pm 3.6 & \pm 0.01 & \pm 0.06 \\
\hline
\end{tabular}


Table B.3: Model estimates for benthic community cover and ecological indices. Generalized linear models were used to determine the relationship between $\Omega_{a r}$ and mean benthic cover data (percent coral, macroalgae, and crustose coralline algae (CCA) cover) and mean ecological indices (Shannon genera diversity, genera richness, and Shannon genera evenness) per site. Linear model estimates are reported, but all response variables were also fit to log-linear and polynomial models with no change in model significance.

\begin{tabular}{lrrrr}
\hline Parameter & Estimate & $\mathrm{SE}$ & t-value & $\mathrm{p}$-value \\
\hline Coral cover $(\%)$ & -18.992 & 9.852 & -1.928 & 0.102 \\
Macroalgae cover (\%) & 0.62 & 0.702 & 0.883 & 0.411 \\
CCA cover (\%) & 0.103 & 0.752 & 0.136 & 0.896 \\
Genera diversity & -0.156 & 0.364 & -0.428 & 0.683 \\
Genera richness & -3.244 & 1.418 & -2.288 & 0.062 \\
Genera evenness & 0.094 & 0.739 & 1.276 & 0.249 \\
\hline
\end{tabular}


Table B.4: Model estimates for changes in the abundance of dominant Palauan coral genera across the $\Omega_{a r}$ gradient. Changes in the abundance of the eight most abundant coral genera (total abundance $>50$ individuals) were fit to negative binomial (NB) or log-linear (LL) models based on Akaike Information Criterion.

\begin{tabular}{lcrrrrr}
\hline Genus & Abundance Rank & Model & Estimate & SE & Z or t & p-value \\
\hline Porites (all) & 1 & LL & -2.141 & 0.847 & -2.559 & 0.043 \\
Porites (massive) & 1 & LL & -2.993 & 0.67 & -4.463 & 0.004 \\
Porites (branching) & 1 & LL & -0.774 & 1.099 & -0.704 & 0.508 \\
Acropora & 2 & NB & 3.658 & 0.873 & 4.188 & $<0.001$ \\
Montipora & 3 & NB & 1.683 & 0.767 & 2.194 & 0.028 \\
Favites & 4 & NB & -0.516 & 0.862 & -0.599 & 0.549 \\
Pachyseris & 5 & NB & -4.988 & 1.22 & -0.488 & $<0.001$ \\
Pocillopora & 6 & NB & 3.105 & 1.104 & 2.812 & 0.005 \\
Favia & 7 & LL & -1.019 & 0.66 & -1.542 & 0.174 \\
Anacropora & 8 & NB & -2.72 & 1.513 & -1.798 & 0.072 \\
\hline
\end{tabular}


Table B.5: Model fits for coral skeletal growth parameters. The relationship between $\Omega_{a r}$ and Porites and Favia annual rates of extension, density, and calcification rates were fit to generalized linear models (GLMs). Porites boring data were fit to two separate models: logistic regression was used to evaluate presence/absence of boring across $\Omega_{a r}$, and a loglinear GLM was fit to nonzero site mean boring percentages.

\begin{tabular}{lrrrr}
\hline Parameter & Estimate & $\mathrm{SE}$ & t-value & p-value \\
\hline Favia extension & -0.022 & 0.018 & -1.242 & 0.34 \\
Favia density & 0.091 & 0.029 & 3.187 & 0.086 \\
Favia calcification & 0.031 & 0.016 & 1.956 & 0.19 \\
Porites extension & 0.005 & 0.071 & 0.076 & 0.942 \\
Porites density & 0.186 & 0.102 & 1.82 & 0.119 \\
Porites calcification & 0.174 & 0.079 & 2.22 & 0.068 \\
Porites boring presence/absence & -2.228 & 0.477 & -4.663 & $<0.001$ \\
Porites boring percentage & -2.213 & 0.765 & -2.891 & 0.034 \\
\hline
\end{tabular}


Table B.6: List of reef sites where coral genera were observed and the total number of individuals counted across all sites. Numbers for sites refer to Figure B-1 and genera abbreviations refer to Figure 3-3.

\begin{tabular}{|c|c|c|c|}
\hline Genus & Genus Code & Reef Sites Observed & Total Individuals \\
\hline Acanthastrea & Aca & 10 & 2 \\
\hline Acropora & Acr & $1,5,6,7,9,10,11$ & 651 \\
\hline Anacropora & Ana & $1,2,6$ & 58 \\
\hline Astreopora & Ast & 2,10 & 5 \\
\hline Ctenactis & Cte & $2,5,6$ & 9 \\
\hline Cyphastrea & Cyp & $1,7,9,10$ & 7 \\
\hline Diploastrea & Dip & 2 & 2 \\
\hline Echinophyllia & Epy & $1,2,9$ & 24 \\
\hline Echinopora & Epo & $1,2,7,10,11$ & 8 \\
\hline Favia & Fav & $1,2,5,6,7,9,10,11$ & 59 \\
\hline Favites & Fvt & $1,2,5,7,9,10,11$ & 146 \\
\hline Fungia & Fun & $1,2,5,6,9,10$ & 36 \\
\hline Galaxea & Gal & $1,6,7,9,10,11$ & 17 \\
\hline Goniastrea & Goa & $1,2,7,9,10,11$ & 36 \\
\hline Goniopora & Gop & $2,5,6$ & 6 \\
\hline Heliopora & Hel & 11 & 1 \\
\hline Herpolitha & Her & 6 & 1 \\
\hline Hydnophora & Hyd & $7,9,10,11$ & 10 \\
\hline Leptastrea & Lep & 2 & 9 \\
\hline Leptoria & Let & 9,11 & 14 \\
\hline Leptoseris & Leo & 2 & 2 \\
\hline Lobophyllia & Lob & 1,2 & 22 \\
\hline Merulina & Mer & 1,2 & 22 \\
\hline Millepora & Mil & $6,7,9,10,11$ & 23 \\
\hline Montastrea & Moa & $5,7,9$ & 4 \\
\hline Montipora & Mon & $1,2,6,7,9,10,11$ & 280 \\
\hline Mycedium & Myc & 1 & 24 \\
\hline Pachyseris & $\mathrm{Pac}$ & $1,2,5$ & 76 \\
\hline Pavona & Pav & $2,5,6,7$ & 24 \\
\hline Pectinia & Pec & $1,2,5,6,11$ & 19 \\
\hline Physogyra & Phy & 1 & 1 \\
\hline Platygyra & Pla & 2,7 & 11 \\
\hline Plesiastrea & Ple & 11 & 8 \\
\hline Plerogyra & $\mathrm{Plg}$ & 1 & 13 \\
\hline Pocillopora & Poc & $1,6,7,9,10,11$ & 70 \\
\hline Porites & Por & $1,2,5,6,7,9,10,11$ & 1293 \\
\hline Psammocora & Psa & $2,5,7$ & 3 \\
\hline Seriatopora & Ser & 6 & 11 \\
\hline Stylophora & Sty & $7,9,11$ & 5 \\
\hline Symphyllia & Sym & $1,5,9,10$ & 33 \\
\hline Turbinaria & Tur & 2 & 10 \\
\hline
\end{tabular}




\section{B.1 Calculations for changes in $\Omega_{a r}$ over time in Palau}

The $\Omega_{a r}$ at site 10 in 2000 was calculated from average total alkalinity (TA), dissolved inorganic carbon (DIC), temperature, and salinity data collected offshore of the barrier reef in September and April 2000 by Watanabe et al. (2006). There were not enough data from 1994 to calculate $\Omega_{a r}$ at site 10 directly. Kayanne et al. (2005) present partial pressure of $\mathrm{CO}_{2}\left(p \mathrm{CO}_{2}\right)$ data for 1994, but not a second carbonate parameter. Therefore, the rate of

change in $\Omega_{a r}$ just offshore of the barrier reef at site 10 from 2000 to today, using both the average offshore $\Omega_{a r}$ from our 2012 and 2013 data, was used to backcast $1994 \Omega_{a r}$. Using the 2000-2012 rate of change gives an estimate for $1994 \Omega_{a r}$ of 3.91 and the 2000-2013 rate of change gives a $1994 \Omega_{a r}$ of 3.83 . The average of these two estimates for $1994 \Omega_{a r}$ is $3.87 \pm$ 0.06 (standard deviation). In addition, $1994 \Omega_{a r}$ was estimated using average $2000 \mathrm{TA}$ and salinity data from Watanabe et al. (2006), average 1994 temperature data from Kayanne et al. (2005), and DIC was adjusted until calculated $p \mathrm{CO}_{2}$ matched the average 1994 pCO2 reported in Kayanne et al. (2005) (348 $\mu \mathrm{atm})$. This method estimates a $1994 \Omega_{a r}$ of 3.82, which is within error of the backcasting estimate. 


\section{Appendix C}

\section{Supplementary materials for chapter 4}

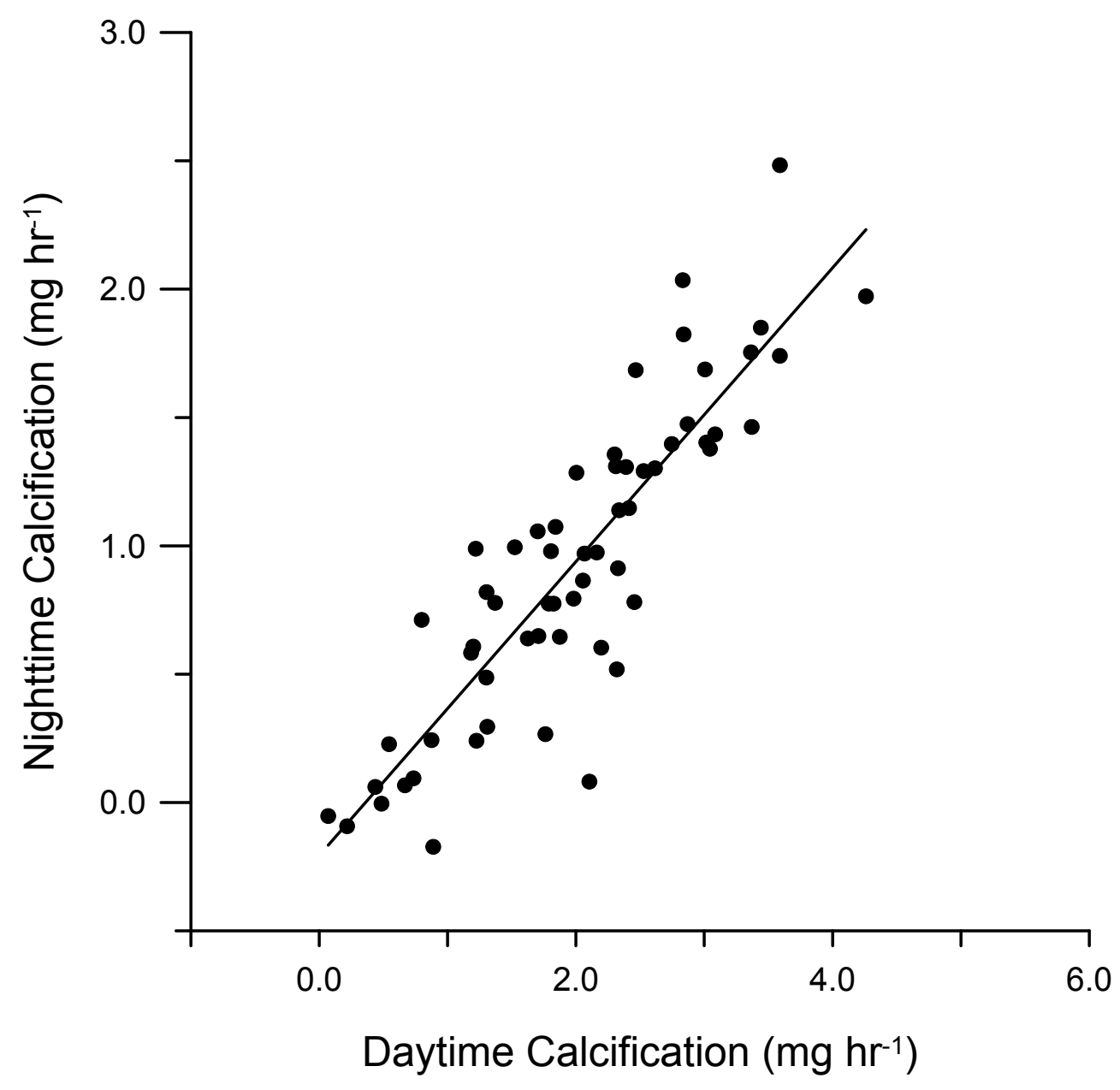

Figure C-1: Daytime vs. nighttime alkalinity anomaly calcification rates. Each point represents the calculated day vs. night calcification rate of an individual coral colony $(\mathrm{n}=$ 60 ), drawn with a line of best fit. The relationship between day:night calcification rates was approximately $2: 1(\mathrm{r}=0.88, \mathrm{p}<0.001)$. 


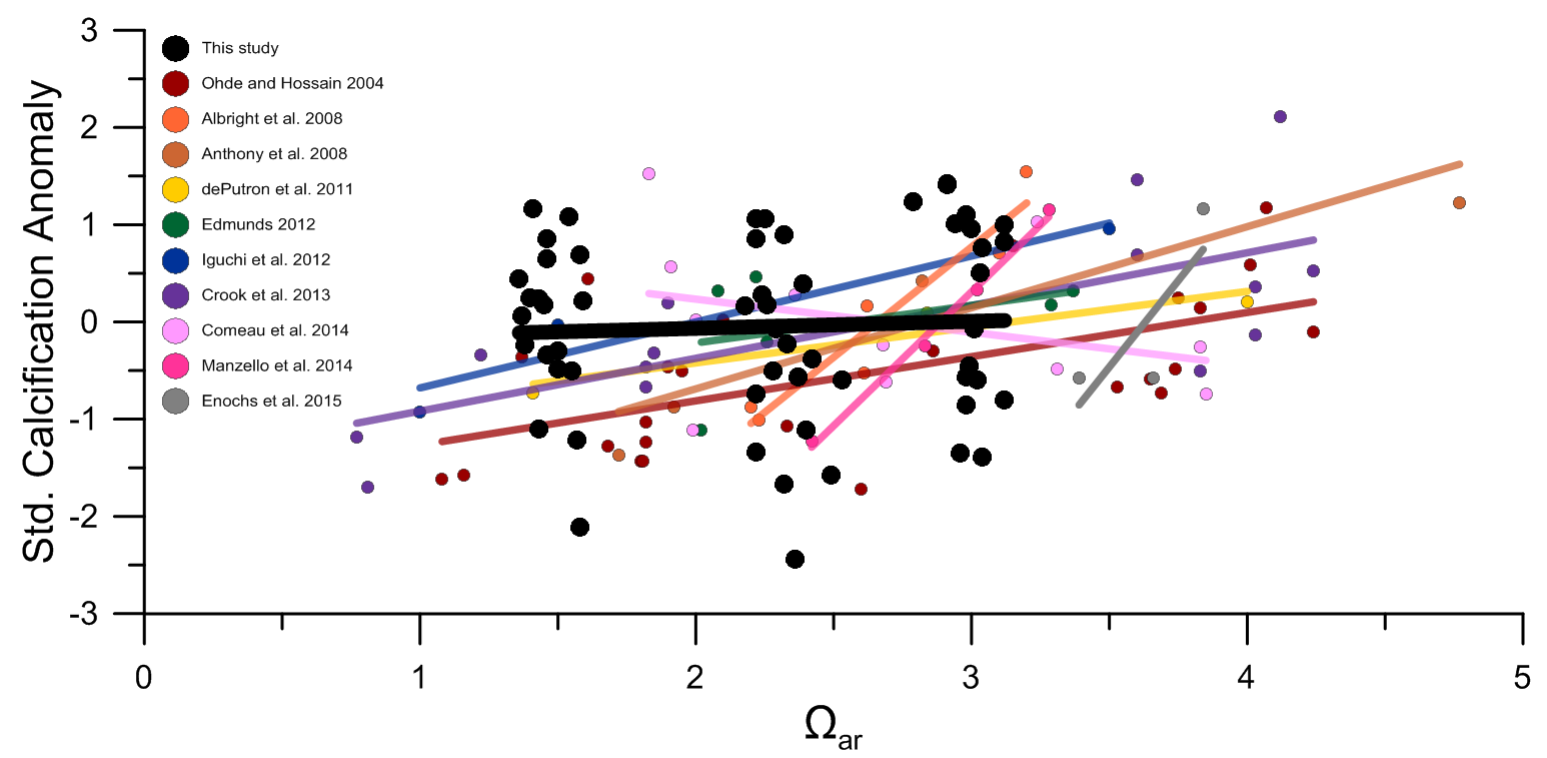

Figure C-2: Porites calcification sensitivity to acidification across field observations and laboratory experiments. Porites coral calcification responses to declining $\Omega_{a r}$ in a $\mathrm{CO}_{2}$ manipulation experiment in Palau (this study; black) versus the calcification responses observed in ten other studies of massive Porites corals (colored). All data are plotted as standardized calcification anomalies, which were calculated for each study by subtracting the measured calcification rate of each coral from the overall calcification mean and dividing by the standard deviation. Lines represent the linear line of best fit for each data set. 


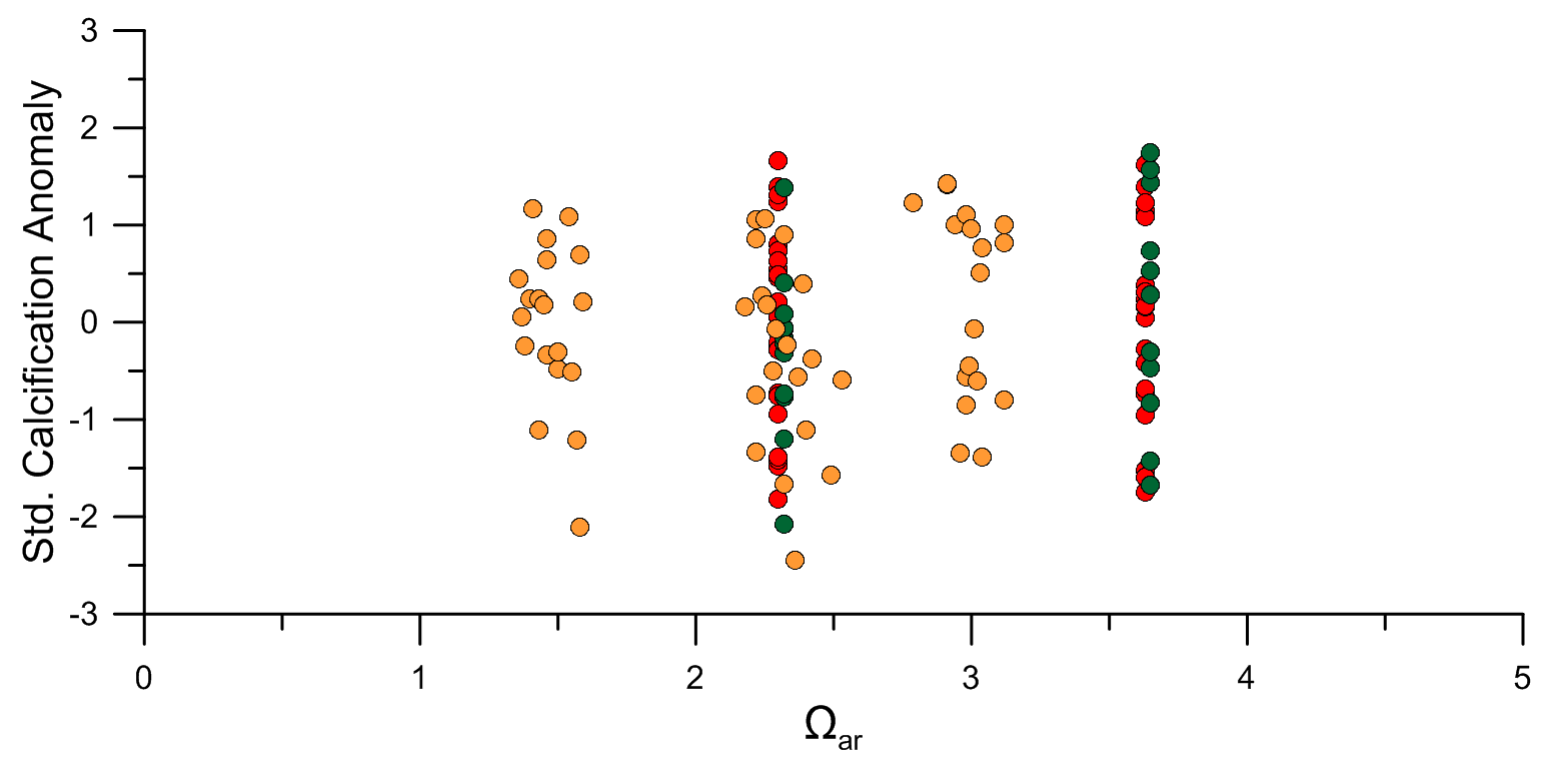

Figure C-3: Palau Porites calcification responses to $\Omega_{a r}$ in the $\mathrm{CO}_{2}$ manipulation experiment (yellow) and reciprocal transplant (in corals returned to their original reef; red), plotted with calcification rates measured in Porites coral skeletal cores (green) from the two reefs included in this study (Barkley et al., 2015). Calcification data are plotted as standardized calcification anomalies, which were calculated for each data set by subtracting the measured calcification rate of each coral from the overall calcification mean and dividing by the standard deviation. 
Table C.1: Generalized linear model results for coral calcification rates in a laboratory $\mathrm{CO}_{2}$ manipulation experiment. Porites corals were collected from two reefs at naturally distinct $\Omega_{a r}\left(\Omega_{a r}=3.7\right.$ and $\Omega_{a r}=2.3$, "Reef" $)$ and incubated at three $\Omega_{a r}$ levels $\left(\Omega_{a r}=1.5,2.3,3.0\right.$, " $\Omega_{a r}$ ") for 8 weeks $(\mathrm{n}=10$ per treatment group). Calcification rates were measured using both buoyant weight (overall weight change over 8 weeks) and mean day/night alkalinity anomaly measurements (end of experiment).

\begin{tabular}{lrrrr}
\hline Variable & Estimate & SE & t-statistic & p-value \\
\hline Buoyant Weight & & & & \\
Intercept & 0.911 & 3.091 & 0.295 & 0.769 \\
$\Omega_{a r}$ & 1.786 & 1.327 & 1.346 & 0.184 \\
Reef & -0.830 & 4.276 & -0.194 & 0.847 \\
$\Omega_{a r} \times$ Reef & -0.665 & 1.821 & -0.365 & 0.716 \\
\hline Alkalinity Anomaly & & & & \\
Intercept & 0.035 & 0.015 & 2.288 & 0.026 \\
$\Omega_{a r}$ & 0.010 & 0.007 & 1.449 & 0.153 \\
Reef & -0.020 & 0.021 & -0.935 & 0.354 \\
$\Omega_{a r} \times$ Reef & 0.004 & 0.009 & 0.495 & 0.622 \\
\hline
\end{tabular}


Table C.2: Linear mixed effects model results for weekly coral calcification rates. Porites corals were collected from two reefs at naturally different $\Omega_{a r}\left(\Omega_{a r}=3.7\right.$ and $\Omega_{a r}=2.3$, "Reef") and incubated at three $\Omega_{a r}$ levels $\left(\Omega_{a r}=1.5,2.3,3.0, " \Omega_{a r}\right.$ ") for 8 weeks $(\mathrm{n}=10$ per treatment group). Surface area normalized growth rates measured each week by buoyant weighing were fit to linear mixed effects models. Parameter estimates are reported for an AIC-best fit model in which week, $\Omega_{a r}$, reef or origin, and the interaction of $\Omega_{a r}$ and reef of origin were included as fixed effects and individual coral colonies were considered as random effects to account for repeated measurements on the same coral through time.

\begin{tabular}{lrrrr}
\hline Model Parameter & Estimate & $\mathrm{SE}$ & t-statistic & p-value \\
\hline Intercept & -4.689 & 3.088 & -1.518 & 0.130 \\
Week & 1.555 & 0.182 & 8.568 & $<0.001$ \\
$\Omega_{a r}$ & 1.017 & 1.220 & 0.834 & 0.405 \\
Reef & -2.662 & 3.970 & -0.923 & 0.360 \\
$\Omega_{a r} \times$ Reef & 0.762 & 1.662 & 0.458 & 0.647 \\
\hline
\end{tabular}


Table C.3: Two-way ANOVA results for reciprocal transplant experiment. Porites corals were collected from a naturally high- $\Omega_{a r}$ reef $\left(\Omega_{a r}=3.7\right)$ and a naturally low- $\Omega_{a r}\left(\Omega_{a r}=\right.$ 2.3) reef ("Original Reef") and either returned to their original reef or transplanted to the opposite reef ("Transplant Reef"). Two-way ANOVAs were conducted on calcification rates of corals sampled after 2 months and after 17 months $(n=10-12$ per treatment group).

\begin{tabular}{lcrrrr}
\hline Variable & df & SS & MS & F-value & p-value \\
\hline 2 month transplant & & & & & \\
Original Reef & 1 & 91.35 & 91.35 & 0.539 & 0.467 \\
Transplant Reef & 1 & 2710.22 & 2710.22 & 15.989 & $<0.001$ \\
Interaction & 1 & 2181.39 & 2181.39 & 12.869 & $<0.001$ \\
Residuals & 40 & 6780.22 & 169.51 & & \\
\hline 17 month transplant & & & & & \\
Original Reef & 1 & 127.93 & 127.93 & 0.827 & 0.369 \\
Transplant Reef & 1 & 10.57 & 10.57 & 0.068 & 0.795 \\
Interaction & 1 & 5988.56 & 5988.56 & 38.713 & $<0.001$ \\
Residuals & 39 & 6032.97 & 154.69 & & \\
\hline
\end{tabular}




\section{Appendix D}

\section{Supplementary materials for chapter 5}

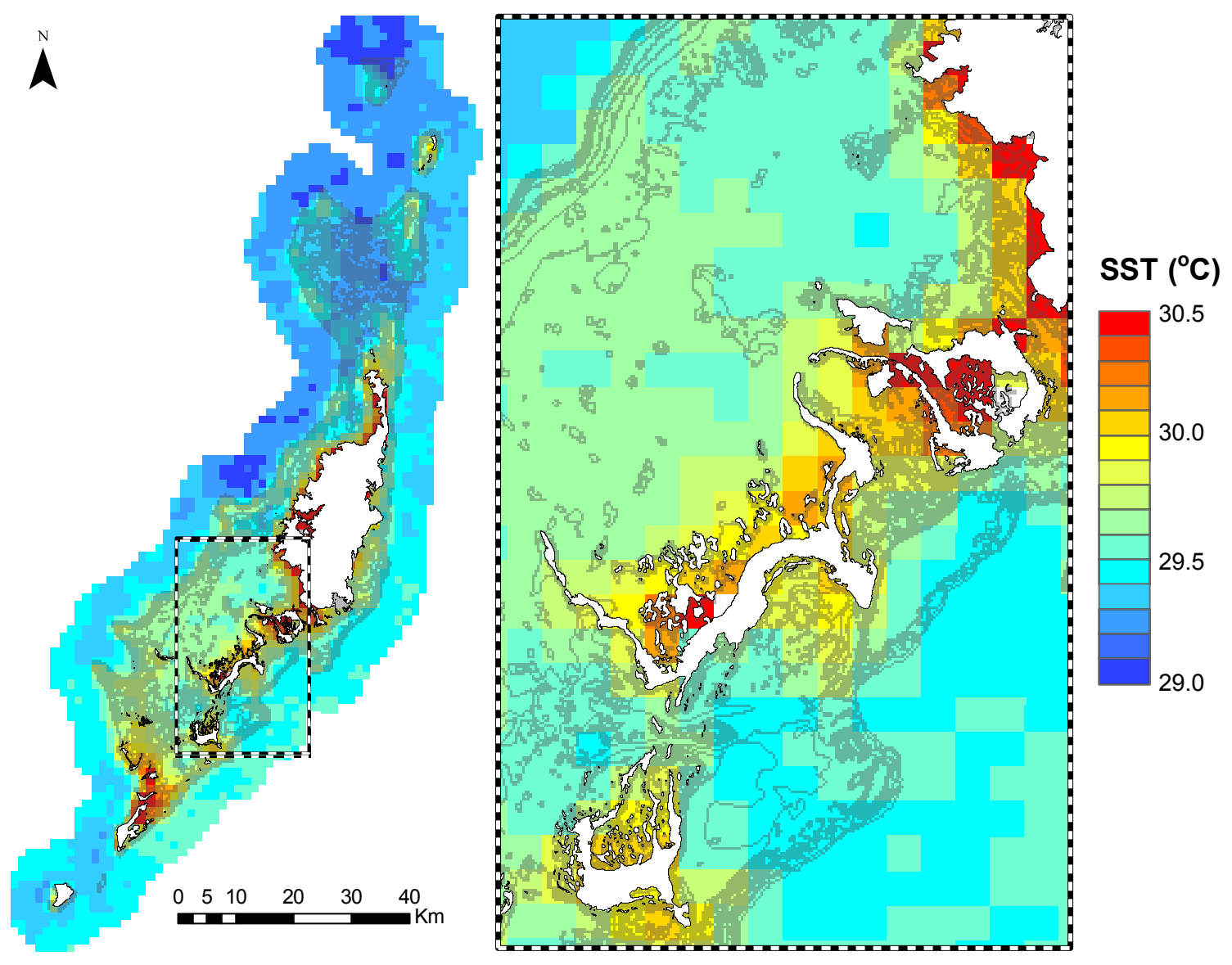

Figure D-1: Satellite sea surface temperature (SST) climatology for the Palau archipelago (2003-2011) accessed from the MODIS Aqua satellite at $1.5 \mathrm{~km}$ resolution. 

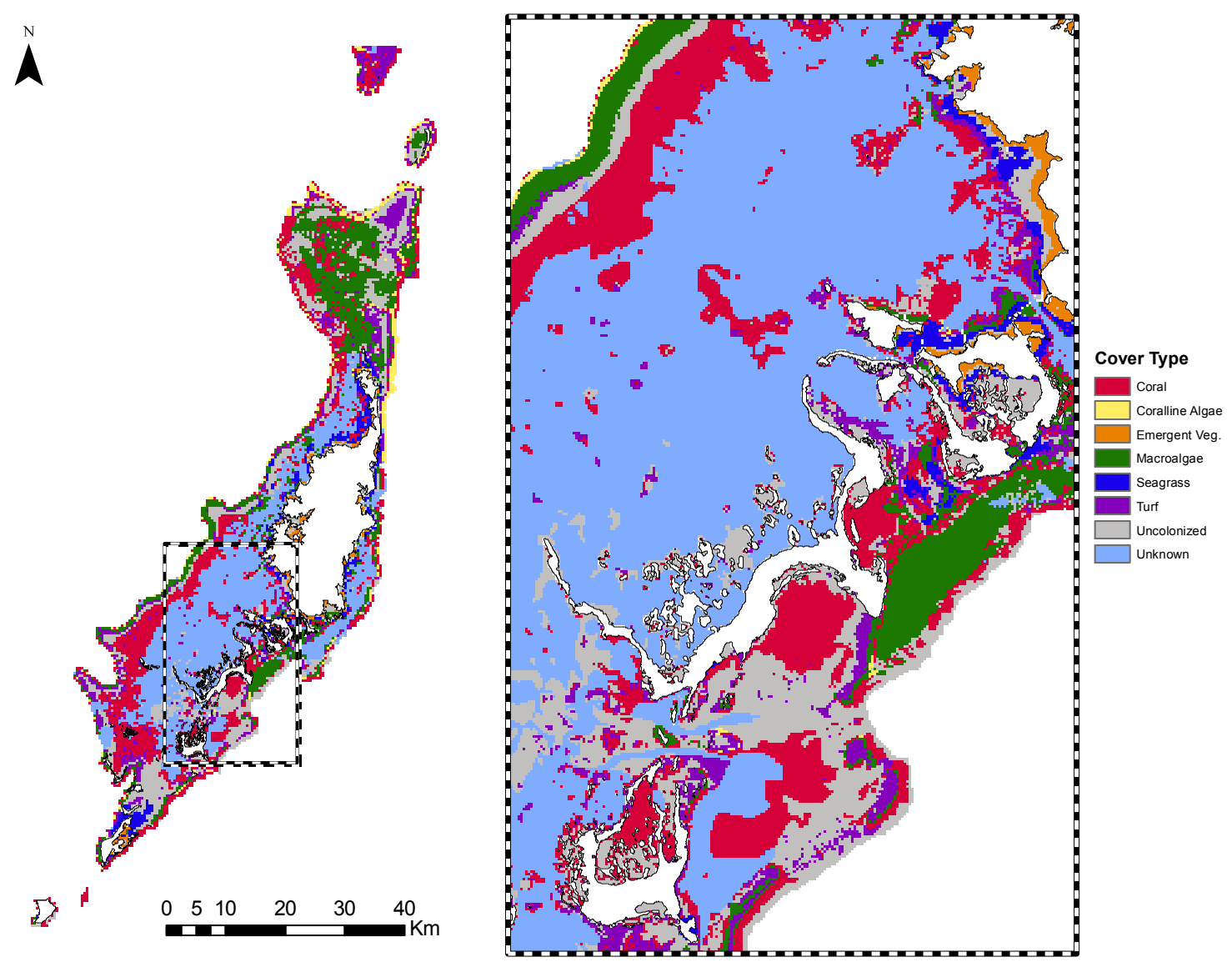

Figure D-2: Benthic cover types for the Palau archipelago. Cover types are classified by the dominant type of living organism found on the benthos: "coral" is defined as any reef location with $>15 \%$ coral cover or where hard coral is the dominant cover type, while classification as "coralline algae", "emergent vegetation", "macroalgae", "seagrass", and "turf algae" are designated if cover is either $>50 \%$ or dominant. White areas represent land, and inset shows Rock Islands. Data were accessed from NOAA's National Centers for Coastal Ocean Science (http://products.coastalscience.noaa.gov). 

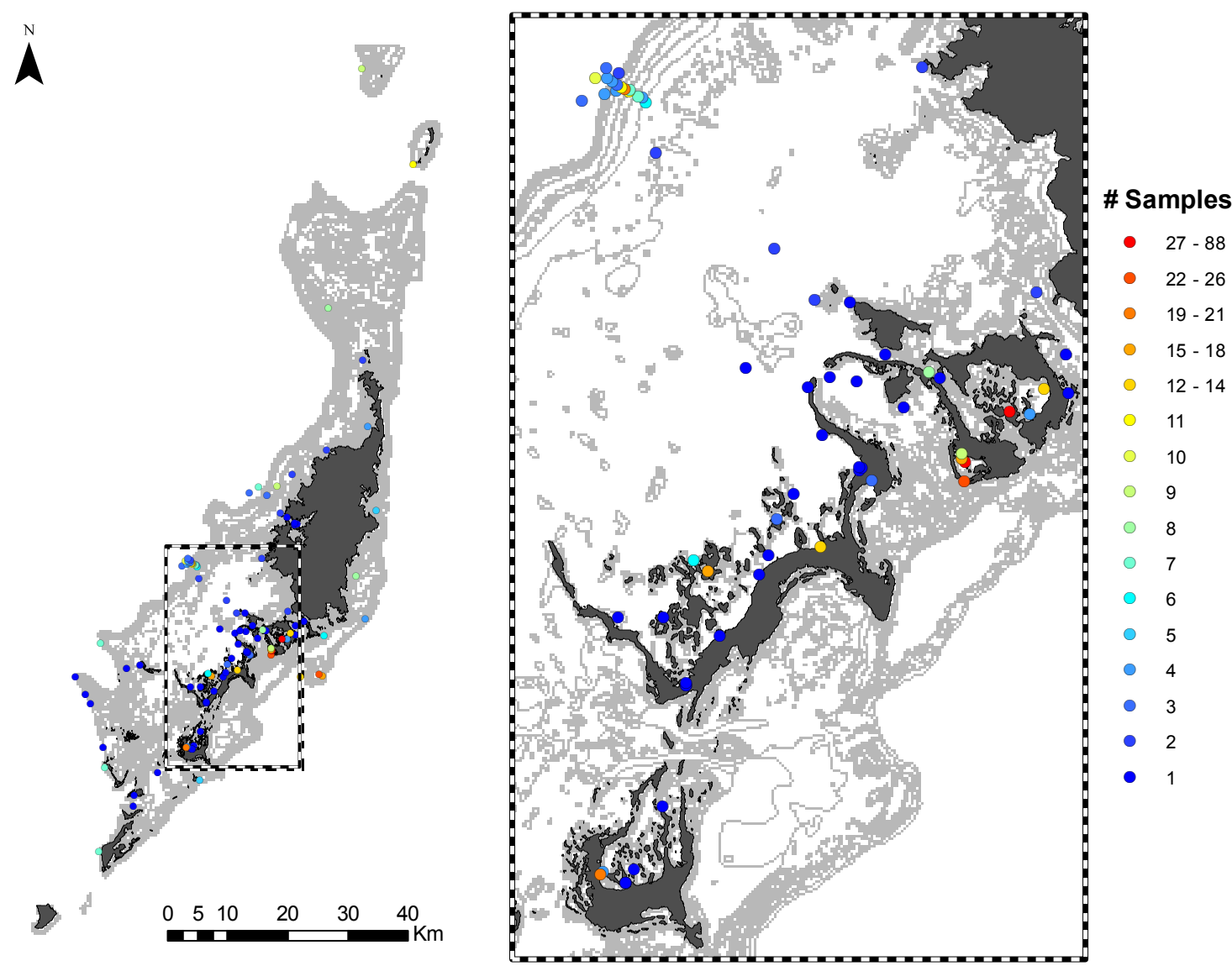

Figure D-3: Location and number of water samples collected across Palau from 2011-2015 and used for seawater chemistry mapping. Water samples for salinity, total alkalinity (TA), and dissolved inorganic carbon (DIC) were collected between dawn and dusk on $19-24$ September 2011, 28 March - 7 April 2012, 7 - 9 December 2012, 1 - 15 November 2013, 9 24 August 2014, and 22 January - 7 February 2015. 

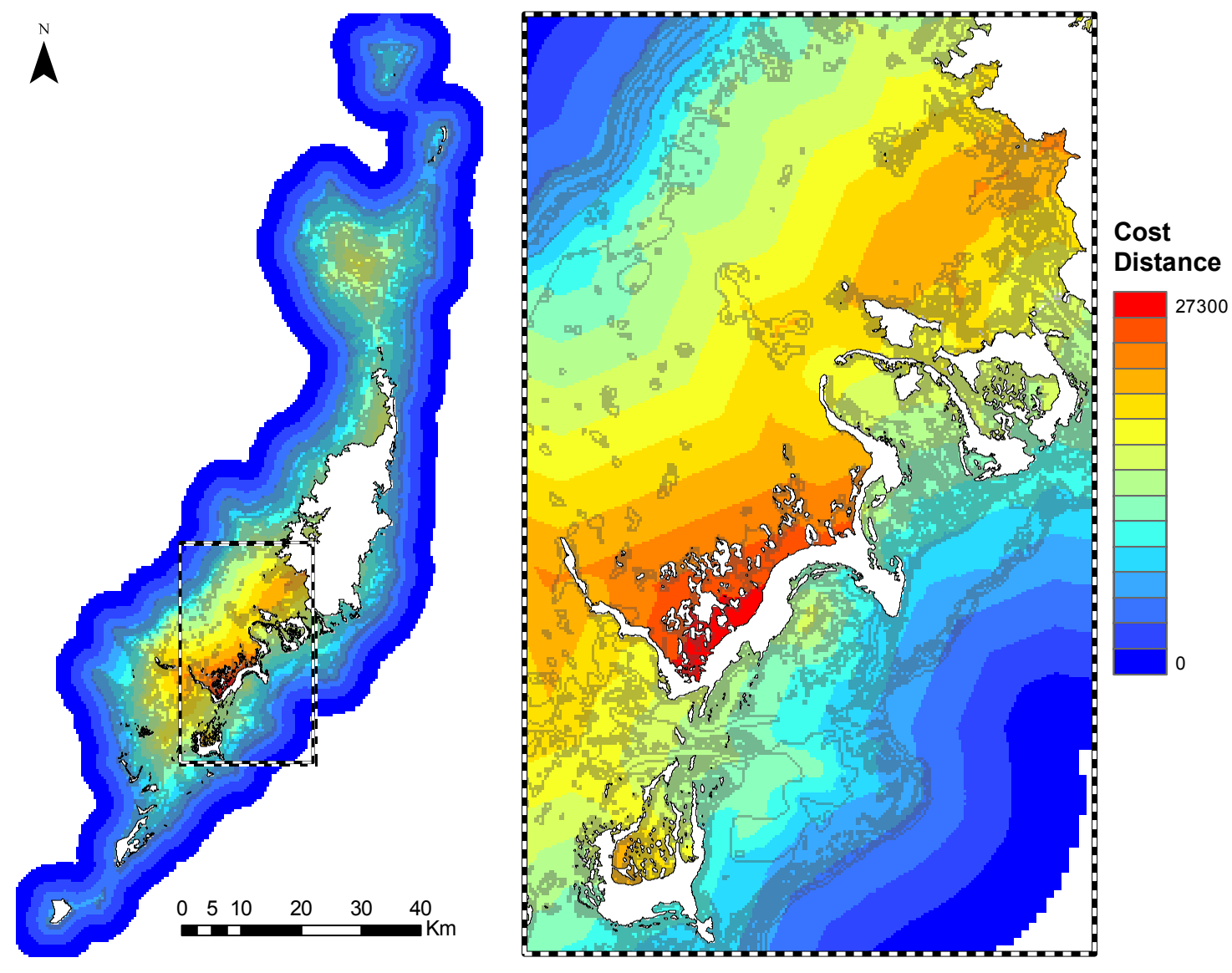

Figure D-4: Cost distance calculation for seawater chemistry interpolation. Accumulated cost distance was calculated to each grid cell from a source $5 \mathrm{~km}$ offshore of the barrier reef. Cells with coral as the predominant cover type were assigned a cost of 3 , while all other cells were assigned a cost of 1 (C.f. Figure D-2). High cost distance scores indicate that water moving to that grid cell from offshore traveled either a long distance, traveled over areas with coral, or a combination of both. White areas represent land and gray contouring indicates submerged reef. Inset shows Rock Islands. 

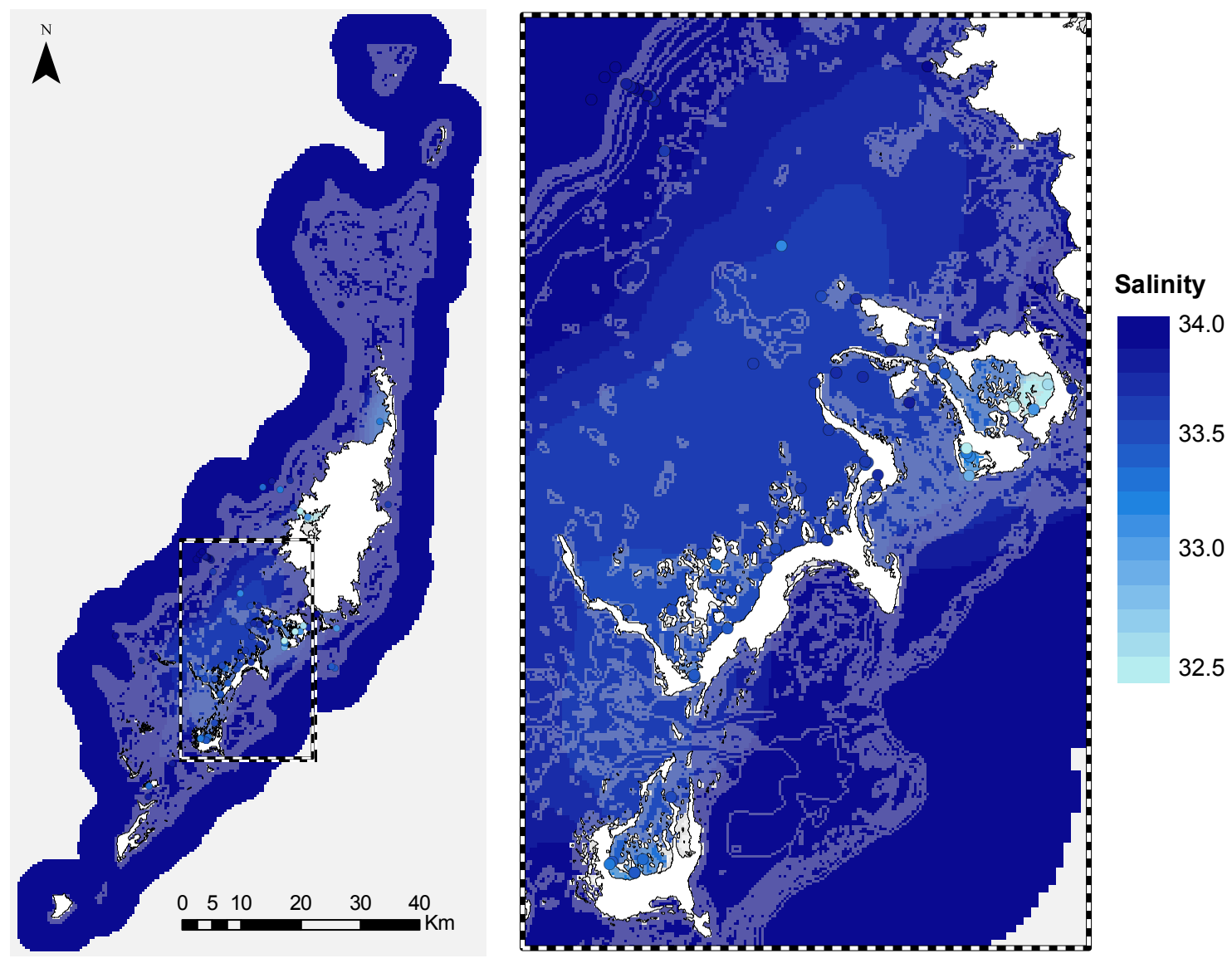

Figure D-5: Salinity data for the Palau archipelago. Points show the location and value of discrete water samples, with mean values shown for sites where multiple samples were collected. Shading contours were estimated between sample points using diffusion interpolation with land barriers over a cost surface derived from coral cover and distance from offshore (Figure D-4). Offshore values for salinity were set to 33.9. White regions represent land, and shaded gray contours are submerged reef. Inset highlights the Rock Islands. 

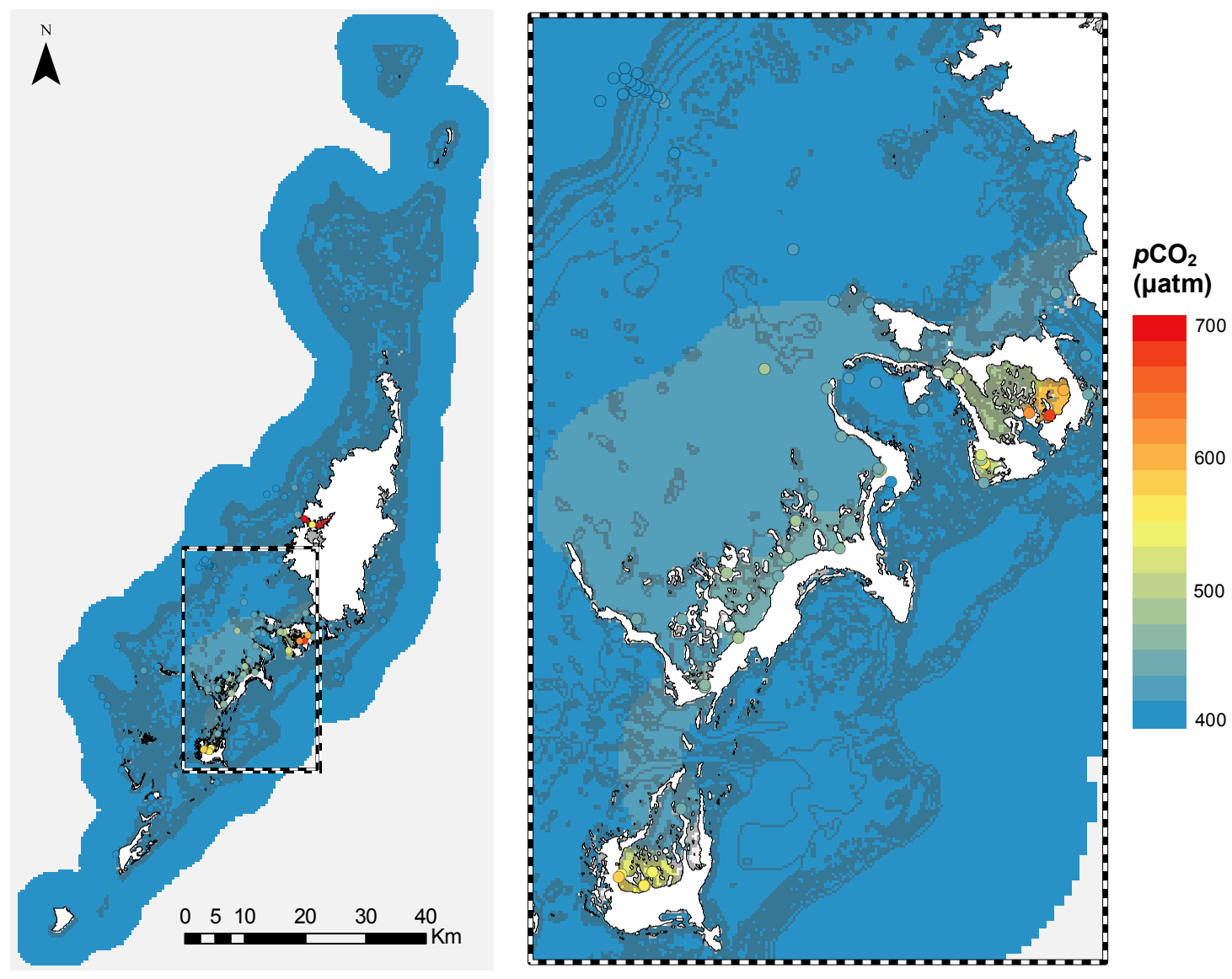

Figure D-6: $p \mathrm{CO}_{2}$ data for the Palau archipelago. Points show the location and value of discrete water samples, with mean values shown for sites where multiple samples were collected. Shading contours were estimated between sample points using diffusion interpolation with land barriers over a cost surface derived from coral cover and distance from offshore (Figure D-4). Offshore ocean values for $p \mathrm{CO}_{2}$ were set at $400 \mu \mathrm{atm}$. White regions represent land, and shaded gray contours are submerged reef. Inset highlights the Rock Islands. 

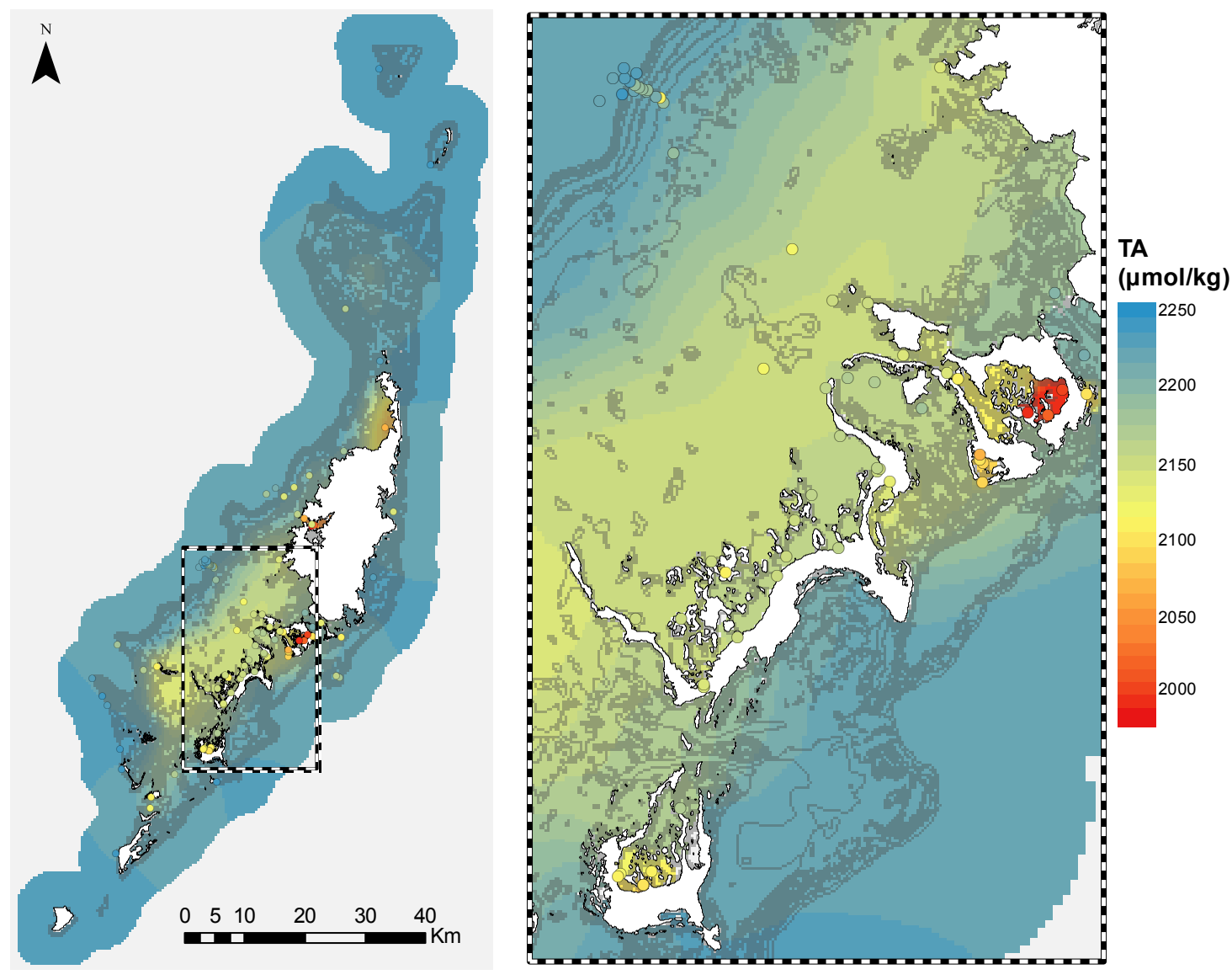

Figure D-7: Total alkalinity (TA) for the Palau archipelago. Points show the location and value of discrete water samples, with mean values shown for sites where multiple samples were collected. Shading contours were estimated between sample points using diffusion interpolation with land barriers over a cost surface derived from coral cover and distance from offshore (Figure D-4). Offshore ocean values for TA were set at $2220 \mu \mathrm{mol} \cdot \mathrm{kg}^{-1}$. White regions represent land, and shaded gray contours are submerged reef. Inset highlights the Rock Islands. 

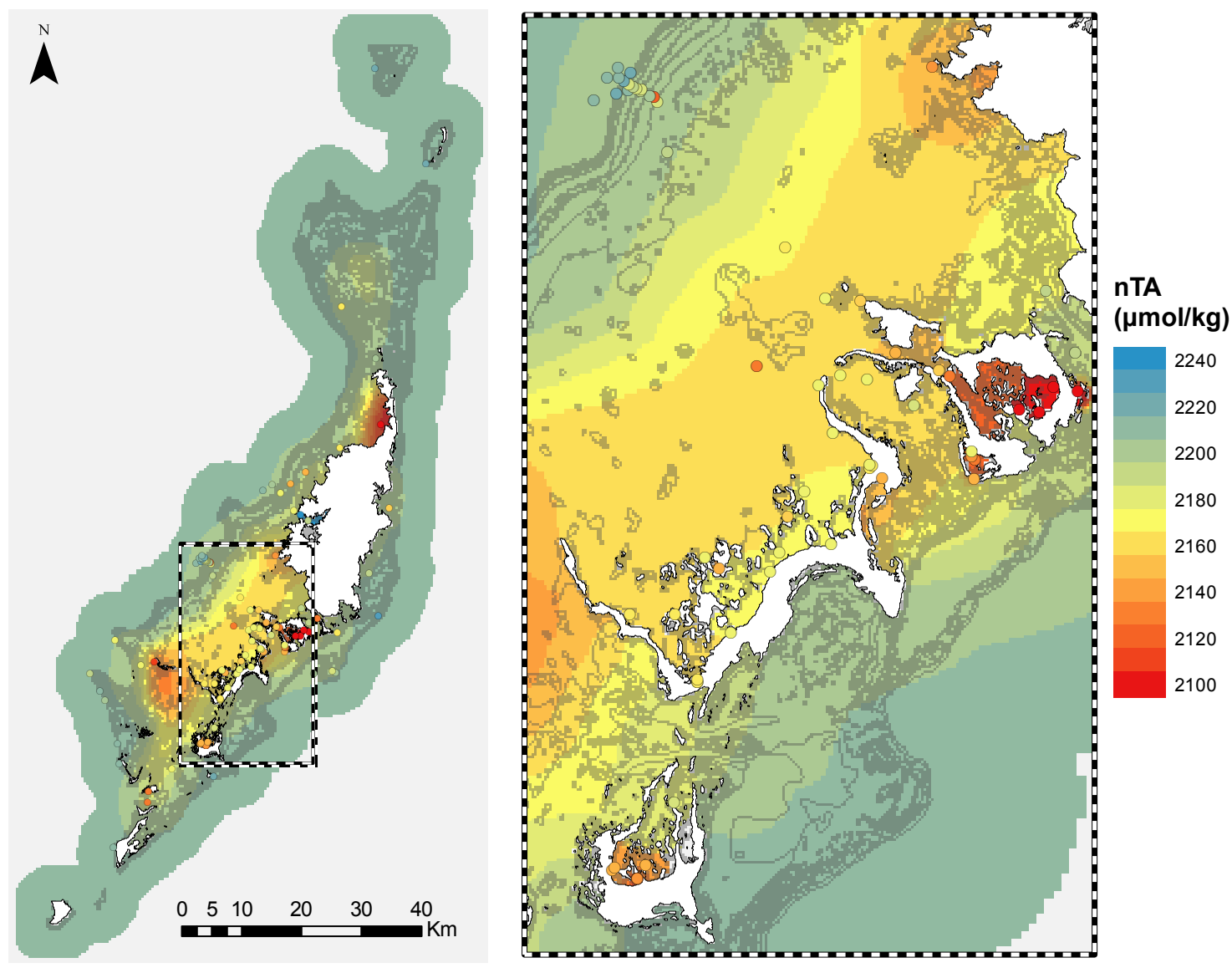

Figure D-8: Salinity-normalized TA (nTA) for the Palau archipelago. Points show the location and value of discrete water samples, with mean values shown for sites where multiple samples were collected. Shading contours were estimated between sample points using diffusion interpolation with land barriers over a cost surface derived from coral cover and distance from offshore (Figure D-4). TA values were normalized to an open ocean salinity of 33.9. White regions represent land, and shaded gray contours are submerged reef. Inset highlights the Rock Islands. 

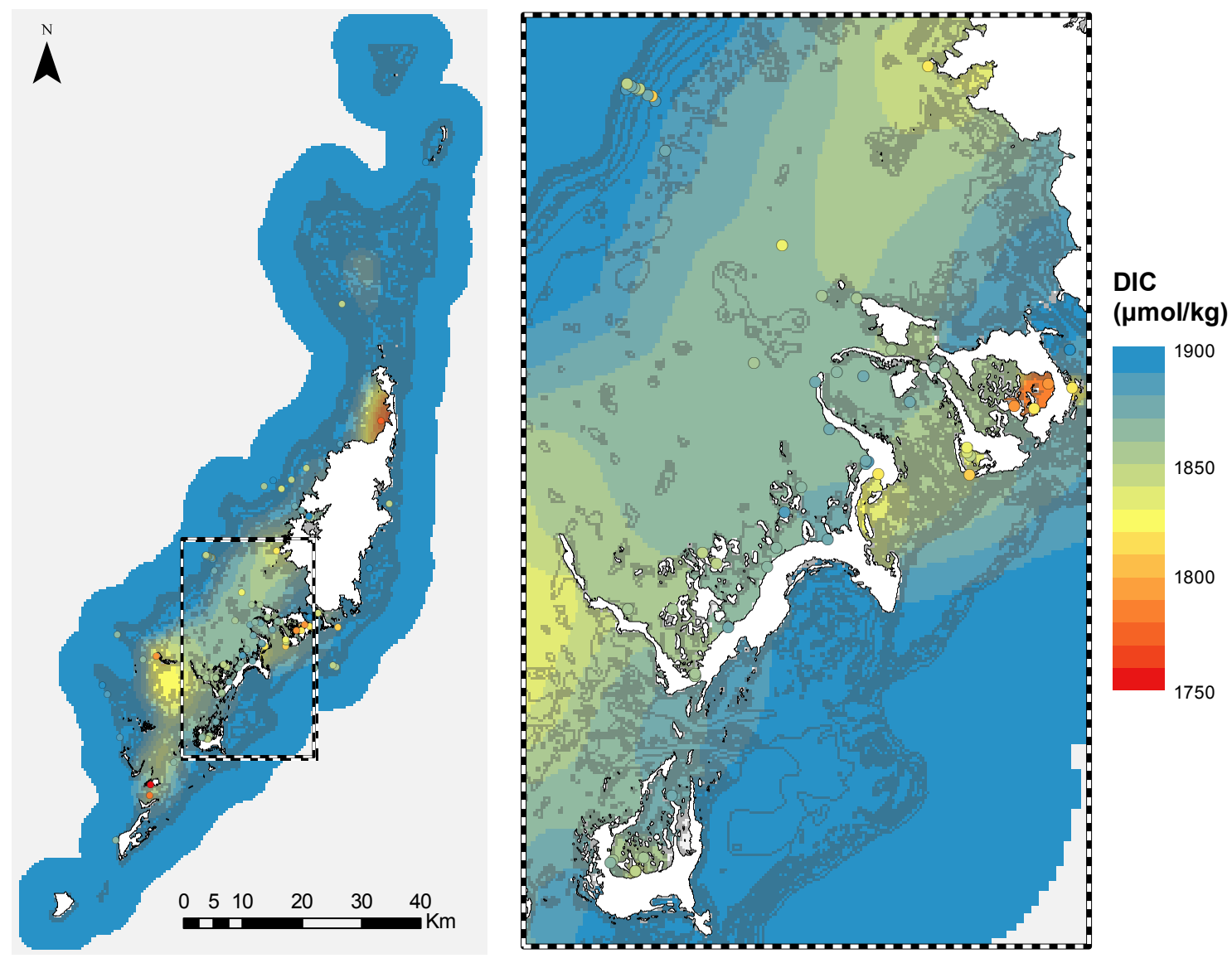

Figure D-9: Dissolved inorganic carbon (DIC) for the Palau archipelago. Points show the location and value of discrete water samples, with mean values shown for sites where multiple samples were collected. Shading contours were estimated between sample points using diffusion interpolation with land barriers over a cost surface derived from coral cover and distance from offshore (Figure D-4). Offshore ocean values for DIC were set at 1900 $\mu \mathrm{mol} \cdot \mathrm{kg}^{-1}$. White regions represent land, and shaded gray contours are submerged reef. Inset highlights the Rock Islands. 

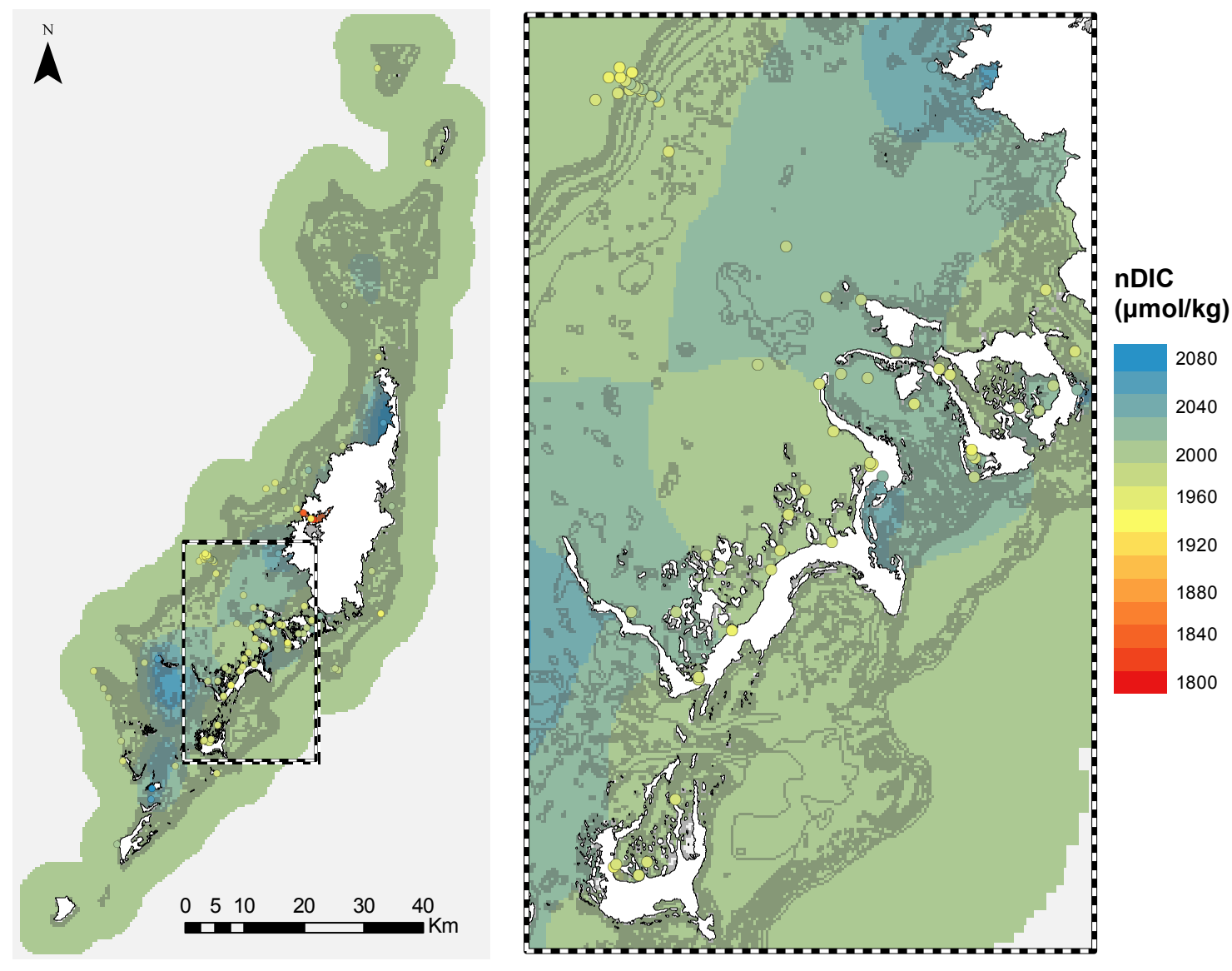

Figure D-10: Salinity-normalized dissolved inorganic carbon (nDIC) for the Palau archipelago. Points show the location and value of discrete water samples, with mean values shown for sites where multiple samples were collected. Shading contours were estimated between sample points using diffusion interpolation with land barriers over a cost surface derived from coral cover and distance from offshore (Figure D-4). DIC values were normalized to an open ocean salinity of 33.9. White regions represent land, and shaded gray contours are submerged reef. Inset highlights the Rock Islands. 

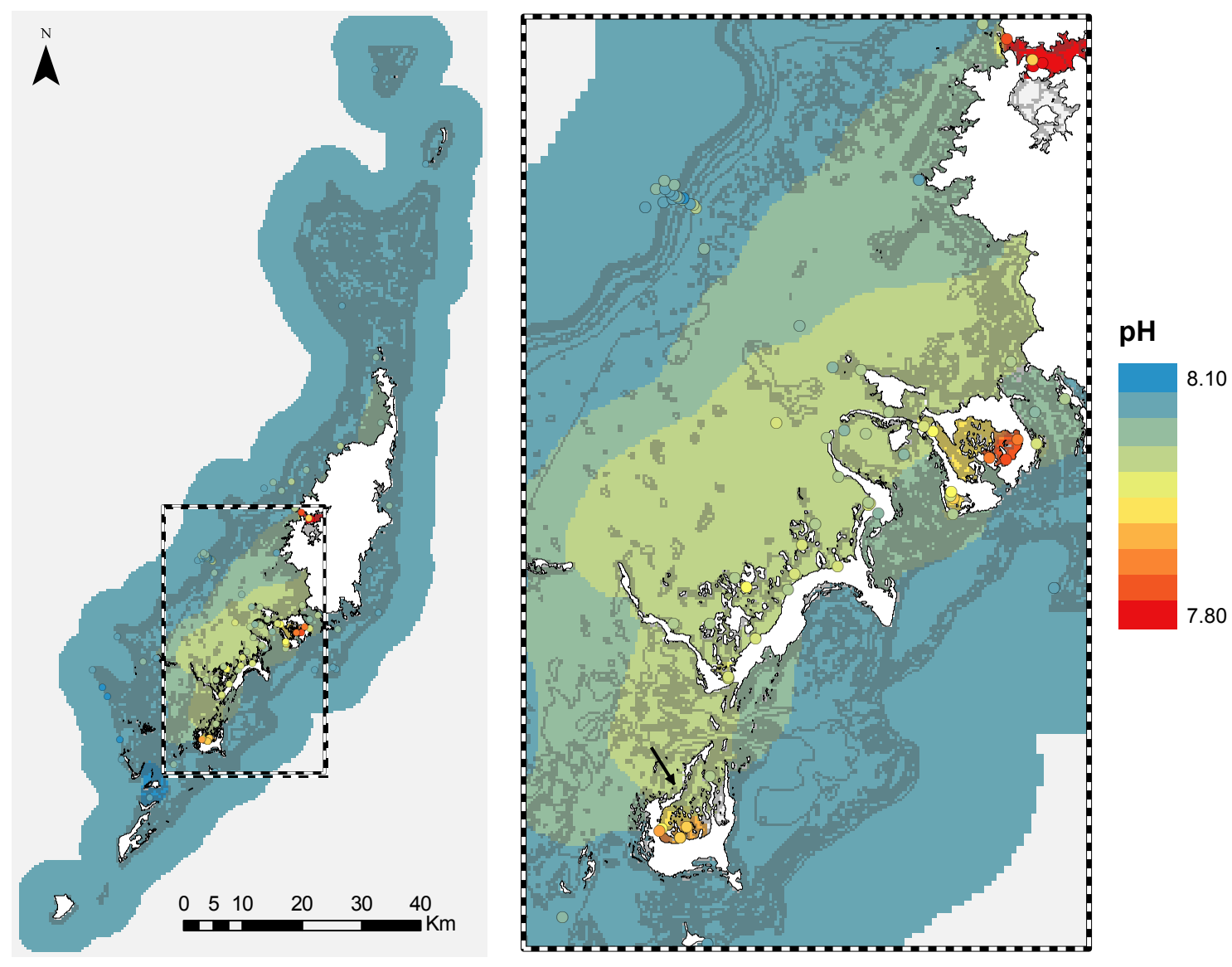

Figure D-11: pH (total scale) for the Palau archipelago. Points show the location and value of discrete water samples, with mean values shown for sites where multiple samples were collected. Shading contours were estimated between sample points using diffusion interpolation with land barriers over a cost surface derived from coral cover and distance from offshore (Figure D-4). Offshore ocean values for $\mathrm{pH}$ were set to 8.06. White regions represent land, and shaded gray contours are submerged reef. Inset highlights the Rock Islands. 

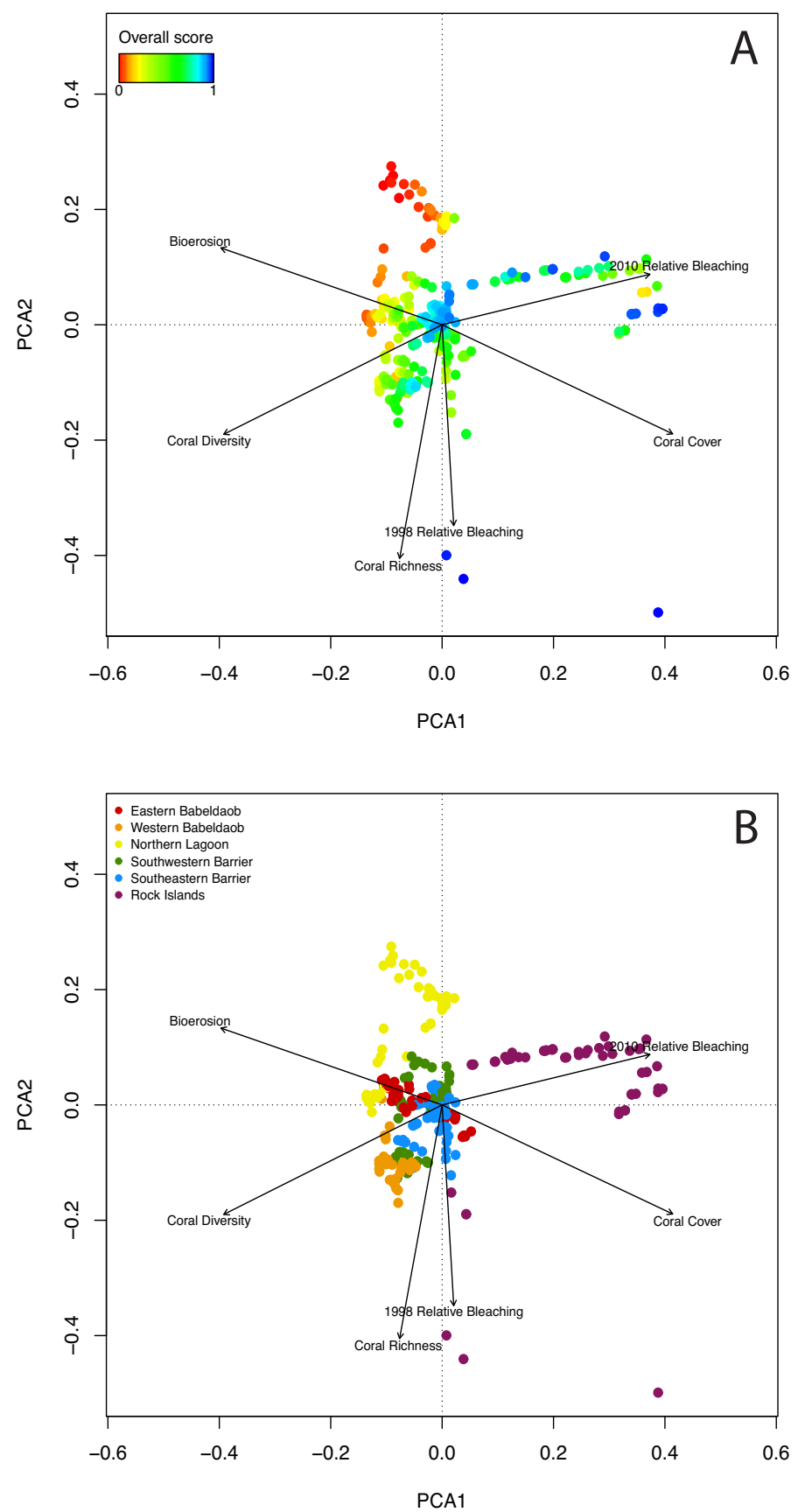

Figure D-12: Principal component analysis (PCA) for climate change resilience scores. (A) The relative contributions of 1998 and 2010 coral bleaching, coral community ecology indices, and ocean acidification indicators to overall climate change resilience scores. (B) PCA scores for six reef zones in Palau. Data points were randomly sampled from 325 locations around the Palau archipelago and are colored by overall climate change resilience score (A) or reef zone (B). Scores for the six climate change resilience variables are overlaid as vectors. The suite of climate change resilience indicators varied significantly based on reef zone (redundancy analysis, pseudo- $\mathrm{F}_{1,323}=88.8, \mathrm{p}<0.001$ ). 


\section{Appendix E}

\section{A note on coral calcification rates}

The analysis of Porites calcification rates across Palau's acidification gradient (Chapter 3) demonstrates that average coral calcification rates from 2006 to 2010 show no sensitivity to $\Omega_{a r}$ (Figure 3-4E), suggesting that Palau's Porites corals have an unusually high acidification tolerance. This five-year period for calcification analysis was selected based on the collection dates of carbonate chemistry samples (i.e. to approximately match calcification rates with years in which mean values of $\Omega_{a r}$ are known) and the range of annual calcification data available from all coral cores (i.e. 2010 and earlier). The maintenance of calcification rates under declining $\Omega_{a r}$ observed in the field is further supported by experimental results (Chapter 4), which show that calcification rates of Porites corals from two of the reefs included in the in situ calcification analysis are not sensitive to $\Omega_{a r}$ values as low as 1.3 (Figure 4-2). In addition, results from a reciprocal transplant study demonstrate that environmental factors other than $\Omega_{a r}$ have a larger influence on calcification and health than shifts in carbonate chemistry (Chapter 4). Combined with ecological indices that demonstrate that healthy, diverse, and coral-dominated communities are currently living at $\Omega_{a r}=2.3$, these results suggest that Palauan coral calcification rates respond more strongly to non- $\Omega_{a r}$ factors that vary across Palau's reef environments than to changes in $\Omega_{a r}$.

However, coral calcification time series measured in the same coral cores over a longer time period (1990-2013) show that calcification rates of barrier and Rock Island reef corals are significantly different (Chapter 2), with barrier corals showing greater overall calcification rates over this time period (Figure 2-5B and 2-5C). This apparent discrepancy between results in Chapter 2 and Chapters 3 and 4 may be explained by two factors. First, the analysis of long-term calcification rate time series (Chapter 2) included calcification rates

of corals from two reef sites not included in Chapter 3 (Ngerchelong and Siaes). These reef sites, located on the western (leeward) site of the archipelago, had unusually high calcification rates relative to the other lagoonal and eastern barrier reef sites. Second, the two studies considered very different time periods. This is significant given that calcification 
rates of barrier and lagoonal corals have converged over time: growth rates of barrier reef corals have been declining steadily over the past two decades (possibly due to increases in ocean temperature), while there has been no overall change in Rock Island calcification rates. Thus, a comparison of 2006-2010 calcification means across reef sites captures a five-year window in which rates were particularly similar. However, because high-resolution spatial and temporal carbonate chemistry data do not exist for 1990-2013, it is not possible to track site-specific changes in the relationship between coral calcification and $\Omega_{a r}$ over time.

Considered together, these results suggest that 1) the time frames considered in coral calcification analysis are critical, especially under changing ocean conditions, and 2) calcification rates of Palau corals appear to be most sensitive to non- $\Omega_{a r}$ environmental factors. These observations therefore suggest that any differences in calcification rates that exist across reef environments relate more to spatial and temporal changes in non- $\Omega_{a r}$ environmental factors than to changes in carbonate chemistry. As a result, the significant difference in multi-decadal calcification rates observed between barrier and Rock Island corals in Chapter 2 is unlikely to be a response to $\Omega_{a r}$. 